\title{
Parametric and predictive analysis of horizontal well configurations for coalbed methane reservoirs in Appalachian Basin
}

Nikola Maricic

West Virginia University

Follow this and additional works at: https://researchrepository.wvu.edu/etd

\section{Recommended Citation}

Maricic, Nikola, "Parametric and predictive analysis of horizontal well configurations for coalbed methane reservoirs in Appalachian Basin" (2004). Graduate Theses, Dissertations, and Problem Reports. 1549.

https://researchrepository.wvu.edu/etd/1549

This Thesis is protected by copyright and/or related rights. It has been brought to you by the The Research Repository @ WVU with permission from the rights-holder(s). You are free to use this Thesis in any way that is permitted by the copyright and related rights legislation that applies to your use. For other uses you must obtain permission from the rights-holder(s) directly, unless additional rights are indicated by a Creative Commons license in the record and/ or on the work itself. This Thesis has been accepted for inclusion in WVU Graduate Theses, Dissertations, and Problem Reports collection by an authorized administrator of The Research Repository @ WVU. For more information, please contact researchrepository@mail.wvu.edu. 


\title{
PARAMETRIC AND PREDICTIVE ANALYSIS OF HORIZONTAL WELL CONFIGURATIONS FOR COALBED METHANE RESERVOIRS IN APPALACHIAN BASIN
}

\author{
Nikola Maricic
}

\author{
Thesis Submitted to the \\ College of Engineering and Mineral Resources \\ At West Virginia University \\ In partial fulfillments of the requirements \\ For the degree of \\ Master of Science \\ In \\ Petroleum and Natural Gas Engineering
}

Dr.Shahab Mohaghegh, Chair of Committee

Dr.Sinisha Jay Jikich

Professor Samuel Ameri
Department of Petroleum and Natural Gas Engineering
Morgantown, West Virginia
2004

Keywords: Petroleum and Natural Gas Engineering, Coalbed Methane, Simulation, Horizontal Wells, Neural Networks 


\section{ABSTRACT \\ PARAMETRIC AND PREDICTIVE ANALYSIS OF HORIZONTAL WELL CONFIGURATIONS FOR COALBED METHANE RESERVOIRS IN APPALACHIAN BASIN}

\section{Nikola Maricic}

It has been a well-established fact that the Appalachian Basin represents a high potential region for the Coalbed Methane (CBM) production. The thin coal beds in the Appalachian basin are characterized by low porosity and permeability values. Due to highly complex reservoir characteristics, different drilling techniques have been developed in order to improve ultimate gas recovery in the shortest possible time. It has been claimed that horizontal drilling is the optimum completion technique used in this region to maximize methane recovery from coalbed reservoirs.

Horizontal wells are considered to be effective in the relatively thin, naturally fractured reservoirs that are characterized by permeability anisotropy. With today's advanced drilling technology, the direction of a horizontal wellbore can be controlled, maximizing the gas production. The objective of this study is to review the various horizontal well configurations used for the recovery of coal bed methane. This study discusses different coalbed properties, and horizontal well patterns, that should be applied in different cases. In addition, the gas recovery and the flow rate associated to the drainage area for each pattern are discussed.

Various reservoir models with diversity of reservoir properties and different horizontal well configurations with various spacing between laterals have been investigated for the best possible gas recovery, using detailed sensitivity analysis, parametric study and intelligent modeling approach. 


\section{ACKNOWLEDGEMENTS}

At the first place, I would like to express my deepest gratitude and appreciation to my advisor Dr. Shahab Mohaghegh who brought me to West Virginia University. Throughout his support, guidance and encouragements during my graduate program, I have completed my studies and the thesis which culminated in the achievement of my degree. He entirely changed my life and without him this would never be possible.

I am deeply grateful to Dr. and Mrs. Sinisha Jikich for the great help since the first moment I came to the USA. During my stay in West Virginia they were supporting, helping and advising me every moment I spent here. I am forever thankful for everything they have done for me.

Sincerely thanks to Professor and Department Chair Samuel Ameri for guidance and support during my graduate studies at West Virginia University. I also appreciate his enthusiasm to be in my committee.

Many thanks to my professors in the Department of West Virginia University for the knowledge they shared with me.

I would like to acknowledge Computer Modeling Group for providing the software used in this study.

Great portion of help and encouragements that I had during my graduate studies I owe to my colleagues and friends Jalal Jalali, Emre Artun, Luisa Rolon, Boyd Huls and Dr. Razi Gaskari. Thank you for the time you spent with me.

Great thanks to my family, especially to my sister Danka, for the constant encouragement and support. She is the best friend I have ever had in my life.

Finally, I dedicate my work to my loving mother Visnjica for all her belief, guidance, support, and encouragement and most importantly for the love she has been giving me all my life. 
ACKNOWLEDGEMENTS iii

TABLE OF CONTENTS IV

LIST OF FIGURES Vi- xii

LIST OF TABLES - xii

CHAPTER I. INTRODUCTION 1

CHAPTER II. LITERATURE REVIEW 3

$2.1 \quad$ Coalbed Methane 3

2.2 Coal Reservoir Engineering 12

$\begin{array}{lll}2.2 .1 & \text { Gas Storage } & 12\end{array}$

2.3 Gas Production from the Coal beds 18

2.4 Coalbed Methane Horizontal Wells 20

$2.5 \quad$ Reservoir Simulators 23

$\begin{array}{lll}2.6 & \text { Artificial Intelligence } & 25\end{array}$

2.6.1 Artificial Neural Networks 25

CHAPTER III. OBJECTIVE AND METHODOLOGY 27

3.1 Statement of Problem 27

3.2 Study Flow Charts 28

3.3 Systematic Approach 31

3.4 Horizontal Well Configurations 34 
3.5 Sensitivity Analysis of Coalbed Methane Productions to Different

Horizontal Well Configurations

3.6 Gas Recovery and Economic Analysis 41

$3.7 \quad$ Rate of Return 45

3.8 Building, Running and Analyzing Coal Bed Methane Model 48

3.8.1 Building the Model 48

3.8.2 Running the Model $\quad 69$

$\begin{array}{lll}\text { 3.8.3 CMG Results / Graph } & 70\end{array}$

$\begin{array}{lll}\text { 3.8.4 3D Results } & 73\end{array}$

$\begin{array}{lll}3.9 & \text { Intelligent Modeling and Analysis } & 77\end{array}$

3.9.1 Data Preparation for the Simulations $\quad 84$

3.10 Data Preparation for the Decline Curve Analysis 88

3.10.1 Decline Curve Analysis $\quad 91$

3.11 Data Preparation for the Neural Network Modeling 104

$\begin{array}{ll}\text { 3.11.1 Neural Network Modeling } & 106\end{array}$

CHAPTER IV. RESULTS AND DISCUSSIONS 127

$\begin{array}{lll}4.1 & \text { Single Lateral Well Example } & 127\end{array}$

4.2 Intelligent Modeling Results 136

$\begin{array}{ll}\text { CONCLUSIONS V. } & 147\end{array}$

$\begin{array}{ll}\text { CHAPTER VI. FUTURE WORK } & 147\end{array}$

$\begin{array}{lr}\text { REFERENCES } & 149\end{array}$ 
Figure 2.1 The Main Steps of the Coalification Process 3

Figure 2.2 Coal Classification Rank 6

Figure 2.3 Major Coal Basins of the World 8

Figure 2.4 Major US Coalbed Methane Resources 9

Figure 2.5 Relationships between the Sorption Isotherm Curve and Gas Content, $\begin{array}{ll}\text { and the Influence on Recovery } & 10\end{array}$

Figure 2.6 A Scheme of a Coal Seam Cleat System 13

Figure 2.7 Desorption Isotherms as a Function of Coal Rank 14

Figure 2.8 Langmuir Isotherm $\quad 15$

Figure 2.9 Molecular Diffusion of Methane in a Coal Matrix 17

Figure 2.10 Coalbed Methane Production Profiles for Gas and Water Rates:

$\begin{array}{ll}\text { Three Phases of Producing Life } & 18\end{array}$

Figure 2.11 Typical Production Performance of a Horizontal Drainage Well 20

Figure 2.12 Eight Basic Applications Existed in the Computer Modeling

Group (CMG) Reservoir Engineering Software 23

Figure 2.13 Neural Network Architecture 26

Figure 3.1 Sensitivity Analysis and Parametric Study Flow Chart 29

Figure 3.2 Intelligent Modeling and Analysis Flow Chart 30

Figure 3.3.An example Explaining Tri Lateral Horizontal Well Shape,

Spacing between Laterals, Lateral Well and Vertical Well 34

Figure 3.4 Five Well Configuration Used in This Study 35

Figure 3.5 A CBM Reservoir Model Including Two Pinnate Shapes 37

Figure 3.6 Six Different Lengths of Single Lateral Horizontal Well Configuration 38

Figure 3.7 Six Different Lengths of Dual Lateral Horizontal Well Configuration 39

Figure 3.8 Six Different Lengths of Dual Lateral Horizontal Well Configuration 40

Figure 3.9 Gas Recovery-Single Lateral Horizontal Well Configurations 41

Figure 3.10 Gas Recovery-Single Lateral Horizontal Well Configurations 41

Figure 3.11 Gas Recovery-Tri Lateral Horizontal Well Configurations 42

Figure 3.12 Gas Recovery-Quad Lateral Horizontal Well Configurations 42

Figure 3.13 Gas Recovery-Pinnate Horizontal Well Configurations 43 
Figure 3.14 Investigated Well Configurations 44

Figure 3.15 Gas Recovery-Best Producers Comparison 44

Figure 3.16 The Best ROR Well Comparison 45

Figure 3.17 The Best ROR Well Comparison 46

Figure 3.18 The Best ROR Well Comparison 46

Figure 3.19 The Creation of the New CMG File 49

Figure 3.20 Flowchart of Creating, Naming and Placing the New CMG File 49

Figure 3.21 Main Form of the CMG Simulator Containing Main Modules 49

Figure 3.22 Input/Output Control Module with Four Available Tabs 50

Figure 3.23 Model Builder Date Selection Form 52

Figure 3.24 Reservoir Description Module with Five Existing Tabs 53

Figure 3.25 Rock Compressibility Form 54

Figure 3.26 Grid Tab in the Reservoir Description Module with Highlighted Button for Creating and Editing Reservoir Grid 54

Figure 3.27 Cartesian Grid Creating Form

Figure 3.28 Plain View of Reservoir 56

Figure 3.29 Set Operation Mode to Probe Allowing User to Specify Property 56

Figure 3.30 General Property Specification Grid 57

Figure 3.31 Block/Corner Value Calculations $\quad 57$

Figure 3.32 Component Properties Form $\quad 57$

Figure 3.33 Rock Type Form 59

Figure 3.34 Rock Fluid Module with the Table Containing Relative 60 Permeability Used in This Study

Figure 3.35 Relative Permeability Curves for the CBM Modeling Used in $\begin{array}{ll}\text { This Study } & 61\end{array}$

Figure 3.36 Initial Condition Module Showing Reservoir Initialization Form, with Water Saturation Value for the Fracture System 62

Figure 3.37 Initial Condition Module Showing Reservoir Initialization Form, with Water Saturation Value for the Matrix 63

Figure 3.38 Numerical Methods 63

Figure 3.39 Snapshot of the Main CBM Form after Entering All Necessary Data 64 Figure 3.40 Add New Date/Time for Well 65 
Figure 3.42 Modification of Well Type at Existing Data and One Single Lateral Well

$\begin{array}{ll}\text { Figure 3.43 Well Perforations Mode } & 67\end{array}$

Figure 3.44 Well Constraints $\quad 68$

Figure 3.45 Snapshot of the CMB Simulator after Building a Model 69

Figure 3.46 Project File .dat Ready for the Simulation 69

Figure 3.47 Form Showing .irf File ready to be Dragged and Dropped on Results 70 Graph Icon

Figure 3.48 Choosing Plotting Options 71

Figure 3.49 Gas and Water Production $\quad 72$

Figure 3.50 Cumulative Gas and Water Production 73

Figure 3.51 The Option of Exporting Graphs to Excel 73

Figure 3.52 Pressure Distribution Couture Fill-IJ 2D Arial 74

Figure 3.53 Pressure Distribution Block Fill-IJ 2D Arial 74

Figure 3.54 Pressure Distribution Contour Lines-IJ 2D Arial 75

Figure 3.55 Pressure Distribution Contour Lines-JK 2D X Sec 75

Figure 3.56 Pressure Distribution 3D View Contour Fill 76

Figure 3.57 Reservoir Model with One Single Lateral Well 78

Figure 3.58 Shape and the Size of the Reservoir Model Used in the Study, Showing also the Size of One Single Block 79

Figure 3.59 Vertical Well Placements in the Reservoir Model-Plain View 80

Figure 3.60 The Shape and the Direction of Well Spreading Through the $\begin{array}{ll}\text { Reservoir-Plain View } & 81\end{array}$

Figure 3.61 Single Lateral Well Configurations $\quad 82$

Figure 3.62 Dual Lateral Well Configurations $\quad 82$

Figure 3.63 Tri Lateral Well Configurations $\quad 82$

Figure 3.64 Quad Lateral Well Configurations 83

Figure 3.65 Pinnate Well Configurations

Figure 3.66 Snapshot of the Form with Variables that Creates Random 84

Numbers as Inputs

Figure 3.67 Simulation Output Data Exported in Excel Spreadsheet 88

Having Data only for Three Years of Production 
Figure 3.68 Header of the Main Input Data File for the Decline Curve

Analysis Indicating Six Parameters that Will be Used by IPDE-IDEA

Software

Figure 3.69 Main Data File which is the Input for the IPDE-IDEA

Figure 3.70 Gas Production versus Time - Actual Data from Existing Well

Figure 3.71 Gas Production versus Time - Synthetic Well 92

Figure 3.72 Main Console of IPDE-IDEA Containing Eight Main Modules 93

Figure 3.73 The Creation of the Main IPDE-IDEA File 94

Figure 3.74 The Creation of the "Data" Folder that Will Contain All Inputs after Importing Into IPDE-IDEA Software

Figure 3.75 "Import Main Data File" Button Will Enable User to Select the Input File and Enter it in the Software 95

Figure 3.76 Loading and Importing Data Form 95

Figure 3.77 The Main Consol after the Successful Import of the Main Data File 96

Figure 3.78 Input Files Created by IPDE-IDEA 97

Figure 3.79 The Main Consol Showing Activation of DCA 97

Figure 3.80 Performing DCA 98

Figure 3.81 The Wells that DCA Has Performed (for the Gas Production) 101

Are Highlighted \& Wells that Need to be Analyzed

Figure 3.82 The Matching of the Two Curves after Performing the Decline Curve Analysis

Figure 3.83 Production Indicators Obtained as the Result of the Decline

Curve Analysis (qi, Di and b)

Figure 3.84 Well Data Form Containing Parameters for Current Investigated

Well for the Monthly Basis for 20 Years of Production

Figure 3.85 Production Indicators Obtained as the Result of the Decline

Curve Analysis

Figure 3.86 Snapshot of the Main Input File for the IDEA Software

Figure 3.87 The Main IDEA Consol with All Explanation for All Existing

Modules

Figure 3.88 IDEA Toolbar Including the Creation of a New File, Opening the New File and Export to Excel Options 
Figure 3.89 The Import of the File Containing the Main Data for the Neural Network Modeling 109

Figure 3.90 Data Analyzer Showing Spread Sheet of Imported Data and Second Tab Attribute Selection

Figure 3.91 Statistical Analysis Form

Figure 3.92 Representation of Data - b versus Pressure (psi)

Figure 3.93 Frequency Distribution of Data

Figure 3.94 2D Data Distribution

Figure 3.95 3D Data Distribution

Figure 3.96 Bubble Chart Showing Distributions and Magnitude of Each Input Parameter

Figure 3.97 Performance Drivers Form, Showing Steps of Output Parameters

Selection, Fuzzy Combinatorial Analysis and Identification of the Parameter Contribution

Figure 3.98 The Graphical Presentation of One of the Inputs

Figure 3.99 The Definition of the Number of Clusters, Scenario and Cluster Data

Distribution after Clustering

Figure 3.100 Data Arrangement in Clusters and Number of Data Existing in Each Cluster

Figure 3.101 Cluster Data Distribution Presented by Graphs /2D

Figure 3.102 Cluster Data Distribution Presented by Graphs 3D-Surface Shape

Figure 3.103 Cluster Data Distribution Presented by Graphs 3D

Figure 3.104 Data Selection Form with the Clustering Methods and Train/Test/Verification Options

Figure 3.105 Neural Network Data Preparation

Figure 3.106 Data Selection Tab Allows User to See Entropy Value and All Clusters for Training, Calibration and Verification Sets as Well as Data Form for All Cases

Figure 3.107 One of Possible Neural Network Architectures 123

Figure 3.108 Training Data-Actual versus Virtual with Obtained R Square 124

Figure 3.109 Verification Data-Actual versus Virtual with Obtained R Square 
Figure 3.110 General Model Behavior Interface

Figure 3.111 General Model Behavior Interface with the Discrete Option

Figure 3.112 Four Curves represent Sw with Different Values, Plotted Pressure Versus Qi

Figure 4.1 Searching for an Outlier

Figure 4.2 Outlier Is Excluded From an NN Modeling

Figure 4.3 Used and Not Used Input Parameters

Figure 4.4 Scenario Results-Clusters

Figure 4.5 Scenario Results-Clusters 3D View

Figure 4.6 Neural Network Data Preparation

Figure 4.7 Neural Net Architecture Used in This Example

Figure 4.8 Cross Plot of Training Data Showing Accuracy of 0.78

Figure 4.9 Cross Plot of Calibration Data Showing Accuracy of 0.89

Figure 4.10 Cross Plot of Verification Data Showing Accuracy of 0.85

Figure 4.11 Cross Plot of Training Data Showing Accuracy of 0.77

Figure 4.12 Cross Plot of Calibration Data Showing Accuracy of 0.89

Figure 4.13 Cross Plot of Verification Data Showing Accuracy of 0.85

Figure 4.14 Single Lateral Well Verification Results for the Output "b"-Gas

Figure 4.15 Single Lateral Well Verification Results for the Output "Di"- Gas

Figure 4.16 Single Lateral Well Verification Results for the Output "Qi”- Gas

Figure 4.17 Single Lateral Well Verification Results for the Output "b"- Water

Figure 4.18 Single Lateral Well Verification Results for the Output "Di"- Water

Figure 4.19 Single Lateral Well Verification Results for the Output "Qi”- Water 138

Figure 4.20 Dual Lateral Well Verification Results for the Output "b"-Gas

Figure 4.21 Dual Lateral Well Verification Results for the Output "Di"-Gas

Figure 4.22 Dual Lateral Well Verification Results for the Output "Qi"-Gas

Figure 4.23 Dual Lateral Well Verification Results for the Output "b"- Water

Figure 4.24 Dual Lateral Well Verification Results for the Output "Di”- Water

Figure 4.25 Dual Lateral Well Verification Results for the Output "Qi”- Water 140

Figure 4.26 Tri Lateral Well Verification Results for the Output "b"-Gas

Figure 4.27 Tri Lateral Well Verification Results for the Output "Di"-Gas

Figure 4.28 Tri Lateral Well Verification Results for the Output "Qi"-Gas 
Figure 4.30 Tri Lateral Well Verification Results for the Output "Di"-Water 142

Figure 4.31 Tri Lateral Well Verification Results for the Output "Qi"-Water 142

Figure 4.32 Quad Lateral Well Verification Results for the Output "b"-Gas 143

Figure 4.33 Quad Lateral Well Verification Results for the Output "Qi"-Gas 143

Figure 4.34 Quad Lateral Well Verification Results for the Output "Di"-Gas 143

Figure 4.35 Quad Lateral Well Verification Results for the Output "b"-Water 144

Figure 4.36 Quad Lateral Well Verification Results for the Output "Qi"-Water 144

Figure 4.37 Quad Lateral Well Verification Results for the Output "Di"-Water 144

Figure 4.38 Pinnate Well Verification Results for the Output "b"-Gas 145

Figure 4.39 Pinnate Well Verification Results for the Output "Di"-Gas 145

Figure 4.40 Pinnate Well Verification Results for the Output "Qi"-Gas 145

Figure 4.41 Pinnate Well Verification Results for the Output "b"-Water 146

Figure 4.42 Pinnate Well Verification Results for the Output "Qi"-Water 146

Figure 4.43 Pinnate Well Verification Results for the Output “Di”-Water 146

Figure 6.1 Future Work 148 
Table 2.1 Main Modules in the CMG Simulator with the Explanations 23

Table 3.1. Input Parameters and Values 32

Table 3.2 Parameters Used in Economic calculation 45

Table 3.3 Relative Permeability Data used in this Study 60

Table 3.4 Data Determining Reservoir Size 77

Table 3.5 Simulation Set of Input Data for the Single Lateral Well Configuration 85

Table 3.6 Simulation Set of Input Data for the Dual Lateral Well Configuration 85

Table 3.7 Simulation Set of Input Data for the Tri Lateral Well Configuration 86

Table 3.8 Simulation Set of Input Data for the Quad Lateral Well Configuration 86

Table 3.9 Simulation Set of Input Data for the Quad Lateral Well Configuration 87

Table 3.10 Main Input Data with Explanations 89

Table 3.11 Three Columns Having Different Sources and Data are combined

In the Unique file that will be Main Input Data File for the Neural

Network Modeling 105

Table 3.12 Two Lateral Well Configurations Attribute Selection for the Predicted

Value of "b".

Table 4.1 Input/Not Used Data 128

Table 4.2 Used and Not Used Input Parameters 130

Table 4.3 Training, Calibration and Verification Results 136 


\section{CHAPTER I INTRODUCTION}

The Coalbed Methane Industry has emerged as a significant source of the natural gas production. Today, Coalbed is considered as a reservoir from which large quantities of gas can be produced. Coalbed formations have played an important role in gas production all over the world, and it has become a significant source of the gas production in the United States.

Coal as a reservoir rock is unusual due to highly complex reservoir characteristics.

However, one of the characteristics that distinguish the coal seams from conventional gas reservoirs is that at the same time, the coal represents both the source and the reservoir rock. In order to evaluate coalbed methane (CBM) reservoirs, to decide how to drill, complete the wells and develop the reservoir in the best economic way, one has to fully understand the internal structure and reservoir characteristics of the coal.

During the metamorphosis of the organic material to coal, huge quantities of methane gas are produced and retained by the coal. A coal seam is a naturally fractured reservoir. The coal seam is heterogeneous and characterized by the two very distinct porous systems: macropores (fracture system) and micropores (coal matrix system). The fracture system is called the cleat system. The coal cleat system generally is orthogonal with one direction cross-cutting the other and the dominant (more continuous) cleat is commonly called the face cleat. The cleat oriented roughly perpendicular to the face cleat is called the butt cleat. The cleat spacing in coal varies from $1 / 10$ inch to more than one inch, and has a huge impact on the coal deliverability.

The CBM production depends highly on the fracture system, fracture spacing and fracture connection. The porosity and permeability of the cleat system allows a well to produce the gas. If a cleat system is not developed enough, one cannot produce the gas. This occurs due to the low values of porosity and permeability in the matrix, making it impossible for gas production from the matrix. At the beginning, the system is in equilibrium. Typically, water must be produced continuously from coal seams to reduce reservoir pressure and release the gas. The dewatering process can take from few days to several months, which among other factors depends on CBM well configuration. 
Generally, the water production declines until the gas rate reaches the peak value. This time-to-peak-gas is a critical parameter since the gas production starts declining after reaching the maximum. Upon reaching the peak, gas production starts to decline, and behavior of CBM production becomes similar to conventional reservoirs.

The major portion of the gas in storage in the coal is in an adsorbed state, whereas most of the gas in conventional reservoirs is in a free state within the pore structure of the rock. Since large amounts of gas can be stored at low pressures in coal reservoirs, the reservoir pressure must be drawn down to a very low level to achieve high gas recovery. As water is removed from the cleat system, the reservoir pressure is starting to decrease. This causes the gas to desorb from the microspore surfaces and to diffuse into the fracture system. Coal is relatively friable and compressible compared to the rock in many conventional reservoirs, and the permeability of coal is more stress dependent than most reservoir rocks. The most important properties to measure are coal thickness, cleat permeability, gas content, and the sorption isotherm.

The two most important parameters in evaluating a coal bed methane prospect are the total gas-in-place and the gas deliverability of the reservoir. These parameters are determined largely by the physical properties of the coal system.

Reservoir simulators represent a necessary tool today, for proper developing and managing reservoirs. However, this software is highly expensive tools and requires proper training and knowledge of a user. A large amount of data is necessary for starting simulation modeling. The chances that small independent producer can afford a simulator and an engineer to use it, as well as sufficient amount of data from the investigated reservoir, are small. As a result, this study was conducted in order to develop an optional solution for producers in the Appalachian Basin. 


\section{CHAPTER II}

\section{LITERATURE REVIEW}

\subsection{Coal as a Reservoir}

By definition, coal is not just a unique substance, but a heterogeneous mixture of different components. The natural components of the coal are water, mineral components and methane. Coal is basically a rock that originates from plant tissues, and wood that flourished several hundred million years ago.

Over the years the peat began to accumulate, and became covered by sand and clay. The weight of all overlaying sediments caused the underlying peat to become compacted, which over the years became denser, and eventually formed into coal. The plant debris underwent chemical and physical modifications, resulting in a black or brown colored rock that is friable, combustible, and contains gas. When organic material is buried, compressed, and dewatered, the material called peat is formed. It represents a result of the decomposition and disintegration of plants that grow in swamps. If the peat form is more deeply buried, pressure and temperature increase, and water from the peat starts to vaporize. The process by which the vegetal matter is transformed progressively through peat, lignite, sub-bituminous, bituminous to anthracite is called coalification. Methane and other gases are produced by anaerobic fermentation, alteration of bacteria and by coalification. Figure 2.1 illustrates the major steps and products during the coalification process.

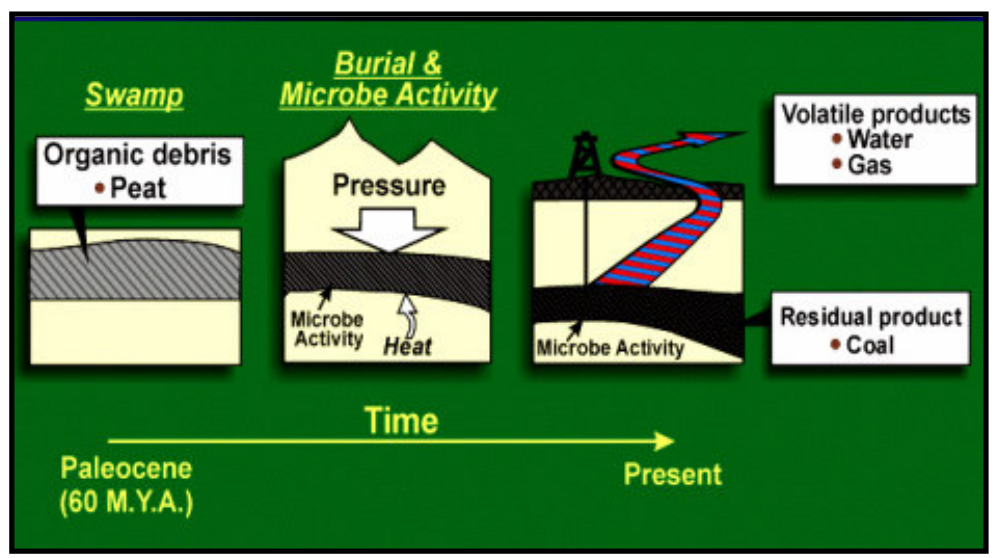

Figure 2.1 The Main Steps of the Coalification Process 
One unusual thing about coal is that it serves both as the source rock and reservoir. This means that gas is formed and kept in the coal, which is different from the conventional reservoirs where the gas and fluid migrate are present over the long periods of time; from the source rock they move into a trap that creates a hydrocarbon reservoir. Compared to the conventional hydrocarbon rocks, that are usually sandstone; several very significant differences need to be highlighted. They are: greater compressibility of the coal, very low effective porosity of the coal, and the way that gas has been stored in the rock (adsorption of the gas on the coals structure).

Coal maturation is based upon the proportions of carbon present in coals - the greater the proportion of carbon present, the higher the rank of the coal, and the bigger the change of the coal from the original plant debris of which it was composed. Rank denotes the type of chemical changes that coal has undergone during time. A promotion in rank denotes the natural processes where the carbon content of a coal is increased, while the hydrogen and oxygen content decrease. The issue of a coal rank is very important because of the direct influence on the storage capacity of coal.

The three levels of coal rank are:

Lignite - A brownish-black coal in which the alteration of vegetal material has proceeded further than in peat, but not so far as sub-bituminous coal, also called brown coal.

Bituminous - Varieties of soft coal which burn freely with a flame and yield volatile matter when heated.

Anthracite - A hard black lustrous coal with 92 percent or more of fixed carbon (dry, mineral matter-free), also called hard coal. The permeability of these coals is usually very low (Mawor et al., 1996)

The rank of coal usually increases directly proportionally with depth due to the high sensitivity to temperature, pressure and deposition time. Some other variables can also have a significant affect on the coal rank. As a result, the coals at the same depth do not have to be in the same rank. In general, the harder the coal, the higher the gas content, but also the lower the permeability. 
As a result, the most commercial coals are considered the coals within the range between sub-bituminous to semi-anthracite. These usually provide optimum gas content and sufficient permeability necessary for gas production.

Porosity represents a percentage of rock volume or void space that can contain fluids or gases. Porosity for coals of medium-volatile bituminous through anthracite rank is typically less than five percent. Coal pores can be classified into three sizes-macropores (>500 $\AA$ ), mesopores (20 to $500 \AA$ ), and micropores (8 to $20 \AA$ ). Porosity tends to decrease with rank into the low-volatile bituminous stage, and then it increases as additional volatiles are lost and pore space is left open.

Physical and chemical properties of a coal vary significantly from one coal seam to the other one. The three basic and fundamental characteristics of a coal in general are: grade (the relative percentage of organic to mineral components), type (various organic components), and rank (the level of maturation, ranging from peat through anthracite). 


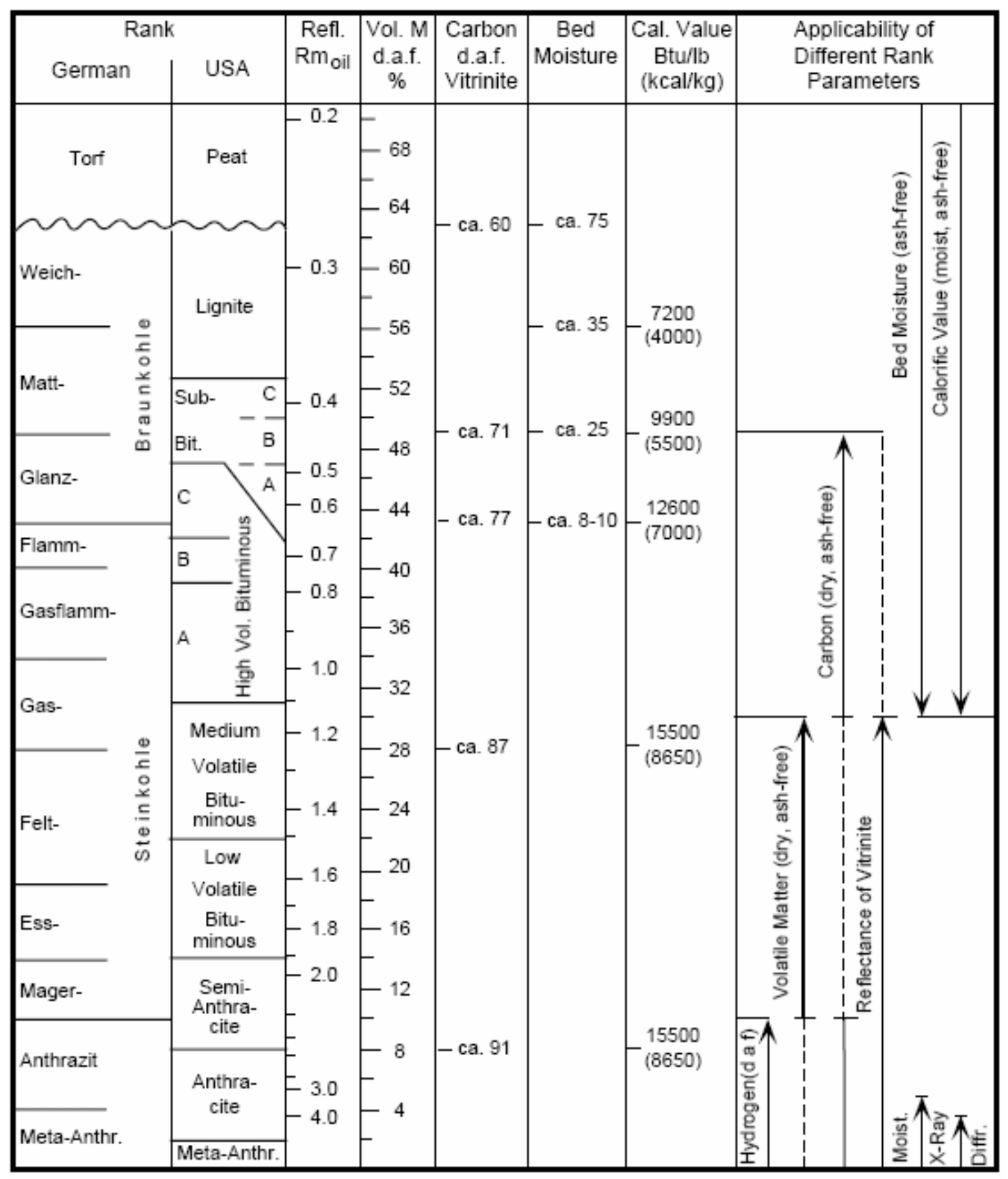

Figure 2.2 Coal Classification Rank (Reprinted from Mawor et al., 1996) 
Gas production from coal represents a relatively new technology in petroleum industry. Not so long ago, did a methane gas that is associated with coal mining represent only great threat and main danger to mineworkers. Twenty years ago, people started to realize that producing gas from the coals before mining cannot only help and drastically decrease the danger of blowout in the mines, but can also be used as a fuel. In 1982, the gas production from the coals in the United States was zero.

Until 1980, when GRI initiated Coalbed Methane research program, the methane gas from the coal has been considered just a big problem in the mining industry, and nothing more. There are several reasons that coal beds have not been considered potential gas reservoirs. In the first place, coals are relatively thin strata, and it was thought that they were not able to store economical amounts of gas in order to be produced. Even though the producers drilled through coals in order to reach deeper horizons, they had not noticed the importance of coalbed methane, because no gas or little gas had been shown at the surface during drilling operations, and usually water had been produced initially. The main reason for this misunderstanding is that the reservoir and storage mechanism are totally different than the mechanism in the conventional sandstone collectors. The gas is adsorbed on the surface of the coal, and in order to be produced, a certain amount of water needs to be produced. Gas from the coal can be produced only after initial dewatering of the system, and upon reaching very low pressure. Therefore, the methane has not been often shown immediately at the surface, which was the main reason for overlooking coalbed methane as a potential gas resource. 


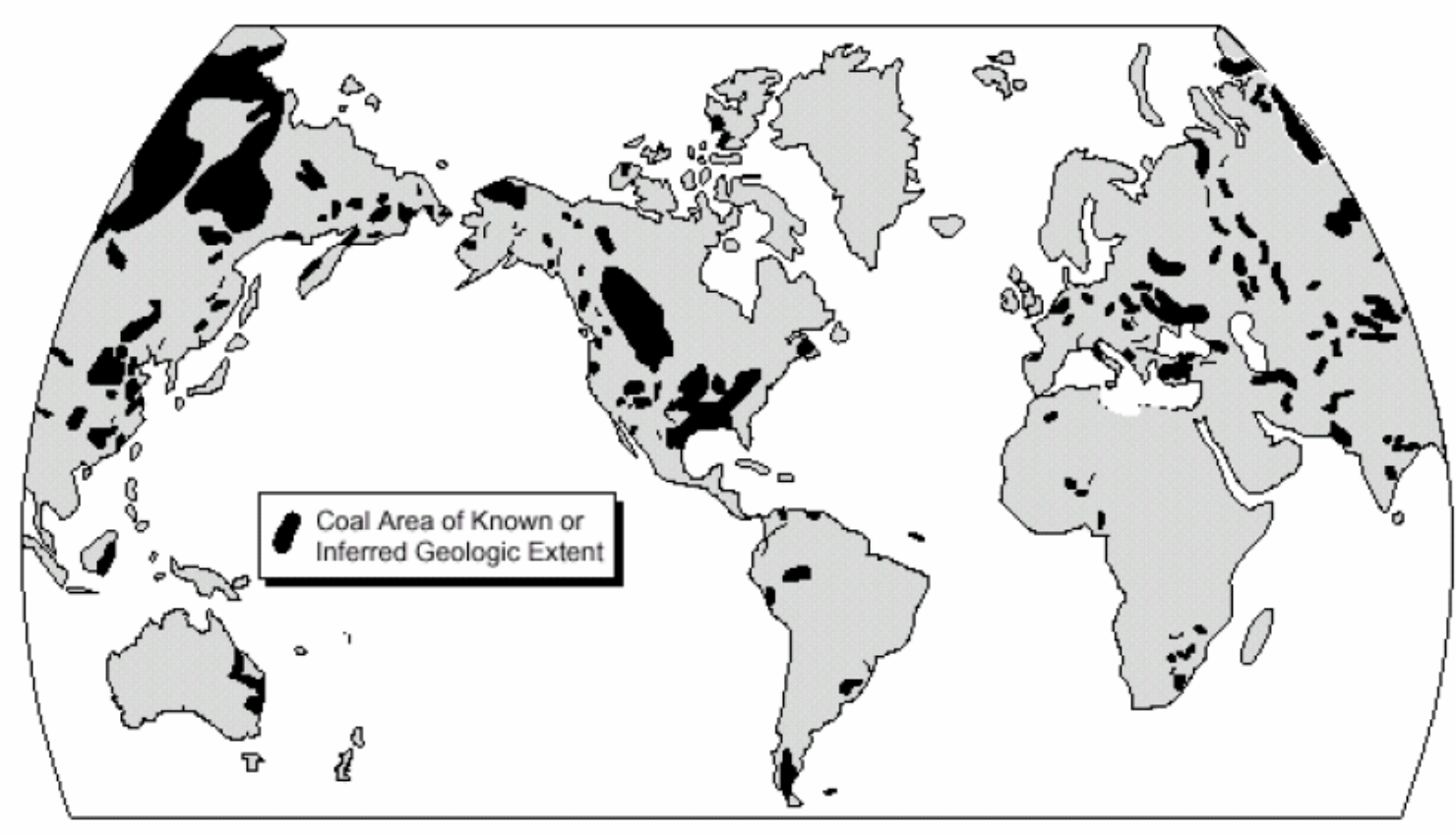

Figure 2.3 Major Coal Basins of the World (Reprinted from Mawor et al., 1996)

Coalbed reservoirs in the United States contain an estimated 703 Tcf (trillion cubic feet) of natural gas resource, holding $11.7 \%$ (141.4 Tcf) of the total recoverable US natural gas resources, and in 1997 accounted for $5.9 \%$ (1.13 Tcf) of total annual US natural gas production (Nelson, 1999)

The major coalbed methane resources in the United States are located in 12 basins:

San Juan, Warrior, Wind River, Greater Green River, Illinois, Piceance, Arkoma, Central and Northern Appalachian, Uinta, Power River and Raton (Figure 2.4).

The two most productive basins are Black Warrior in Alabama and San Juan in northern New Mexico. The total estimated CBM gas reserves are 20 Tcf and 88 Tcf respectively. 


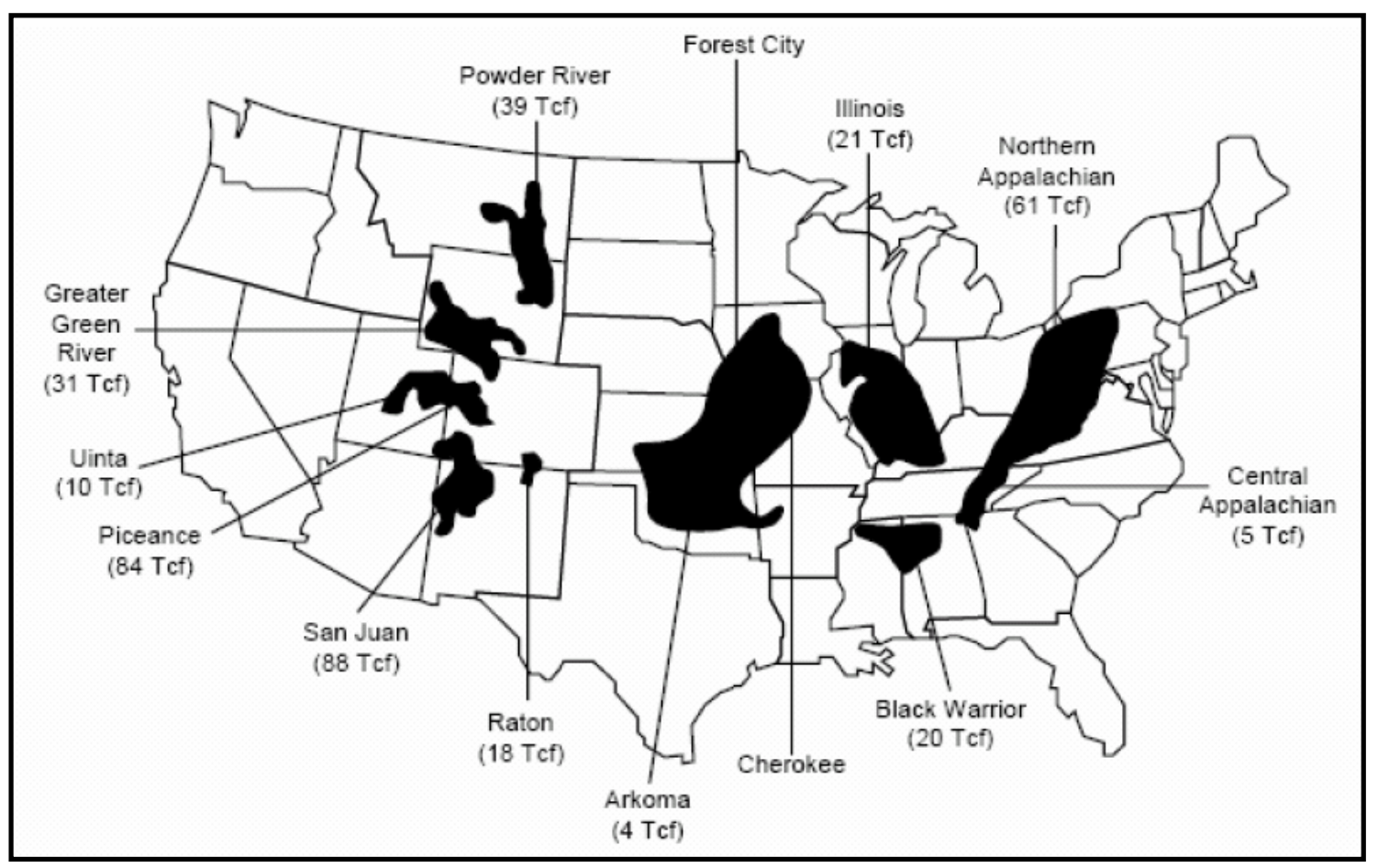

Figure 2.4 Major US Coalbed Methane Resources (Reprinted from Mawor et al., 1996)

As mentioned before, the coal reservoir characteristics are much different than the characteristics of conventional reservoirs. These unique coal characteristics are the main reason for different engineering approach to CBM. The most important CBM characteristics that need to be very well understood before any approach into CBM development are:

1. Coal is a source rock and the reservoir rock at the same time;

2. The coal storage mechanism;

3. The fracture system of the coals;

4. Coals often need to be dewatered before any gas production;

5. The unique mechanical coal properties.

Unlike a conventional sandstone reservoir, gas is formed in the coal and remains in it, without any movement to any other potential reservoir. The gas in the conventional reservoirs is in the free state within the pore structure of the collector rock. In the case of a coal, the gas is adsorbed onto the internal structure of the coal. In this way, a large amount of gas can be stored in the coal rock. 
The fracture system of the coal represents one of the most important characteristics of the coal that enables a large amount of methane to be released from the structure. Typically, a coal is water saturated at initial conditions. Fractures of the coal are full of water, and the coal needs to be dewatered in order to lower reservoir pressure, and initiate gas desorption from the matrix into the fracture system. Coal is considered to be a very friable source rock compared to the other conventional sandstones. In certain locations (e.g., San Juan Basin), fracture treatment that introduces cavitations of the well bore might have very significant influence on the increase of the gas production (Mawor et al., 1996). Unlike gas storage in conventional reservoirs, the adsorbed gas on the coal surface allows a much higher amount of gas to be stored in the coal than in the sandstone at equal pressures. The reason for which the gas is kept in the adsorbed state is the water that can be found in the most of the virgin coals, which provides the pressure in the reservoir.

An important mechanism that controls production is the relation between the gas content and the sorption isotherm, as shown in Figure 2.5. The sorption isotherm defines the relation between the pressure and the capacity of a given coal to hold gas at a constant temperature. The gas content is a measurement of the actual gas contained in a given coal reservoir.

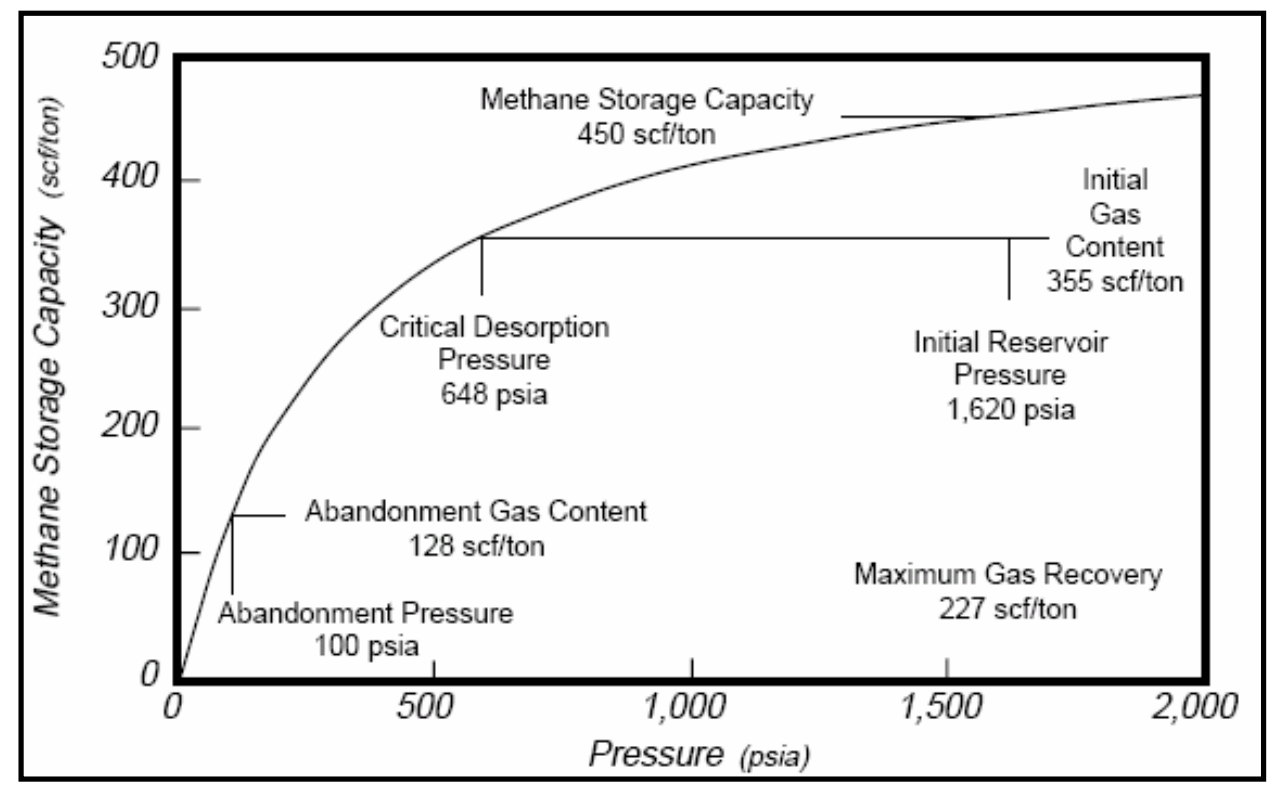

Figure 2.5 Relationships between the Sorption Isotherm Curve and Gas Content, and the Influence on Recovery (Reprinted from Scrufnagel, R., 1994) 
A coal seam is a natural fractured reservoir. The coal seam is heterogeneous and characterized by the two very distinct porous systems: macropores (fracture system) and micropore (coal matrix system). The fracture system is called the cleat system. Generally, the coal cleat system is orthogonal with one direction cross-cutting the other, and the dominant (more continuous) cleat is commonly called the face cleat, whereas the cleat oriented roughly perpendicular to the face cleat is called the butt cleat. The cleat spacing in coal varies from 1/10 inch to more than one inch, and has the huge impact on the coal deliverability.

The CBM production highly depends on the fracture system, fracture spacing and fracture connection. The porosity and permeability of the cleat system allows a well to produce the gas. The two most important parameters in evaluating a coal bed methane prospect are the total gas in-place and the gas deliverability of the reservoir. These parameters are determined largely by the physical properties of the coal. A prerequisite for economic gas flow rates is sufficient coal permeability.

Most gas and water flows through the coal cleat system and other fractures. Cleat is a miners' term for the natural system of vertical fractures that have been formed in most coals usually as a result of the coalification process. Typically, the cleat system in coal comprises two or more sets of sub parallel fractures that are oriented nearly perpendicular to the bedding.

One characteristic that makes coal reservoirs different from conventional gas reservoirs is the manner in which the gas is stored. The cleat system usually creates permeability anisotropy with greater permeability, which is often in the face cleat direction. Substantial gas production differences have been observed in holes drilled horizontally through coal seams. In the Pittsburgh coal beds, flow rates per foot of a hole were found to be about four times higher in the holes drilled perpendicular to the face cleat than in those drilled perpendicular to the butt cleat. Gas can exist in a coal seam in two ways. It can be present as free gas within the natural porosity of the coal (joints and fractures), and it can be present as an adsorbed layer on the internal surfaces of the coal. 
Hydrogeology has an important role in the gas production from the coals. In most cases, coals are water saturated, and water needs to be removed from it in order to lower the reservoir pressure. Once sufficient water is removed and reservoir pressure is lowered, a gas desorption can take place. If aquifer overlays or is associated with the coal group, dewatering the system might be very problematic or may make methane production uneconomical. Understanding the coal petrology is necessary for the reservoir engineer because it provides insight into the gas storage capacity and cleat development, which represents the prerequisite in the coalbed methane gas production.

\subsection{Coal Reservoir Engineering}

The CBM production highly depends on the fracture system, fracture spacing and fracture connection. The porosity and permeability of the cleat system allows a well to produce gas. If a cleat system is not developed enough, one cannot produce the gas. The reason is the scarce presence of porosity and permeability in the matrix, and the absolute impossibility of gas production from the matrix. At the beginning, the system is in equilibrium. The cleat system is usually $100 \%$ saturated with water, and the gas is stored into the matrix which is inaccessible to water, or the water exists in the matrix as a mist (very low percentage 1-5\%). Typically, water must be produced continuously from coal seams to reduce reservoir pressure and release the gas.

\subsubsection{Gas Storage}

The major portion of the gas storage in the coal is in an adsorbed state, whereas most of the gas in conventional reservoirs is in a free state within the pore structure of the rock. Since large amounts of gas can be stored at low pressures in coal reservoirs, the reservoir pressure must be drawn down to a very low level in order to achieve high gas recovery. As water is removed from the cleat system, the reservoir pressure starts to decrease. It causes the gas to desorb from the micropore surfaces, and to diffuse into the fracture system, from where it can reach the other fractures that are connected to the well bore. 


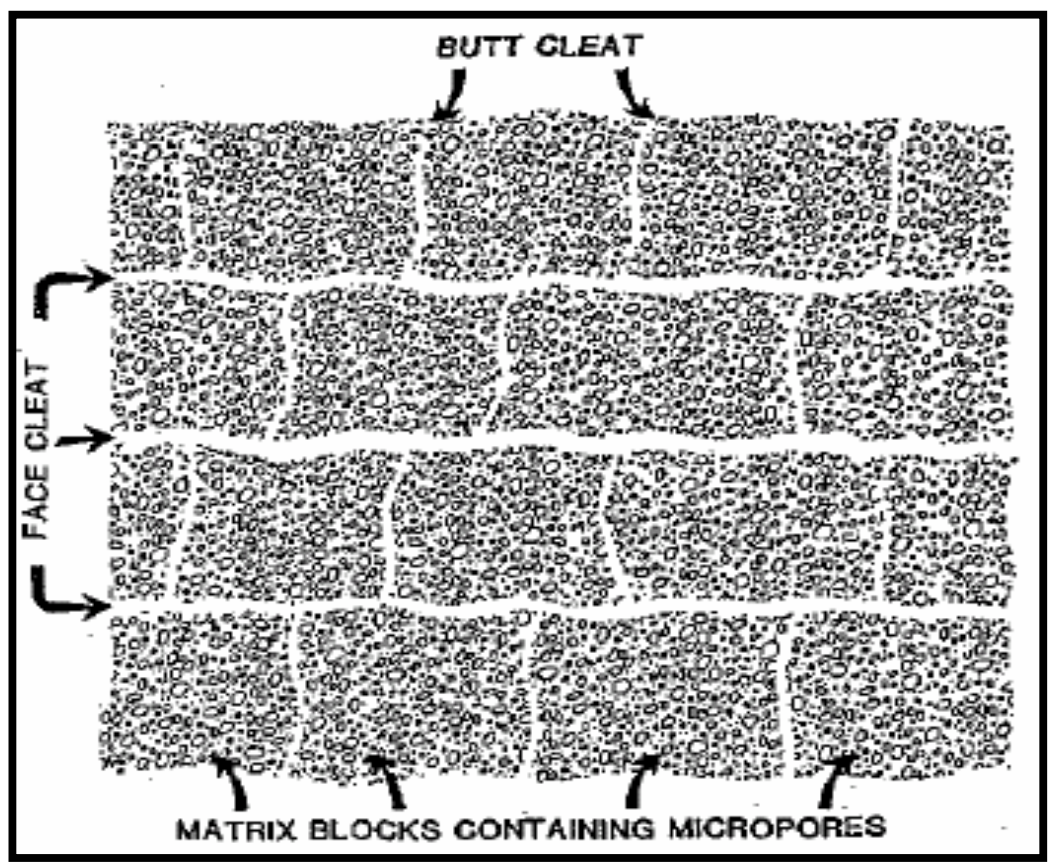

Figure 2.6 A Scheme of a Coal Seam Cleat System

(Reprinted from Ertekin, T., King, G., 1984)

The coal matrix is heterogeneous, and it is characterized by two porosity systems. In the terms of reservoir engineering, coal represents a naturally fractured reservoir. It consists of the matrix and fractured system, which is also called cleat system. The macropores (fractures) constitute the cracks inherent in coals. The cleat system is consisted of two major components - the face and butt cleat system. The face cleat is continuous throughout the reservoir and can drain large areas, while butt cleats are discontinuous, usually terminating at the intersection with the face cleats. The cleat system represents the main path through which gas and water flow. Methane in the coal can exist in the two different states. It can be present as a free gas within the natural porosity of the coal (secondary porosity), or more often as an adsorbed layer on the surface of the coal structure.

Only can the small amount of gas be found in the free state, while the majority of the gas exists as adsorbed gas on the internal surfaces of the coal. The very fine micropore structure of the coal has a very high capacity of storage for the methane. The total effective porosity to water is less than two percent, while the effective porosity to free gas in the same coal might be up to ten percent. Unfractured portions of coal are relatively impermeable to gas and water, which implies that in-situ permeability of a coal, depends 
predominantly on the cleat system. Because of the coal's property of having a large internal structure, gas molecules can be packed tightly, and as the product of this effect, a huge amount of gas can be stored. The adsorption process is directly influenced by pressure, temperature and coal rank. As pressure and coal rank increase (larger burial depth) and temperature decreases, the methane capacity of coal increases. In general, deeper coals will store higher gas amounts than shallower coals.

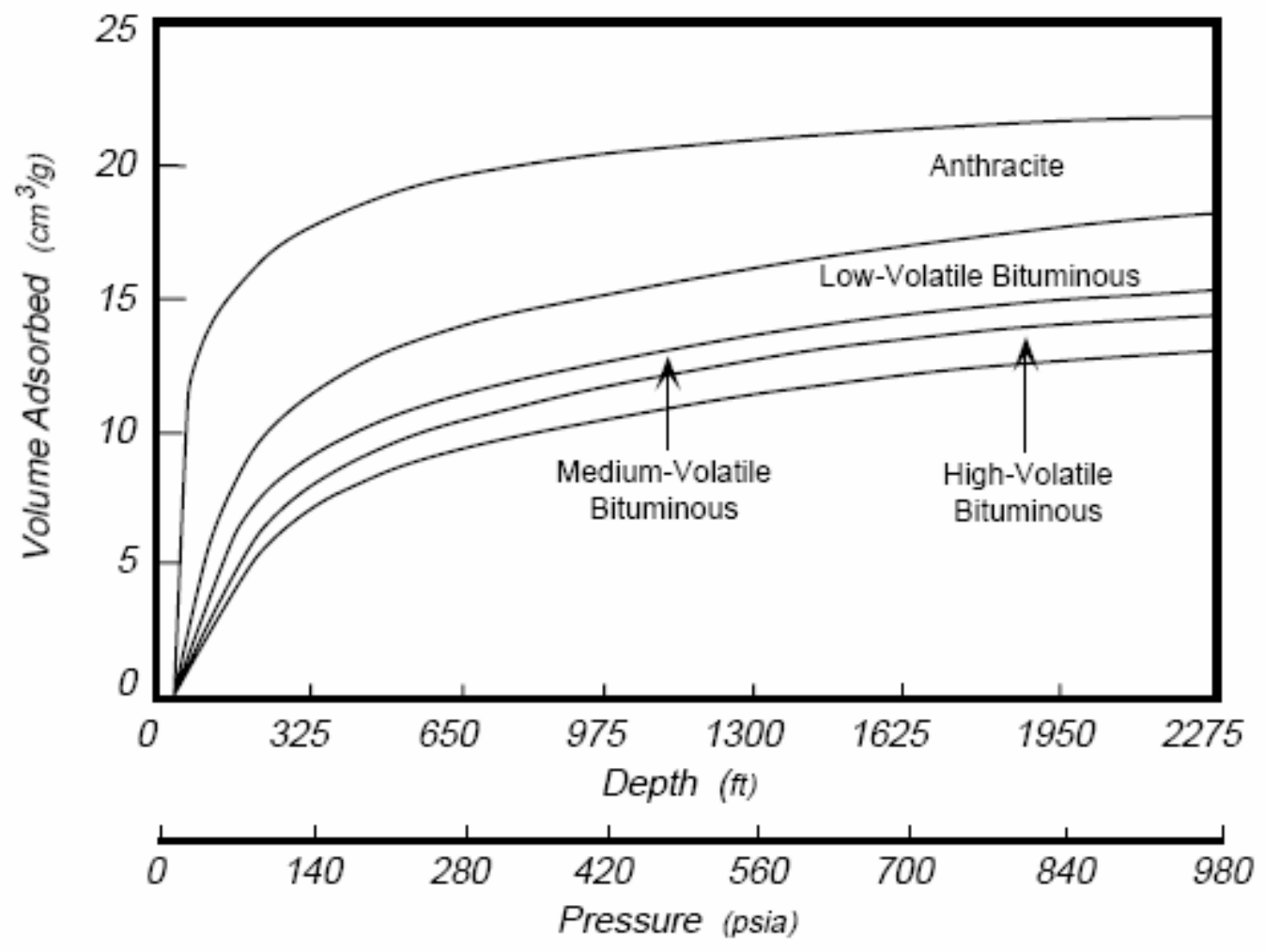

Figure 2.7 Desorption Isotherms as a Function of Coal Rank

(Reprinted from Mawor et al., 1996)

With the increase of a coal's rank, coal's capacity increases as well. The quantity of methane generated as coal progresses from peat to anthracite is greater than the capacity of the coal seams' ability to absorb it. 


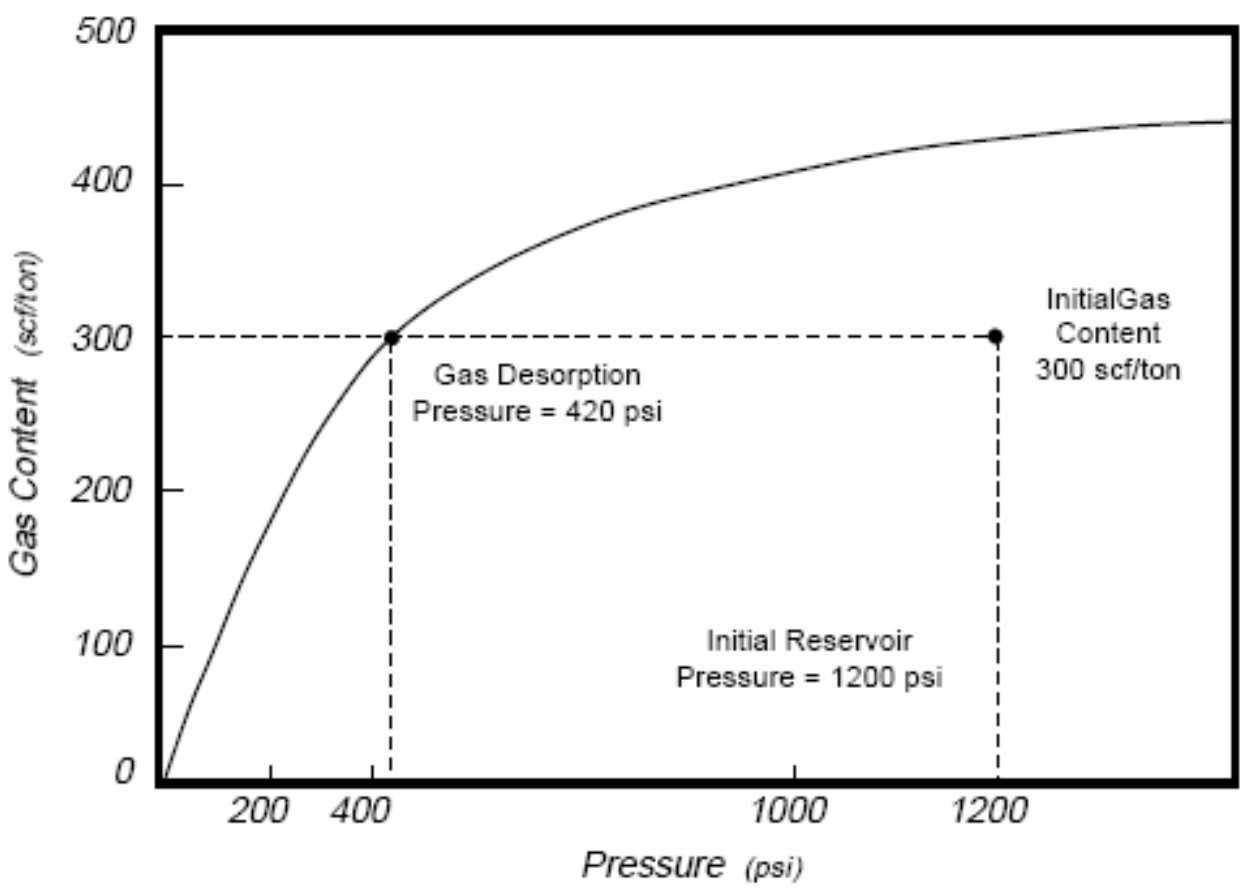

Figure 2.8 Langmuir Isotherm

(Reprinted from Mawor et al., 1996)

The status of the stored gas in the coal can be determined by using Langmuir Isotherm. If we have an undersaturated coal (a spot under the curve, 300 scf/day), a well cannot produce gas until system is dewatered. Once pressure is lowered so that it reaches the isotherm curve, we can easily calculate the pressure at which gas starts to desorb, and production takes place (420 psi for the example shown above).

Langmuir Isotherm, presented above, best describes the connection between pressure and adsorbed capacity of coals. Desorption isotherm shows that the adsorbed gas concentration in the coal matrix changes as a function of the free gas pressure in the coal cleat system. Therefore, it represents the association between the flow in the matrix system and the flow in the cleat system. The Langmuir Equation defines this non-linear relationship:

$C_{m}=$ Matrix gas concentration, $\mathrm{scf} / \mathrm{ft}^{3}$

$V_{L}=$ Dry, ash-free Langmuir volume constant, scf/ton

$p=$ Pressure in fracture system, psia

$p_{L}=$ Langmuir pressure constant, psia

$\rho_{B}=$ Bulk density, $\mathrm{g} / \mathrm{cm}^{3}$

$$
C_{m}=\frac{V_{L} p}{p_{L}+p}\left(0.031 \rho_{B}\right)
$$


The other byproduct of the coalification process that takes an important place in analyzing coalbed methane is water. It can be stored in coals in two ways: (a) as bound water in the coal matrix, and (b) as free water in the coal cleat system. Matrix bound water is not mobile, and has not shown any significant influence in methane recovery from coal.

However, the free water, held in the cleat system, represents one of the critical parameters in methane production. The free water is mobile at high water saturations (higher than 30 percent). Many coal deposits are active aquifer systems and are 100 percent water saturated in the cleat system. Those that are not aquifers may not be totally water saturated. Typical irreducible water saturation for a well-cleated coal is in the range of 20 to 50 percent of the interconnected cleat volume (Mawor et al., 1996)

Diffusion is the process represented by random motion of molecules from an area of high concentration to an area of lower gas concentration. Fick's law mathematically describes the diffusion process:

$$
q_{g m}=\frac{8 \pi D V_{m}}{s_{f}^{2}}\left(C_{m}-C(p)\right)
$$

$$
\begin{aligned}
q_{g m}= & \text { Gas production rate from the coal } \\
& \text { matrix, scf } / \text { day } \\
D= & \text { Diffusion coefficient, } \mathrm{ft}^{2} / \text { day } \\
V_{m}= & \text { Matrix volume, } \mathrm{ft}^{3} \\
s_{f}= & \text { Fracture spacing, } \mathrm{ft} \\
C_{m}= & \text { Matrix gas concentration, } \mathrm{scf} / \mathrm{ft}^{3} \\
C(p)= & \text { Equilibrium concentration at } \\
& \text { matrix-cleat boundary, } \mathrm{scf} / \mathrm{ft}^{3}
\end{aligned}
$$


High

Methane

Concentration

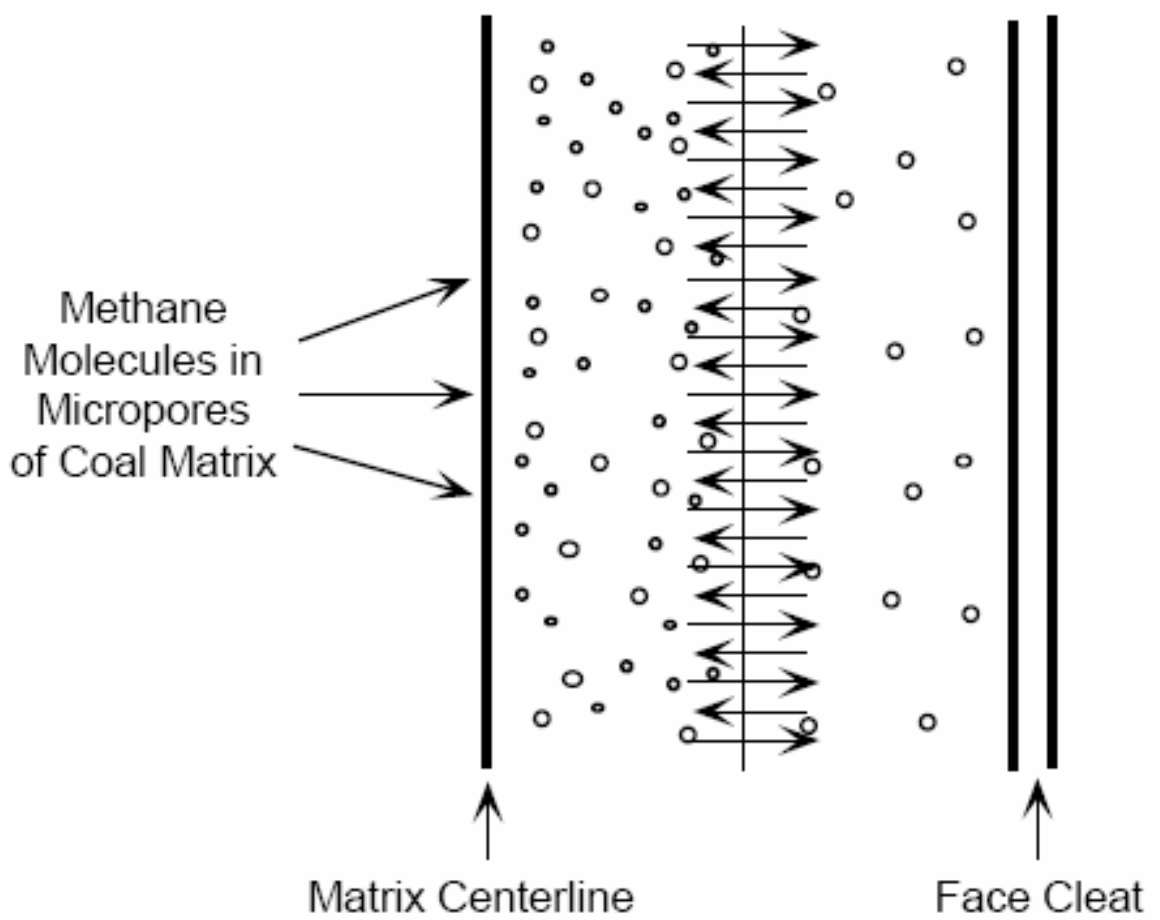

Figure 2.9 Molecular Diffusion of Methane in a Coal Matrix

(Reprinted from Mawor et al., 1996)

The diffusion coefficient (D) is determined by desorbing methane from a core in a laboratory and measuring the rate of desorption as a function of time. It is related to sorption time, ( $\tau$, days), and cleat spacing $(\mathrm{s} f, \mathrm{ft})$. Sorption time is referred as the time required for methane molecules to desorb off of the coal surface and diffuse through the coal into the cleat system. In coals, this time can vary from less than one day to over 300 days, depending on coal composition, rank, and cleat spacing (Boyer C. M. et al., 1990). Sorption time can be calculated by using the following equation:

$$
\tau=\frac{s_{f}{ }^{2}}{8 \pi D}
$$


The methane flow in the coal starts with lowering the pressure in order to produce the free gas and water from the natural system, and to desorb methane from the cleat surface. Releasing gas from the matrix by diffusion compensates the variation in concentration. Desorption is controlled by pressure gradients, while diffusion is controlled by concentration gradient. Once the gas reaches a cleat or fracture, the flow of methane through the coal can be described by using Darcy's Law. Darcy's Law is applied to reservoirs with the simultaneous flow of more than one fluid by including the effective permeability to each flowing phase (Mawor et al., 1996)

\section{Gas Production from the Coal beds}

During the lifetime of the coalbed methane production, the gas production passes through three distinct phases. The behavior of the production curve for the coalbed methane differs significantly from the decline gas curve in the conventional reservoirs. The inclining gas rate tendency occurs in the early lifetime of coalbed methane well since water originally occupied the fracture system in the reservoir, which controls flow to the well. In order to lower initial reservoir pressure, achieve a pressure difference, and allow disorbing process to take place, water must be removed from the cleat system. This process is called dewatering.

The production profile of coalbed methane well is shown in figure 2.10.

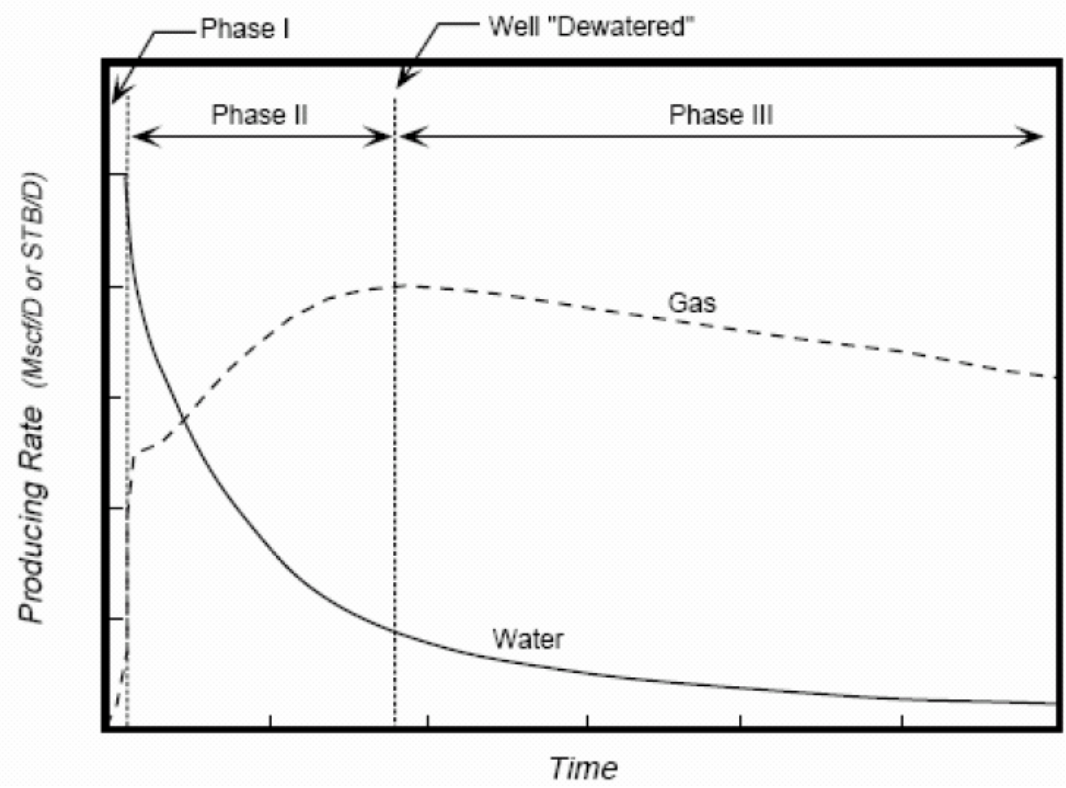

Figure 2.10 Coalbed Methane Production Profiles for Gas and Water Rates: Three Phases of Producing Life (Reprinted from Mawor et al., 1996) 
Phase $\mathbf{I}$ is characterized by a constant water production rate and declining flowing Bottom hole pressure. During this phase, the well is being "pumped-off", and the gas rate may be inclining. The gas rate may also decline, depending on the near-well relative permeability characteristics of the reservoir. At the end of phase I, the well has reached its minimum flowing bottom hole pressure.

Phase II is characterized by the "negative decline" in the gas production rate and a significant decline in the water production rate. Phase II is characterized by several dynamic changes in reservoir flow conditions:

- Water relative permeability decreases;

- Gas relative permeability increases;

- Outer boundary effects become significant (pseudo steady state flow);

- Gas desorption rates change dynamically.

Phase II is described by a dramatic decrease in the water production and increase of the gas production rate. The water relative permeability decreases and the gas relative permeability increases. Outer boundary effects become significant and gas desorption rates change dynamically (Mawor et al., 1996)

Phase III begins when reservoir flow conditions have been stabilized. The well has reached its peak gas rate, and gas production is characterized by a more typical decline trend. During this phase, water production is low and/or negligible, and gas and water relative permeability changes very little. The well is considered to be "dewatered" at the beginning of phase III. At this point, water production has reached a low (and sometimes negligible) level, and gas and water relative permeability changes little hereafter. Pseudosteady state flow exists for the rest of phase III. Interference effects can greatly improve the economic recovery of gas from coal seams. For example, a single isolated well, drilled in a wildcat area, may have a much different productivity response than an average development well, which is drilled in the same area and is influenced by offset well interference. These differences can be estimated using a reservoir simulation model that includes reservoir data from the wildcat well, and the effects of offset well 
interference. Alternately, a closed well pattern (such as a 5-spot) may be used to test the potential of recovering methane from coals in wildcat areas (Mawor et al., 1996).

\section{Coalbed Methane Horizontal Wells}

The history of drilling horizontal wells in the coalbed dates from nearly 50 years ago, precisely 1958. The goal of first horizontals was to degasificate the coal seams, several years prior to mining operations, in order to lower the possibility of underground explosion and accidents in the mines. Upon introduction of horizontal degasification wells, mine safety has been improved immensely. Some of coal companies, which have been engaged in degasification of coal seams, reported a significant amount of produced gas. Several techniques have been developed for production of methane from virgin coals and coal seams undergoing mining operations. The methane can be drained through horizontal holes with small diameter. The original permeability of the coal seam predominantly depends on the presence of the cleat system. The face cleat is continuous through the reservoir, and capable of draining large areas. One of the main advantages of the horizontal wells is that the well direction, shape, and position can be controlled. By using horizontal wells, an almost perfect position of the well can be determined and performed in respect to principal permeability directions of the coal. The proper positioning of the well, as well as the proper length of a borehole, drilled perpendicular to a main fracture system of the coal, can contribute to draining large areas.

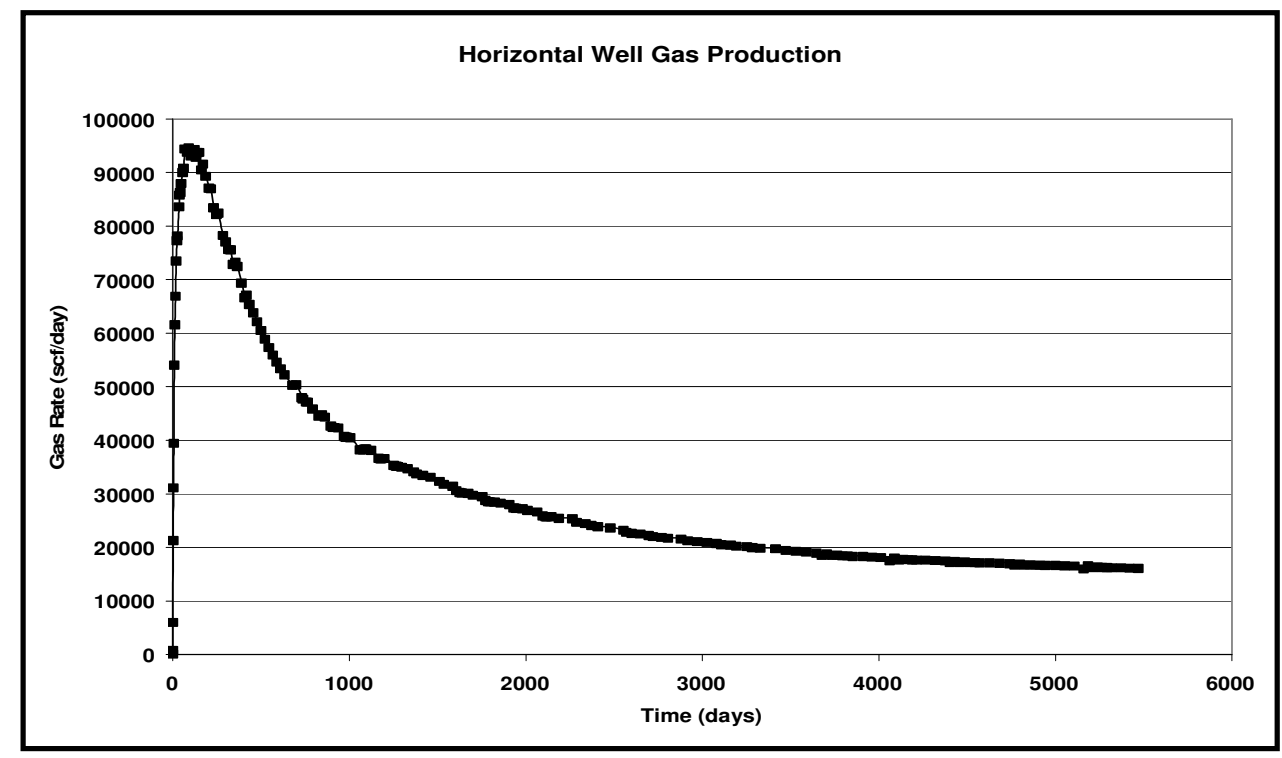

Figure 2.11 Typical Production Performance of a Horizontal Drainage Well 
It is obvious that with the longer horizontal pattern of the well, the gas deliverability of the well is better. The question is which shape of a horizontal well to drill in order to stimulate the well to produce the larger amount of gas in the shortest possible time. Drilling horizontal wells in coal seams is highly important to the sweep efficiency. The higher the length of a well bore and its contact with a coal seam, the shorter the time of gas sweeping and water production. Usually, the gas flow curves of vertical and horizontal wells will significantly differ from each other. In a very short time, the horizontal well will dewater the system, and a significant water production will take a short period of time. The gas flow peak will occur very soon after the well starts to produce gas. The most important part of the gas flow curve is the one after the gas flow peak. The slope of curve is of essential importance, since from that point on, the well will produce gas like a conventional gas reservoir. The flatter the curve, the better the gas production will be for the rest of the well life.

Interference effects can greatly improve the economic recovery of gas from coal seams. For example, a single isolated well, drilled in a wildcat area, may have a much different productivity response than an average development well that is drilled in the same area and is influenced by offset well interference. Using a reservoir simulation model that includes reservoir data from the wildcat well, and the effects of offset well interference can estimate these differences.

The issue is that the horizontal wells, due to much longer perforated length than the thickness of the coal seam is, are capable of draining the system very fast. The dewatering process will take place immediately when the well is drilled due to the length of the well, and the system could be dewatered in a short period of time. As a consequence, the adsorption process will happen very soon, and the well will elicit a very steep negative decline curve. But after reaching the peak, the gas production will start to decrease immensely, again due to a very large amount of the area that the horizontal well can sweep. We will have a very fast gas production process, represented by a very sharp incline curve. Again, here it is important to mention that the most influenced part of a gas flow rate curve on the gas production, and the future behavior of well production is the shape and angle of the curve a well performs after the negative decline period of 
production. In other words, after the peak of gas production, the pseudo steady state will take place, and the less steep curve means better production in the future.

Actually, the gas flow peak has a big influence on the overall and cumulative production of the well, and also the economic issue will have different behavior. But, the most important issue is that of the type of a curve, representing gas production after the peak.

We can compare two gas production curves. If one of them has a high gas peak, but after reaching the maximum production, a very steep decline occurs, and the other one does not perform a high production, but the steady state flow curve is much smoother, and the decline is not so sharp, then the other well will have high overall production. 


\section{Reservoir Simulators}

Computer Modeling Group Simulator

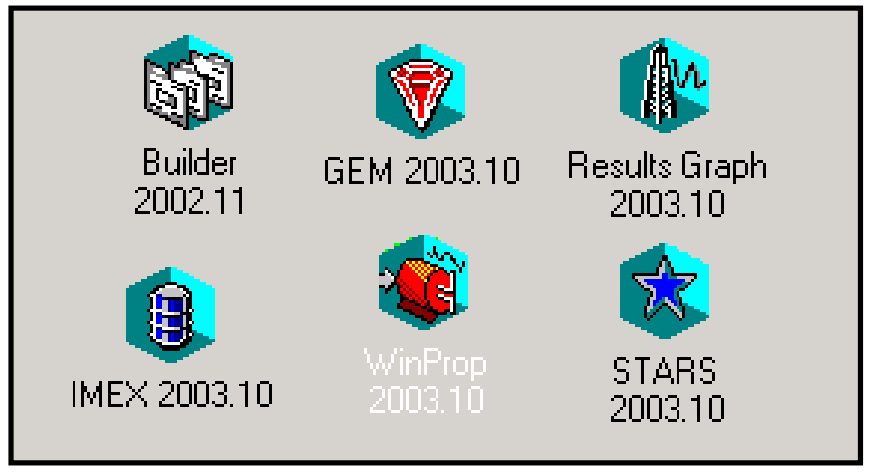

Figure 2.12 Eight Basic Applications Existed in the Computer Modeling Group (CMG) Reservoir Engineering Software

CMG (Computer Modeling Group) model is reservoir engineering software, used for reservoir capacity and hydrocarbon potential determination and recovery.

Reservoir simulators are built on reservoir models that include the petrophysical characteristics required to understand the behavior of the fluids over time. Usually, the simulator is calibrated using historic pressure and production data in a process referred to as "history matching." Once the simulator has been successfully calibrated, it is used to predict future reservoir production under a series of potential scenarios, such as drilling new wells, injecting various fluids or stimulation (www.glossary.oilfield.slb.com).

\begin{tabular}{|l|l|l|}
\hline$\#$ & \multicolumn{1}{|c|}{ Module } & \multicolumn{1}{c|}{ Explanation } \\
\hline $\mathbf{1}$ & BUILDER & Preprocessing Application \\
\hline $\mathbf{2}$ & IMEX & Black Oil Simulator \\
\hline $\mathbf{3}$ & STARS & Steam Thermal Advanced Process \\
\hline $\mathbf{4}$ & GEM & Generalized Equation-of-State \\
\hline $\mathbf{5}$ & WINPROP & Phase Behavior Analysis \\
\hline $\mathbf{6}$ & RESULTS & Post processing \\
\hline
\end{tabular}

Table 2.1 Main Modules in the CMG Simulator with the Explanations 
For the purpose of this study GEM - Generalized Equation-of-State has been used as the simulator including three modules:

- Grid Builder;

- Model Builder;

- Results (Graphs and 3D).

BUILDER is an application used in the preparation of reservoir simulation models. It makes the design and preparation of reservoir models faster and more efficient. It does this by helping engineers navigate the often complex processes involved in preparing a model.(Garcia, A., 2004.)

GEM is CMG's fully compositional simulator, used to model any type of reservoir where the importance of the fluid composition and their interactions are essential to the understanding of the recovery process. It is an essential engineering tool for modeling very complex reservoirs with complicated phase behavior interactions that impact directly on the recovery mechanisms employed to optimize the recovery. (Garcia, A., 2004.)

Results Graph is a 2D graph of well production and injection data from simulator runs, and from common historical production data sources. It is controlled and defined by the user to provide all the options that the user needs to better understand the reservoir. Results $3 \mathrm{D}$ is a module that produces high quality scaled $2 \mathrm{D}$ and $3 \mathrm{D}$ views of all grid based simulator data, and links the displayed wells directly to the graphing capabilities of Results Graph. (Garcia, A., 2004.)

Detailed explanation of using this simulator is explained in CHAPTER IV. OBJECTIVE AND METHODOLOGY under "Building, Running and Analyzing a Coal Bed Methane Model" sub chapter. 


\section{Artificial Intelligence}

Artificial Intelligence represents a tool of so called smart tools that are attempting to imitate life. In the petroleum industry, these tools have been used to solve problems related to pressure transient analyses, well log interpretation, reservoir characterization, and candidate well selection for stimulation, among other things. One of the most used artificial intelligent tools, that was also used in this study, is Artificial Neural Networks.

\section{Artificial Neural Networks}

Artificial Neural Networks (ANNs) were born from the desire of creating artificial systems that are capable of intelligent computation similar to the one that the human brain performs. ANNs represent one of the most widely used artificial intelligence tools.

Artificial neural networks ANNs are one of the most widely used artificial intelligence tools in many disciplines. ANNs are an analog, adaptive, distributive, and highly parallel system, capable of extracting information and storing knowledge to be used in pattern recognition problems. ANNs provide a powerful tool to perform non-linear, multidimensional interpolation. This feature makes it possible to capture the existing nonlinear relationships between the input parameters and the output of the system. For successful training, the neural networks must be exposed to sufficient and representative data in order to gain knowledge to accurately predict new situations. Substantial applicability for artificial neural networks has been found in the petroleum and natural gas industry (www.IntelligentSolutionsInc.com, 2004). 


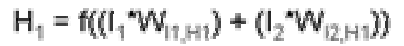

$$
\begin{aligned}
& \left.\mathrm{H}_{2}=\mathrm{f}\left(\mathrm{l}_{1} \mathrm{~W}_{(1, \mathrm{H})}\right)+\left(\mathrm{d}_{2} \mathrm{~W}_{2, \mathrm{H}}\right)\right) \\
& \mathrm{O}=f\left(\mathrm{H}_{1}{ }^{*} \mathrm{~W}_{\mathrm{H} 1 \mathrm{O}} \mathrm{O}\right)+\left(\mathrm{H}_{2} \mathrm{~W}_{\mathrm{H2}} \mathrm{O}\right)
\end{aligned}
$$

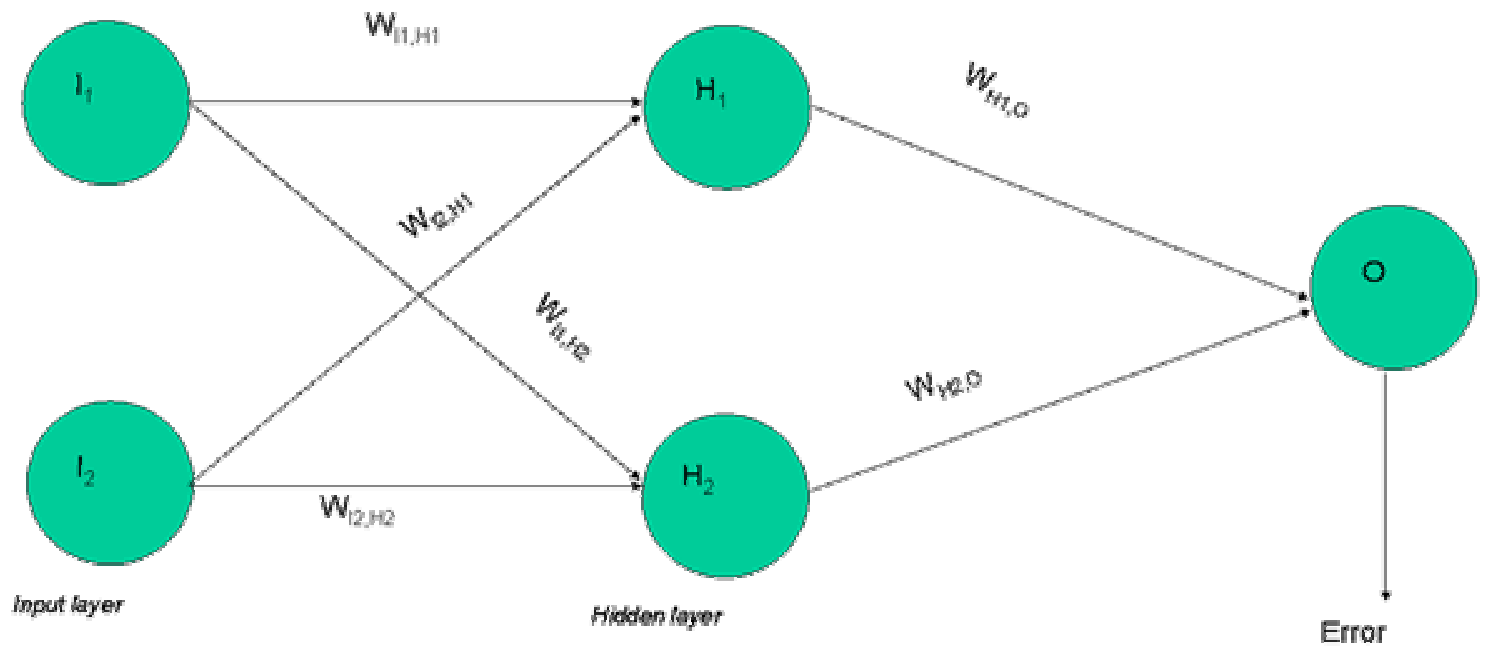

Neural Network Architecture

Figure 2.13 Neural Network Architecture 


\section{CHAPTER III.}

\section{OBJECTIVE AND METHODOLOGY}

\subsection{Statement of Problem}

Due to very thin reservoirs found in the North East part of USA, the option of horizontal well drilling and completion represents interesting approach for CBM field development. However, even with the leading edge drilling tools and ability of performance of various horizontal shapes in the state of the art manner, it is still a question of how certain horizontal configurations would affect CBM recovery in the terms of time, investment, and ultimate recovery and rate of return.

Different coal properties dictate ultimate recovery and system behavior during the production, for a certain type of well. In other words, the very same well configuration will have different performance for different reservoirs. Prior to any approach of field development and infill drilling decision, the reservoir properties should be studied in detail.

Detailed sensitivity analysis and parametric studies have been performed in order to determine the influence of horizontal well configurations on the gas production and dewatering time, as well as the influence of reservoir properties changing with well properties.

The goal of this study was to determine the optimum horizontal well configuration for the given coal reservoir properties. 


\subsection{Study Flow Charts}

This project offers a different approach to the classical models, used to model horizontal wells, simulate current, and predict future production of the coalbed methane. The advantage of the approach taken in this study is that Virtual Intelligence does not require mathematical modeling of a given problem. In other words, no equation, iteration nor derivations are required.

In order to achieve the objective of this study determined beforehand, the methodology consisted of two main steps as follows:

1. Parametric Study of Coalbed Methane production to different Horizontal Well Configurations

2. Intelligent Modeling and Analysis

In order to better explain the various steps performed in this study, the following flowcharts were created: 


\section{Parametric Study}

Horizontal Well Configuration Definition - HWC

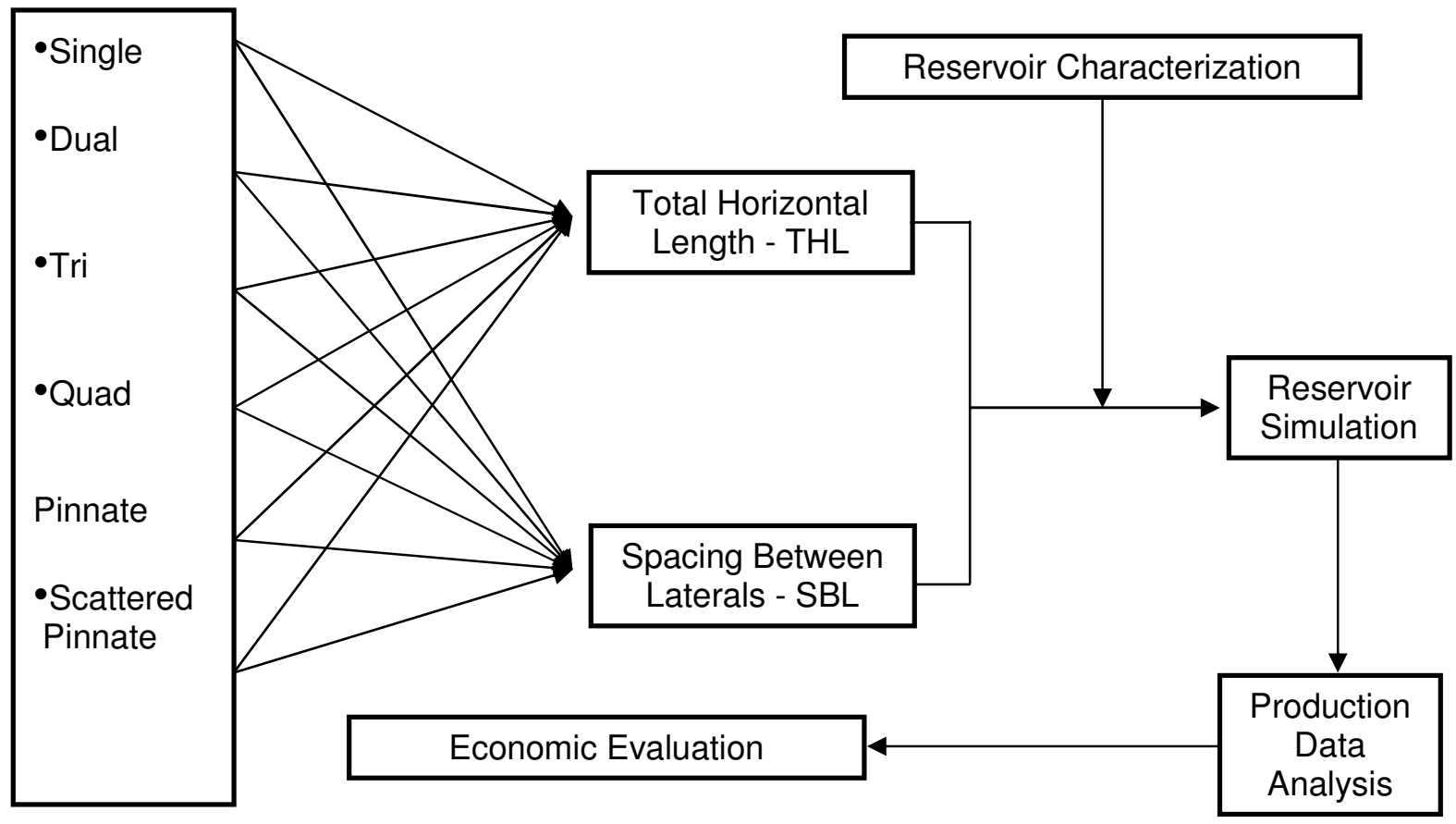

Figure 3.1 Sensitivity Analysis and Parametric Study Flow Chart 


\section{Intelligent Modeling and Analysis}

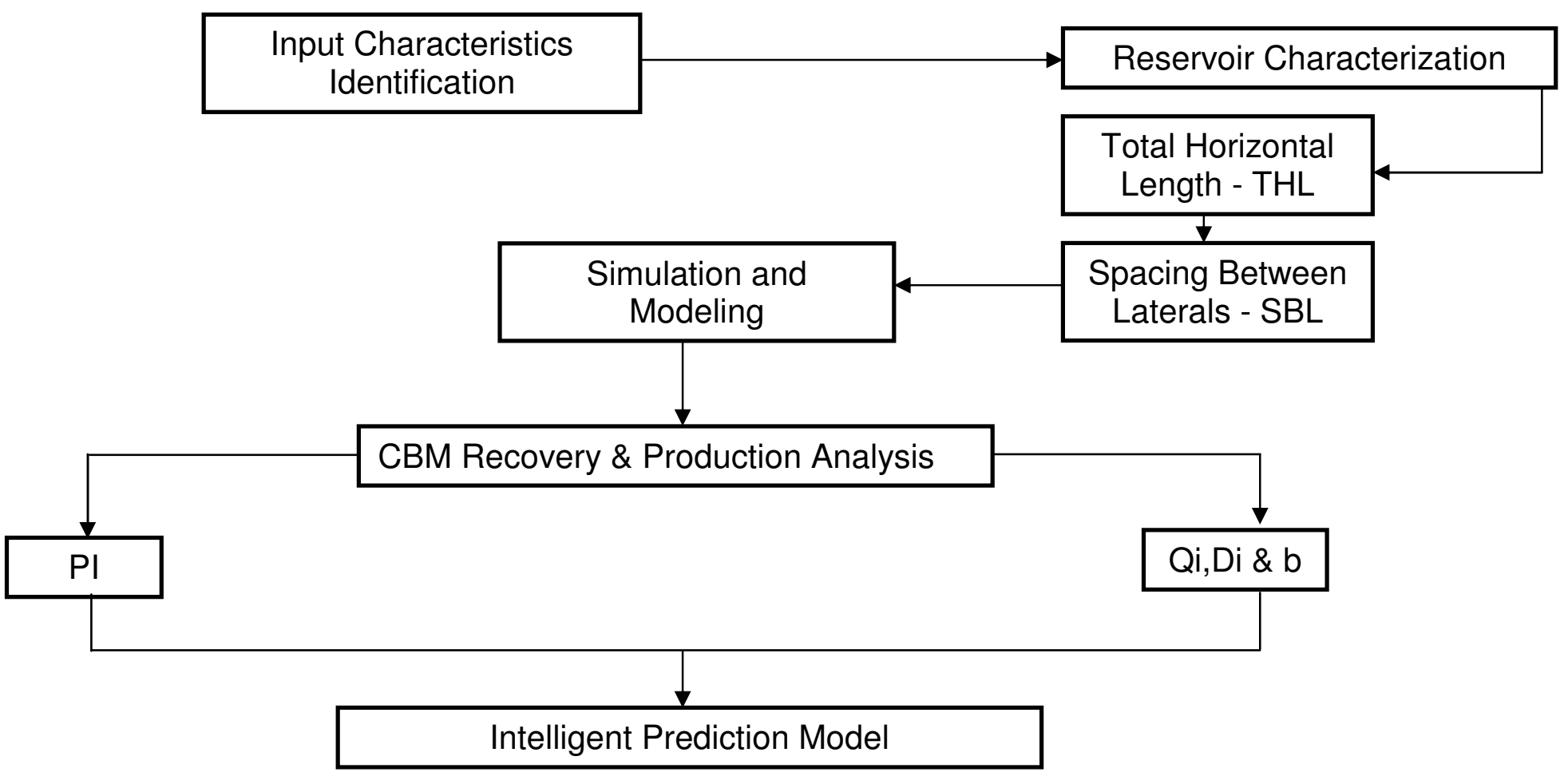

Figure 3.2 Intelligent Modeling and Analysis Flow Chart 


\subsection{Systematic Approach}

Sensitivity analysis was the first step performed in the study of two different approaches to this problem. For that purpose, the main input file was created having all reservoir parameters of interest to coalbed methane production. The goal was to perform a set of simulations using the very same inputs, but changing only parameters regarding horizontal wells. Drainage area was kept constant and for the first set of simulation only horizontal length of the well and SBL (spacing between laterals) were continuously changed step by step. Once SBL was determined (the narrowest one), it will remain constant, changing only horizontal length from the smallest to the biggest length, while running the simulator for each different scenario that took place. The maximum length of a horizontal well is constricted by the shape and size of a reservoir. Upon creating all possible scenarios for a minimum value of SBL, a new SBL, with the higher value than the previous one, was introduced. Again, the same procedure took place, keeping SBL constant, while changing horizontal length from minimum to maximum.

Naturally, the single lateral well configuration was the first one to be investigated. This was the only case in the whole study where SBLs were not used. Following the completion of all possible cases for this configuration of horizontal wells, another configuration was introduced. Having two lateral horizontal wells, the whole previously defined approach took place for this new configuration. The very same procedure was applicable to trilateral and quad lateral horizontal well configurations.

The problem having pinnate shape required some change in this approach. Obviously, there is no SBL existing with the single lateral horizontal configuration, but dual, tri and quad lateral configurations possess SBL, which was investigated in these three cases. In the terms of pinnate horizontal well shape, another scenario was made because of the specific shape of this well configuration. Another dimension has been added to the specific well configuration, allowing us not only to change the horizontal length of a well and SBL, but also the number of laterals. 
The second approach to sensitivity analysis required the definition of coalbed reservoir properties subject to change during the study. Knowing all the steps performed in the first method of this analysis, this time the minimum well length and SBL have been defined and kept constant, while changing reservoir data one by one. After changing all parameters for the given well, only was horizontal length subject to change having the same SBL. Now, the same well with the same SBL, but bigger length, was used in the sensitivity study again, applying all sets of previously determined variables, running the simulator for each. Once that well reaches its maximum length, we introduce the new well spacing and perform parametric study again. After reaching the maximum length for the maximal well spacing of that well configuration, the new well configuration is introduced, and the same procedure applied.

The goal of this approach was to introduce the new model dimension, and that is one change of reservoir variables at a time, for the whole applicable set of data. More than one thousand and five hundred simulations have been made, with the variety of input data.

In the Intelligent model approach, the whole set of reservoir variable has been changed, at the same time including well parameters. Upon thoughtful investigation of available CBM published data, and creating databases for the hundreds of existing coals, it has been decided that changing more than one parameter at the time will be crucial to the accuracy of future work. This time the goal was to get as scattered output data from simulator as possible, because that diversity will have huge influence on Neural Network model prediction. This reason led us toward the Intelligent Modeling and Analysis approach.

Set of data (from13 to 18 variables, depending on well configuration) was created and maximum and minimum numbers defined for each parameter. Once the Excel spreadsheet was created, a small Visual Basic program was written in Visual Basic for Application (Excel software), which created random numbers for each parameter, constricted by previously defined minimum and maximum values. This was the key 
decision in this study, because using this method to establish inputs for the simulator provided us with a whole new situation of reservoir conditions, horizontal well length, and SBL as well. As a product, the very different gas and water production data have been obtained and analyzed.

Having such a big diversity in the modeling allowed further Decline Curve Analysis for the practically realistic models and production declines, which significantly reflects the results of the study.

Chapter four discusses the results and conclusions of the study as well as the application in Petroleum engineering industry, which was the goal and the bottom line of this research. 


\subsection{Horizontal Well Configurations}

Starting point of this research was determining the different horizontal well configurations that would be used and implemented in the study. As result, the five mostly common horizontal well shapes used in the Petroleum Industry came to be tested:

1. Single lateral;

2. Dual lateral;

3. Tri lateral;

4. Quad lateral;

5. Pinnate.

No matter which horizontal shape has been applied to the reservoir simulator, vertical length (depth from the surface to the point where the well starts inclining to the horizontal) is constant in all cases during this study.

Vertical Length (Depth)

Horizontal Length

Spacing between Laterals
(VT)

(HL)

(SBL)

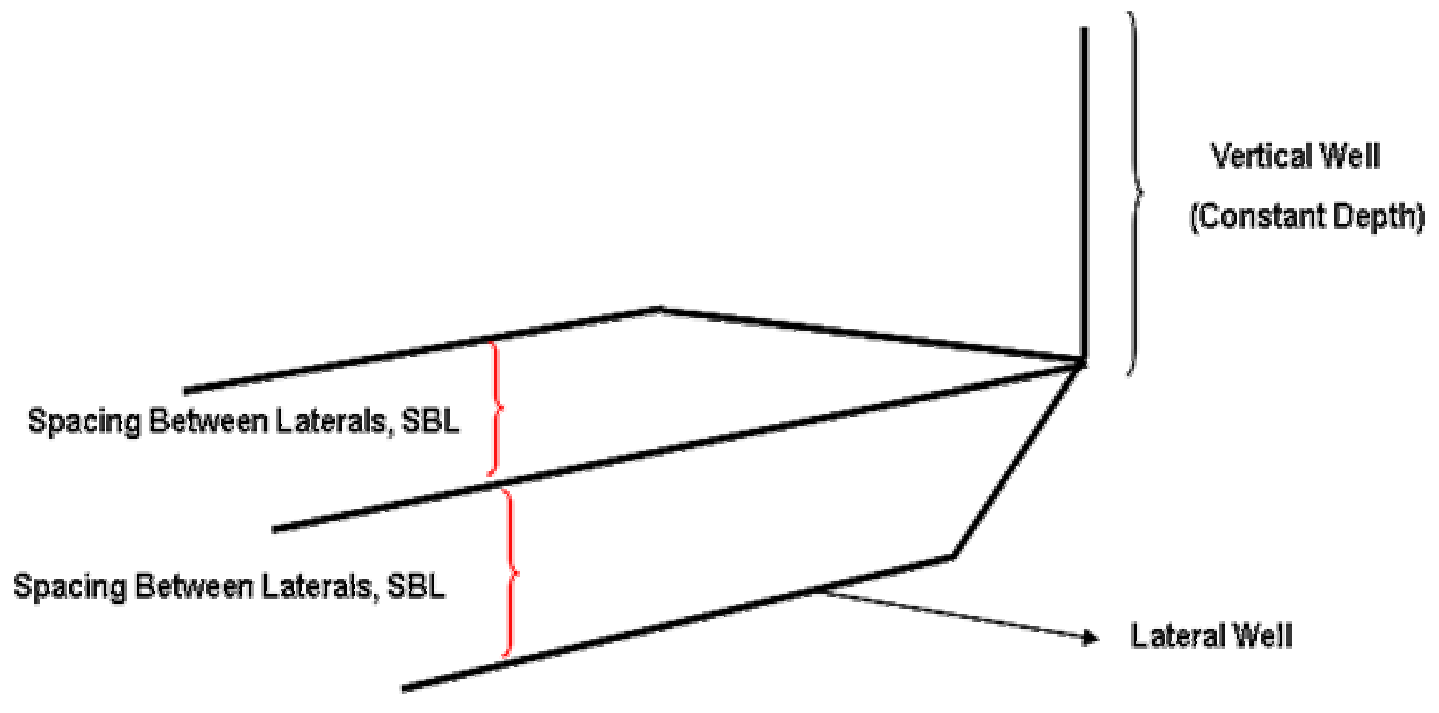

Figure 3.3. An example explaining Tri Lateral Horizontal Well Shape, Spacing between Laterals, Lateral Well and Vertical Well 
The set of figures shown below represents five different well shapes used in the study.

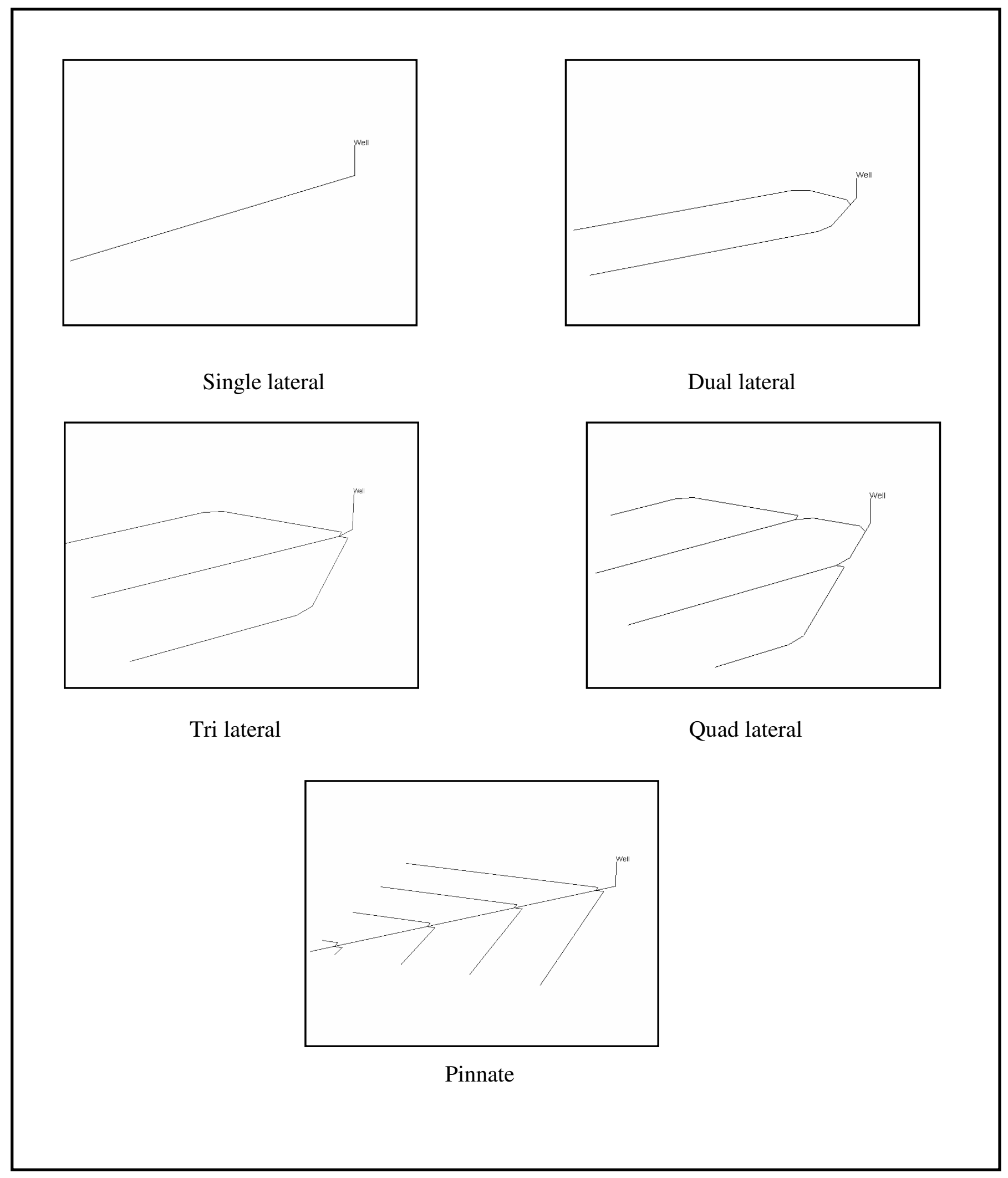

Figure 3.4 Five Well Configuration Used in This Study 


\subsection{Sensitivity Analysis of Coalbed Methane Production to Different Horizontal Well Configurations}

Sensitivity analysis represents a set of simulations in which all parameters are constant, but only one is an actual variable. This approach enables us to monitor changes of simulation outputs influenced by only one variable. The first step taken in this part of the approach was to develop a model representing CBM, and test it using different wells. Dual porosity model was used to create CBM reservoir including Gilman and Kazemi shape factor calculation. Cartesian grid model has been chosen for the modeling of CBM reservoir as well as two mandatory constraints: operate minimum bottom hole pressure of $50 \mathrm{psi}$, and operate gas rate maximum 1,000,000 ft3/day.

\begin{tabular}{|l|c|}
\hline \multicolumn{1}{|c|}{ INPUT PARAMETER / UNITS } & VALUE \\
\hline Thickness, $\mathrm{ft}$ & 4 \\
\hline Gas Content, scf/ton & 350 \\
\hline Langmuir Volume Constant -VL, scf/ton & 480 \\
\hline Langmuir Pressure Constant -PL, $\mathrm{psi}$ & 167.5 \\
\hline Production Time, years & 15 \\
\hline Pressure, $\mathrm{psi}$ & 450 \\
\hline Grid Top depth, $\mathrm{ft}$ & 1000 \\
\hline Porosity Matrix, fr. & 0.005 \\
\hline Porosity Fracture, fr. & 0.08 \\
\hline Permeability $-\mathrm{i}, \mathrm{md}$ & 0.0001 \\
\hline Permeability $-\mathrm{j}, \mathrm{md}$ & 0.0001 \\
\hline Permeability $-\mathrm{k}, \mathrm{md}$ & 0.0001 \\
\hline Fracture spacing $-\mathrm{i}, \mathrm{ft}$ & 0.05 \\
\hline Fracture spacing $-\mathrm{j}, \mathrm{ft}$ & 0.05 \\
\hline Fracture spacing $-\mathrm{k}, \mathrm{ft}$ & 0.05 \\
\hline Sw (matrix), \% & 0.5 \\
\hline Sw (fracture), $\%$ & 100 \\
\hline Permeability fracture $-\mathrm{i}, \mathrm{md}$ & 8 \\
\hline Permeability fracture $-\mathrm{j}, \mathrm{md}$ & 8 \\
\hline Permeability fracture $-\mathrm{k}, \mathrm{md}$ & 2 \\
\hline Temperature, $\mathrm{F}$ & 75 \\
\hline Rock Density, gr/cc & 1.442 \\
\hline Coal Desorption Time, days & 231 \\
\hline Ash Content , fr. & 0.05 \\
\hline Production Time, years & 15 \\
\hline BHP, psi & 30 \\
\hline Pressure Gradient psi/ft & 0.43 \\
\hline
\end{tabular}

Table 3.1. Input Parameters and Values 
Using Input parameters shown in the Fig.12, a reservoir has been created, with the following properties:

- 320 Acre Drainage Area;

- Block Size 120x120;

- Number of Blocks 30x30;

- Homogeneous Model.

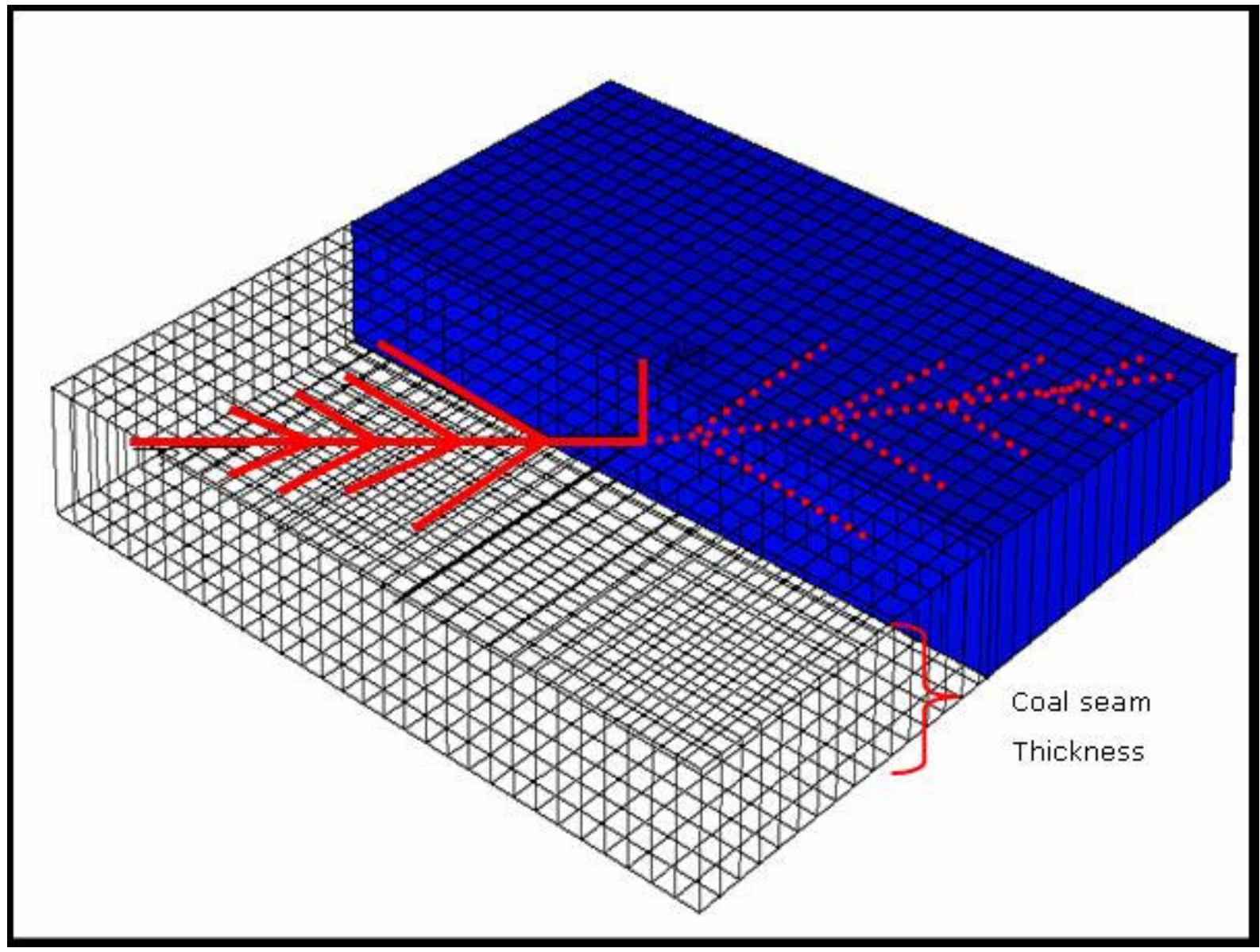

Figure 3.5 A CBM Reservoir Model Including Two Pinnate Shapes 

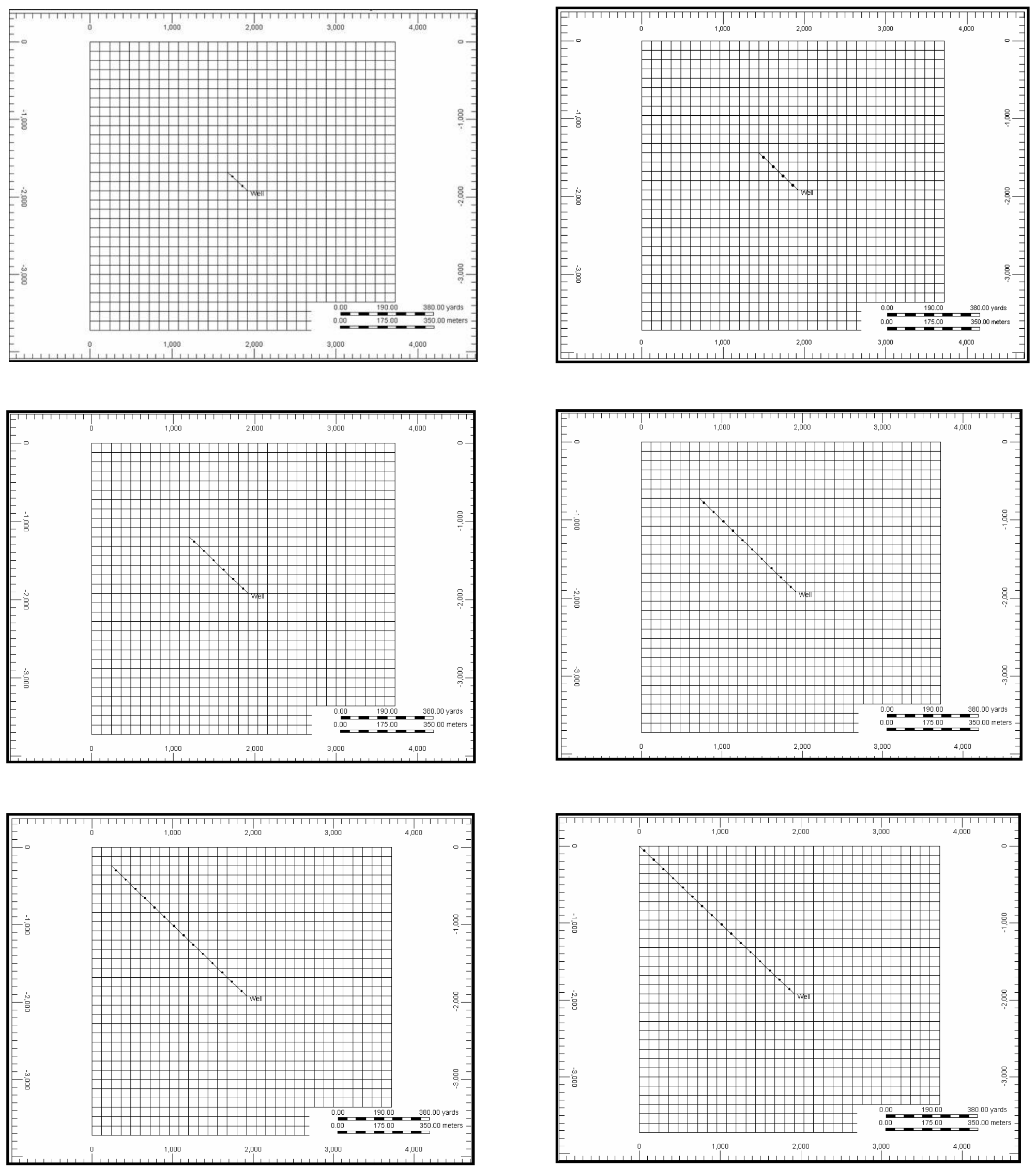

Figure 3.6 Six Different Lengths of Single Lateral Horizontal Well Configuration 

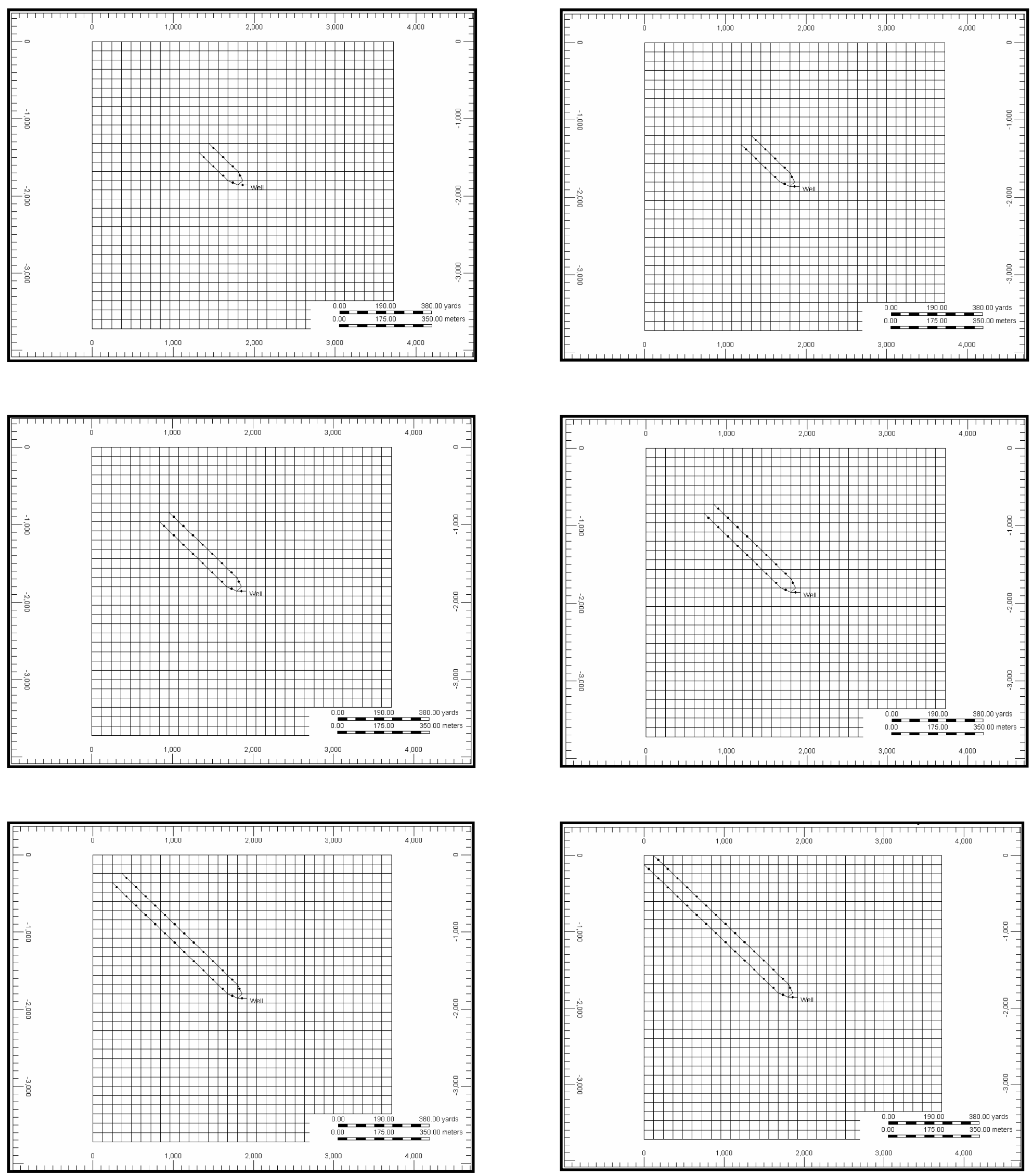

Figure 3.7 Six Different Lengths of Dual Lateral Horizontal Well Configuration 

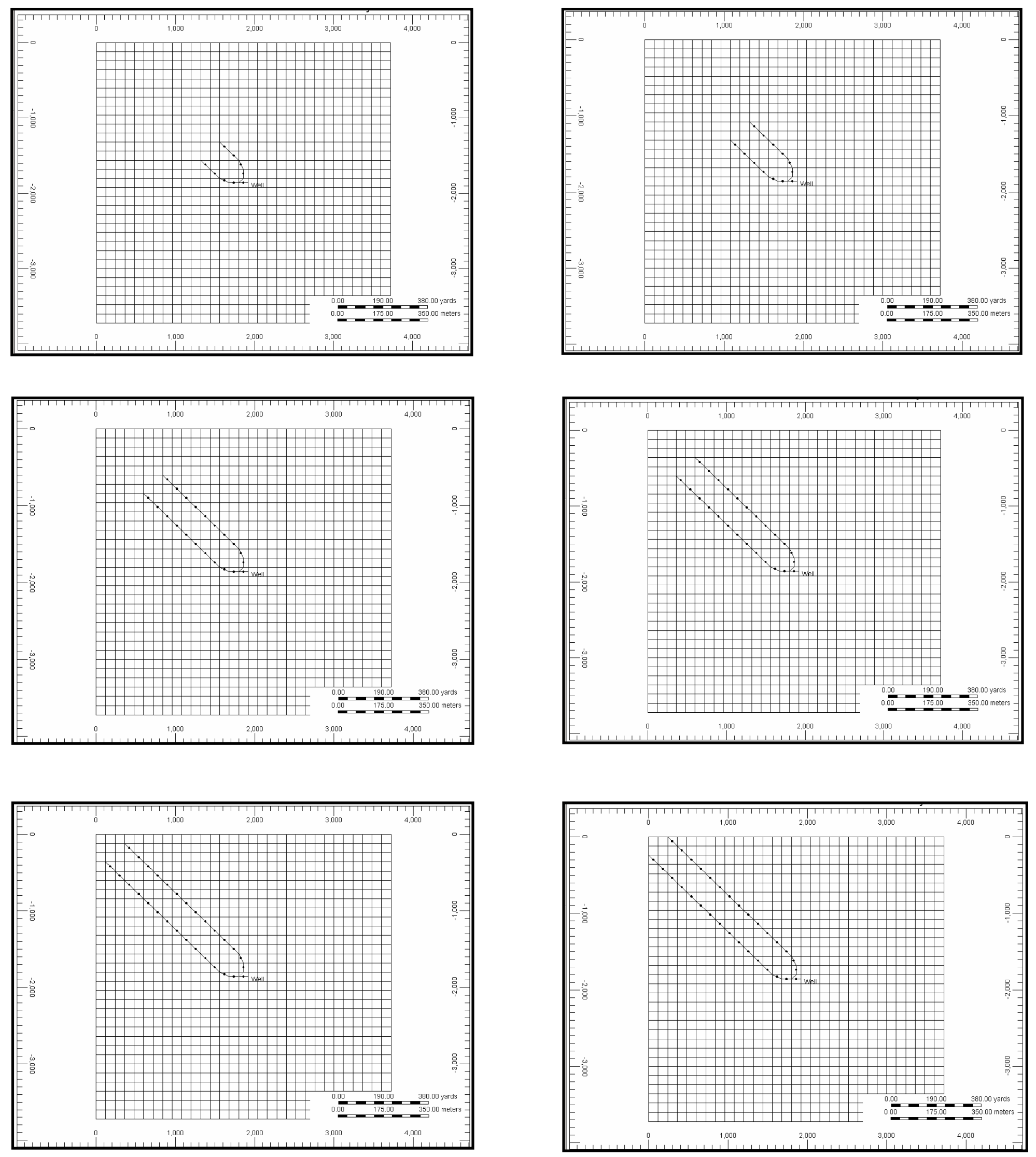

Figure 3.8 Six Different Lengths of Dual Lateral Horizontal Well Configuration 
After changing all values for spacing between laterals and lengths for Dual lateral well configurations, the very same method was applied for the rest of the investigated horizontal wells.

\subsection{Gas Recovery and Economic Analysis}

In order to investigate gas recovery, two basic values had to be calculated:

Initial Gas In Place $=820$ MMscf

$\square$ Initial Water In Place $=500,000$ bbls

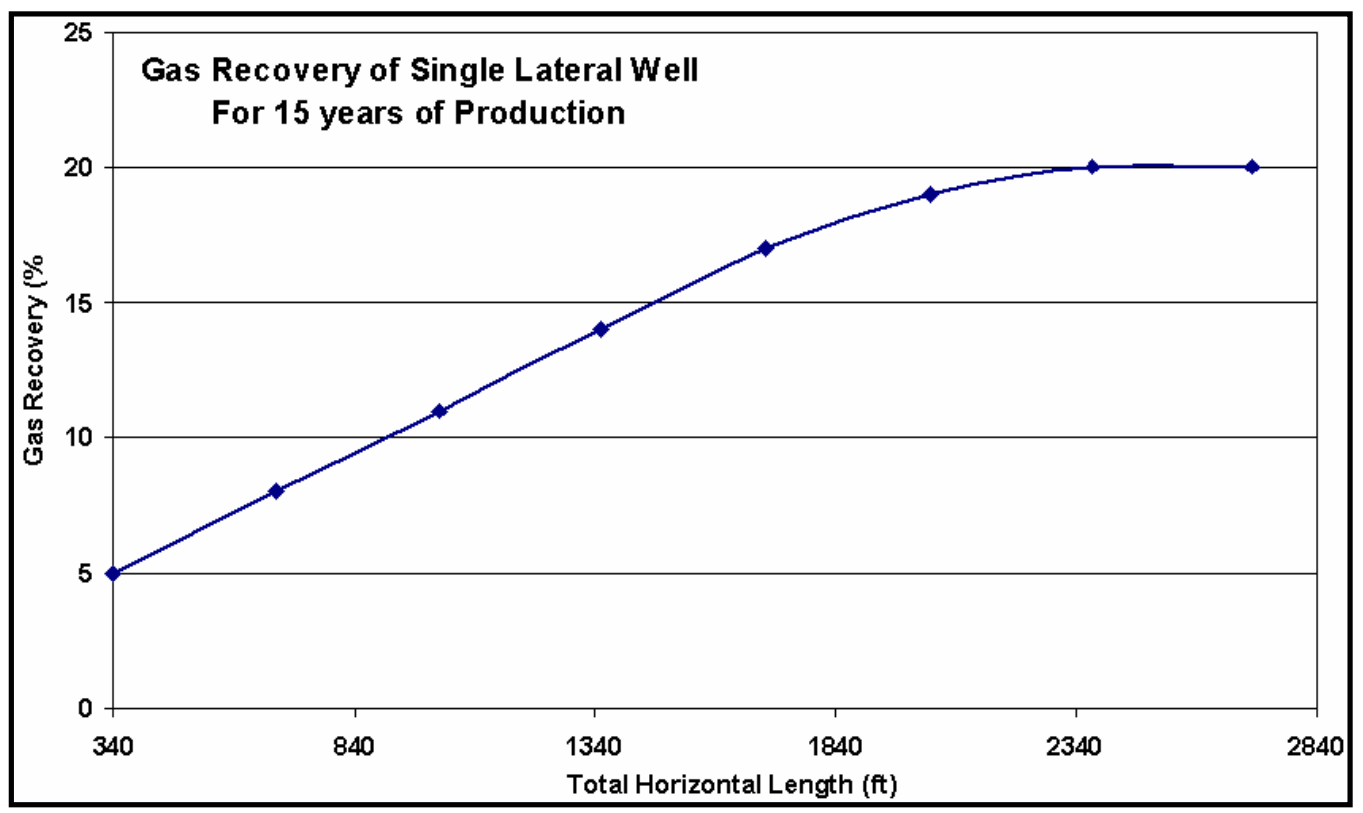

Figure 3.9 Gas Recovery-Single Lateral Horizontal Well Configurations

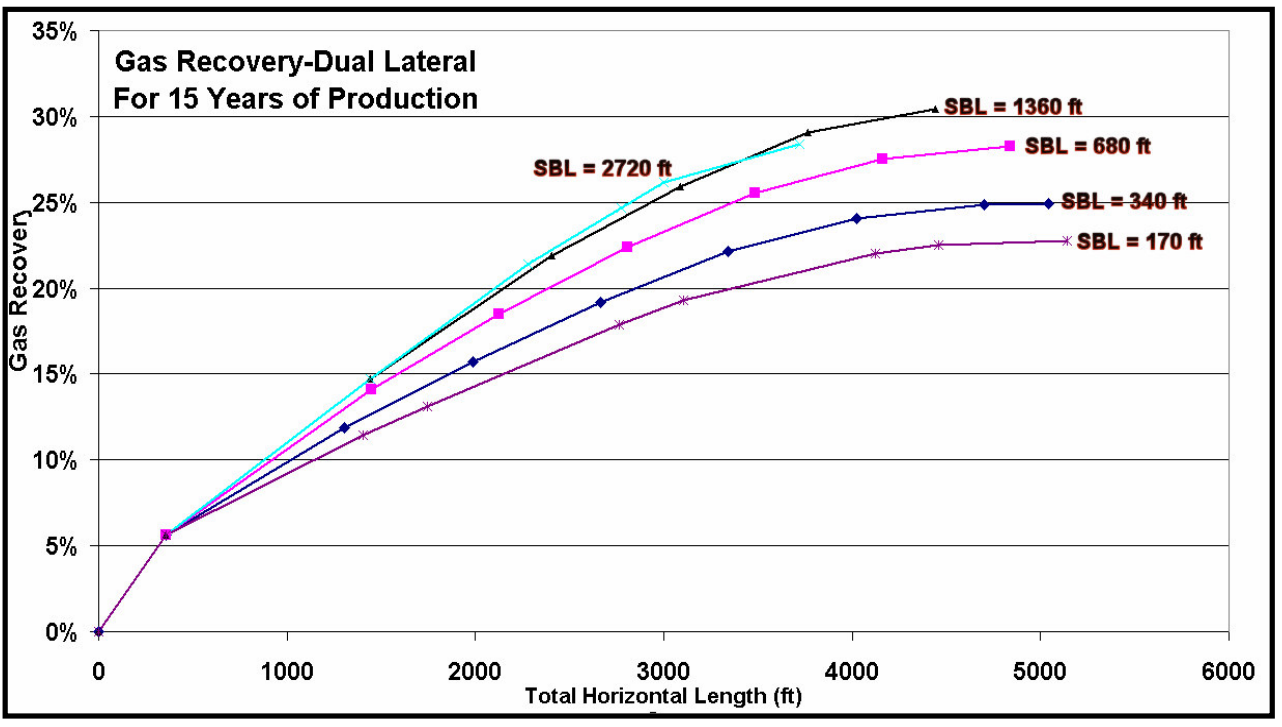

Figure 3.10 Gas Recovery-Single Lateral Horizontal Well Configurations 


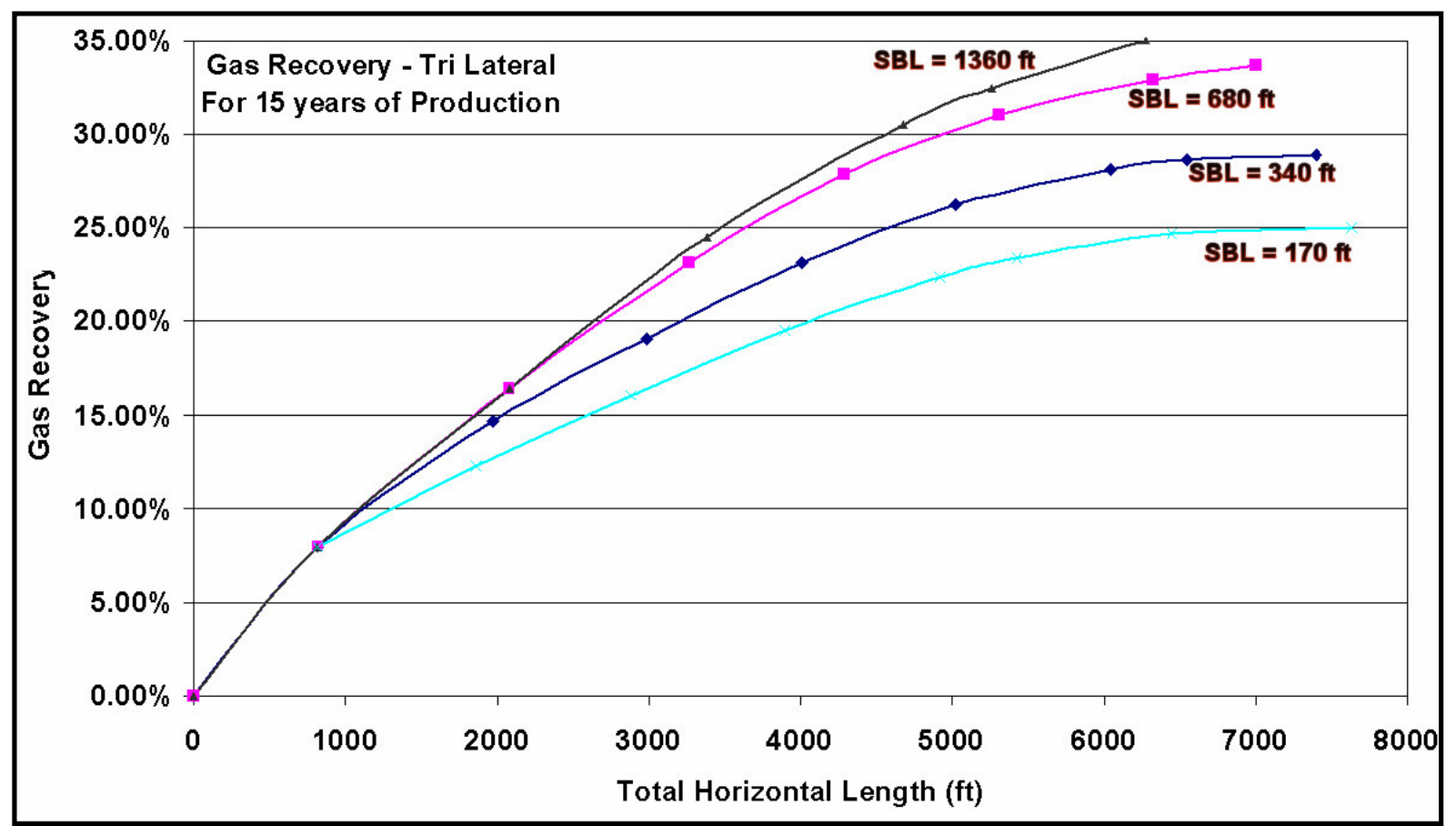

Figure 3.11 Gas Recovery-Tri Lateral Horizontal Well Configurations

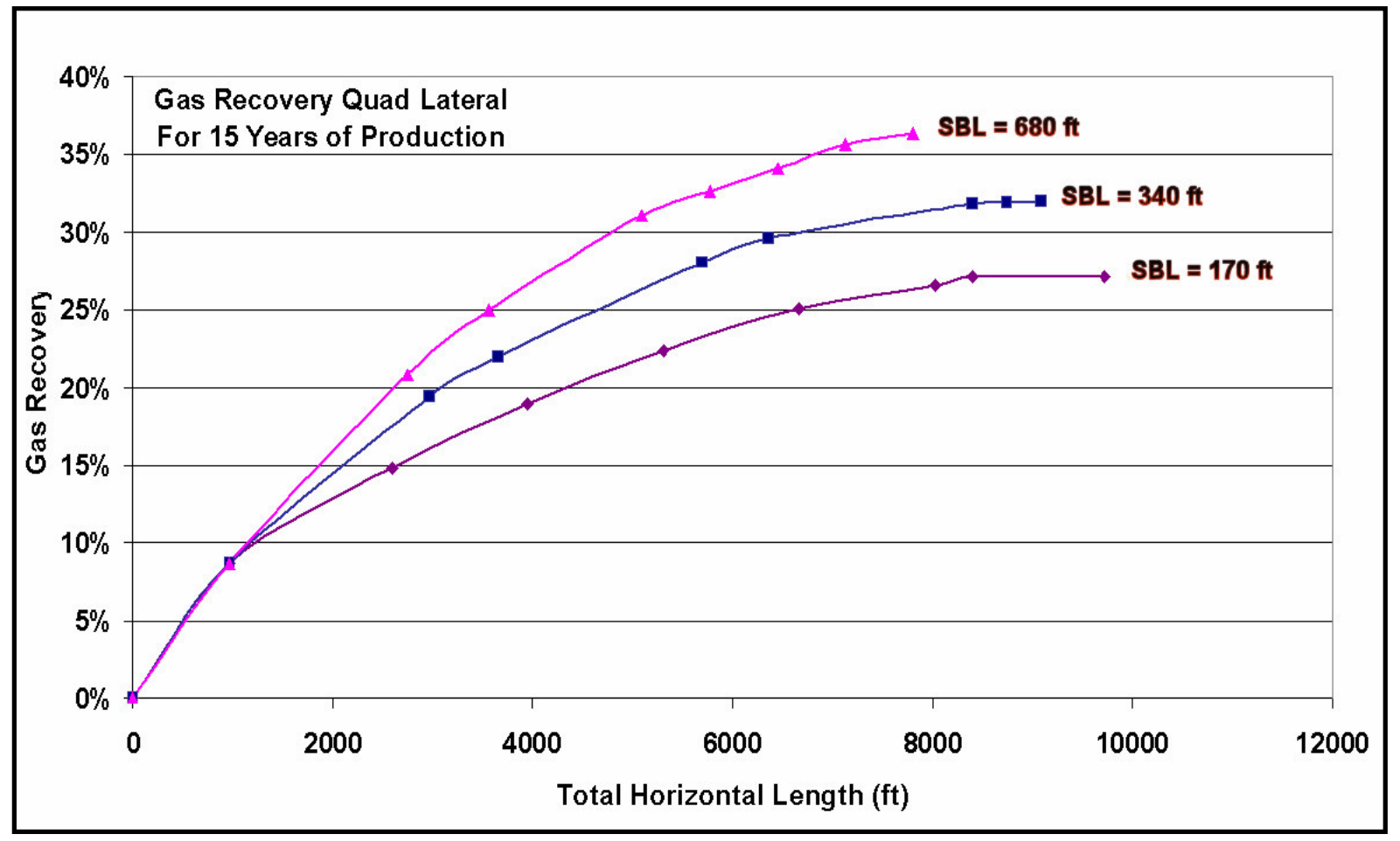

Figure 3.12 Gas Recovery-Quad Lateral Horizontal Well Configurations 


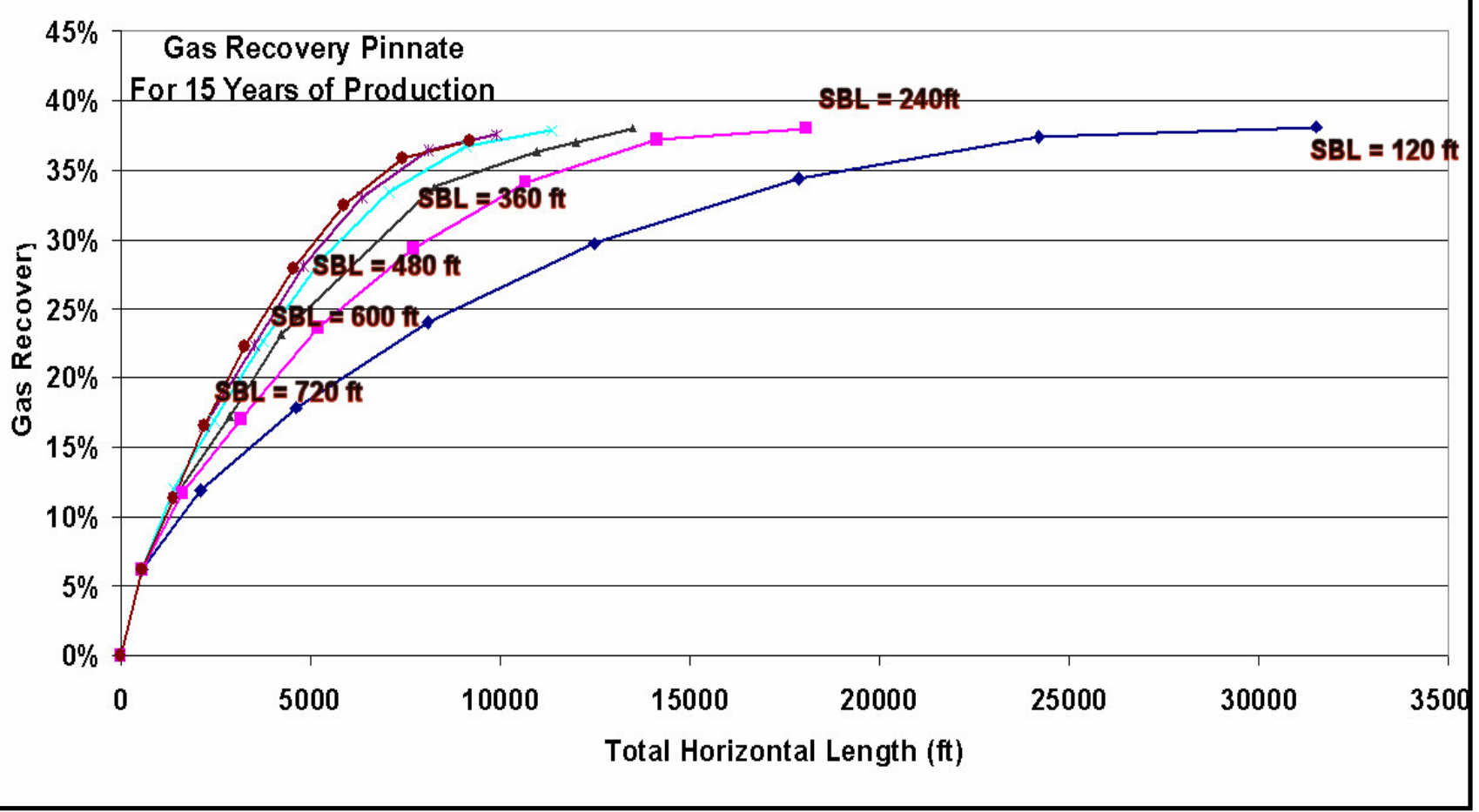

Figure 3.13 Gas Recovery-Pinnate Horizontal Well Configurations

For the comparison of pinnate shape, another well configuration was added, this timeScattered Pinnate. The shape is almost the same as a regular pinnate, the only difference is the kick off point in the horizontal is not the same for the two laterals (the same knot), but is little bit shifted. The reason for that was to investigate possible improvements in the gas production and ultimate recovery.

The best producers from five different well configurations have been compared together. From our investigation, it seems to be that the quad lateral well with the spacing between laterals of $680 \mathrm{ft}$ and total horizontal length of $8000 \mathrm{ft}$ is the one with the highest gas recovery (around 36\%). The strongest competitor, pinnate well configuration have a little bit better recovery (38\%), but for the total horizontal length of $18000 \mathrm{ft}$. The question is if it is payable to invest in drilling of additional ten thousand feet of horizontal section for gas recovering of 3-5\% more. If we compare these two horizontal well configurations for the same total horizontal length of $8000 \mathrm{ft}$, it is obvious that quad lateral configurations can recover 5-10\% more gas. 

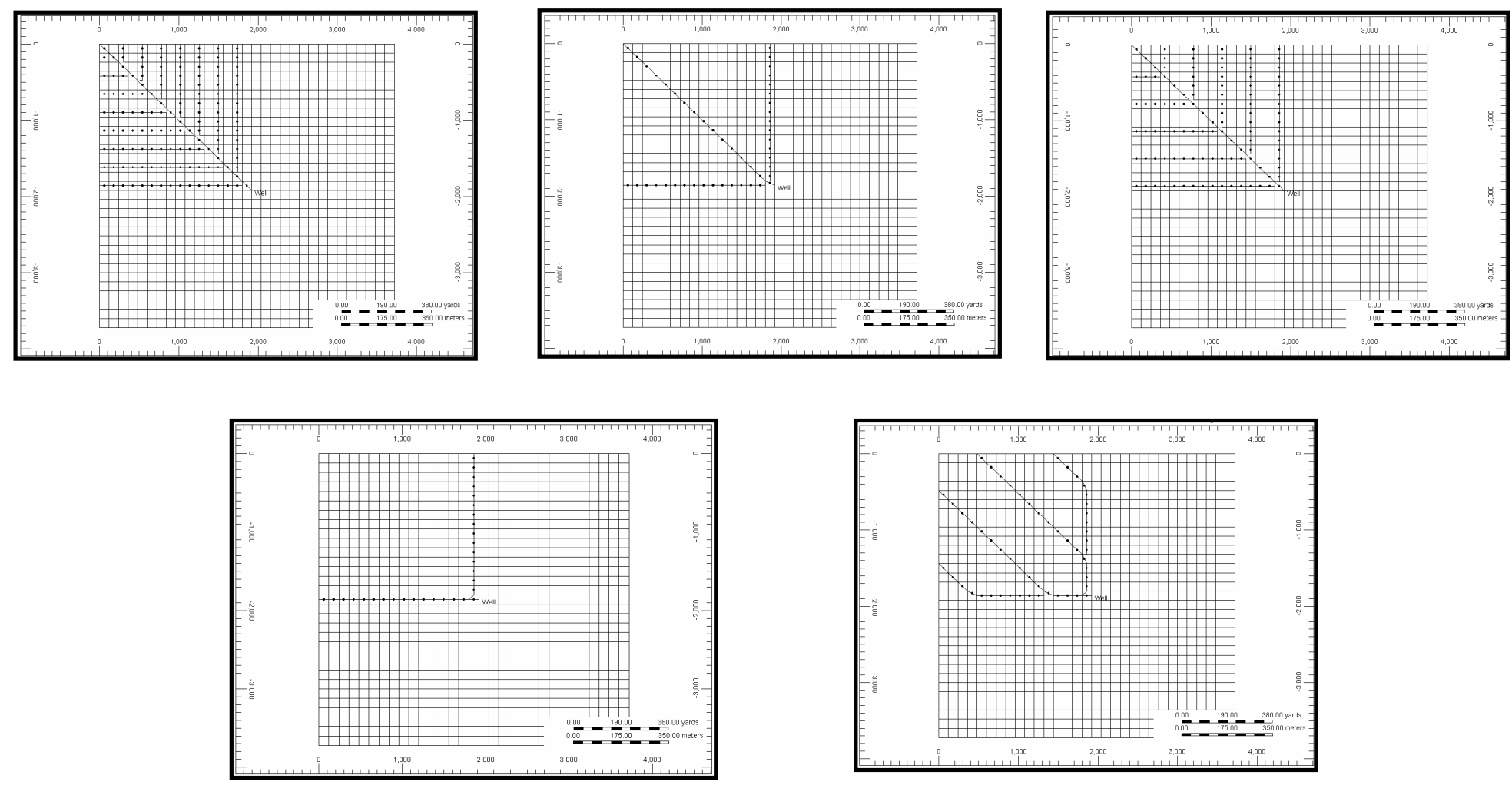

Figure 3.14 Investigated Well Configurations

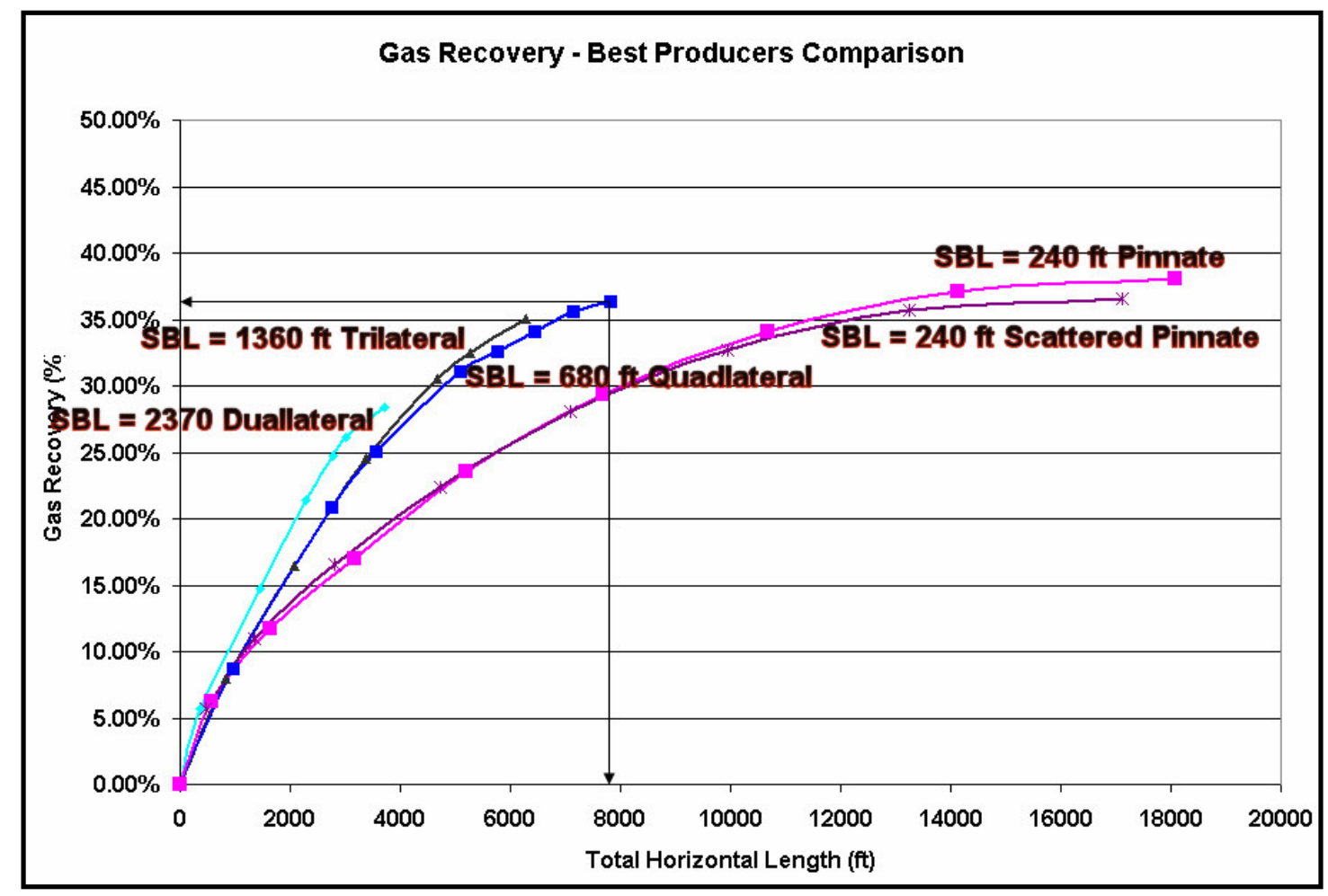

Figure 3.15 Gas Recovery-Best Producers Comparison 


\subsection{Rate of Return}

Following table shows parameters included into rate of return Calculation.

\begin{tabular}{|l|rr|}
\hline Gas Price, MCF & $\$$ & 5.00 \\
\cline { 2 - 3 } Operating Cost, MCF & $\$$ & 0.50 \\
\hline Water Disposal, bbl & $\$$ & 1.50 \\
\hline Vertical Portion of the well & $\$$ & 100,000 \\
\hline Horizontal Drilling Cost $\$ / \mathrm{ft}$ & & $\$ 10, \$ 25, \$ 50$ \\
\hline
\end{tabular}

Table 3.2 Parameters Used in Economic calculation

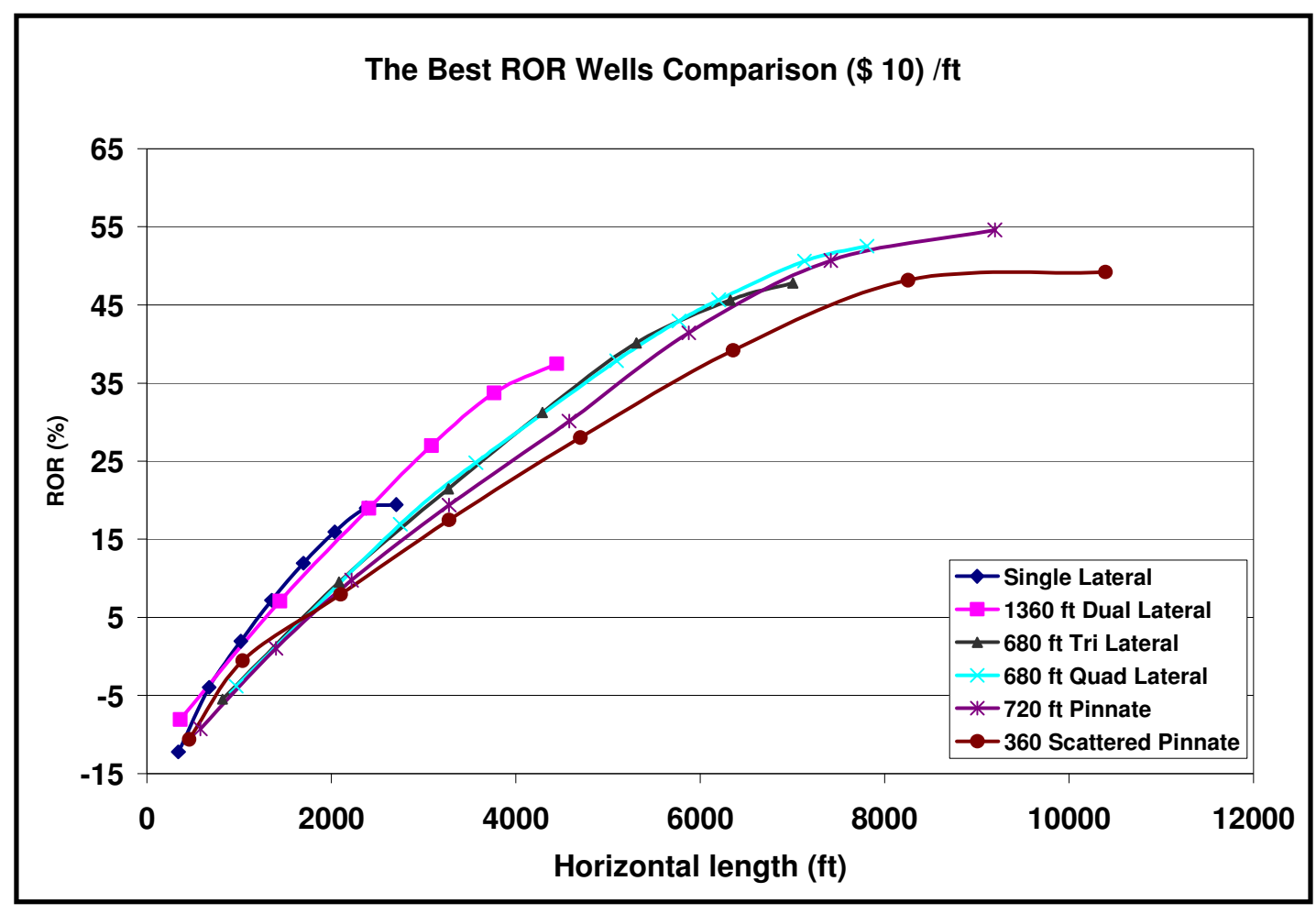

Figure 3.16 The Best ROR Well Comparison 


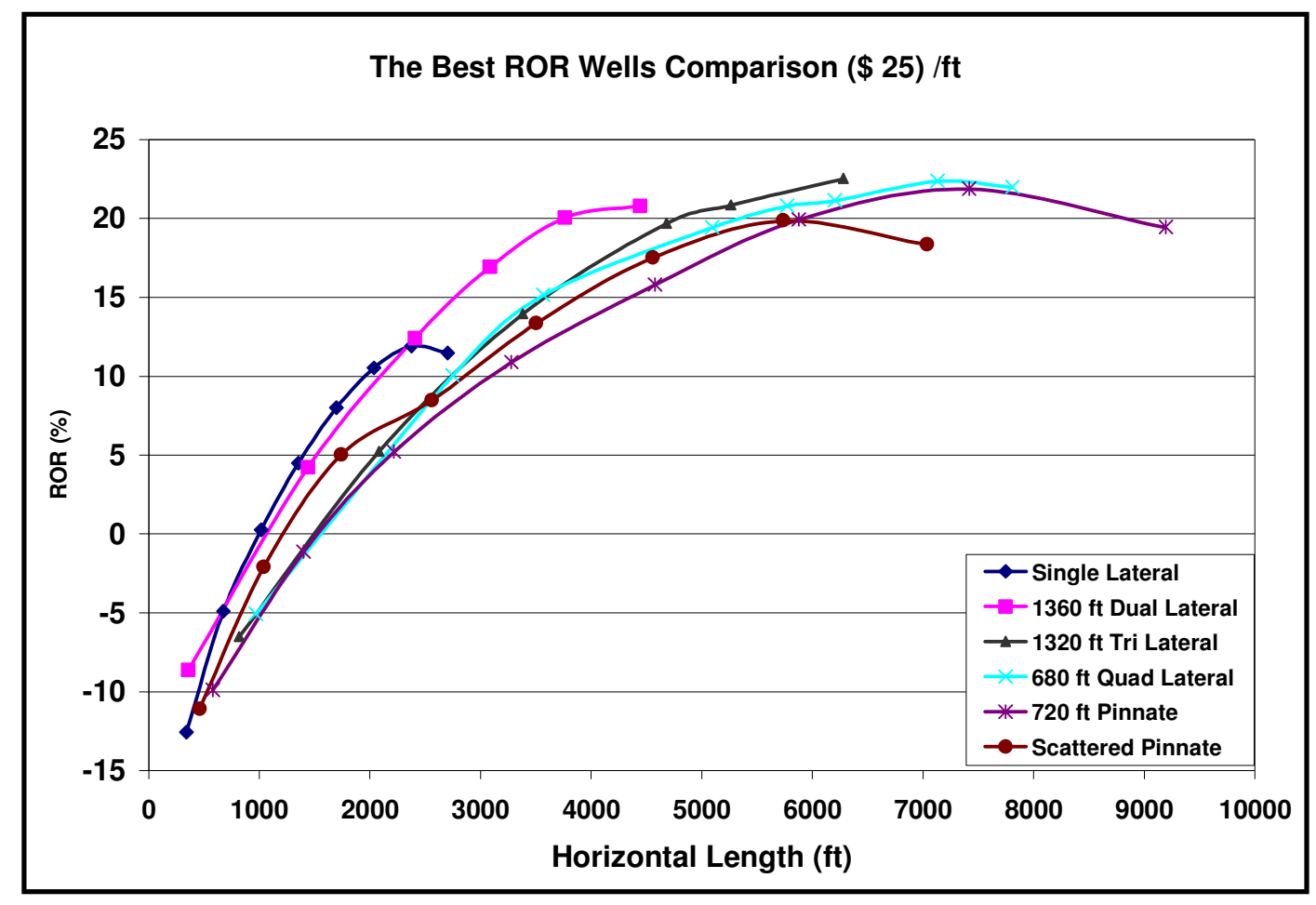

Figure 3.17 The Best ROR Well Comparison

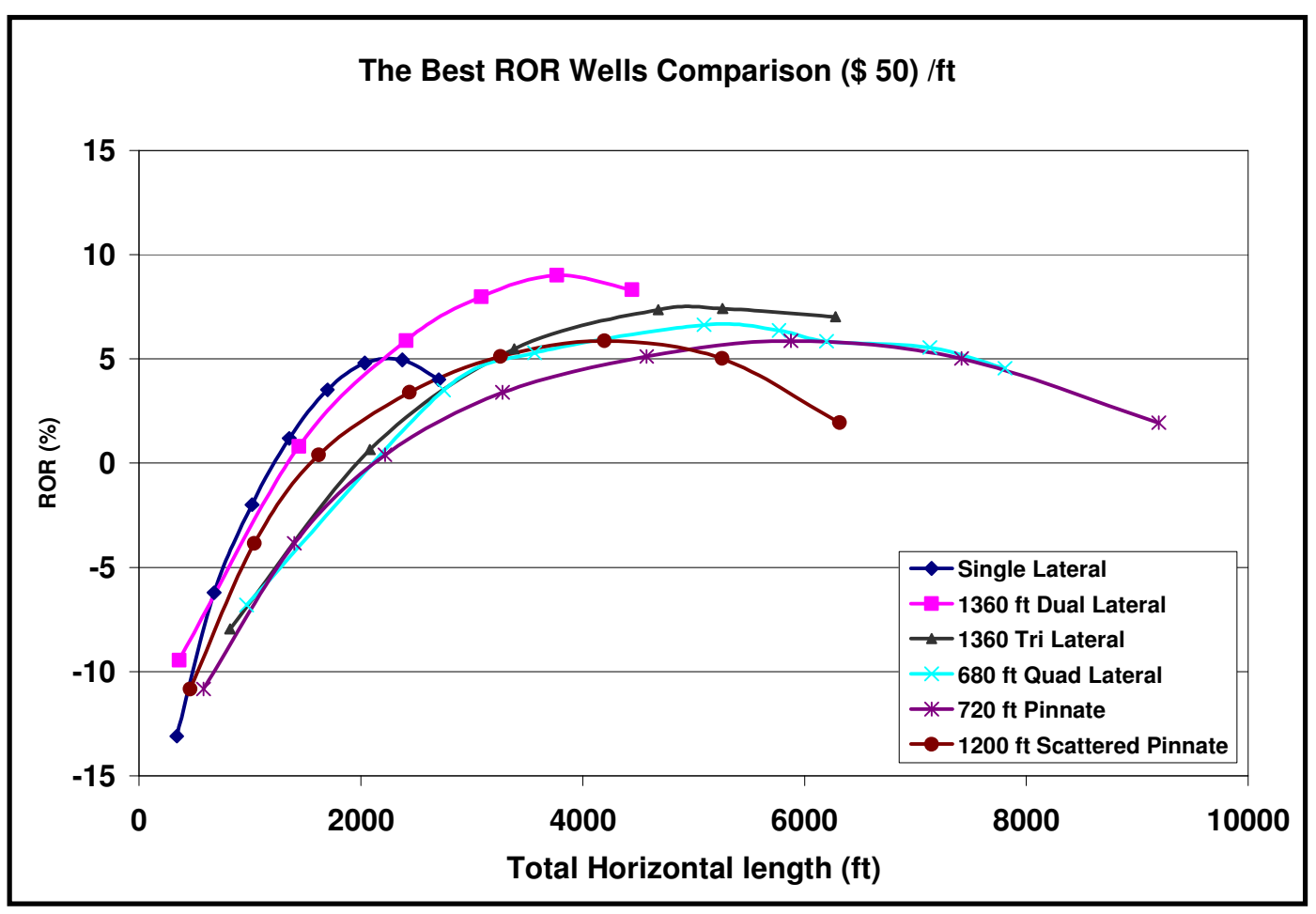

Figure 3.18 The Best ROR Well Comparison 
$\square$ The well spacing that produces the biggest interference effect is $680 \mathrm{ft}$

$\square$ The shape of well that has the best recovery factor for 15 years project is Pinnate with 240 SBL.

$\square$ The drilling cost / ft dictates the ROR

- Case $1 \$ 50 / \mathrm{ft}-1320 \mathrm{ft}$ Dual Lateral

- Case $2 \$ 25 / \mathrm{ft}-1320 \mathrm{ft}$ Tri Lateral

- Case 3 \$10/ft - $720 \mathrm{ft}$ Pinnate 


\subsection{Building, Running and Analyzing a Coal Bed Methane Model}

This study was based on the coal bed methane reservoir engineering model. The first and the most important part was building the reservoir model that will be realistic and would allow us to perform various sets of changes while monitoring the behavior of our system. Herewith, the detailed approach to the model building, running and analyzing the model is performed, in order to explain the way and the reasons for creating this specific reservoir.

Three main steps for the Simulation of any reservoir are:

1. Creating the reservoir model (Building);

2. Running the simulation (Running);

3. Plotting simulation results (Analyzing); (Including Results 3D option).

\subsubsection{Building the Model}

GridBuilder is used to create the grid portion of simulation input datasets for CMG's reservoir simulators. It is used in conjunction with CMG's ModelBuilder, which is used to create no grid portions of the dataset. GridBuilder is invoked directly from ModelBuilder. The GridBuilder supports all three CMG simulators, IMEX, GEM and STARS. Constructing a simulation grid consists of three main steps. First, user describes the grid geometry in aerial (or plane) view and positions it over your geological maps. Second, the user creates your three dimensional grid by interpolating the reservoir structure and rock properties from your geological maps. The final step is to specify the well completion locations in the grid, from well positions on the geological maps, from 3D well trajectories, or by entering them manually (CMG Reservoir Simulator Tutorial, 2003)

Once the main model is open the following frame will show up. On the left side a dropdown menu can be seen, and user can choose the name and path where the new file will be created. 


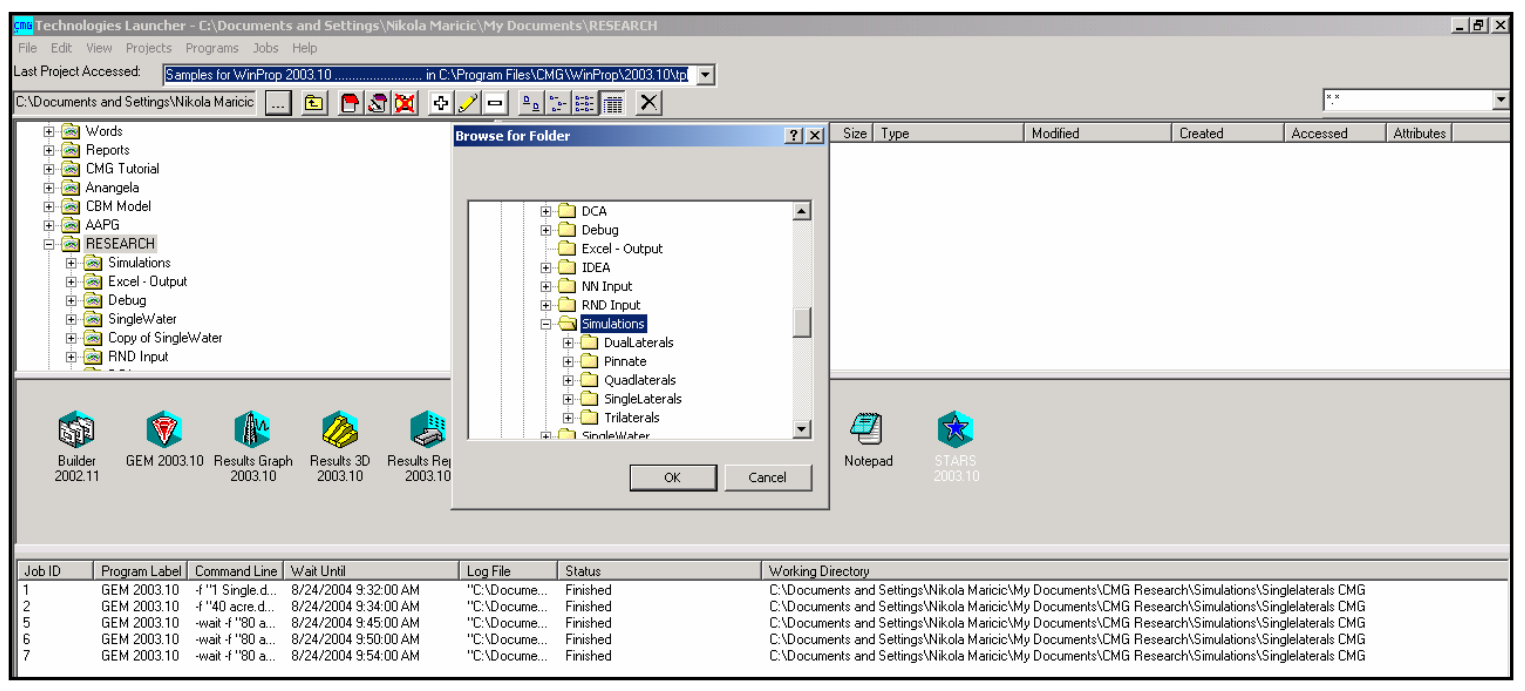

Picture 3.19 The Creation of the New CMG File

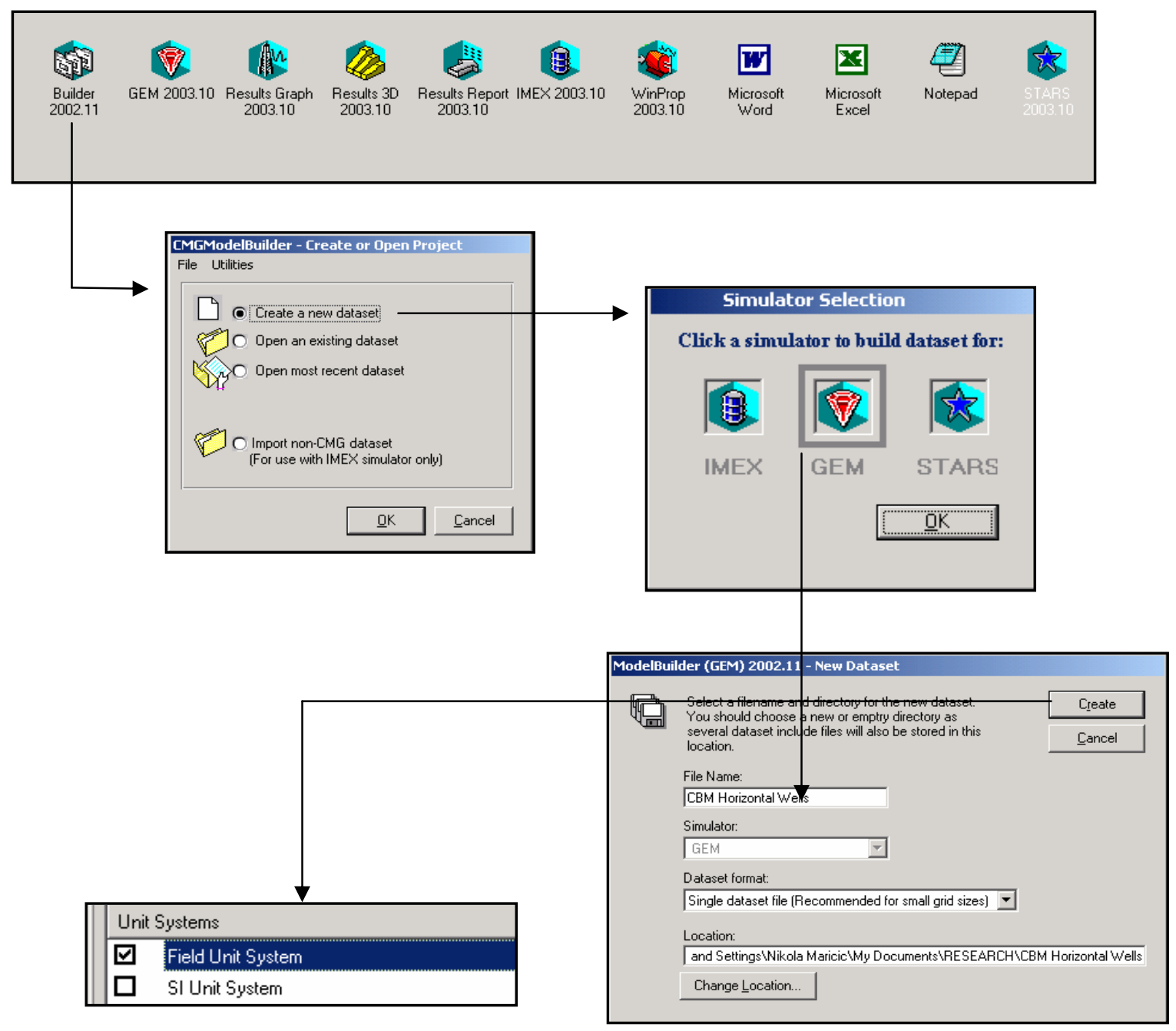

Figure 3.20 Flowchart of Creating, Naming and Placing the New CMG File 
Using BUILDER icon, found on the left of the menu bar, "Create and open Project" form opens, where one can define the new project. After choosing among creating the new project, opening the existing one or letting the software open the most recent dataset, the "Simulation Section" window will appear, allowing user to choose between three available simulators:

1. GEM, Generalized Equation-of-State Model Compositional Reservoir Simulator;

2. IMEX, Black Oil Simulator;

3. STARS, Steam Thermal Advanced Processes.

For the coalbed methane simulation, Generalized Equation-of-State Model Compositional Reservoir Simulator or GEM is one to be used. After confirming GEM and clicking on the GEM icon, the CMG Software will allow user to name the project and choose where to save it. By using "Create" button, the form with Unit System will take place, and "Field Unit System" needs to be checked. Upon performing this described set of steps, the new model is named, and ready to be formed.

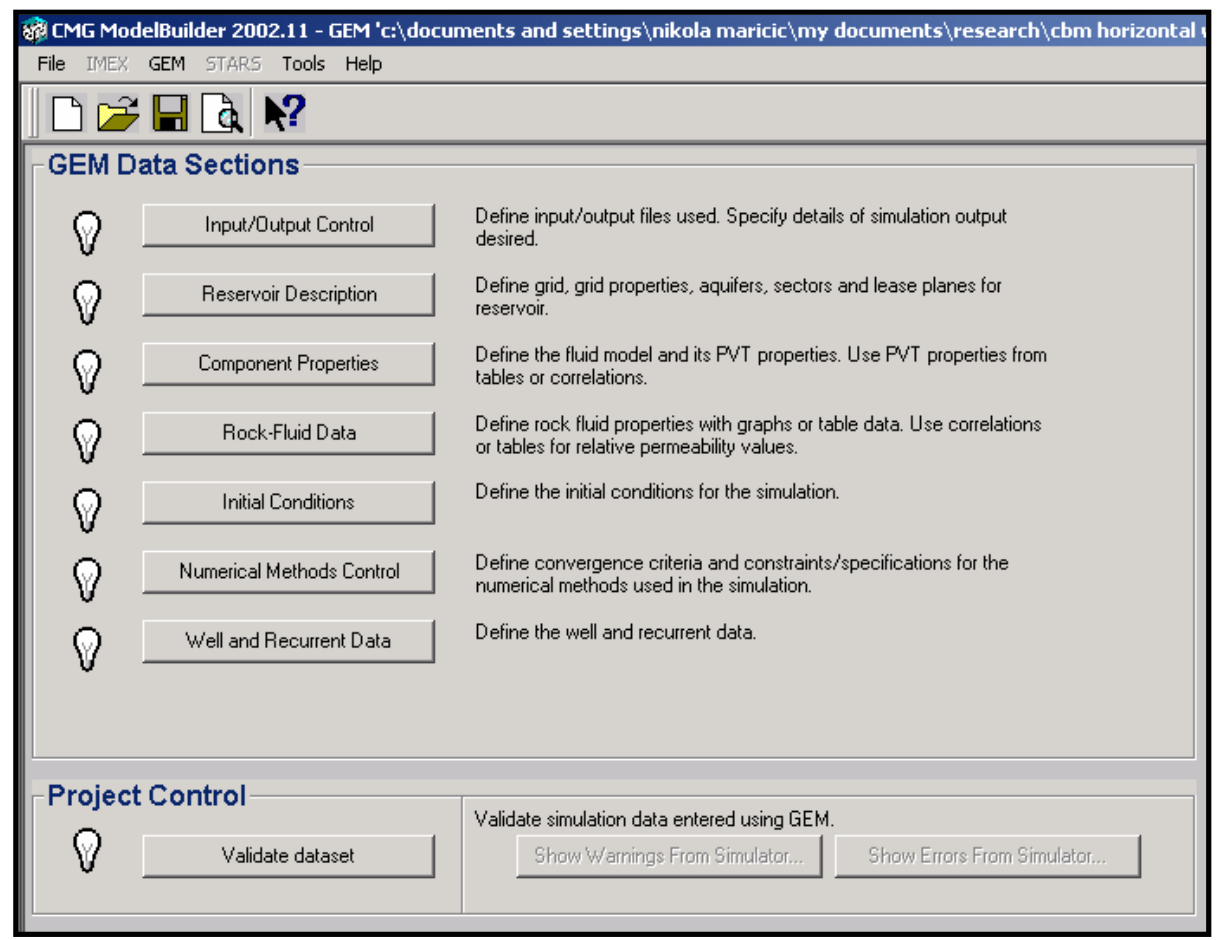

Figure 3.21 Main Form of the CMG Simulator Containing Main Modules 
As shown above, the main form of the CMG Simulator consisted of 7 main modules, placed in the "GEM Data Section", and one module in the "Project Control". These seven modules represent the most important part of the simulator, because this is the place where all coal properties should be entered during the creation of the reservoir, before running the model. These seven "GEM Data Section" modules are:

1. Input/Output Control;

2. Reservoir Description;

3. Component Properties;

4. Rock Fluid Data;

5. Initial Conditions;

6. Numerical Method Control;

7. Well and Recurrent Data.

Control Model is:

1. Validate Dataset

In the next couple of pages, a thorough approach and explanation how to use different modules are explained.

First Module in the "GEM Data Section" is "Input/Output Control". However, only certain modules are used for the GEM, and only they will be explained, while the rest will be skipped. Once it is opened, a form will pop up with the four available tabs:

1. Output File;

2. Restart File;

3. Simulation Output and Control;

4. Simulation Units.

"Output File" tab will allow user to determine different parameters, but only Case ID and the Title should be named in this case." Simulation Output and Control" should be used to determine parameters that user wants to see in the 3-D view after the simulation is performed (exe. Pressure distribution through the reservoir). The green bulb indicates the proper entry of data in the model, allowing us to take the next step. The next step is determining the start of gas production in the model, and in this case it is January 1, 2004. 


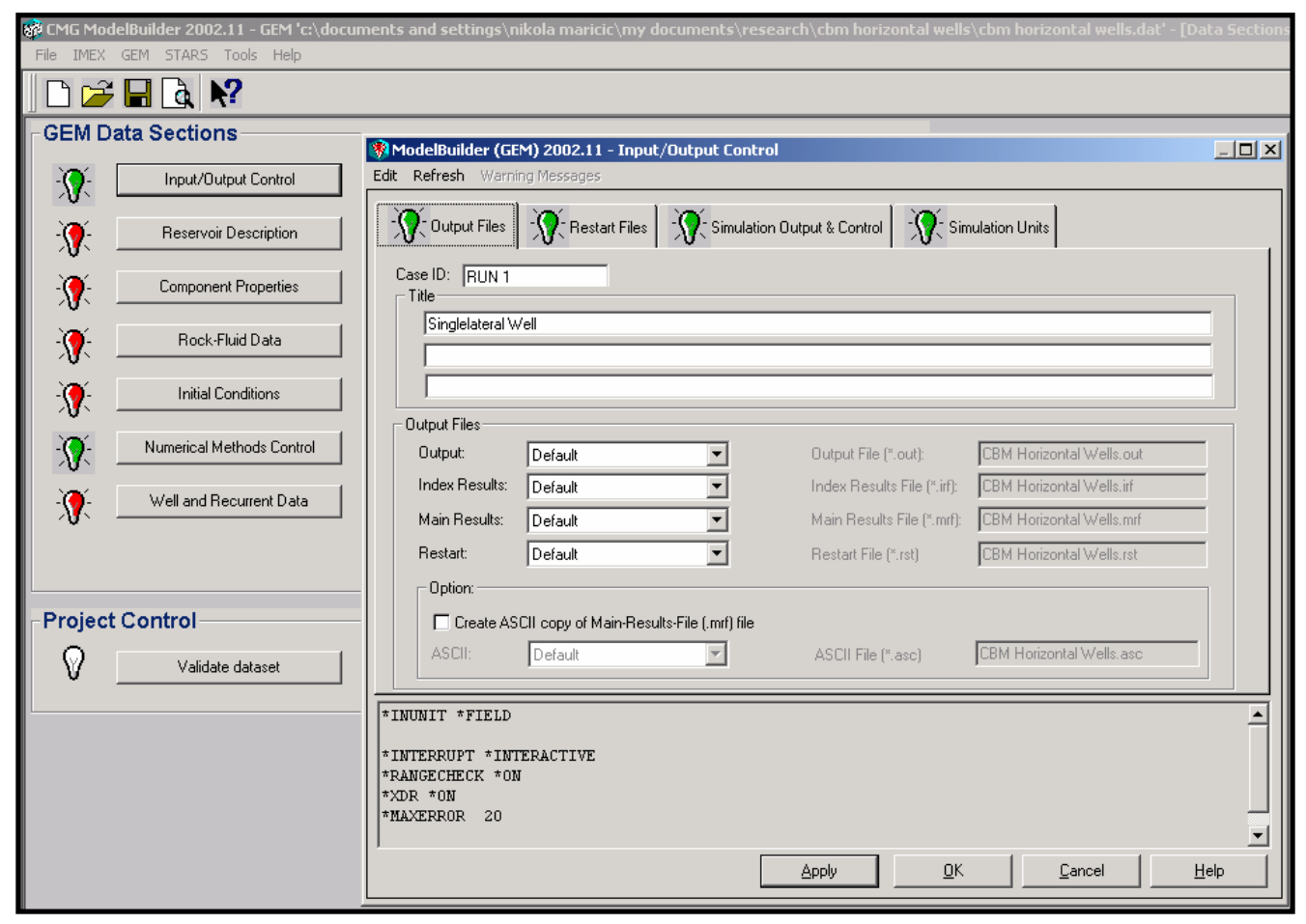

Figure 3.22 Input/Output Control Module with Four Available Tabs

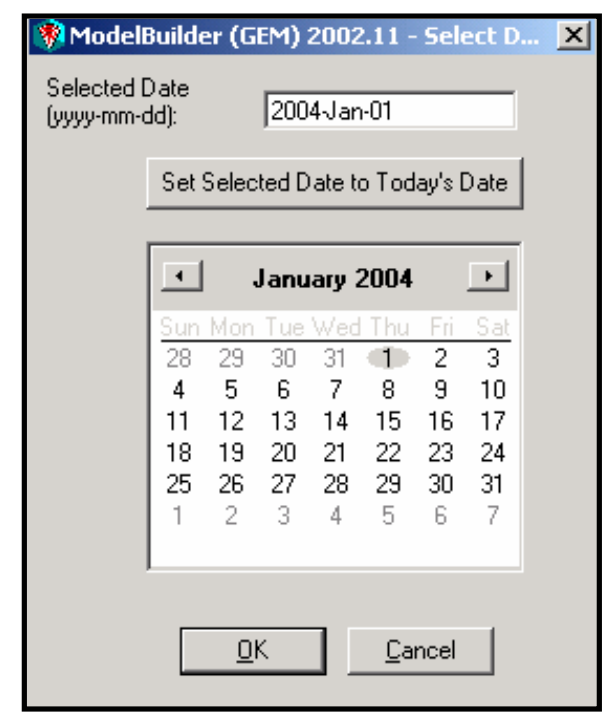

Figure 3.23 Model Builder Date Selection Form 
The very first step that represents the building of a reservoir is Reservoir Description.

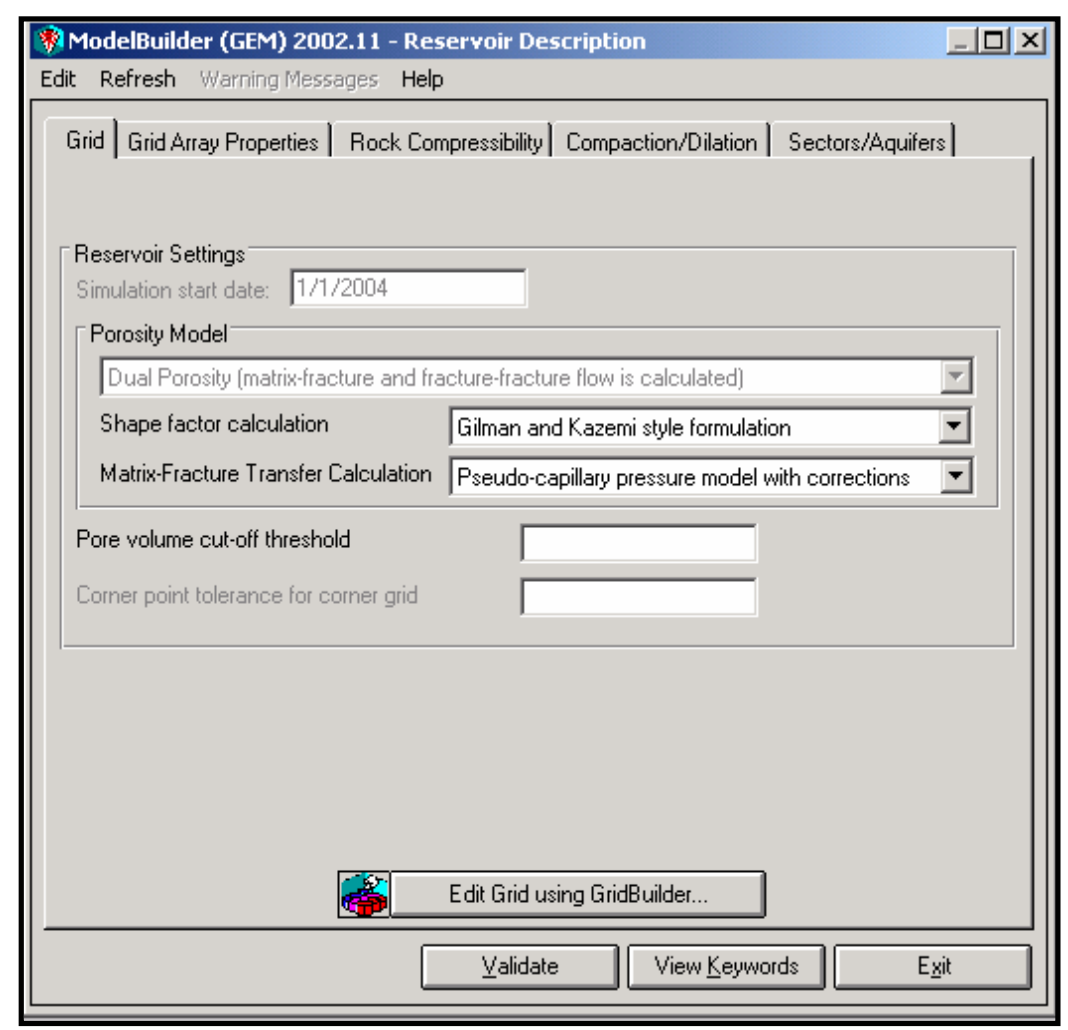

Figure 3.24 Reservoir Description Module with Five Existing Tabs

Upon determining the start date, and using the first tab called "Grid", porosity model needs to be determined (in this study, "Dual porosity model" with the matrix-fracture and fracture- fracture flow calculation is used).

We used "Shape Factor calculation" - Gilman and Kazemi style formulation "MatrixFracture Transfer" Calculation - Pseudo Capillary pressure model with corrections.

Rock Compressibility tab allows user to enter pressure and rock compressibility data, both for the matrix and fracture system. 


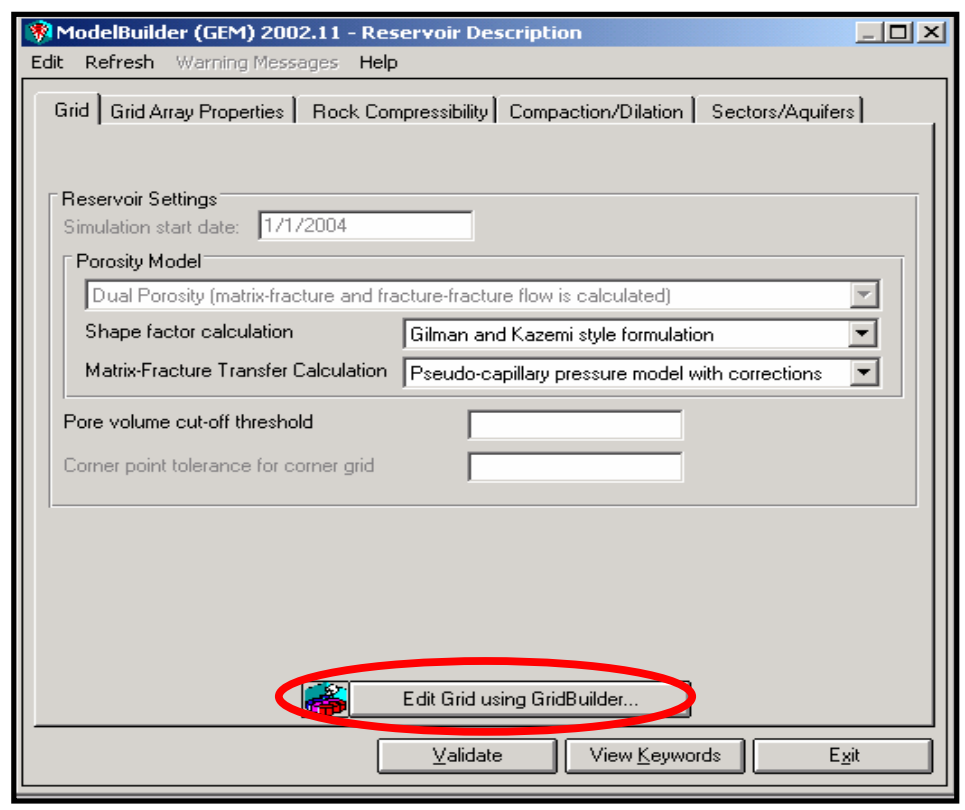

Figure 3.25 Rock Compressibility Form

When all data are entered into this tab, user can press the validate button, and come back again to the main form for the "Reservoir Description" module. This time grid system needs to be made, and therefore the button "Edit Grid Using Grid builder" should be used.

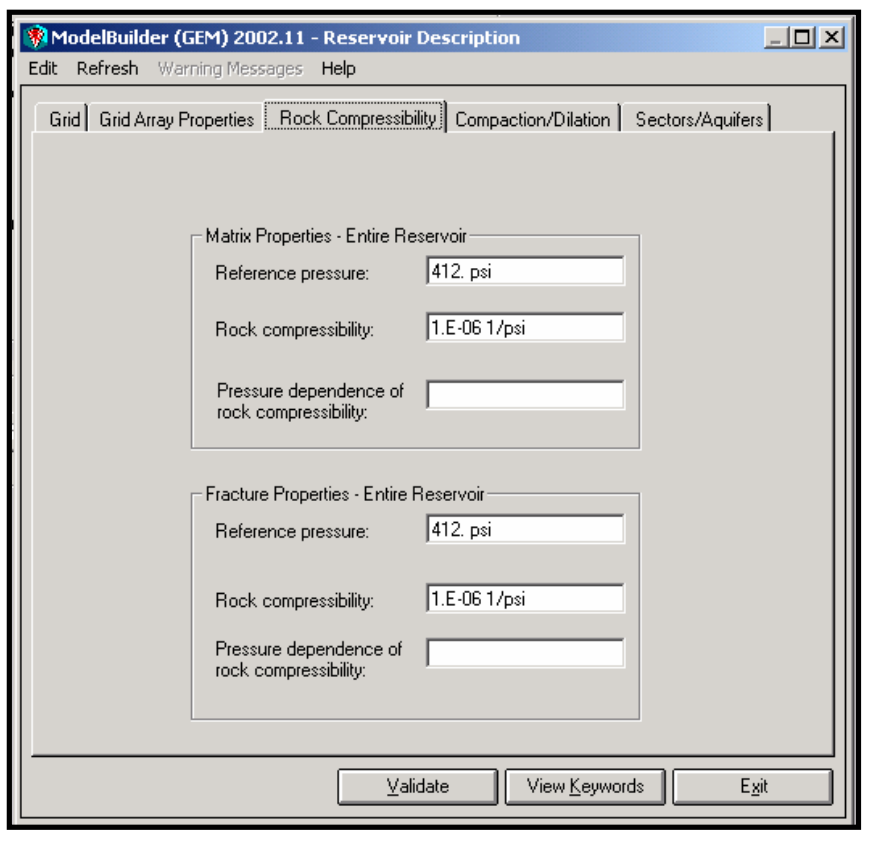

Figure 3.26 Grid Tab in the Reservoir Description Module with Highlighted Button for Creating and Editing Reservoir Grid 
When this button is pressed, the kind of grid that will be used in the modeling needs to be chosen. For the purpose of this study, it was predetermined that the most suitable grid model would be Cartesian. When determining the simple Cartesian model, I,J and K (length of the reservoir as well as thickness) coordinates of the reservoir have to be known. For this case, it has been decided that 44 X 44 square blocks need to be created, with the length value of $70.7 \mathrm{ft}$ each.

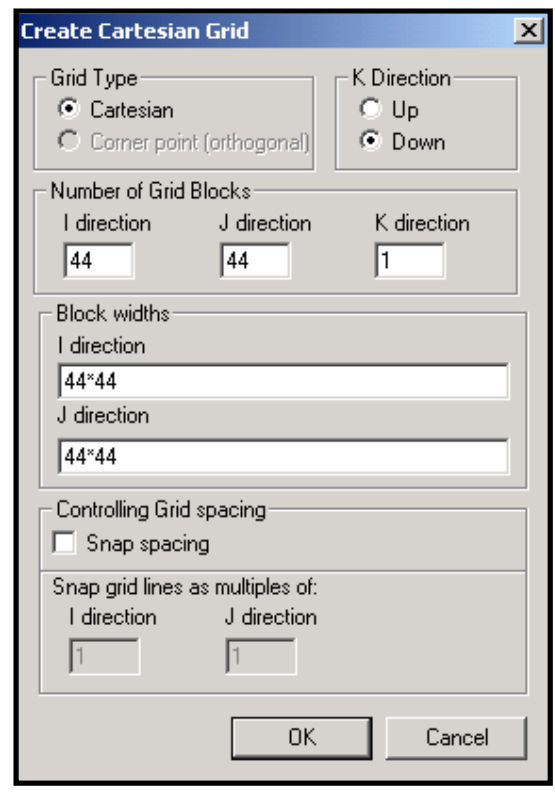

Figure 3.27 Cartesian Grid Creating Form 


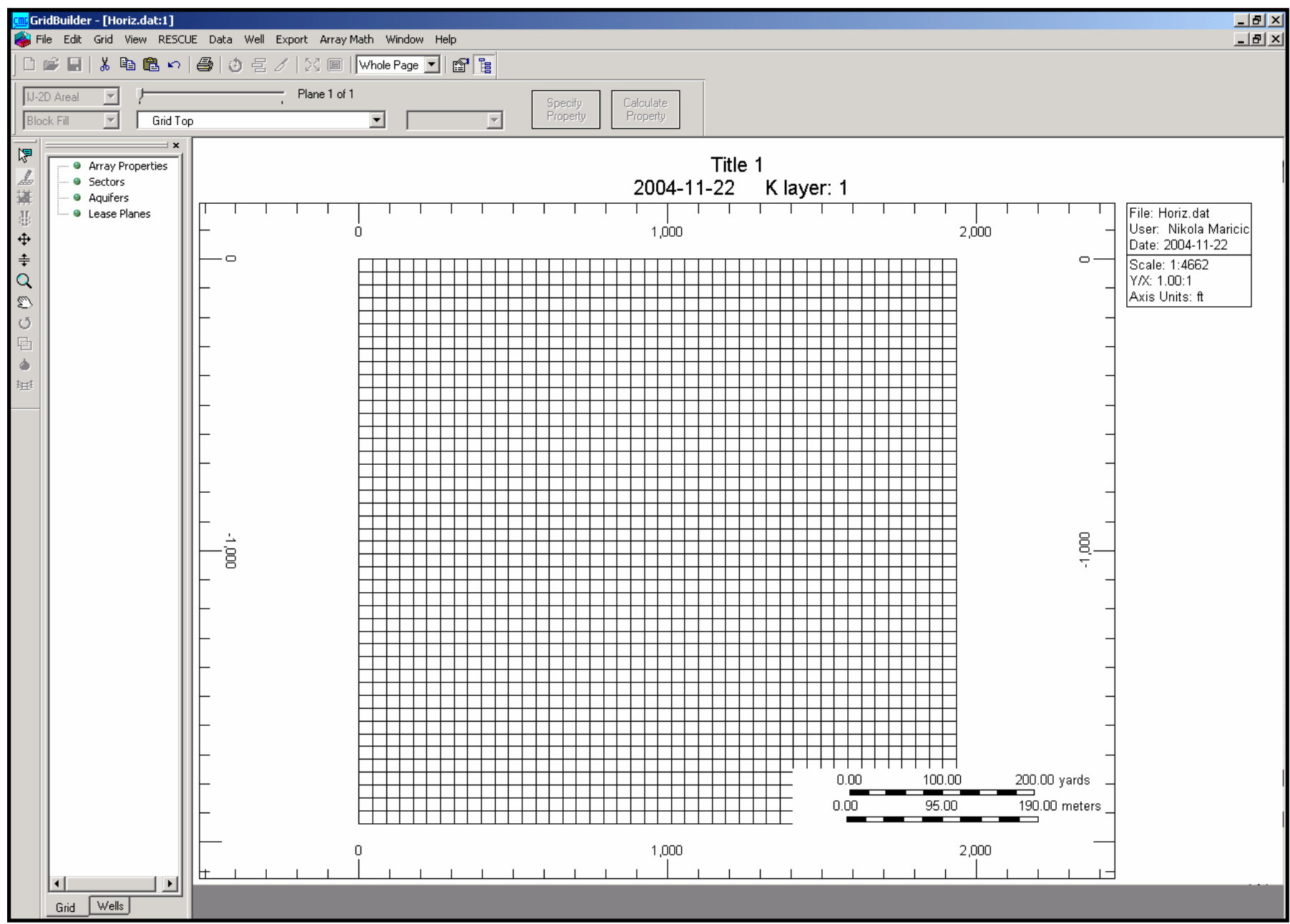

Figure 3.28 Plain View of Reservoir

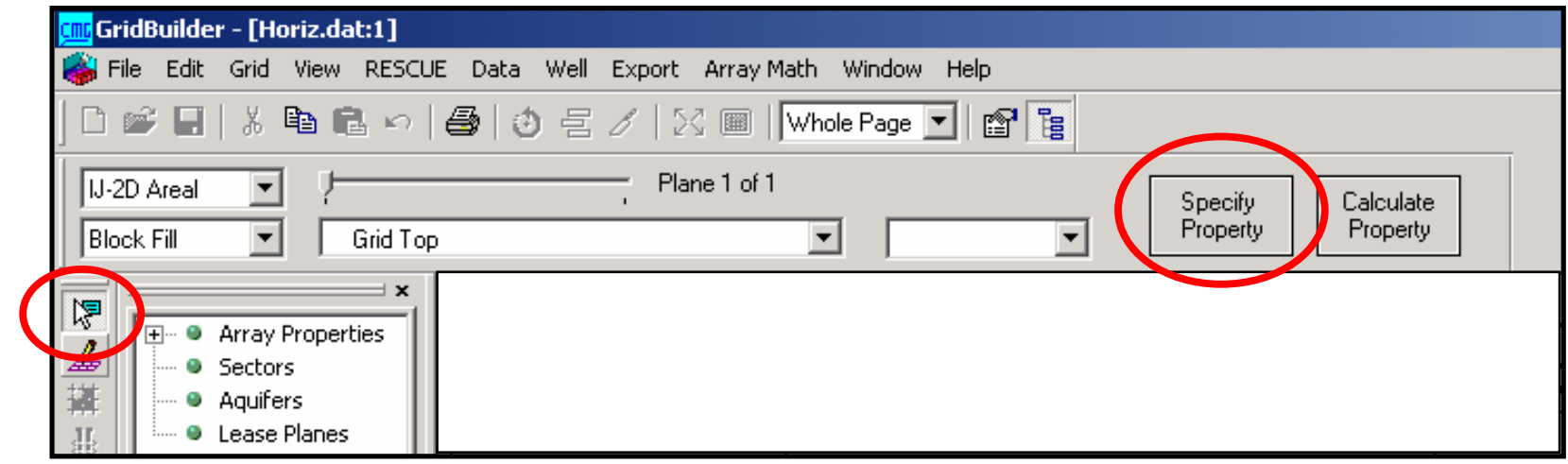

Figure 3.29 Set Operation Mode to Probe Allowing User to Specify Property 


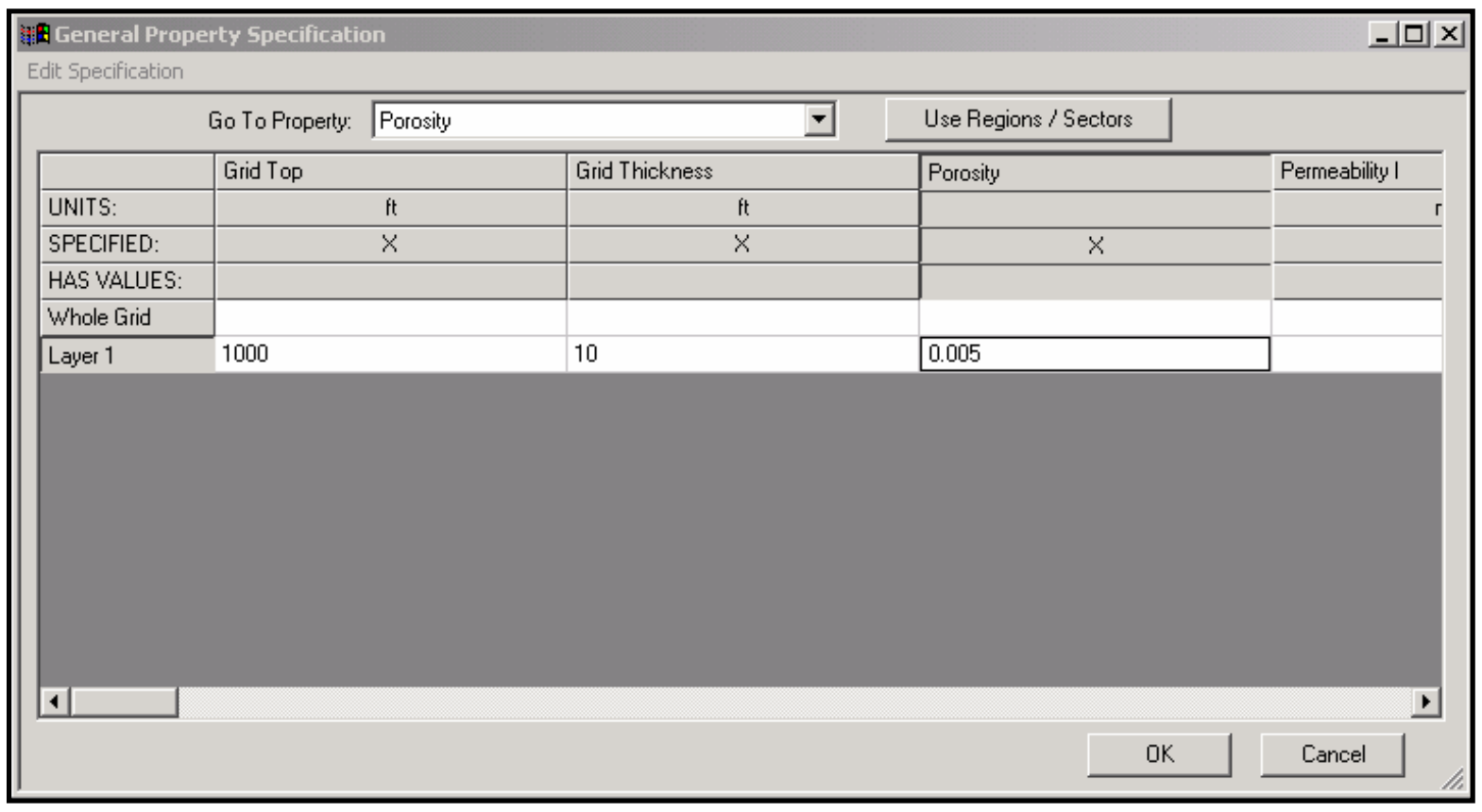

\section{Figure 3.30 General Property Specification Grid}

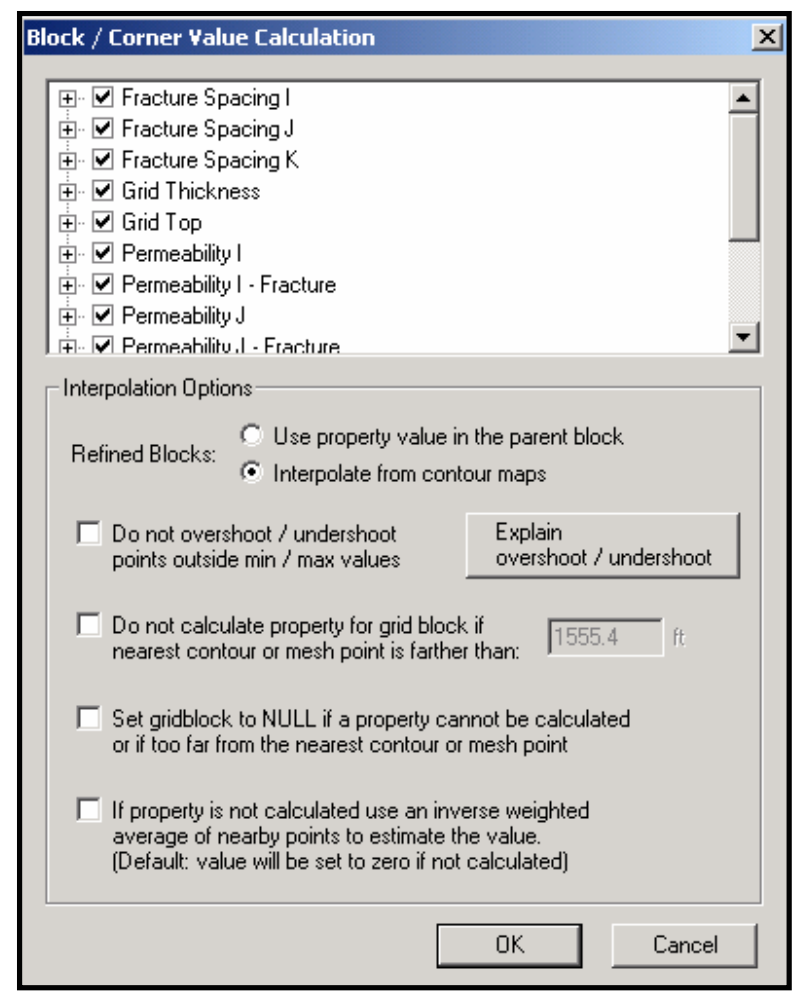

Figure 3.31 Block/Corner Value Calculations 
"Rock Compressibility" tab requires the entrance of pressure reference and rock compressibility for the both matrix and fracture. Model Builder is a visual interface based pre-processor software for CMG's IMEX, GEM and STARS simulators. Model Builder belongs to the Builder series of CMG software, and is used to prepare input information for a reservoir simulation run. Typically, Model Builder accepts from the user certain input information regarding a simulation run to be conducted, and writes this information into an ASCII dataset file(s) using the appropriate simulator keywords. The user could then submit this dataset to the simulator for simulation (CMG Reservoir Simulator Tutorial, 2003).

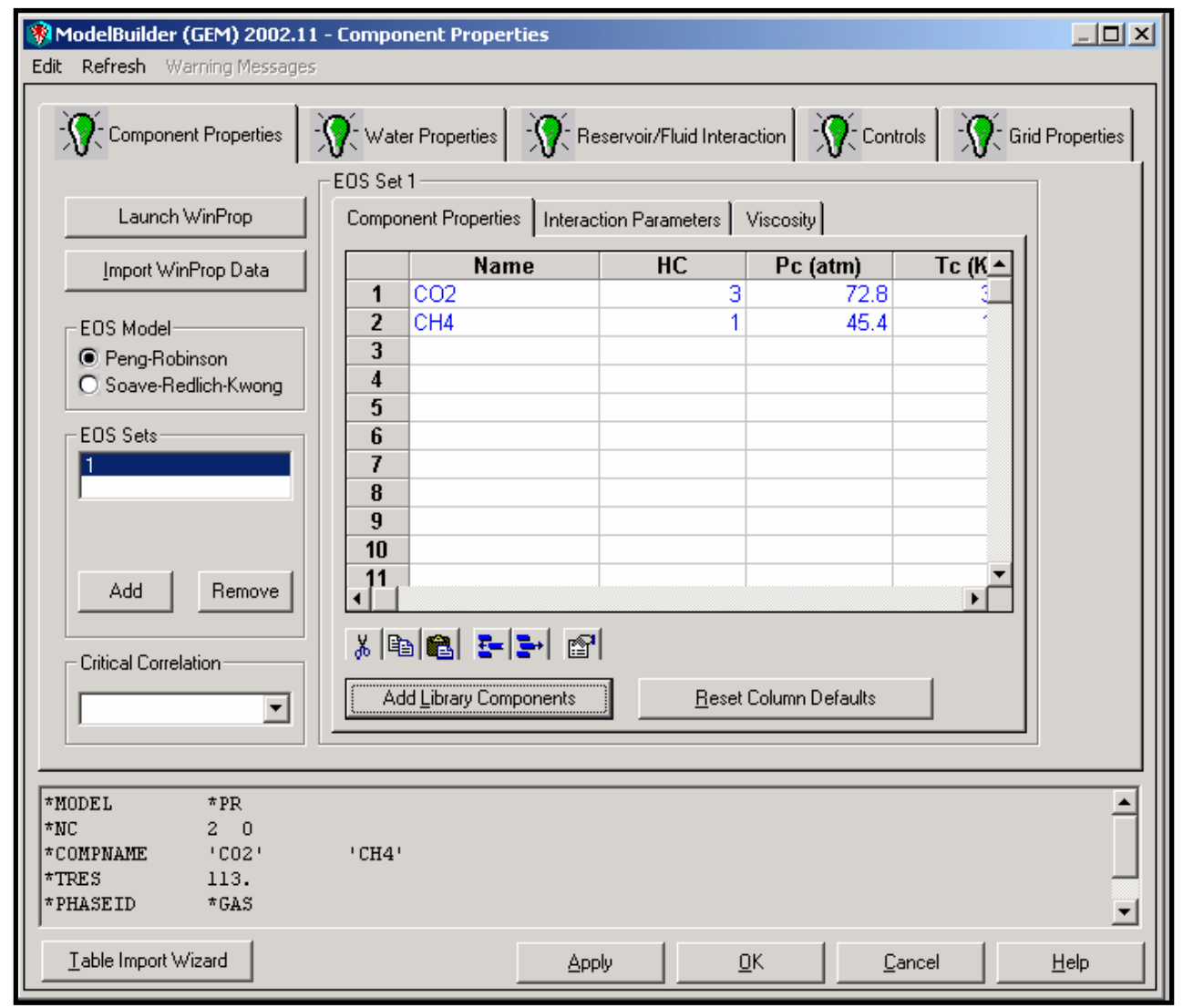

Figure 3.32 Component Properties Form

In the first tab of "Component Properties", the Peng Robinson Equation of State has been chosen and gaseous $\mathrm{CO} 2$ and $\mathrm{CH} 4$ added into the system. In the third tab called "Reservoir Fluid/Interaction", constant reservoir temperature is entered (113 F). Under "Control" tab Single Phase Fluid Identity we have only Gas. 


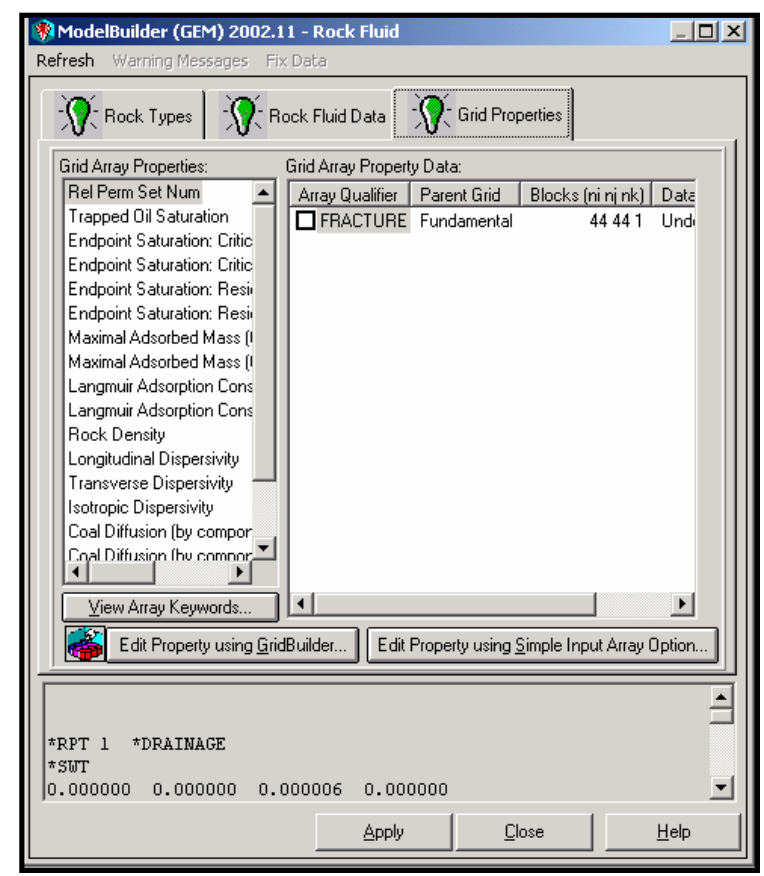

Figure 3.33 Rock Type Form

When the fourth in the row module "Rock Fluid Data" is opened, the third tab called

"Grid properties" is the one that maybe has the most important data to be input:

1. Maximal Adsorbed Mass;

2. Langmuir Adsorption Constant;

3. Coal Desorption Time;

4. As known, one of the most important parameters determining the amount of gas that can be produced from the coal is Gas Content (msf/ton)-amount of gas (msf) contained in the one ton of coal. In the case of CMG/GEM Simulator, Gas Content is not directly available, but it is described and calculated using Maximal adsorbed mass (gmol/pound) and Langmuir Adsorption Constant (1/psi).

Correlations with the gas content are as follows:

1 scf/ton $=0.000597625 \mathrm{gmol} / \mathrm{pound}$

$1 \mathrm{gmol} /$ pound $=1673.289183 \mathrm{scf} /$ ton 
Having Vl and Pl and using these correlations with Langmuir Equation, it is easy to calculate the Gas Content presented in the coal:

$$
G c=\frac{V l * P l}{V l+P l}
$$

For the Rock Property, the constant of $90 \mathrm{lb} / \mathrm{ft} 3$ is used for all simulations done in this study. "Rock Fluid Data Section" requires entering relative permeability curves. Two different sets of data are provided:

1. Relative Permeability Curve for oil/gas (Water-Oil Table);

2. Relative Permeability Curve for liquid/gas (Liquid Gas Table).

\begin{tabular}{|c|c|}
\hline Sg & Krg \\
\hline 0 & 1 \\
\hline 0.1 & 0.72 \\
\hline 0.3 & 0.401 \\
\hline 0.5 & 0.216 \\
\hline 0.7 & 0.09 \\
\hline 0.9 & 0.018 \\
\hline 1 & 0 \\
\hline
\end{tabular}

\begin{tabular}{|c|c|}
\hline Sw & Krw \\
\hline 0 & 0 \\
\hline 0.1 & 0.013 \\
\hline 0.3 & 0.024 \\
\hline 0.5 & 0.088 \\
\hline 0.7 & 0.251 \\
\hline 0.9 & 0.601 \\
\hline 1 & 1 \\
\hline
\end{tabular}

Table 3.3 Relative Permeability Data used in this Study

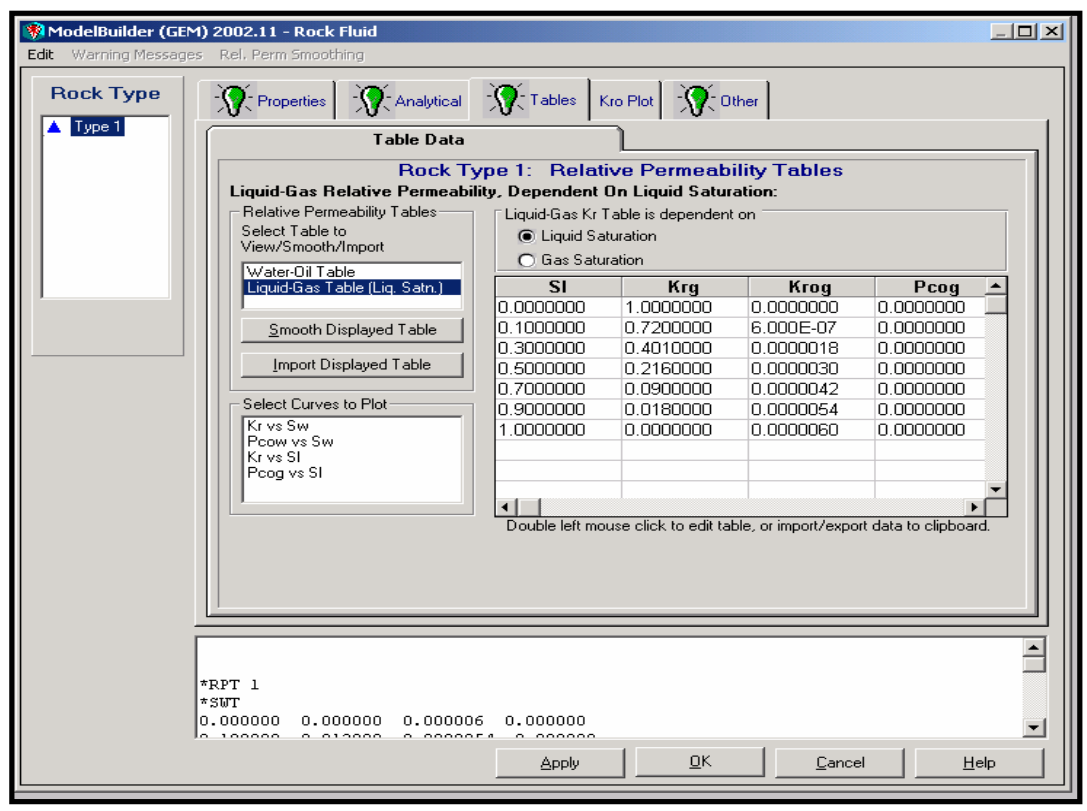

Figure 3.34 Rock Fluid Module with the Table Containing Relative Permeability Used in This Study 

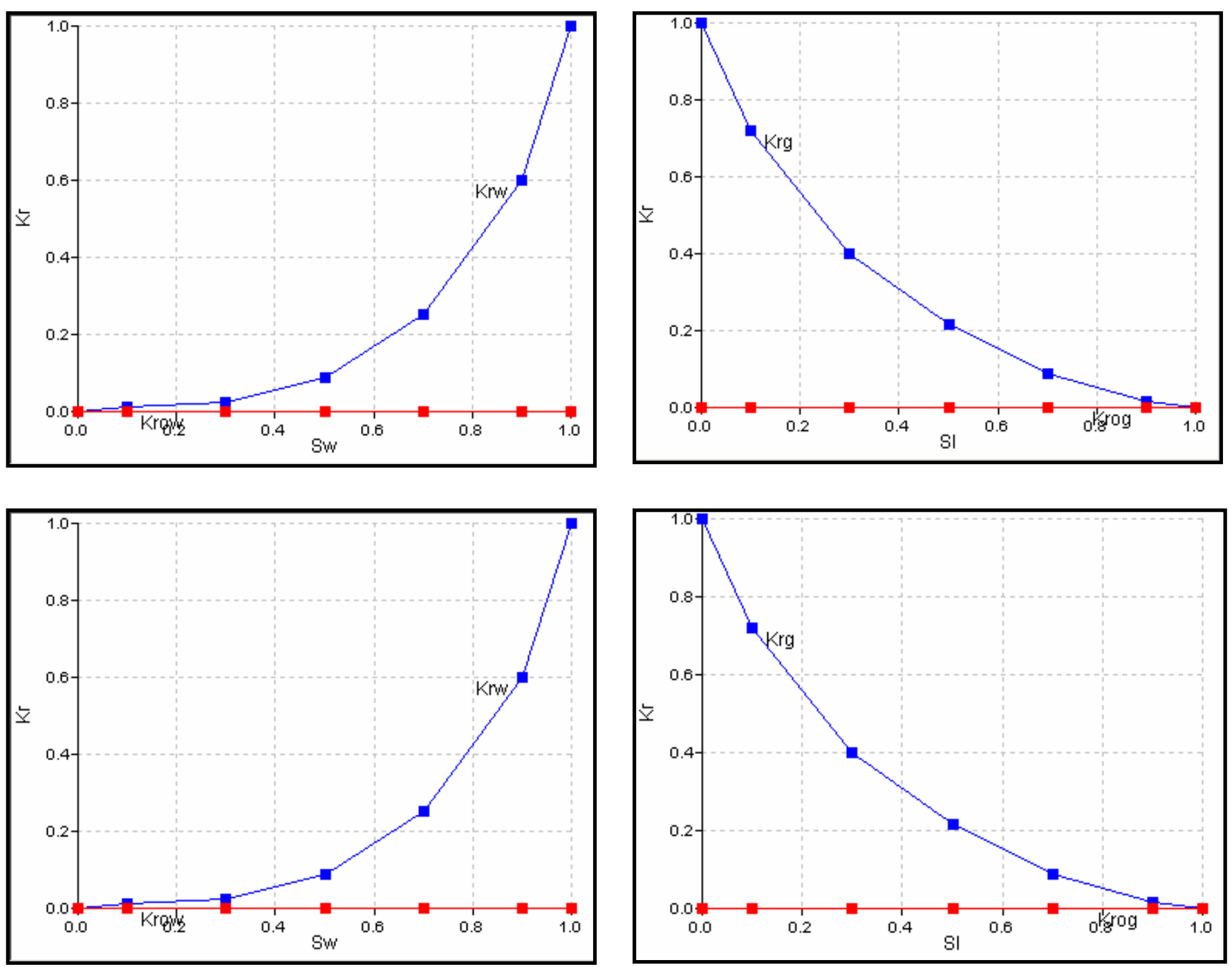

Figure 3.35 Relative Permeability Curves for the CBM Modeling Used in This Study 
Under the "Initial Conditions" module, we are dealing with "Grid Properties". Here the Initial water saturation in the matrix and fracture system is defined, as well as initial reservoir pressure. In the virgin coal, the value for the water saturation is so low (practically mist) and is modeled here as a constant having value of $0.5 \%$. On the other hand, the percentage of water in the cleat system varies from simulation to simulation. In this example, value of $92.7 \%$ or 0.927 is used.

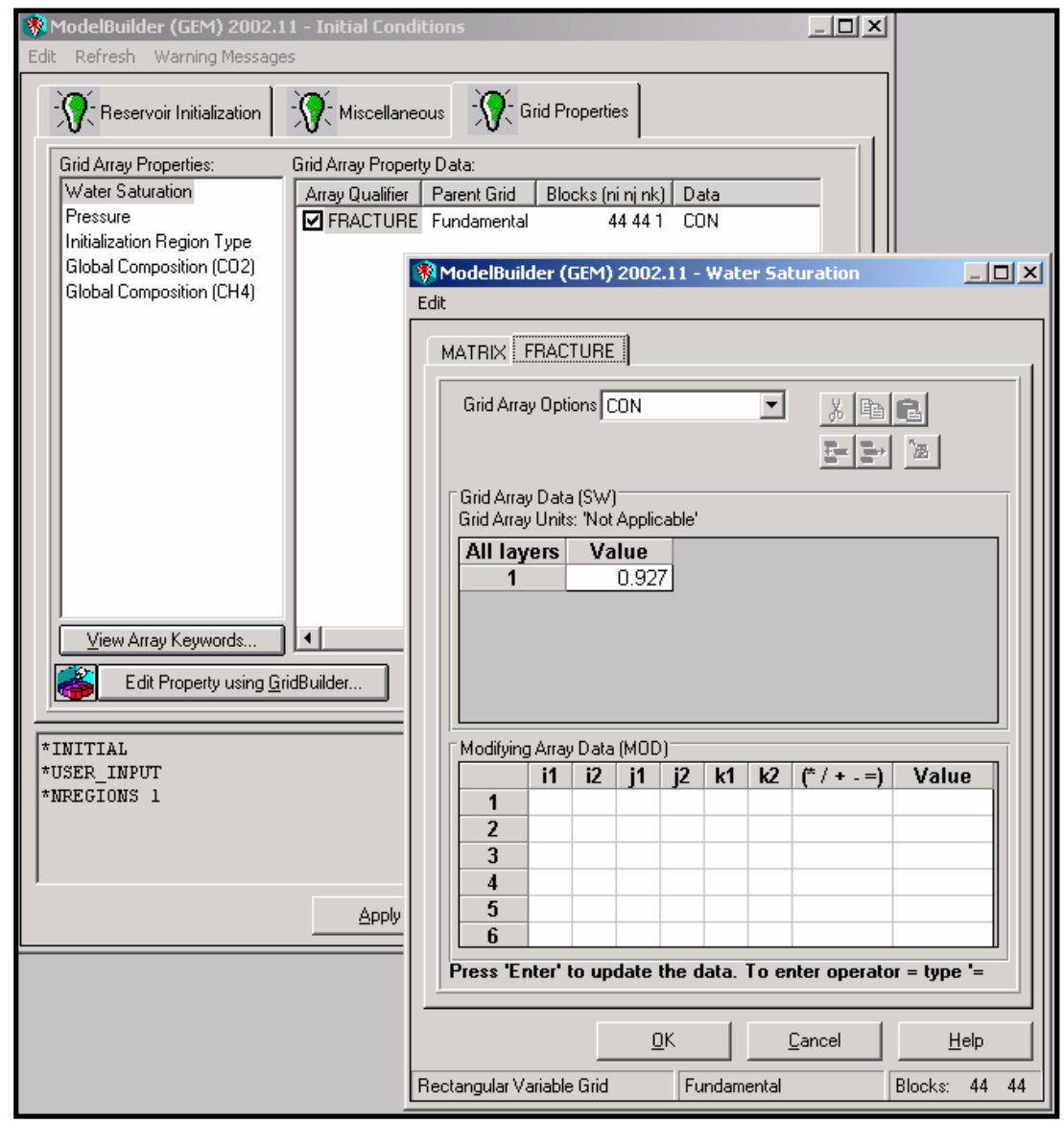

Figure 3.36 Initial Condition Module Showing Reservoir Initialization Form, with Water Saturation Value for the Fracture System 


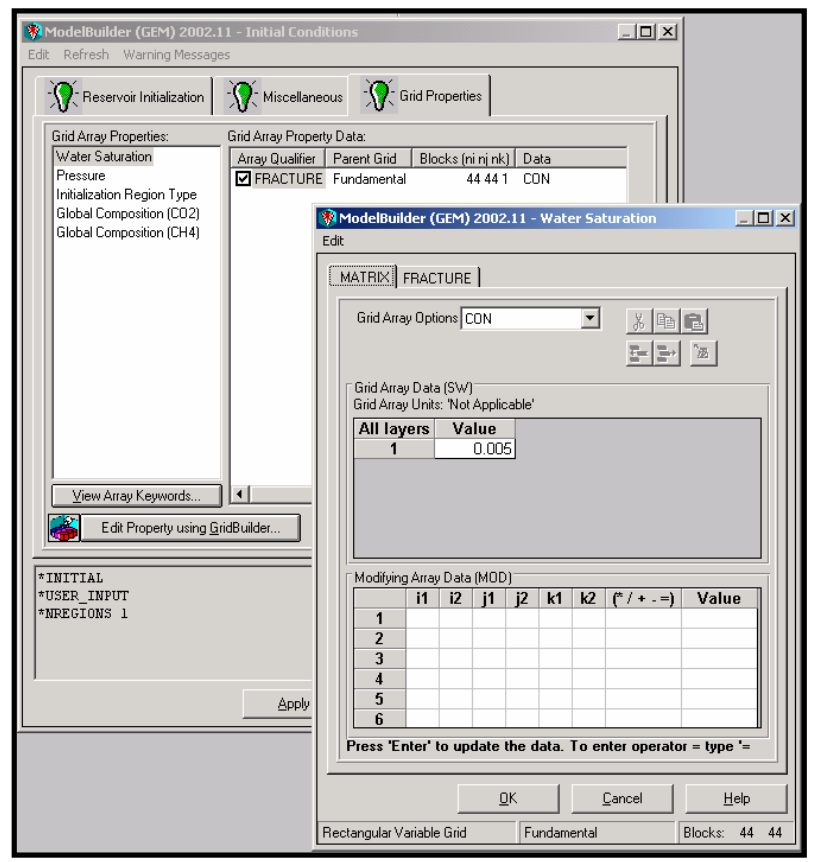

Figure 3.37 Initial Condition Module Showing Reservoir Initialization Form, with Water Saturation Value for the Matrix

When GEM simulator is used, "Numerical Method Control" module should be left with its default values.

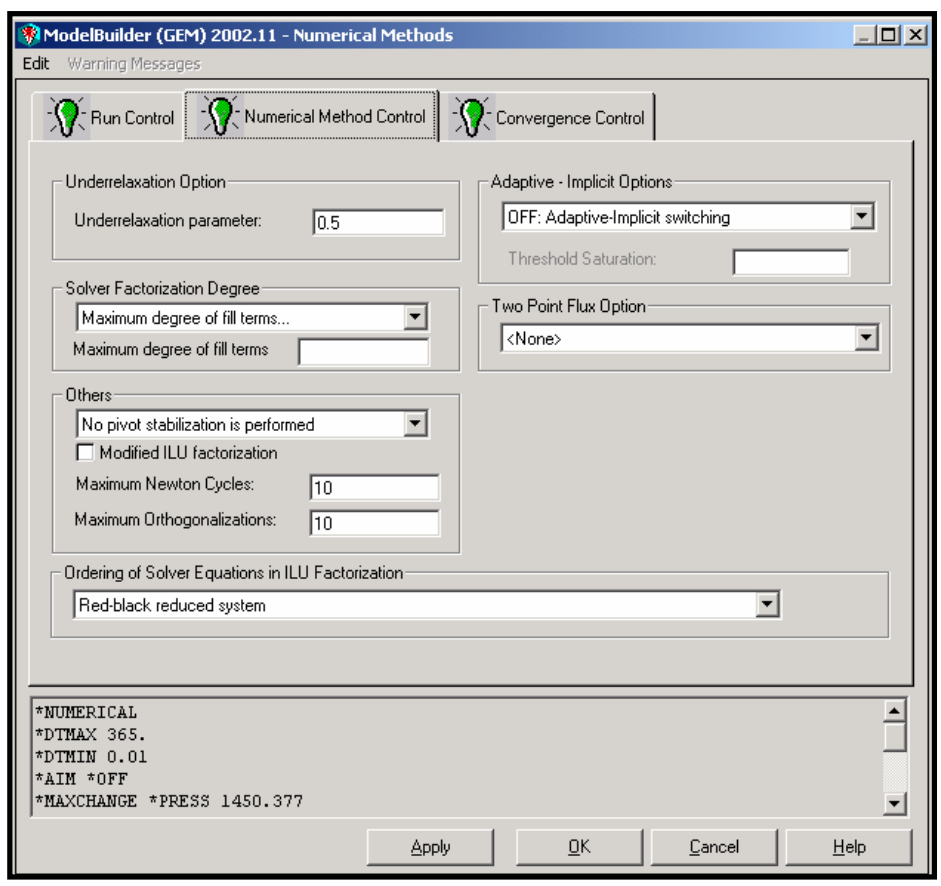

Figure 3.38 Numerical Methods 
Until this point, the user has been creating a CBM reservoir using different coal properties. If every step is performed properly, all but the last bulb will be green, indicating that all parameters have been imported properly. The last model with the last red bulb allows user to create wells.

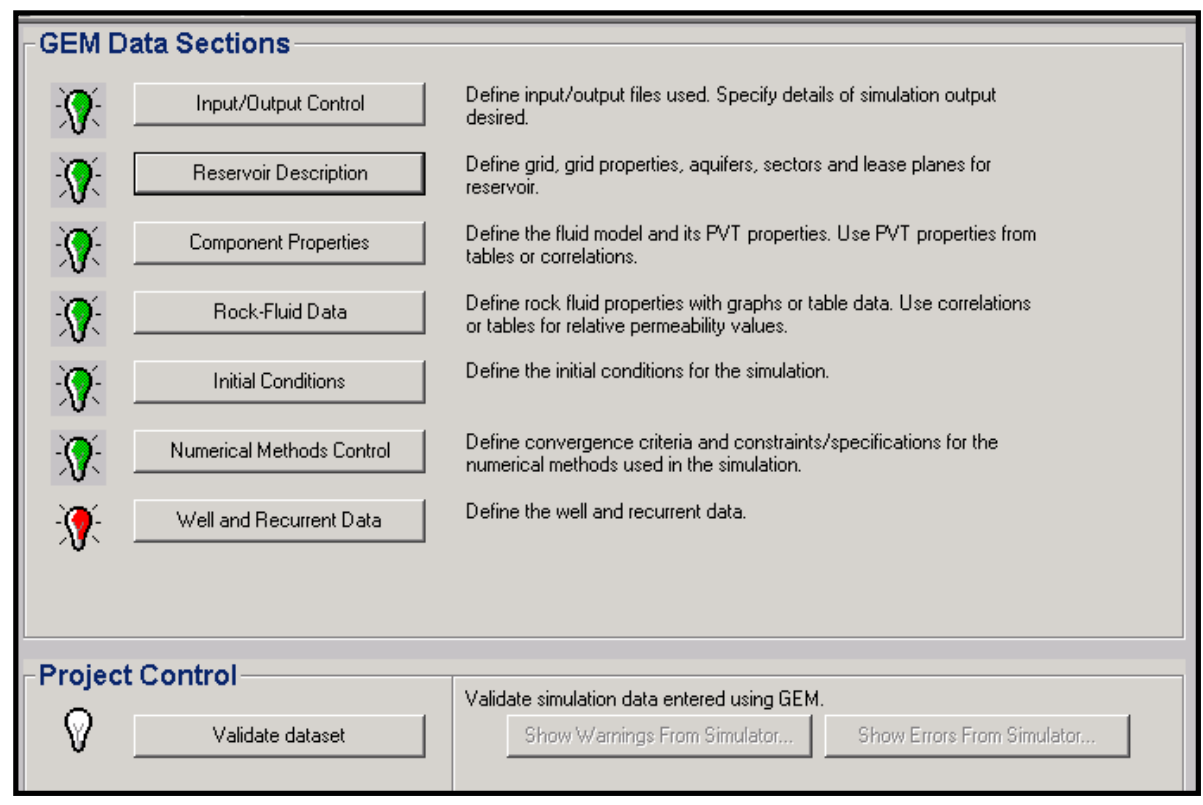

\section{Figure 3.39 Snapshot of the Main CBM Form after Entering All Necessary Data}

The last of seven modules is named "Well and Recurrent Data", which defines wells and recurrent data. The first thing is to define a period of time during which a well will produce, and we will monitor the decline curve in gas production. In this model, time is fixed for 20 years, and step size is in months. After this performance, a set of 240 data (months) is created. 


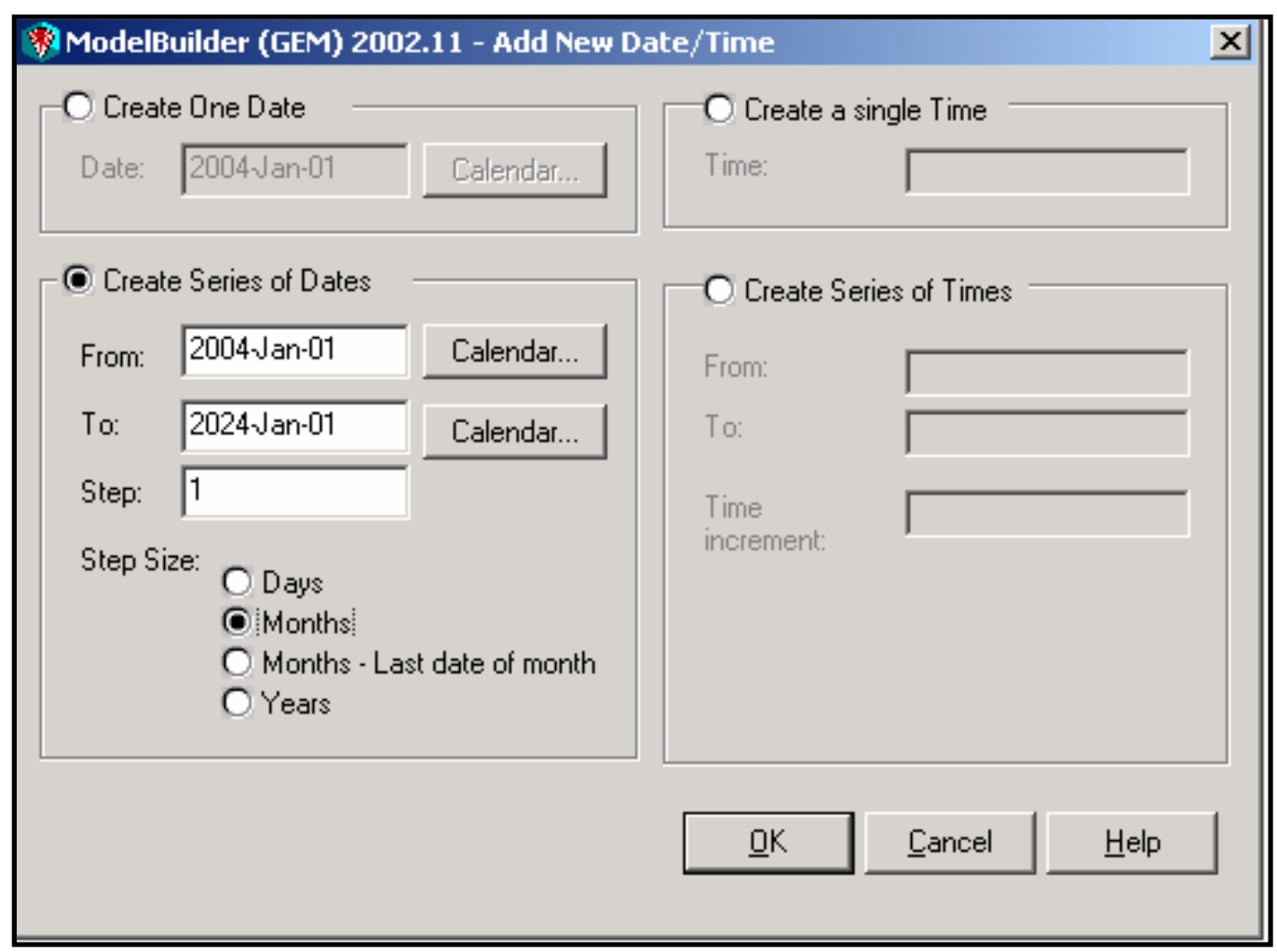

Figure 3.40 Add New Date/Time for Well

When the system is defined and the reservoir is modeled, the only thing left is to define and drill a well.

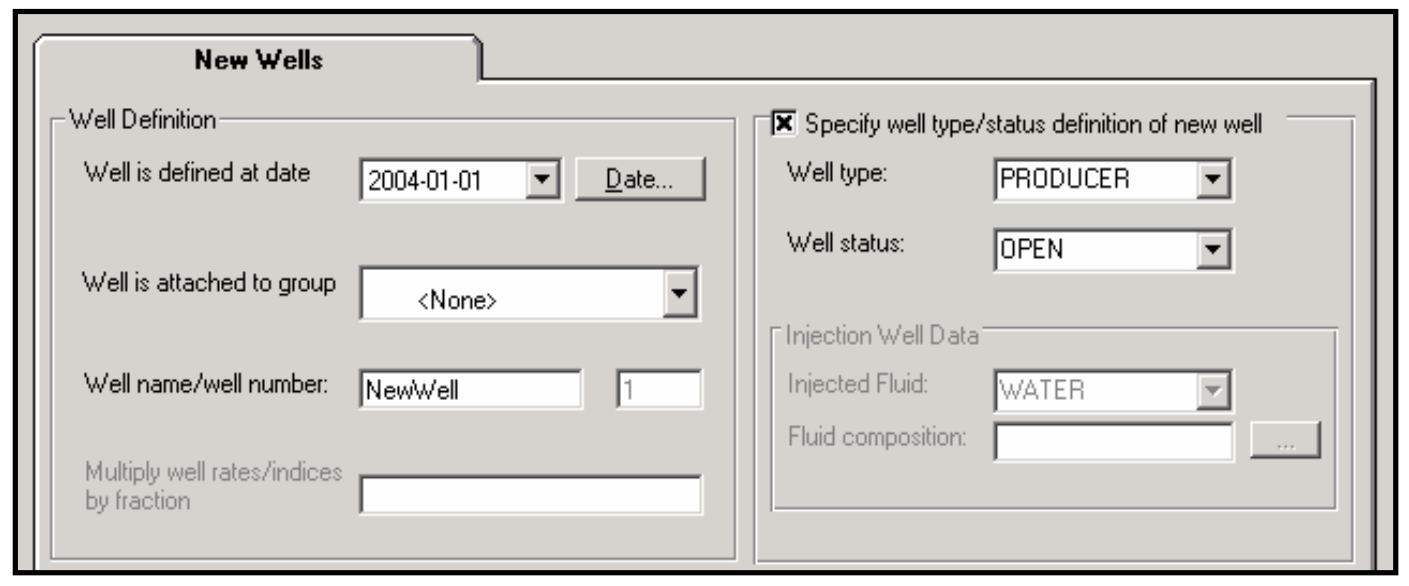

Figure 3.41 Determining Well Type and Well Status 
It is important to define a well as a producer (because this model deals with production wells only), and to set well status as "Open". Upon determining a well as a producer, it is necessary to go back to the "Reservoir Description" model and determine the well position as well as direction and length, as necessary for horizontal wells. The vertical well is drilled in the lower right corner of this model, having coordinates $(44,44$, and 1$)$.

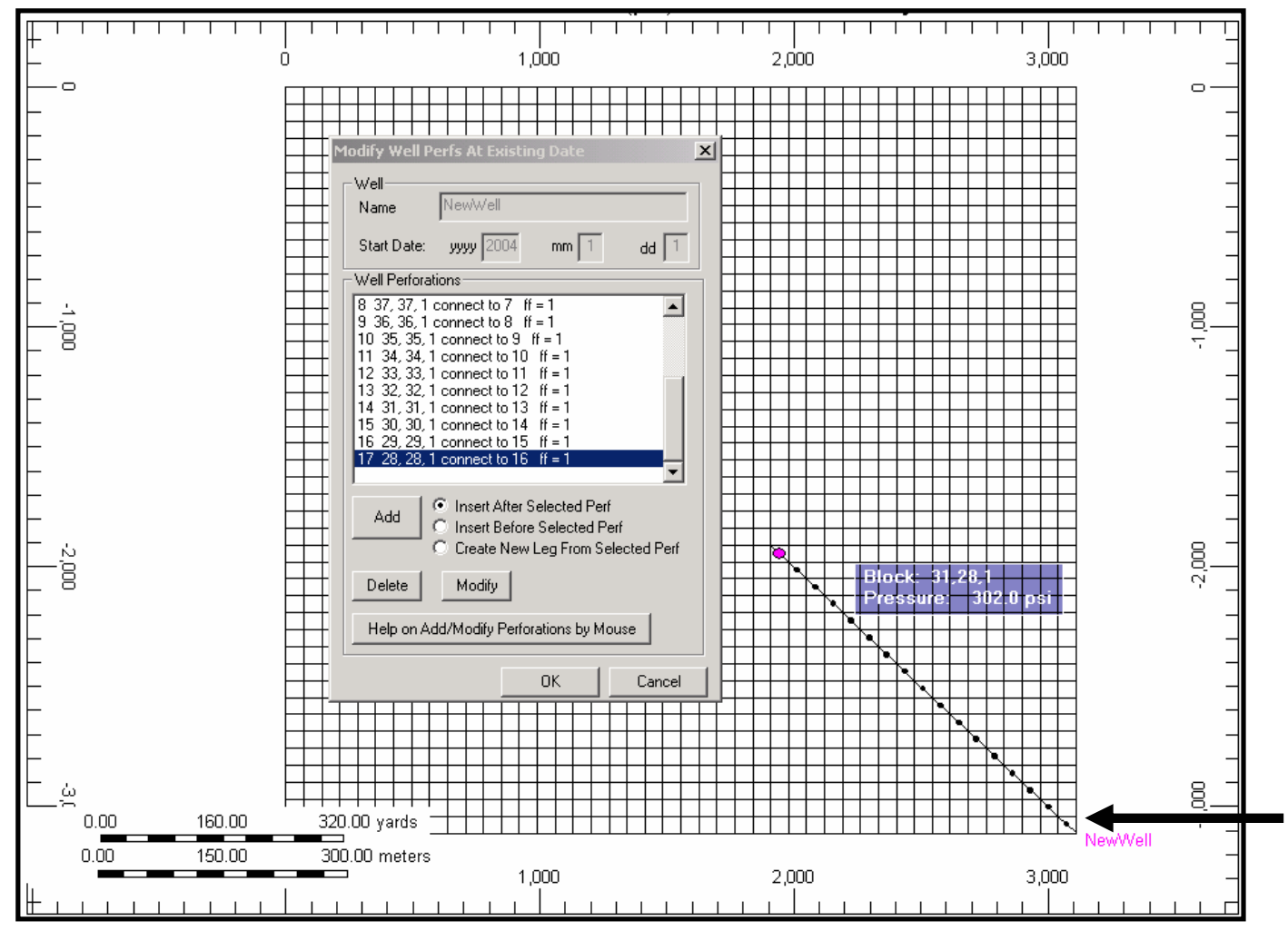

Figure 3.42 Modification of Well Type at Existing Data and One Single Lateral Well

Going back to the "Well and Recurrent Data" module, one can see the well's horizontal length, effective radius, top and bottom of the perforations (in this case open hole), number of the block that the well has been drilled through, as well as a wellbore scheme for this well. 


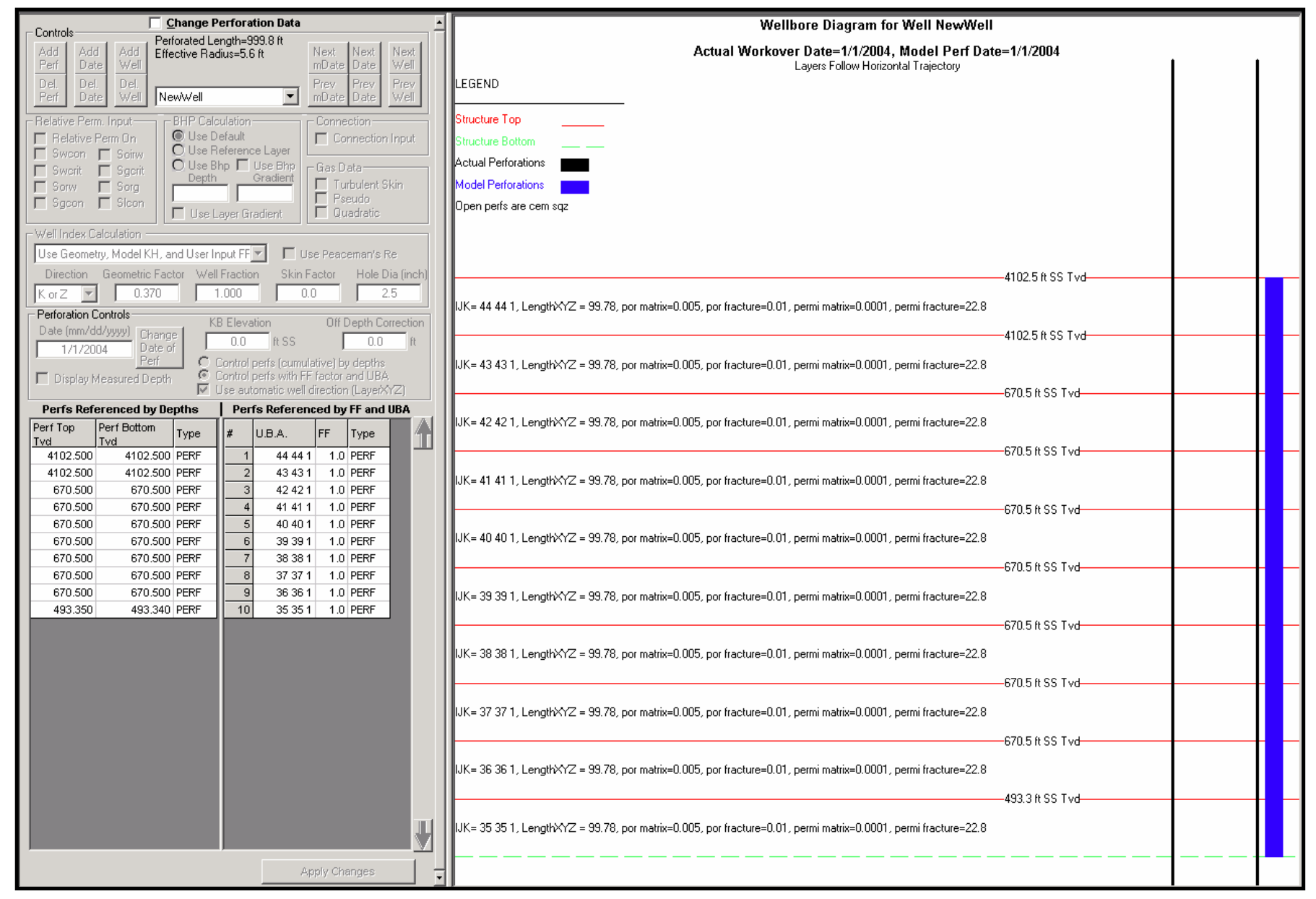

Figure 3.43 Well Perforations Mode 


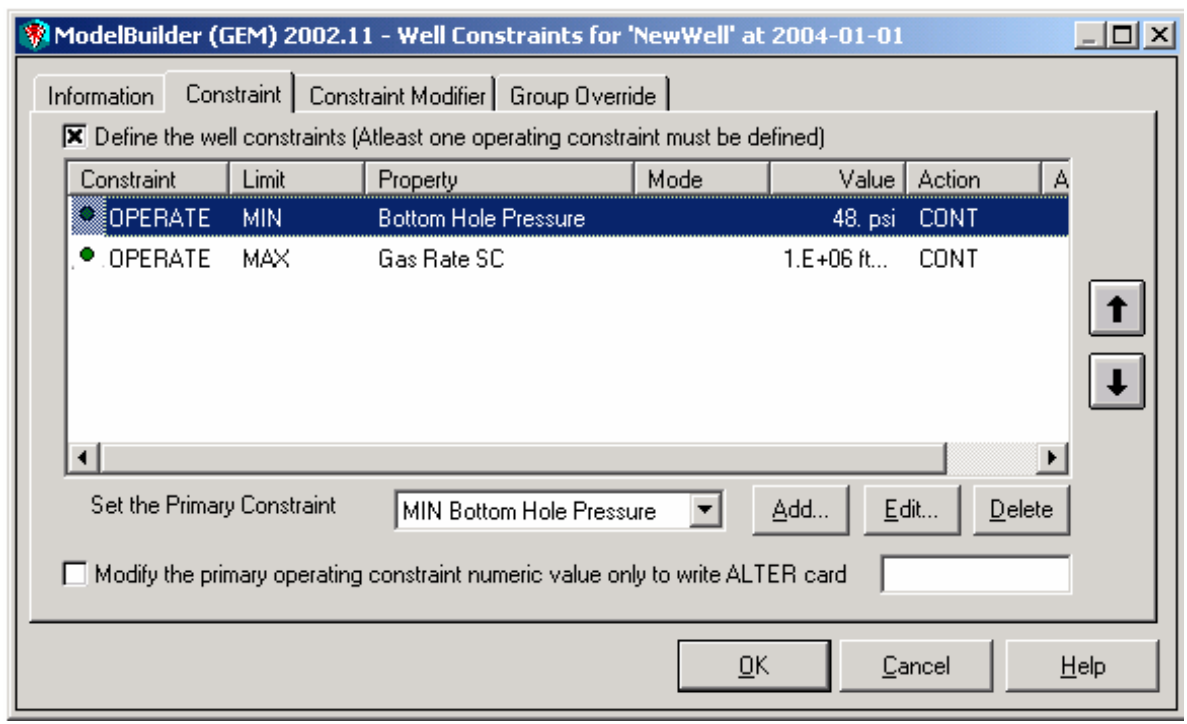

Figure 3.44 Well Constraints

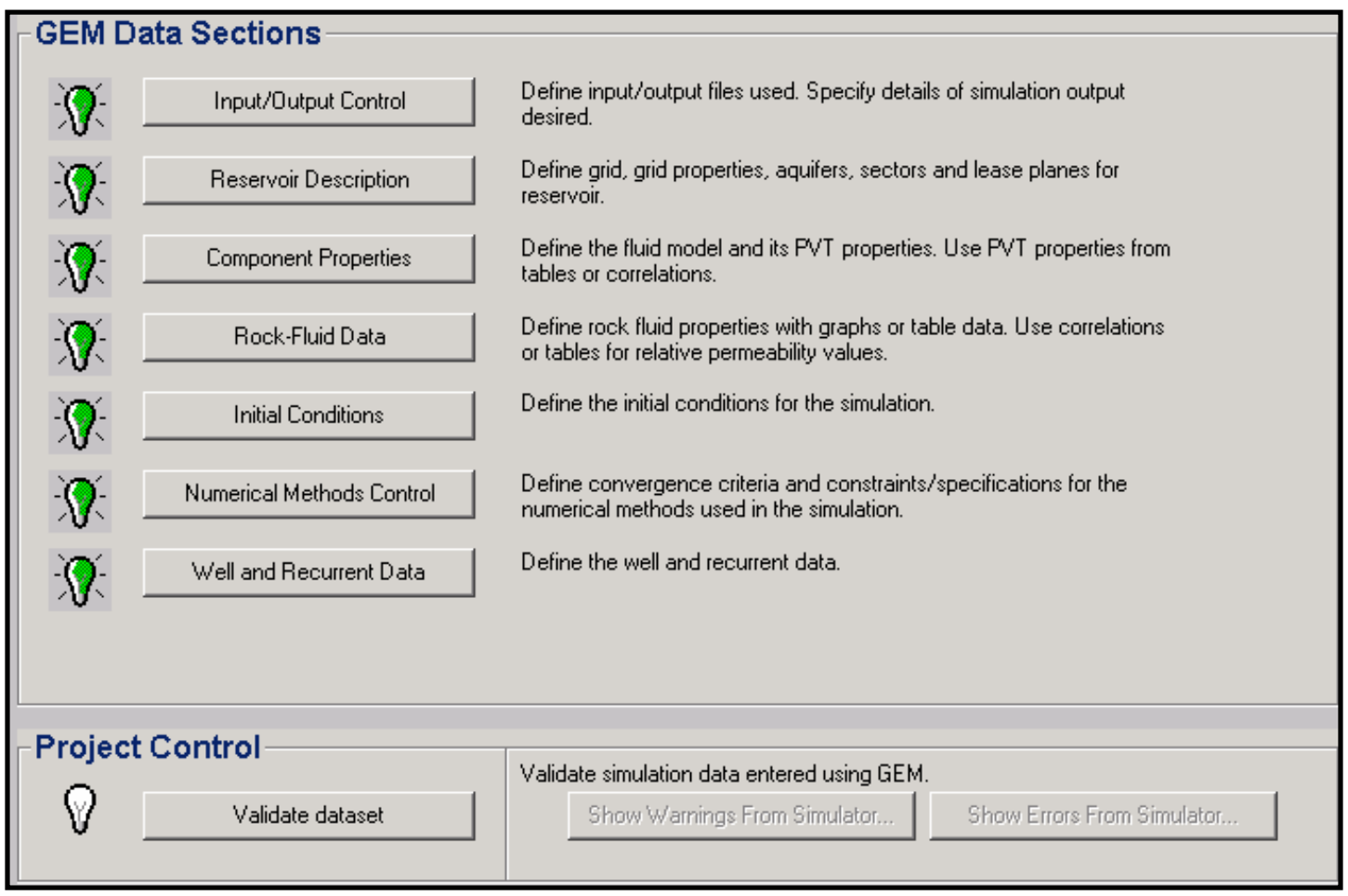

Figure 3.45 Snapshot of the CMB Simulator after Building a Model 
After all modules have been used and different data entered, the only thing left is to validate the dataset using "Validate Dataset" button set in the left lower corner of CMG Model, under "Project Control Option". The goal of this validation option is to validate the created file and suggest some changes, if necessary. After the validation of a newly created model, the .dat file is created and ready for running.

\subsubsection{Running the Model}

After building a model and the validation of entered data, simulator will create .dat file. The easiest way to run the model is to drag and drop .dat file on the GEM icon. Once it is done, CMG Simulator will start calculations.

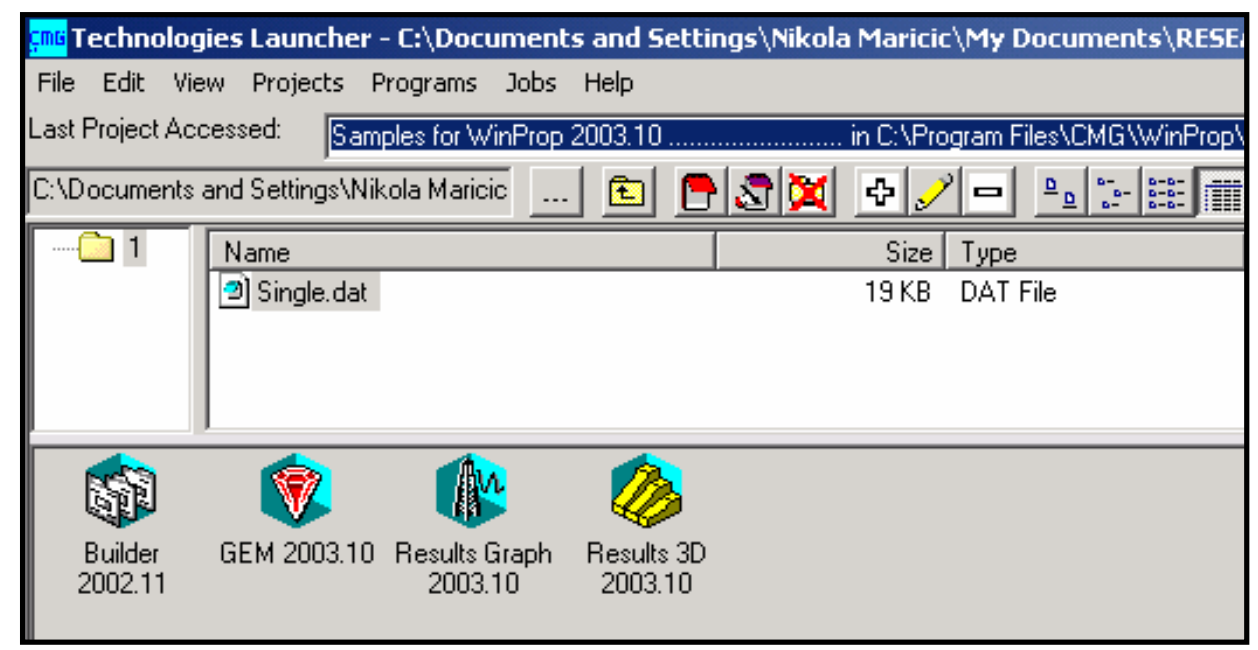

Figure 3.46 Project file .dat ready for the simulation

Upon finishing the simulation, the simulator will create the set of files with the different extension:

.out. (ACSII Output file);

.irf (Index Result file);

.mrf. (Main Results File).

The .irf and .mrf file are used together in Results 3D and Results Graph. 


\subsubsection{CMG Results / Graph}

The results Graph is typically used to plot curves of well properties that vary over time (“Time series properties”). Examples of Time series properties are Cumulative- Oil, Gas and Water; Oil, Gas and Water Rates, etc. These time series properties are read from a simulation output file. The plot can contain as many wells, groups, sectors, leases, or layers as user wants (CMG Reservoir Simulator Tutorial, 2003):

- Data from several different files;

- More than one parameter versus time curves;

- More than one parameter versus parameter curves.

The most important file that represents the simulator output is the file with .irf extension. Now, the same drag/drop process should take place in order to analyze results, but this time the output file should be set at "Result Graph" icon. If dealing with the high number of simulation analyzing the same parameters, a good option is creating a so-called .ses file. With the first .irf file loaded, all the wanted graphs should be created and customized (colors, line thickness, axes, background, that sort of thing). When that is done, template needs to be saved (File/Save template as). Then instead of dropping an irf file onto the Graph icon, the template file should be dropped instead (.ses file). It will ask user which .irf file he/she wants to open, and will then create an identical set of graphs using that file.

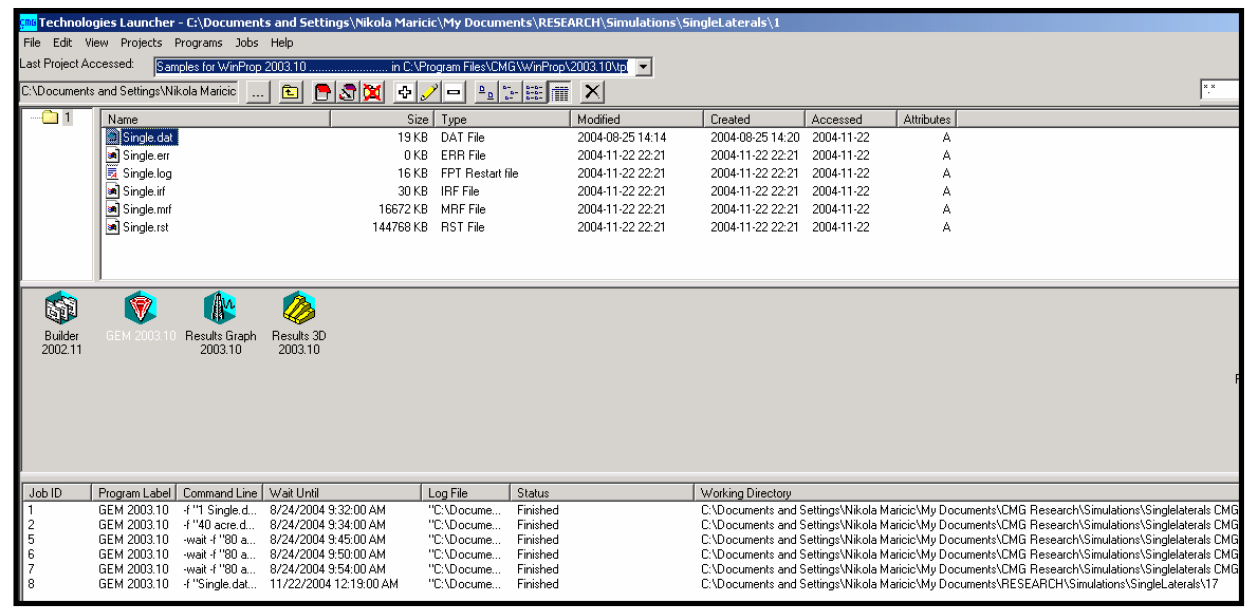

Figure 3.47 Form Showing .irf File ready to be Dragged and Dropped on Results Graph Icon 
Once this action is performed, the Result form will open, allowing user to create a plot. Out of the huge number of offered options, on the $\mathrm{X}$ axis, time needs to be plotted, and for $\mathrm{Y}$ axis, the following four parameters were chosen:

1. Gas Rate SC;

2. Water Rate SC;

3. Cumulative Water SC;

4. Cumulative Gas.

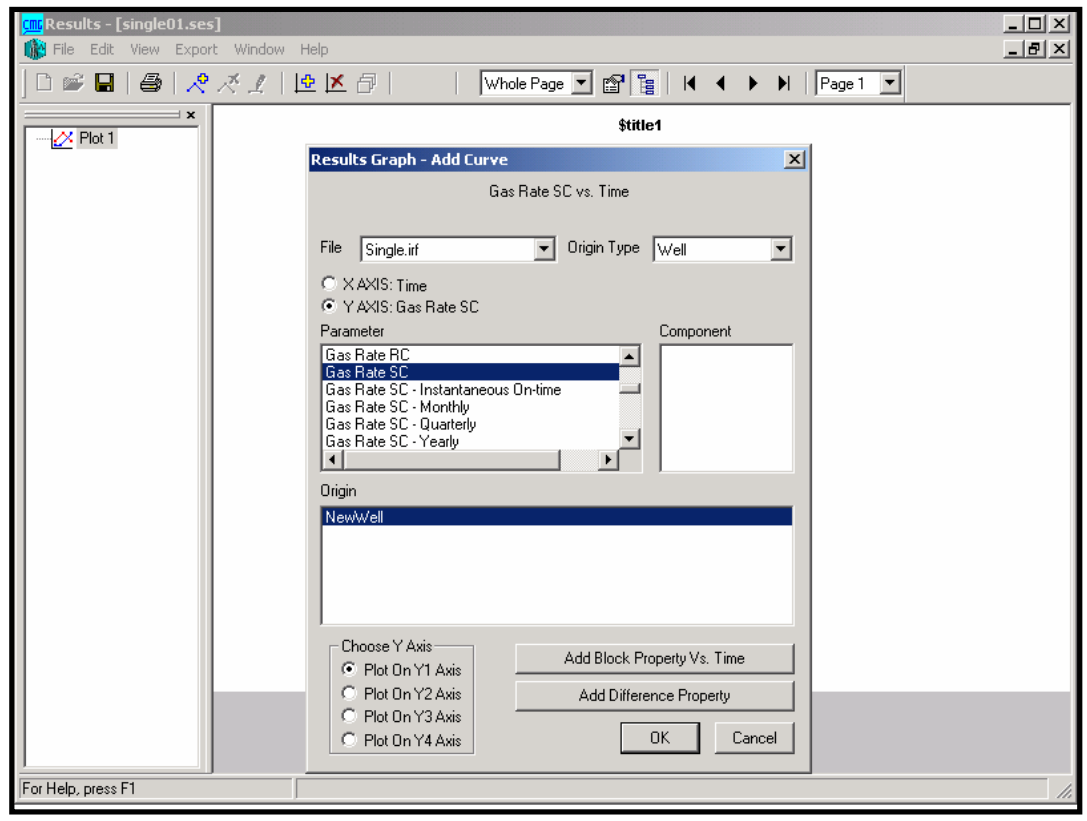

Figure 3.48 Choosing Plotting Options 


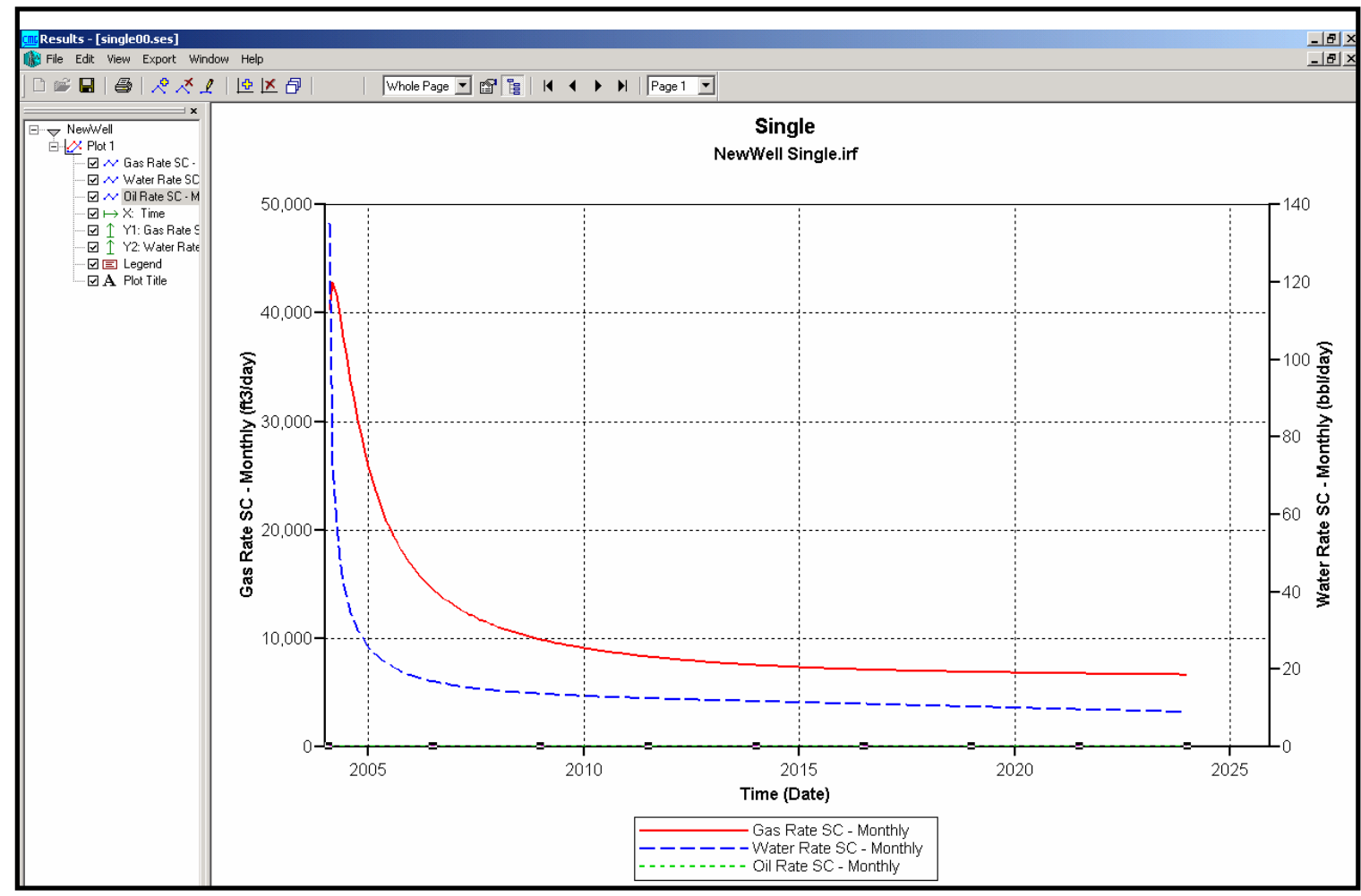

Figure 3.49 Gas and Water production

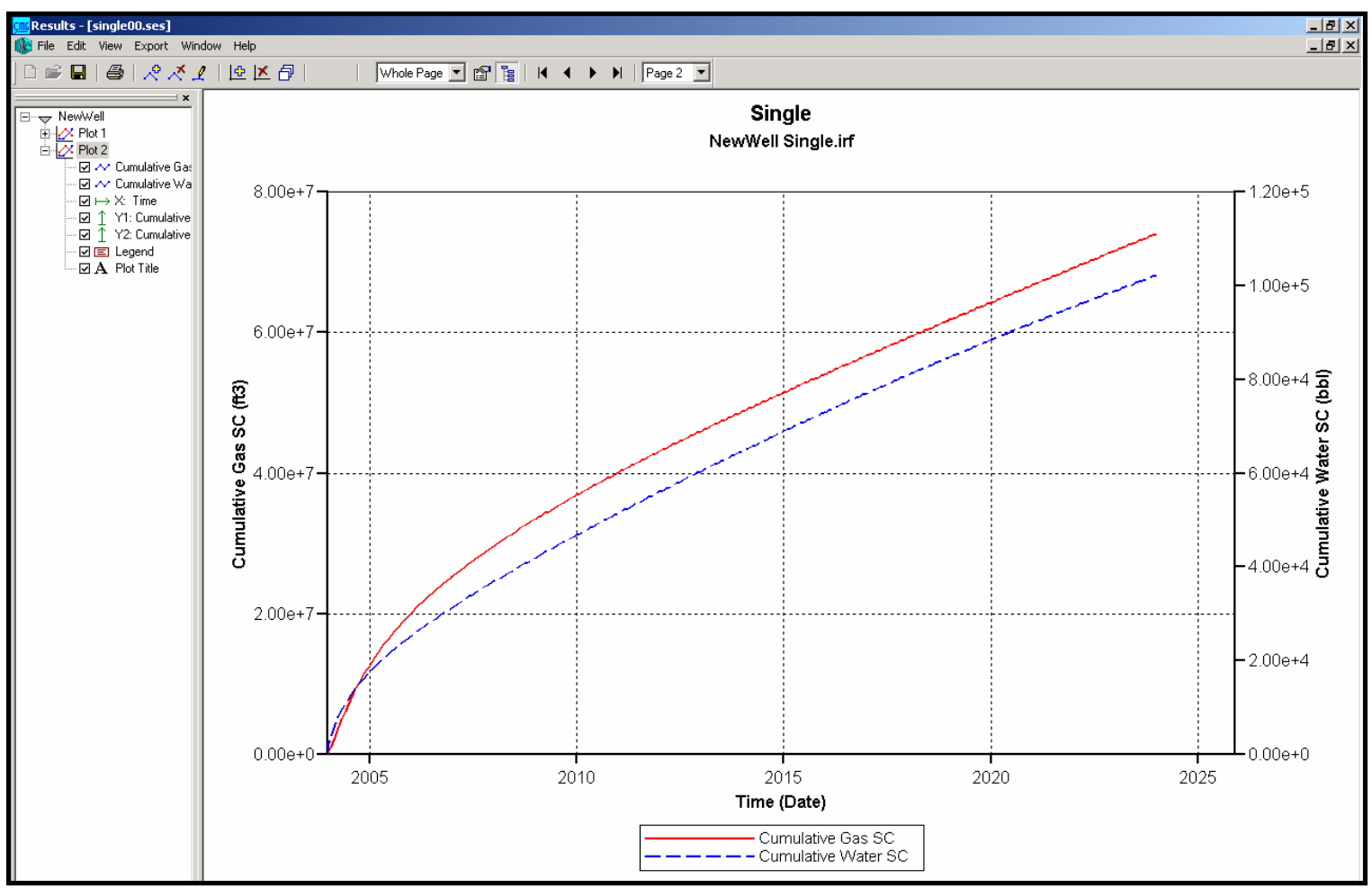

Figure 3.50 Cumulative Gas and Water production 


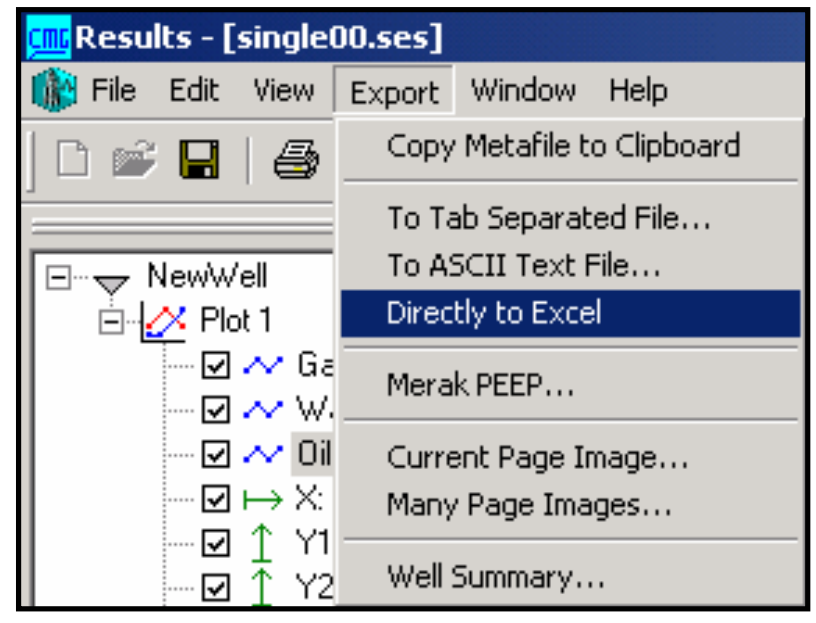

Figure 3.51 Exporting Graphs to Excel option

A very convenient thing in the CMG Simulator is the option of exporting simulation output files directly to Microsoft Excel. From that point, user can use Excel spread sheet, and model it as needed and suitable.

\subsubsection{D Results}

Results-3D lets the user to select either a two-dimensional (2D) or three-dimensional (3D) view of a reservoir simulation grid. Simulator can display any of the grid properties output at any of the output times. Results Graph can be invoked directly from Results 3D, and can have several 2D or 3D views open and a Graph View. 


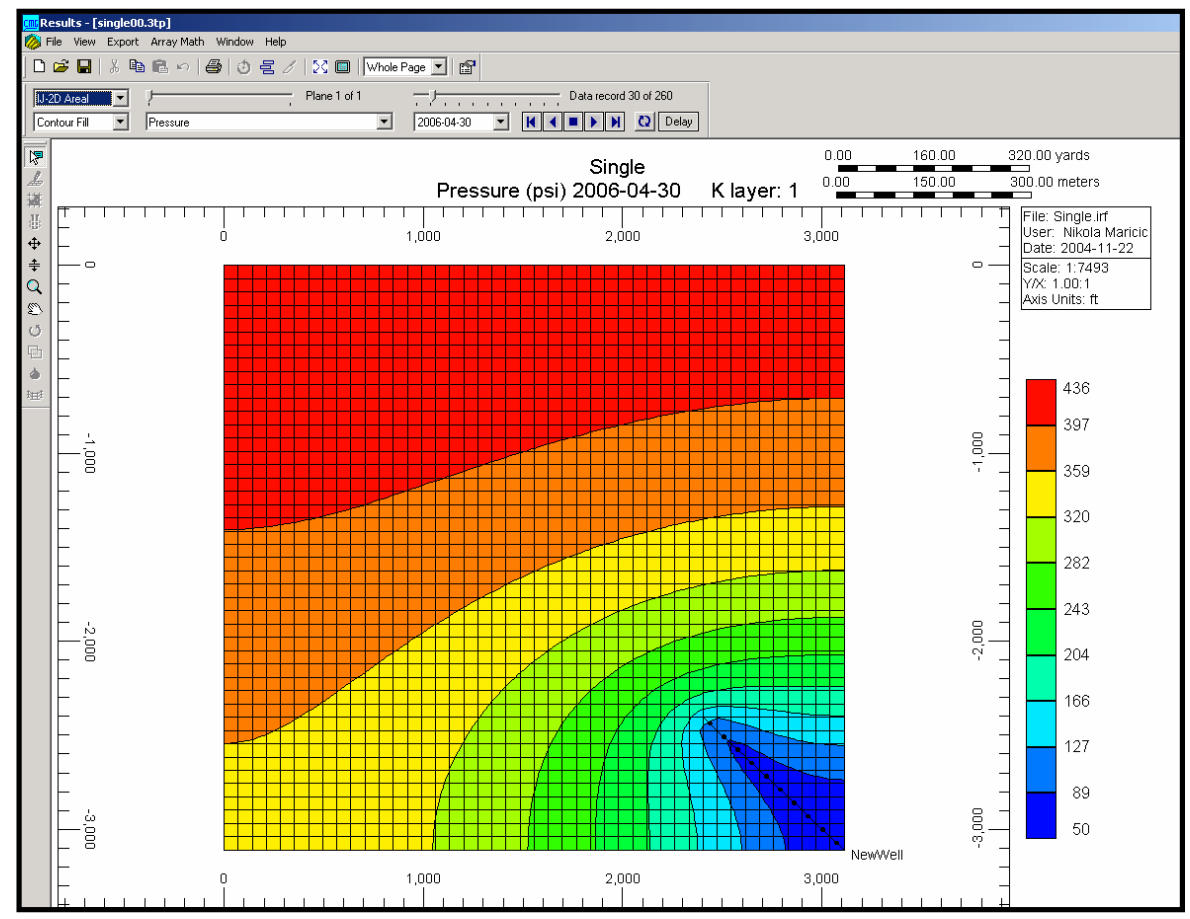

Figure 3.52 Pressure Distribution Couture Fill-IJ 2D Areal

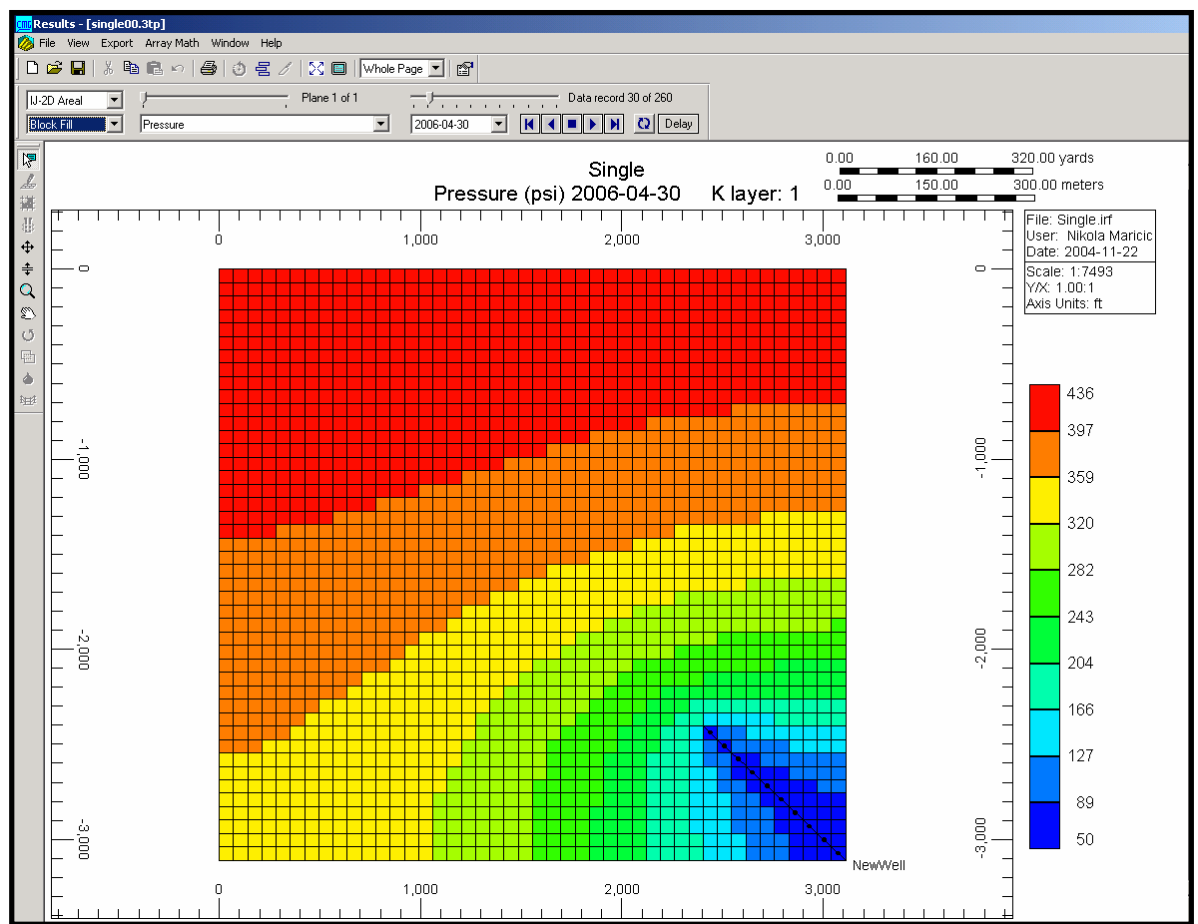

Figure 3.53 Pressure Distribution Block Fill-IJ 2D Areal 


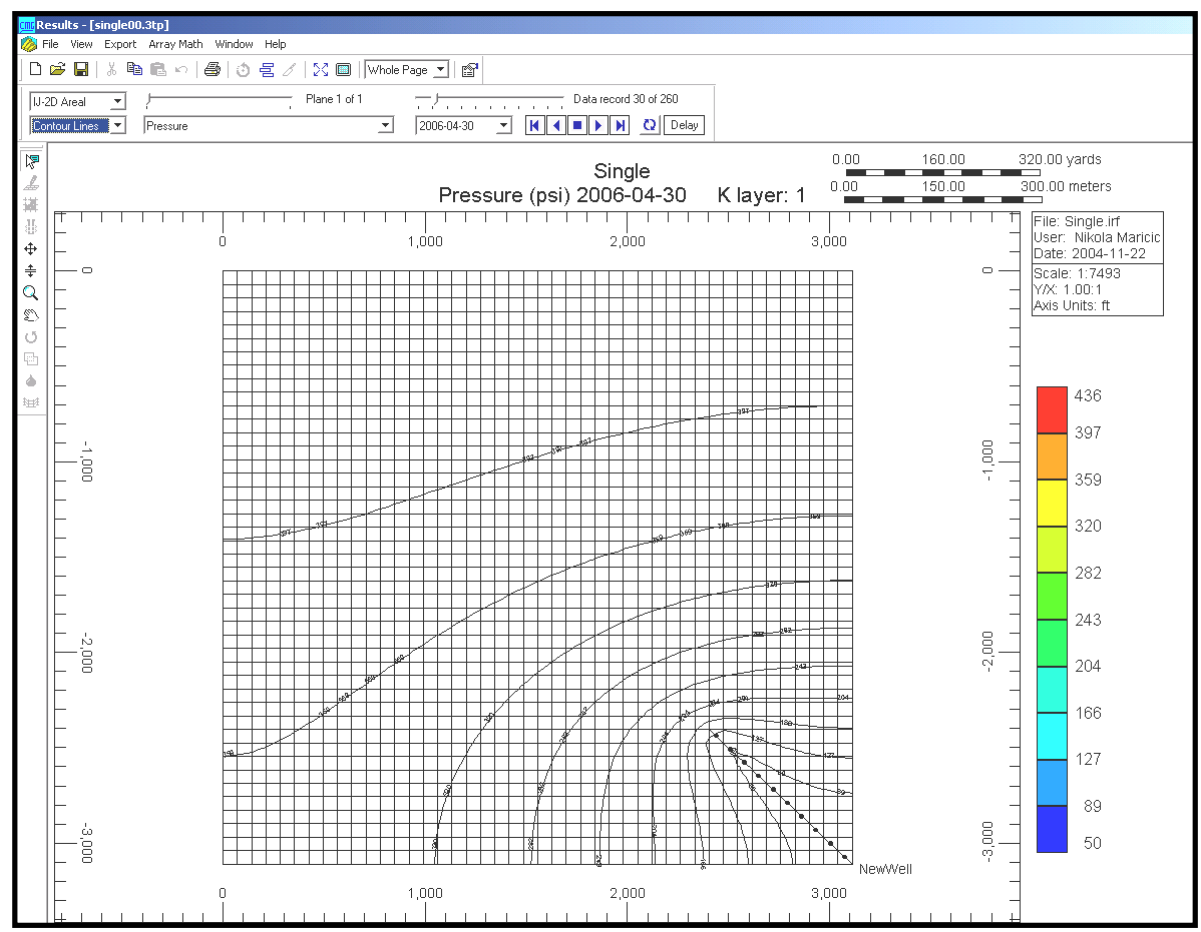

Figure 3.54 Pressure Distribution Contour Lines-IJ 2D Areal

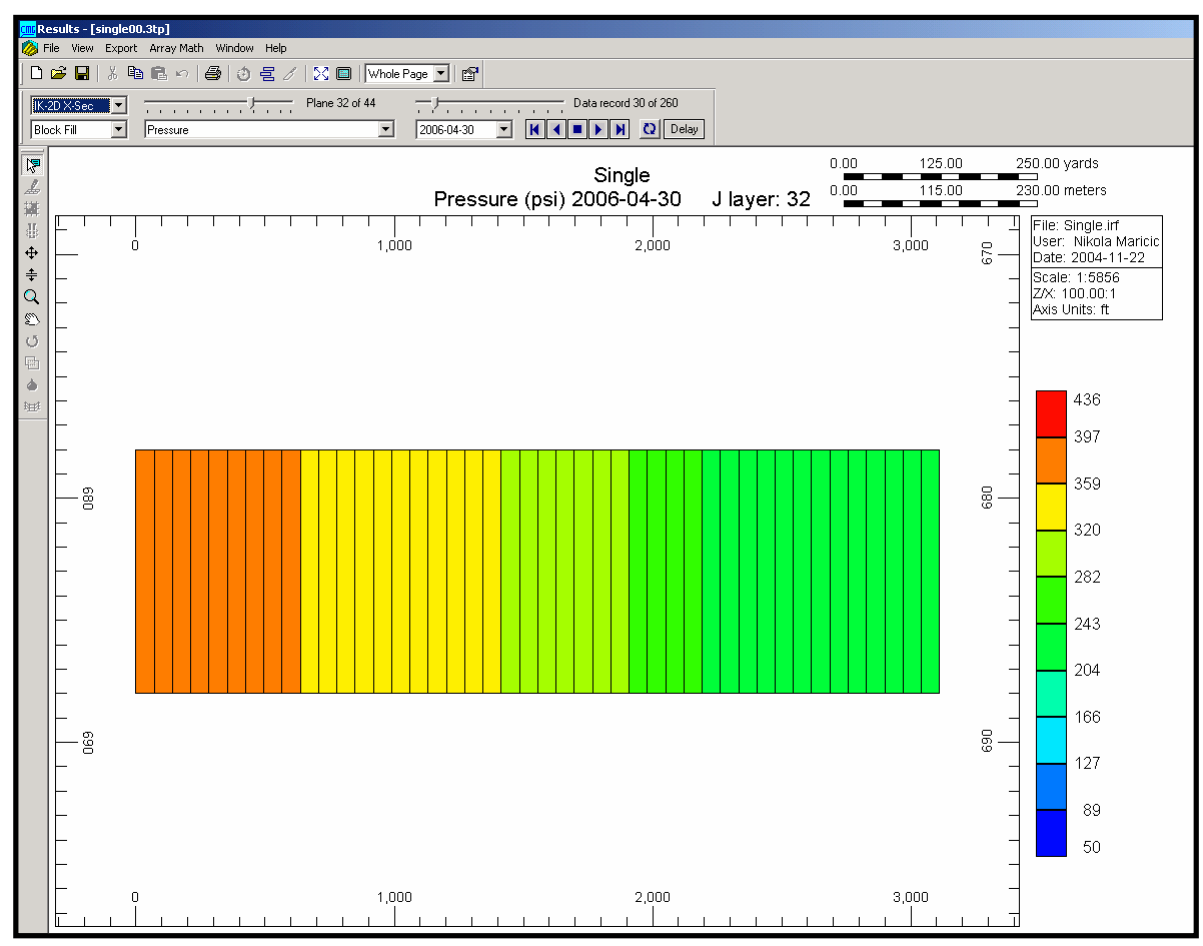

Figure 3.55 Pressure Distribution Contour Lines-JK 2D X Sec 


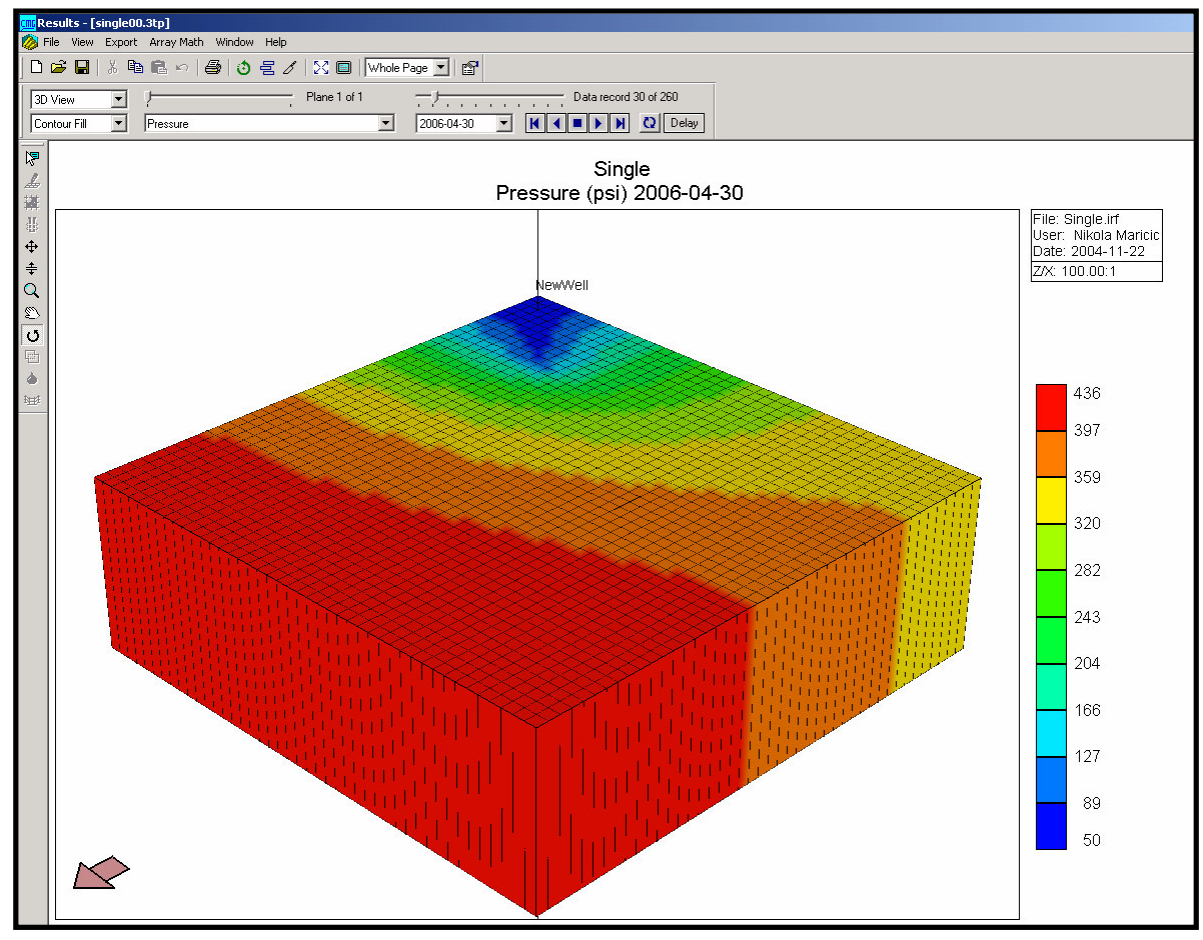

Figure 3.56 Pressure Distribution 3D View Contour Fill 


\subsection{Intelligent Modeling and Analysis}

Parametric analysis represents a set of simulations taking into consideration all combinations of the parameters that are under investigation. The wide-ranging parametric study has been conducted to enhance our understanding of CBM reservoir performance. In this study, five different matrixes have been created, regarding the different well configuration. Data preparation included changing more that 15 input parameters for the each one simulation.

The new approach into the "Horizontal Well Configurations \& Economic CBM Recovery" research project has been preformed. This approach has been determined from two different approaches previously investigated. It is supposed to give us better simulated output files that would be more useful for the Neural Network and Synthetic data modeling. The new CMG model has been made. The Cartesian Grid has been used, and 220 Acre Area of interest has been created. Out of 3 proposed models, the one with 1936 grid blocks has been approved for the Coalbed Methane model for 20 years.

The CBM Reservoir model is determined to be constant throughout this investigation, having 222 acres of drainage area.

\begin{tabular}{||l|c|}
\hline \multicolumn{1}{|c|}{ DATA } & \multicolumn{1}{c|}{ VALUE } \\
\hline Drainage Area (Acre) & 222 \\
\hline Number of Blocks & 1936 \\
\hline X axis & 44 Blocks \\
\hline Y axis & 44 Blocks \\
\hline Shape & Square \\
\hline Grid & Cartesian \\
\hline X axis $(\mathrm{ft})$ & 2828 \\
\hline Y axis $(\mathrm{ft})$ & 2828 \\
\hline Diagonal Length $(\mathrm{ft})$ & 4400 \\
\hline
\end{tabular}

Table 3.4 Data Determining Reservoir Size 


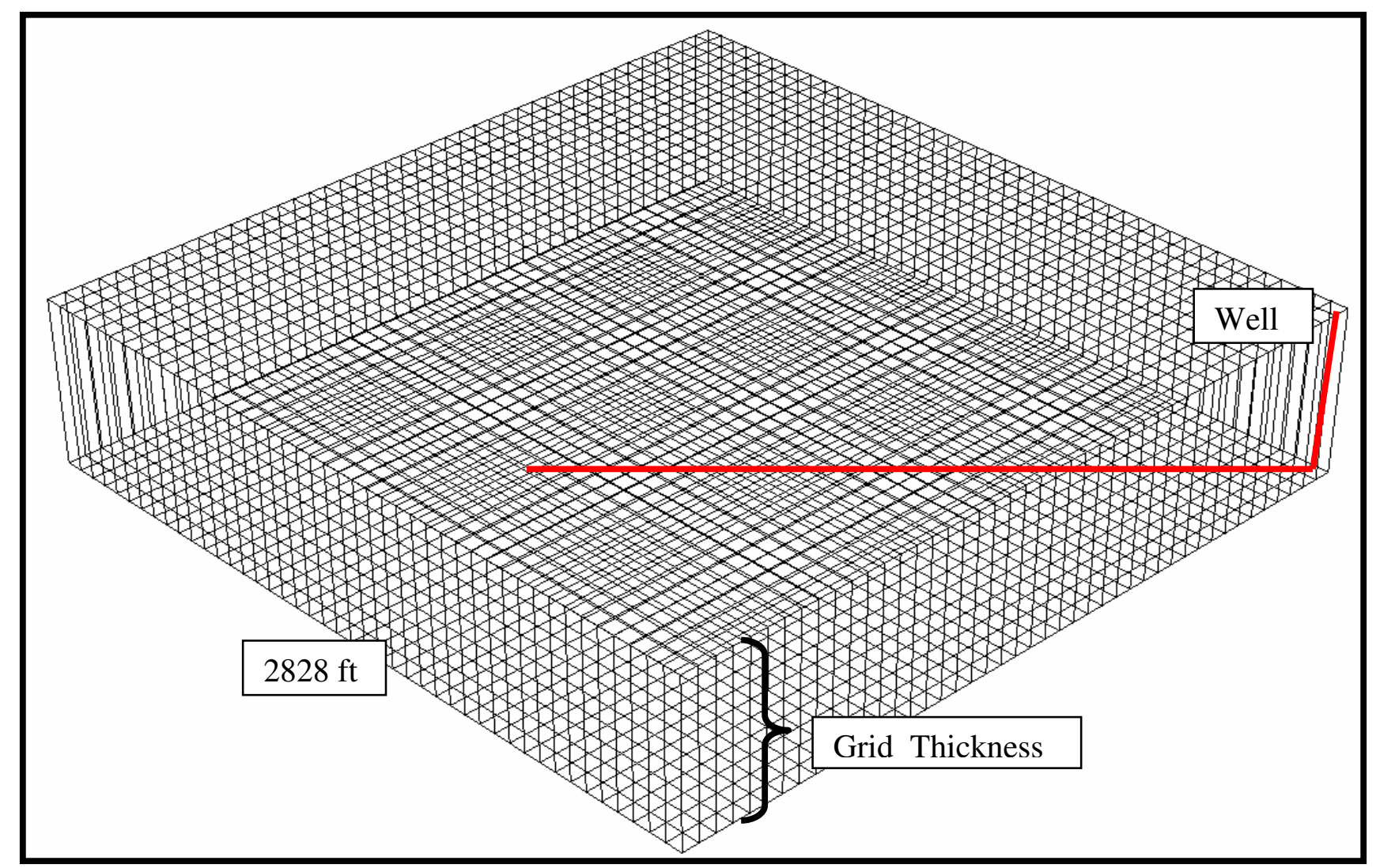

Figure 3.57 Reservoir Model with One Single Lateral Well 


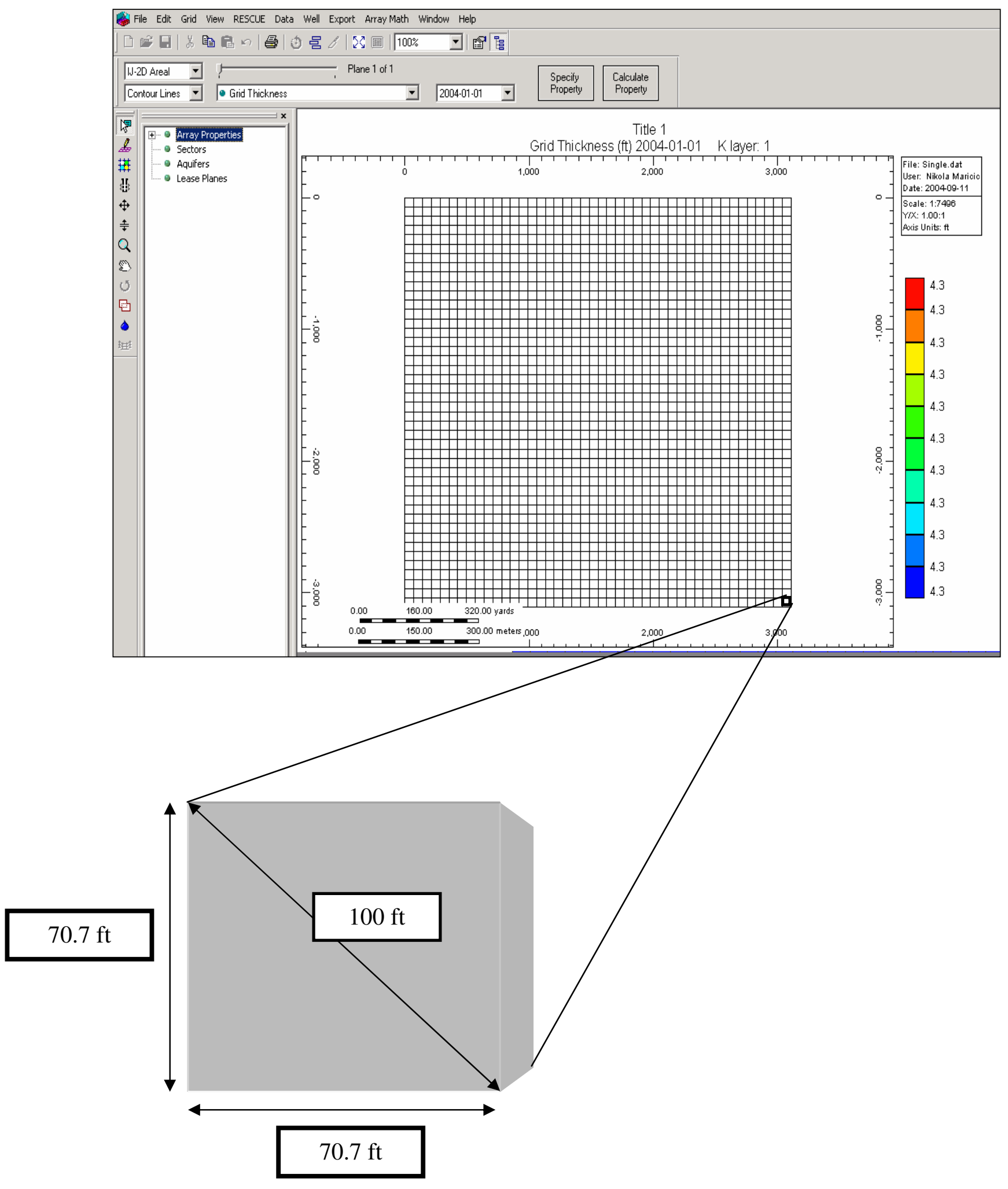

Figure 3.58 Shape and the Size of the Reservoir Model Used in the Study, Showing also the Size of One Single Block 
The diagonal of this squared model is $4400 \mathrm{ft}$. It has been suggested from the Industry experience that $4000 \mathrm{ft}$ are supposed to be used as the maximum length of a horizontal well. Additional $10 \%$ have been added (400ft) as a security factor for the simulation.

In the terms of well configurations, all the shapes (single lateral, dual lateral, trilateral, quad lateral and pinnate) have been used again, but the only difference with the parametric study approach is the location in which the vertical well has been placed. In this case, the vertical well has been shifted from the center of the reservoir (used in the parametric study approach), to the lower right corner of the model.

The reason for that change was a bigger drainage space obtained from changing the well position, resulting in better understanding of CBM model presented here.

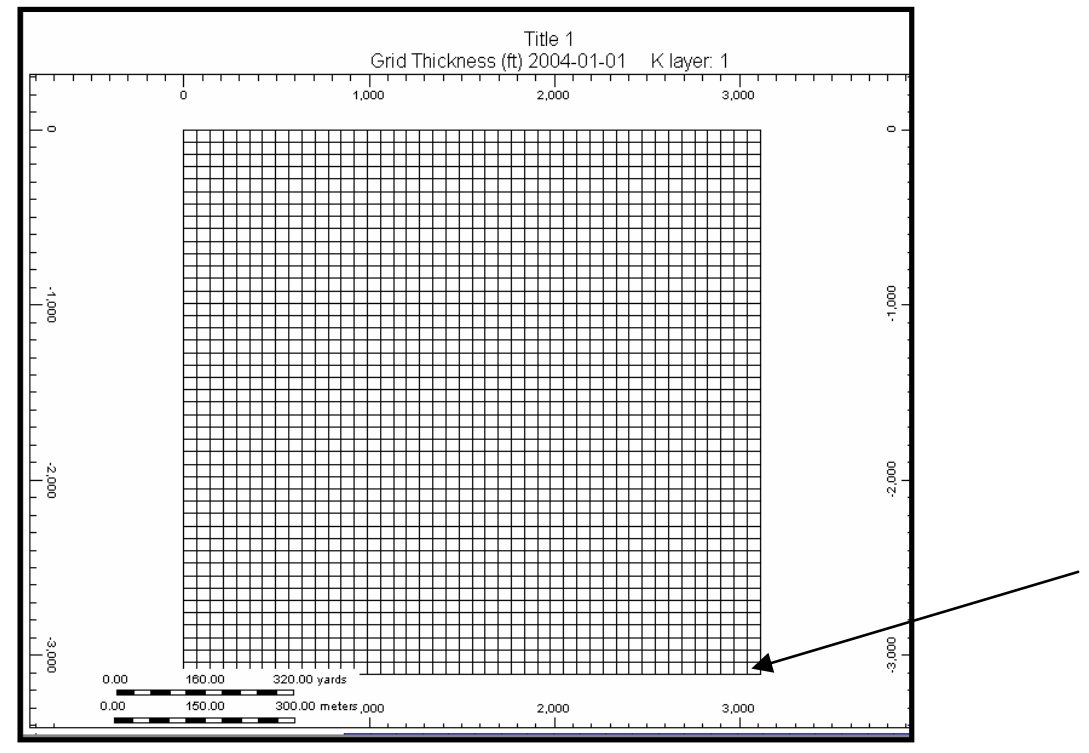

Figure 3.59 Vertical Well Placements in the Reservoir Model-Plain View 


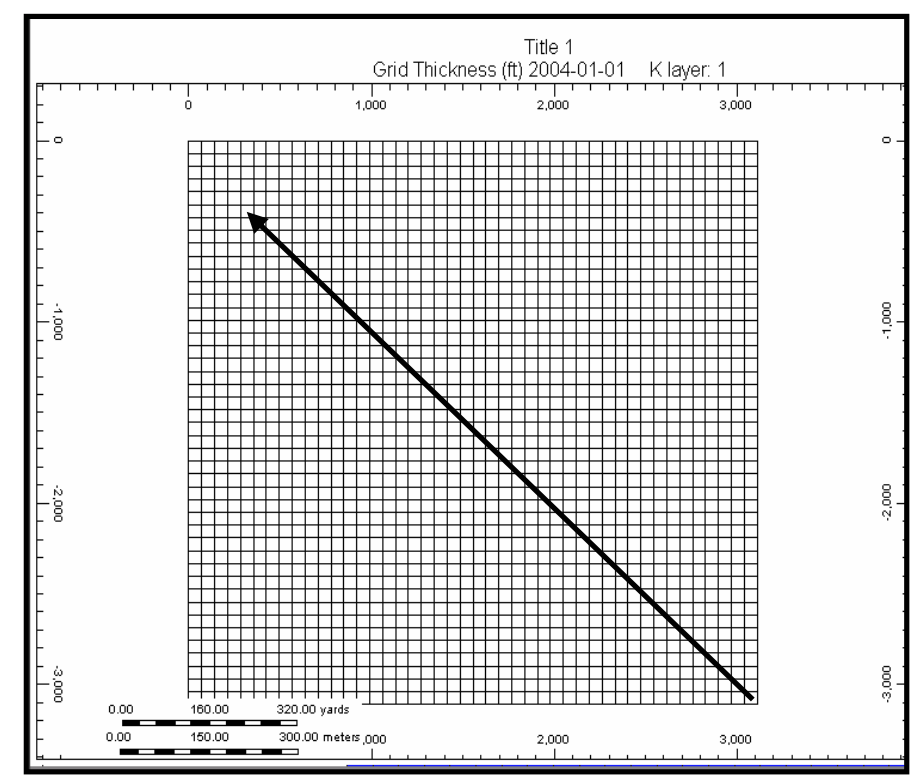

Figure 3.60 The Shape and the Direction of Well Spreading Through the Reservoir-Plain View

Once the vertical well has been placed in the appropriate place, laterals start spreading from the right down corner toward the upper left one. The following graphics represent the general way of laterals spreading throughout the reservoir. 


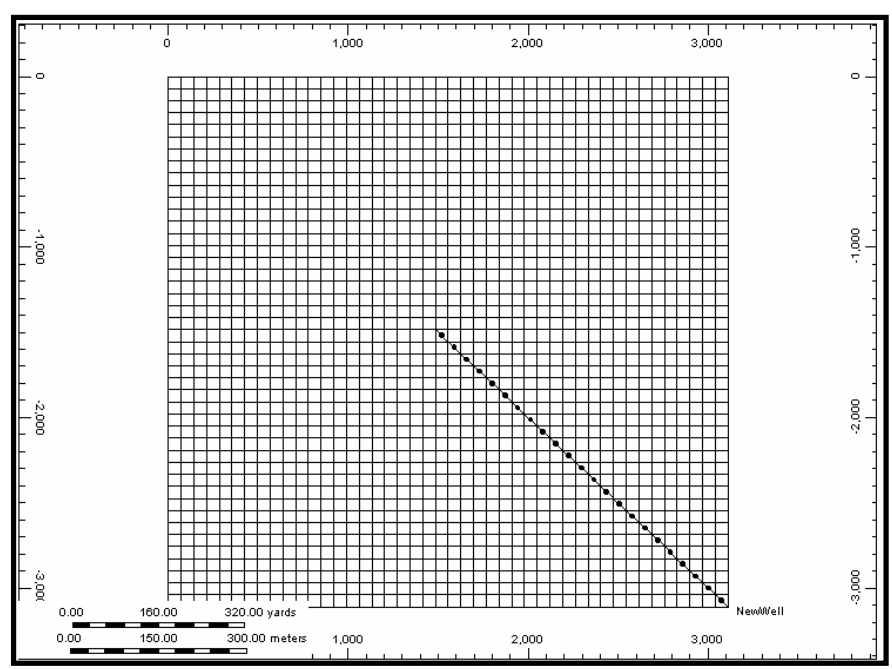

Figure 3.61 Single Lateral Well Configurations

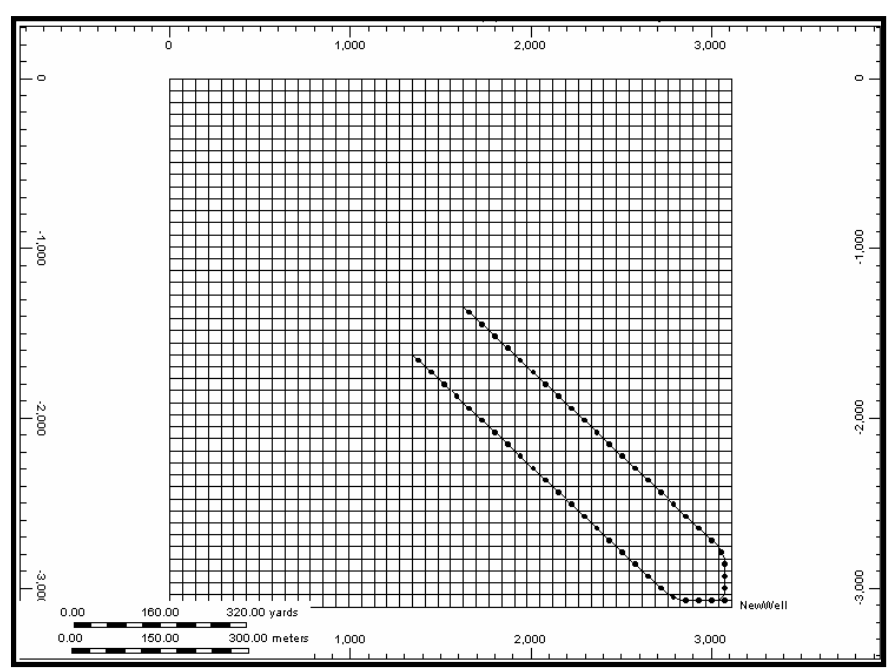

Figure 3.62 Dual Lateral Well Configurations

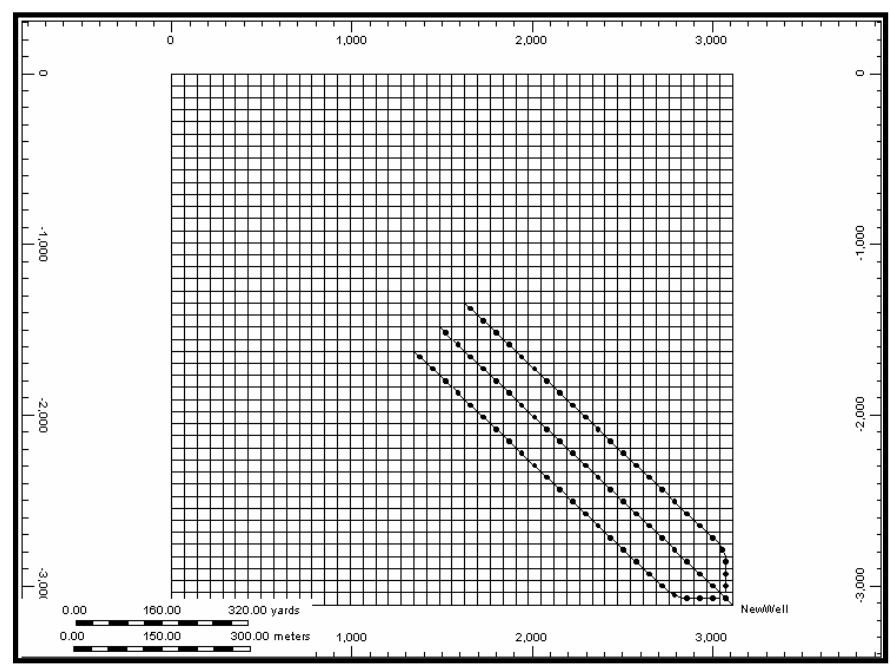

Figure 3.63 Tri Lateral Well Configurations 


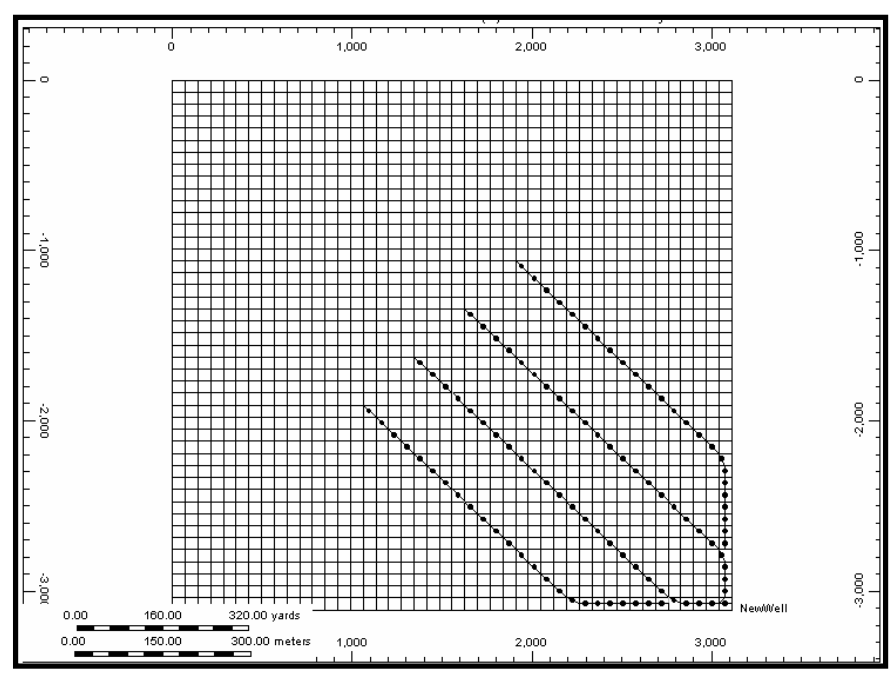

Figure 3.64 Quad Lateral Well Configurations

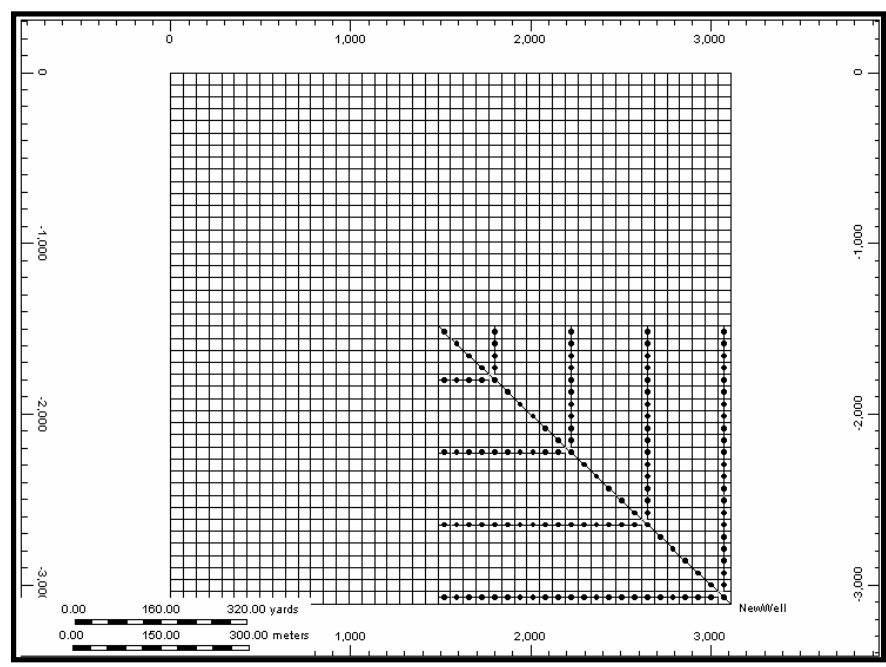

Figure 3.65 Pinnate Well Configurations 


\subsubsection{Data Preparation for the Simulations}

Upon determining the basic parameters of the reservoir size and shape, as well as establishing five different horizontal configurations, the next step was to create the matrix containing the reservoir data subject to change. Upon detailed sensitivity study, comparison of influence of different parameter changes, the decision of using random generated numbers as an input was made. The reason for this idea was the ability of obtaining a highly heterogeneous system.

It has been predetermined that for the Single lateral wells, 100 runs need to be performed. The first step into this new approach of generating simulated gas and water production data for the $\mathrm{CBM}$ recovery was to generate random numbers of 13 input parameters that would be changed for the ultimate number of 100 runs.

\begin{tabular}{|c|lcc|}
\hline \multicolumn{1}{|c}{ VARIABLES } & Min & Max \\
& & & \\
$\mathbf{1}$ & & & \\
$\mathbf{2}$ & PRESSURE (PSI) & 200 & 600 \\
$\mathbf{3}$ & VI (scf/ton) & 100 & 500 \\
$\mathbf{4}$ & PI (psi) & 100 & 300 \\
$\mathbf{5}$ & PAY THICKNESS (FT) & 3 & 12 \\
$\mathbf{6}$ & FRACTURE PERMEABILITY I (md) & 1 & 25 \\
$\mathbf{7}$ & FRACTURE PERMEABILITY j (md) & 1 & 25 \\
$\mathbf{8}$ & FRACTURE PERMEABILITY $\mathbf{k}(\mathbf{m d})$ & 1 & 25 \\
$\mathbf{9}$ & COAL DESORPTION TIME (days) & 5 & 250 \\
$\mathbf{1 0}$ & BHP (psi) & 15 & 50 \\
$\mathbf{1 1}$ & GRID TOPDEPTH (ft) & 300 & 1000 \\
$\mathbf{1 2}$ & POROSITY FRACTURE (fr) & 0.05 & 0.1 \\
$\mathbf{1 3}$ & Sw (fracture) \% & 75 & 100 \\
& Single Leteral Length (ft) & 300 & 4000 \\
\hline
\end{tabular}

Figure 3.66 Snapshot of the Form with Variables that Creates Random Numbers as Inputs 


\begin{tabular}{|l|c|c|}
\hline \multicolumn{1}{|c|}{ VARIABLES } & MINIMUM & MAXIMUM \\
\hline PRESSURE (PSI) & 200 & 600 \\
\hline VI (scf/ton) & 100 & 500 \\
\hline PI (psi) & 100 & 300 \\
\hline PAY THICKNESS (FT) & 3 & 12 \\
\hline FRACTURE PERMEABILITY I (md) & 1 & 25 \\
\hline FRACTURE PERMEABILITY j (md) & 1 & 25 \\
\hline FRACTURE PERMEABILITY k (md) & 1 & 25 \\
\hline COAL DESORPTION TIME (days) & 5 & 250 \\
\hline BHP (psi) & 15 & 50 \\
\hline GRID TOPDEPTH (ft) & 300 & 1000 \\
\hline POROSITY FRACTURE (fr) & 0.05 & 0.1 \\
\hline Sw (fracture) \% & 75 & 100 \\
\hline TOTAL LENGTH (ft) & 300 & 4000 \\
\hline
\end{tabular}

Table 3.5 Simulation Set of Input Data for the Single Lateral Well Configuration

\begin{tabular}{|l|c|c|}
\hline \multicolumn{1}{|c|}{ VARIABLES } & MINIMUM & MAXIMUM \\
\hline PRESSURE (PSI) & 200 & 600 \\
\hline VI (scf/ton) & 100 & 500 \\
\hline PI (psi) & 100 & 300 \\
\hline PAY THICKNESS (FT) & 3 & 12 \\
\hline FRACTURE PERMEABILITY I (md) & 1 & 25 \\
\hline FRACTURE PERMEABILITY j (md) & 1 & 25 \\
\hline FRACTURE PERMEABILITY k (md) & 1 & 25 \\
\hline COAL DESORPTION TIME (days) & 5 & 250 \\
\hline BHP (psi) & 15 & 50 \\
\hline GRID TOPDEPTH (ft) & 300 & 1000 \\
\hline POROSITY FRACTURE (fr) & 0.05 & 0.1 \\
\hline Sw (fracture) \% & 75 & 100 \\
\hline TOTAL HORIZONTAL LENGTH $(\mathrm{ft})$ & 600 & 8000 \\
\hline SPACING BETWEEN LATERALS $(\mathrm{ft})$ & 100 & 4000 \\
\hline
\end{tabular}

Table 3.6 Simulation Set of Input Data for the Dual Lateral Well Configuration 


\begin{tabular}{|l|c|c|}
\hline \multicolumn{1}{|c|}{ VARIABLES } & MINIMUM & MAXIMUM \\
\hline PRESSURE (PSI) & 200 & 600 \\
\hline VI (scf/ton) & 100 & 500 \\
\hline PI (psi) & 100 & 300 \\
\hline PAY THICKNESS (FT) & 3 & 12 \\
\hline FRACTURE PERMEABILITY I (md) & 1 & 25 \\
\hline FRACTURE PERMEABILITY j (md) & 1 & 25 \\
\hline FRACTURE PERMEABILITY k (md) & 1 & 25 \\
\hline COAL DESORPTION TIME (days) & 5 & 50 \\
\hline BHP (psi) & 15 & 1000 \\
\hline GRID TOPDEPTH (ft) & 300 & 0.1 \\
\hline POROSITY FRACTURE (fr) & 0.05 & 100 \\
\hline Sw (fracture) \% & 75 & 12000 \\
\hline TOTAL HORIZONTAL LENGTH (ft) & 1000 & 2000 \\
\hline SPACING BETWEEN LATERALS $(\mathrm{ft})$ & 100 & \\
\hline
\end{tabular}

Table 3.7 Simulation Set of Input Data for the Tri Lateral Well Configuration

\begin{tabular}{|l|c|c|}
\hline \multicolumn{1}{|c|}{ VARIABLES } & MINIMUM & MAXIMUM \\
\hline PRESSURE (PSI) & 200 & 600 \\
\hline VI (scf/ton) & 100 & 500 \\
\hline PI (psi) & 100 & 300 \\
\hline PAY THICKNESS (FT) & 3 & 12 \\
\hline FRACTURE PERMEABILITY I (md) & 1 & 25 \\
\hline FRACTURE PERMEABILITY j (md) & 1 & 25 \\
\hline FRACTURE PERMEABILITY k (md) & 1 & 25 \\
\hline COAL DESORPTION TIME (days) & 5 & 50 \\
\hline BHP (psi) & 15 & 1000 \\
\hline GRID TOPDEPTH (ft) & 300 & 0.1 \\
\hline POROSITY FRACTURE (fr) & 0.05 & 100 \\
\hline Sw (fracture) \% & 75 & 16000 \\
\hline TOTAL HORIZONTAL LENGTH (ft) & 1000 & 1200 \\
\hline SPACING BETWEEN LATERALS $(\mathrm{ft})$ & 100 & \\
\hline
\end{tabular}

Table 3.8 Simulation Set of Input Data for the Quad Lateral Well Configuration 


\begin{tabular}{|l|c|c|}
\hline \multicolumn{1}{|c|}{ VARIABLES } & MINIMUM & MAXIMUM \\
\hline PRESSURE (PSI) & 200 & 600 \\
\hline VI (scf/ton) & 100 & 500 \\
\hline PI (psi) & 100 & 300 \\
\hline PAY THICKNESS (FT) & 3 & 12 \\
\hline FRACTURE PERMEABILITY I (md) & 1 & 25 \\
\hline FRACTURE PERMEABILITY j (md) & 1 & 25 \\
\hline FRACTURE PERMEABILITY $\mathrm{k}(\mathrm{md})$ & 1 & 25 \\
\hline COAL DESORPTION TIME (days) & 5 & 250 \\
\hline BHP (psi) & 15 & 50 \\
\hline GRID TOPDEPTH (ft) & 300 & 1000 \\
\hline POROSITY FRACTURE (fr) & 0.05 & 0.1 \\
\hline SW (fracture) \% & 75 & 100 \\
\hline TOTAL HORIZONTAL LENGTH $(\mathrm{ft})$ & 1000 & 16000 \\
\hline SPACING BETWEEN LATERALS $(\mathrm{ft})$ & 100 & 1200 \\
\hline NUMBER OF LATERALS & 4 & 22 \\
\hline LONGEST LATERAL LENGTH $(\mathrm{ft})$ & 400 & 4000 \\
\hline
\end{tabular}

Table 3.9 Simulation Set of Input Data for the Pinnate Well Configuration

As it could be seen from the tables containing variable inputs, most of the inputs are the same for all well configurations, except those directly related to the horizontal well, shown as the last input in the tables. 


\subsection{Data Preparation for the Decline Curve Analysis (IPDE-IDEA Software)}

After running a model in the reservoir simulator, a set of data will be provided in the form of .irf output file. That file can be used in the Graph Builder directly in the CMG simulator, and data can be analyzed there. However, in order to use outputs from the simulator and prepare it as an input for the Decline Curve Analysis, certain steps need to be followed. First step is to export .irf file (file containing outputs from the Simulator) into Excel. Once the file is exported and data obtained in the form of spread sheet, certain changes can be applied.

\begin{tabular}{|c|c|c|c|c|}
\hline$B$ & C & D & E & $\mathrm{F}$ \\
\hline $\begin{array}{l}\text { TIME } \\
\text { (day) }\end{array}$ & DATE & $\begin{array}{c}\text { Gas Rate SC - Monthly } \\
\text { (ft } 3 / \text { day) } \\
\end{array}$ & $\begin{array}{c}\text { Water Rate SC - Monthly } \\
\text { (bbl/day) }\end{array}$ & $\begin{array}{c}\text { Oil Rate SC - Monthly } \\
\text { (bbl/day) }\end{array}$ \\
\hline & & & & \\
\hline 30.95 & $1 / 31 / 2004$ & 16813.6 & 138.849 & 0 \\
\hline 59.95 & $2 / 29 / 2004$ & 21721 & 78.4426 & 0 \\
\hline 90.95 & $3 / 31 / 2004$ & 22872.4 & 62.3532 & 0 \\
\hline $\begin{array}{l}120.95 \\
151.95\end{array}$ & $4 / 30 / 2004$ & 23241.4 & 53.2884 & 0 \\
\hline $\begin{array}{l}151.95 \\
181.95\end{array}$ & $5 / 31 / 2004$ & $\begin{array}{l}23136.6 \\
227827\end{array}$ & 46.7411 & 0 \\
\hline $\begin{array}{l}181.95 \\
21295\end{array}$ & $6 / 30 / 2004$ & 22782.7 & $\begin{array}{l}41.9694 \\
38.1569\end{array}$ & 0 \\
\hline 243.95 & $8 / 31 / 20044$ & $\begin{array}{l}22267.6 \\
21654.4\end{array}$ & $\begin{array}{l}38.1569 \\
35.0931\end{array}$ & $\begin{array}{l}0 \\
0\end{array}$ \\
\hline 273.95 & $9 / 30 / 2004$ & 21055.9 & 32.7243 & 0 \\
\hline 304.95 & $10 / 31 / 2004$ & 20418.2 & 30.686 & 0 \\
\hline 334.95 & $11 / 30 / 2004$ & 19811.4 & 29.0345 & 0 \\
\hline 365.95 & $12 / 31 / 2004$ & 19229.1 & 27.6392 & 0 \\
\hline 396.95 & $1 / 31 / 2005$ & 18618.6 & 26.3421 & 0 \\
\hline 424.95 & $2 / 28 / 2005$ & 18094.2 & 25.3166 & 0 \\
\hline 455.95 & $3 / 31 / 2005$ & 17542.4 & 24.3117 & 0 \\
\hline 485.95 & $4 / 30 / 2005$ & 17027.3 & 23.4323 & 0 \\
\hline 516.95 & $5 / 31 / 2005$ & 16523.7 & 22.6149 & 0 \\
\hline 546.95 & $6 / 30 / 2005$ & 16055.3 & 21.8907 & 0 \\
\hline 577.95 & $7 / 31 / 2005$ & 15598.7 & 21.2113 & 0 \\
\hline 608.95 & $8 / 31 / 2005$ & 15162.9 & 20.5874 & 0 \\
\hline 638.95 & $9 / 30 / 2005$ & 14763.4 & 20.0317 & 0 \\
\hline 669.95 & $10 / 31 / 2005$ & 14373 & 19.5039 & 0 \\
\hline 699.95 & $11 / 30 / 2005$ & 14012.8 & 19.0283 & 0 \\
\hline 730.95 & $12 / 31 / 2005$ & 13670.8 & 18.5858 & 0 \\
\hline 761.95 & $1 / 31 / 2006$ & 13328.4 & 18.1499 & 0 \\
\hline 789.95 & $2 / 28 / 2006$ & 13040.3 & 17.7895 & 0 \\
\hline 820.95 & $3 / 31 / 2006$ & 12739.6 & 17.4173 & 0 \\
\hline 850.95 & $4 / 30 / 2006$ & 12461.6 & 17.0769 & 0 \\
\hline 881.95 & $5 / 31 / 2006$ & 12189.9 & 16.7459 & 0 \\
\hline 911.95 & $6 / 30 / 2006$ & 11938.9 & 16.4423 & 0 \\
\hline 942.95 & $7 / 31 / 2006$ & 11692.4 & 16.1454 & 0 \\
\hline 973.95 & $8 / 31 / 2006$ & 11458.3 & 15.8649 & 0 \\
\hline 1003.95 & $9 / 30 / 2006$ & 11241.2 & 15.6054 & 0 \\
\hline 1034.95 & $10 / 31 / 2006$ & 11028.3 & 15.3512 & 0 \\
\hline 1064.95 & $11 / 30 / 2006$ & 10830.5 & 15.1157 & 0 \\
\hline 1095.95 & $12 / 31 / 2006$ & 10641.5 & 14.8905 & 0 \\
\hline 1126.95 & $1 / 31 / 2007$ & 10450.1 & 14.6628 & 0 \\
\hline 1154.95 & $2 / 28 / 2007$ & 10287.3 & 14.469 & 0 \\
\hline 1185.95 & $3 / 31 / 2007$ & 10116.7 & 14.2655 & 0 \\
\hline 1215.95 & $4 / 30 / 2007$ & 9957.47 & 14.0753 & 0 \\
\hline 1246.95 & $5 / 31 / 2007$ & 9800.32 & 13.8875 & 0 \\
\hline
\end{tabular}

Figure 3.67 Simulation Output Data Exported in Excel Spreadsheet Having Data only for Three Years of Production 
One of the standard output options, available in the CMG Simulator, under the list of output for a well is daily gas rate on a monthly average. A monthly rate is not directly available; by using the average daily value and exporting to Excel, the monthly average can be easily calculated. The property available in CMG Simulator is called Gas Rate SC - Monthly. For the purpose of this study, gas and water monthly averages had to be calculated.

The column OIL is not used, but the form of spread sheet that has to be imported in the IPDE-IDEA requires that column.

\begin{tabular}{||c|c|c|c|c|c|}
\hline ID & Time & Date & Gas (Mcf/Month) & Water (bbl/Month) & Oil (bbl/Month) \\
\hline
\end{tabular}

Figure 3.68 Header of the Main Input Data File for the Decline Curve Analysis Indicating Six Parameters that Will be Used by IPDE-IDEA Software

\begin{tabular}{|c|c|}
\hline ID & Number of Run/Well Number \\
\hline Time & Days (monthly basis) \\
\hline Date & Lest day of each month for twenty years \\
\hline Gas (Mcf/Month) & Gas Production/Monthly Basis \\
\hline Water (bbl/Month) & Water Production/Monthly Basis \\
\hline Oil (bbl/Month) & No Oil Production \\
\hline
\end{tabular}

Table 3.10 Main Input Data with Explanations

In the next four steps, specific procedure of arranging data in the specific format, which can be read by IPDE-IDEA, will be explained:

1. Export data from the CMG Simulator into Excel;

2. Data obtained from CMG by default are based on daily average production, so it is necessary to modify Gas/Water/Oil production rates into Monthly Average;

3. Obtained data need to be copied/pasted in another Excel spread sheet;

4. Continue with the very same procedure until all runs (in this case 100 wells) are put together in the main Excel spread sheet. 


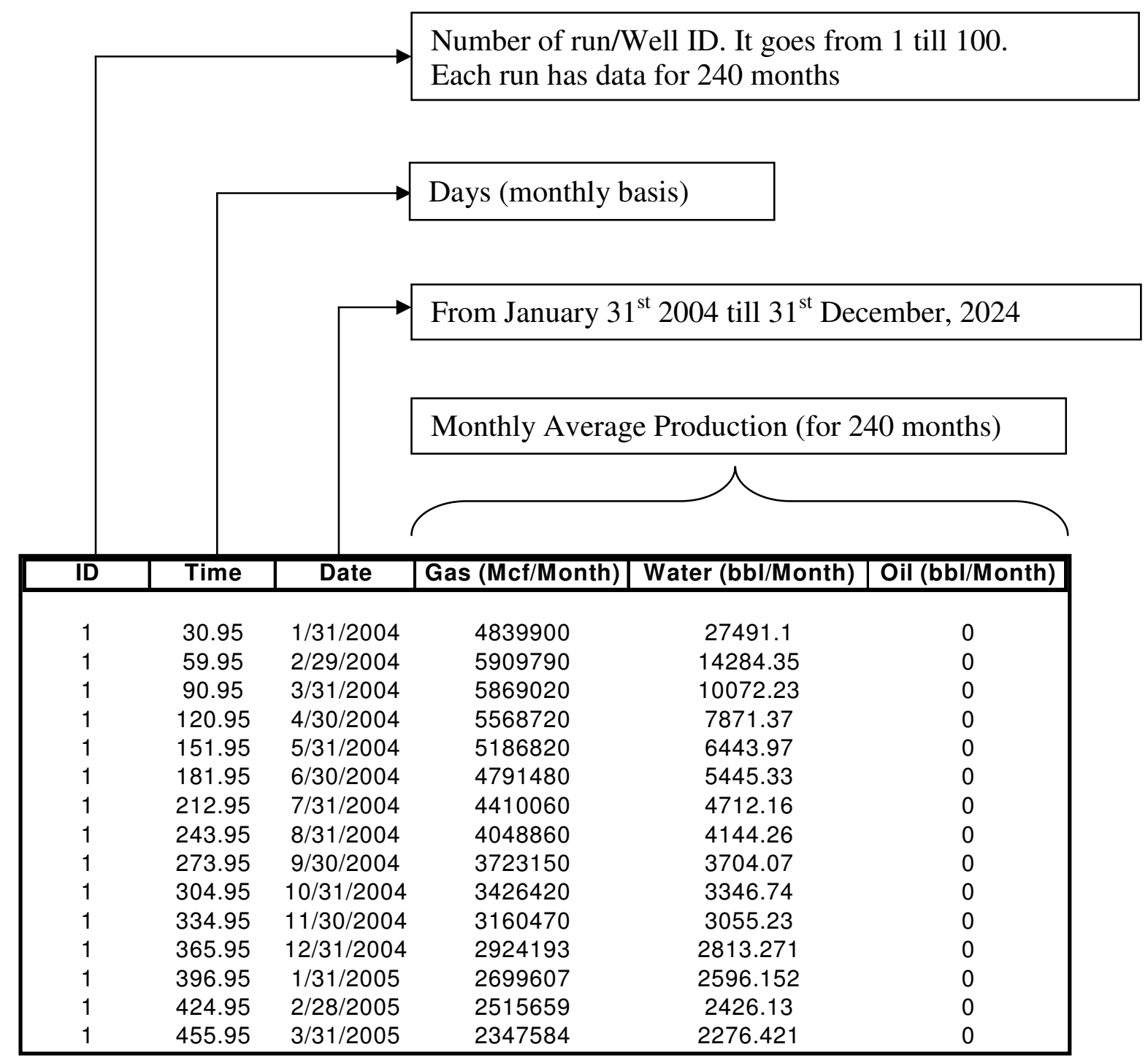

Figure 3.69 Main Data File which is the Input for the IPDE-IDEA

Once production data for all runs are arranged in the previously described fashion, Main Data File is consisted of six columns twenty four thousand rows. Now, when the file having all outputs from the simulator is ready, next step is to use it as an input for the Decline Curve Analysis software. 


\subsubsection{Decline Curve Analysis}

Decline Curve Analysis (DCA) represents the basic method used by Petroleum Engineers, in order to predict the future production of a reservoir. DCA is a method used to fit observed production rates of individual wells, a group of wells or reservoirs by a mathematical function for a purpose of prediction the future production performance by extrapolating the fitted decline function. Decline curve analysis (name after declining trends in production rates), is a widely used method for analyzing the past and future performance of production wells (Jacques Hagoort \& Assoc., 2002).

In this model, Hyperbolic Decline Curve Analysis was used for obtaining Production Indicators ( qi, Di and b). As shown below, these three parameters utterly define the shape of matching curve.

The mathematical formulation of Decline Curve Analysis is:

$$
q=q_{i}\left(1+D_{i} b t\right)^{-\frac{1}{b}}
$$

- q-Production Rate, Vol./unit time;

- qi-Initial Production Rate, Vol./unit time;

- Di-Initial Decline Rate , $\mathrm{t}=0$, per unit time;

○ b-Hyperbolic Exponent;

o t-time.

The goal of DCA is to match real production decline curve with the artificial one, in order to obtain Production Indicators (PI). Once the PIs are obtained, they can be used in further research as the parameters determining production of a particular well.

Outputs from the CMG Simulator (gas and water production), for the period of 20 years, are synthetic results. In other words, decline curves have been smoothed using timing option in the simulator and a sudden change in the flow rate (drop or high), which is normal in the real production performance, are not present here. 
Figures 3.70 and 3.71 represent production of two wells of different amount of gas flow rate, for the same period of time. First graph represents field production date of one existing real well, while graph two shows simulation output of gas production for one synthetic well.

The scattered form is the real one, while smooth curve stands for a simulated well.

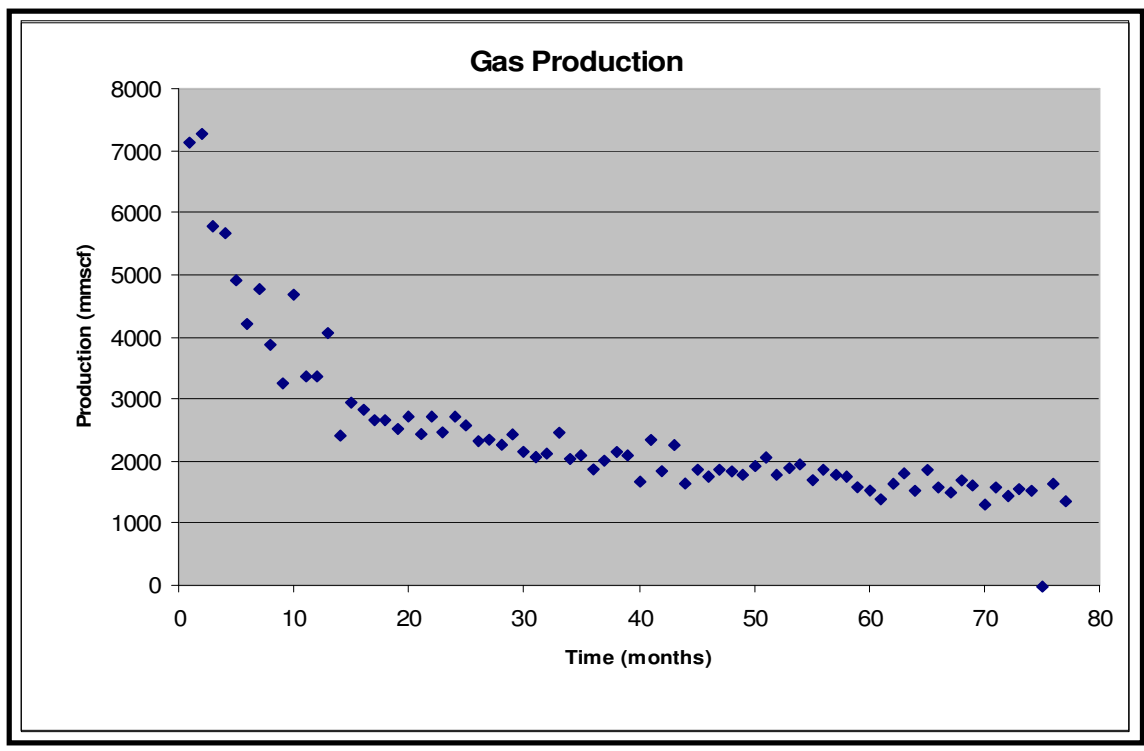

Figure 3.70 Gas Production versus Time - Actual Data from Existing Well

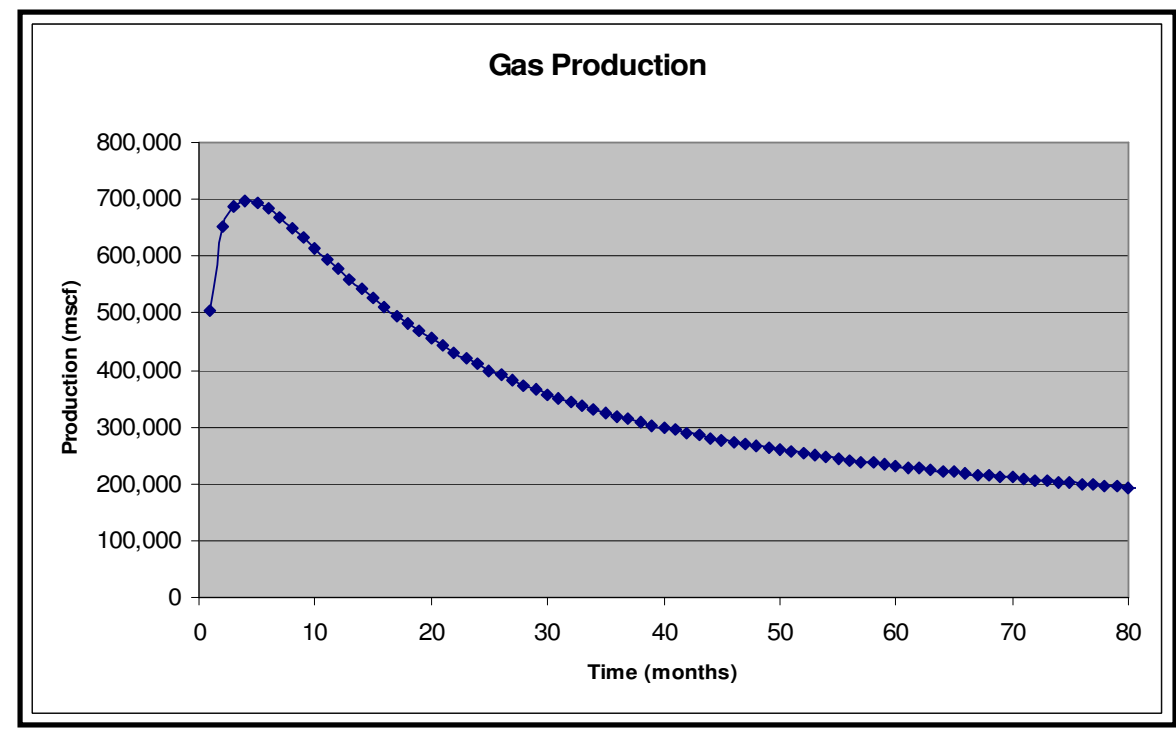

Figure 3.71 Gas Production versus Time - Synthetic Well 
IPDE -IDEA software developed by Intelligent Solutions Inc. is the software allowing a user to perform DCA the very easy way, obtaining Production Indicators automatically. Once the matrix is imported, the software automatically calculates the set of thirteen following records:
1. Best 3 Months CUM;
2. Best 6 Months CUM;
3. Best 9 Months CUM;
4. Best 12 Months CUM;
5. First 3 Months CUM;
6. First 6 Months CUM;
7. First 9 Months CUM;
8. First 1 Year CUM;
9. First 3 Year CUM;
10. First 5 Year CUM;
11. First 10 Year CUM;
12. Last Production;
13. Cumulative.

The main form of IPDE-IDEA consists of eight main modules. However for the purpose of this research, only first two modules are used. These are:

1. Import main data file;

2. Decline Curve Analysis.

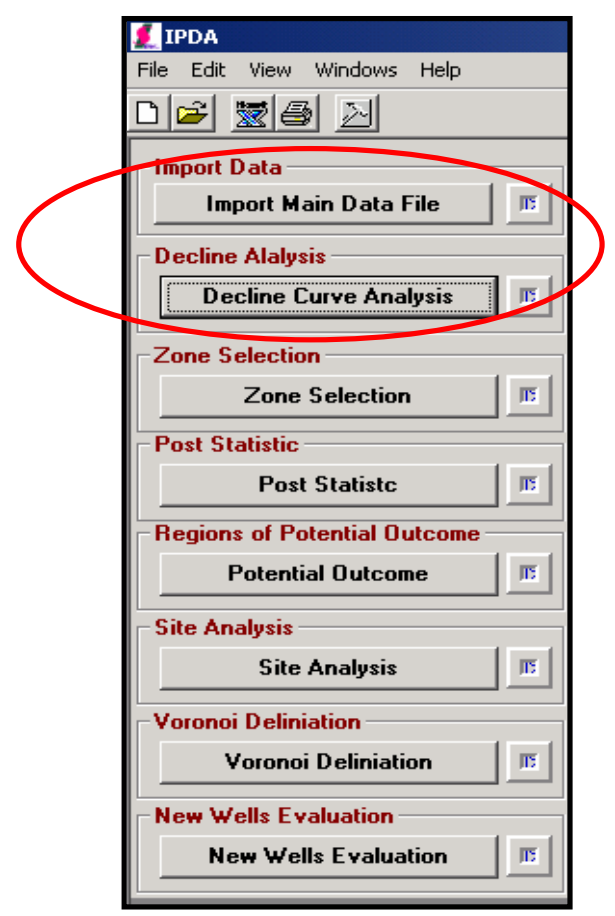

Figure 3.72 Main Console of IPDE-IDEA Containing Eight Main Modules 
The first step, like in the most of the softwares, is creating the main file and selecting a place to store it.

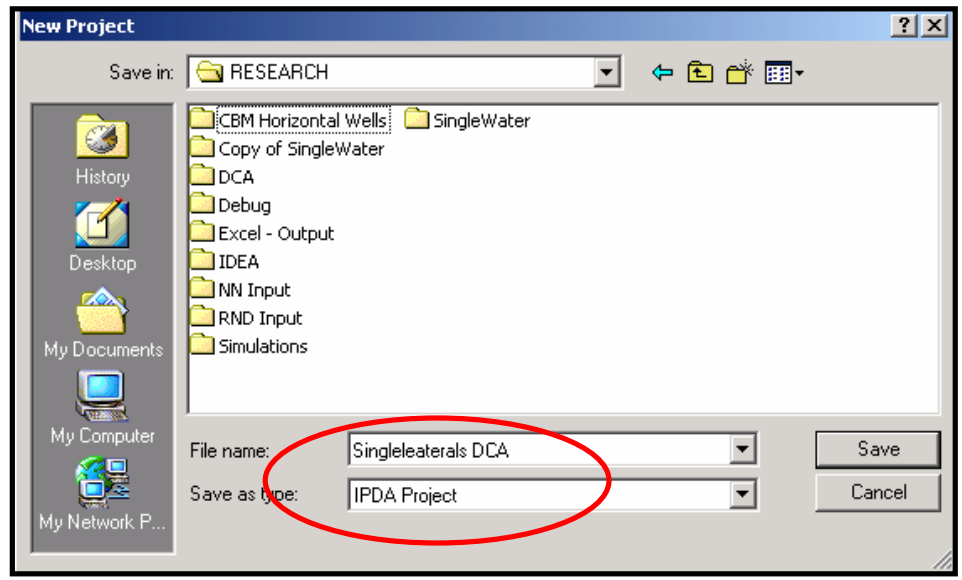

Figure 3.73 The Creation of the Main IPDE-IDEA File

After the procedure of creating and naming the DCA file, IPDE-IDEA will create the folder and a file in it, which is the first step toward importing Excel file containing data necessary for decline analysis. Once the main file with .ipd extension and the folder with the same name are created, user needs to open that file. The software will create another folder named "Data", where all inputs from the Excel will be stored.

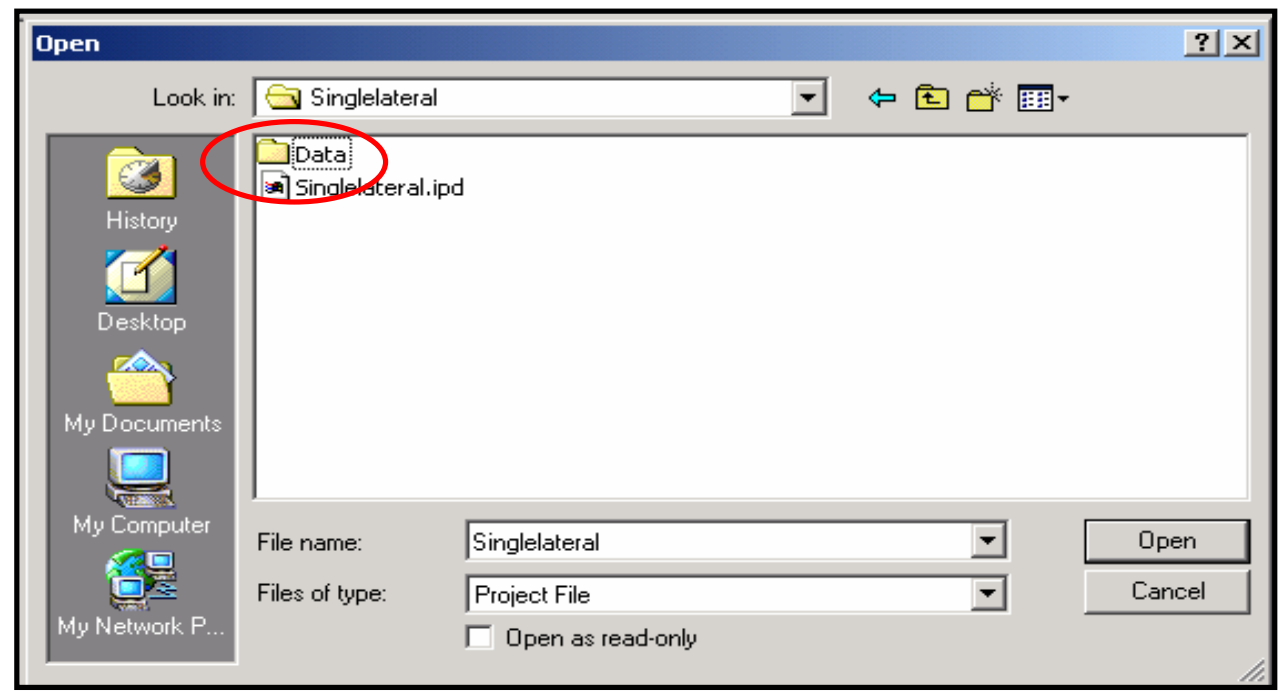

Figure 3.74 The Creation of the "Data" Folder that Will Contain All Inputs after Importing Into IPDE-IDEA Software 


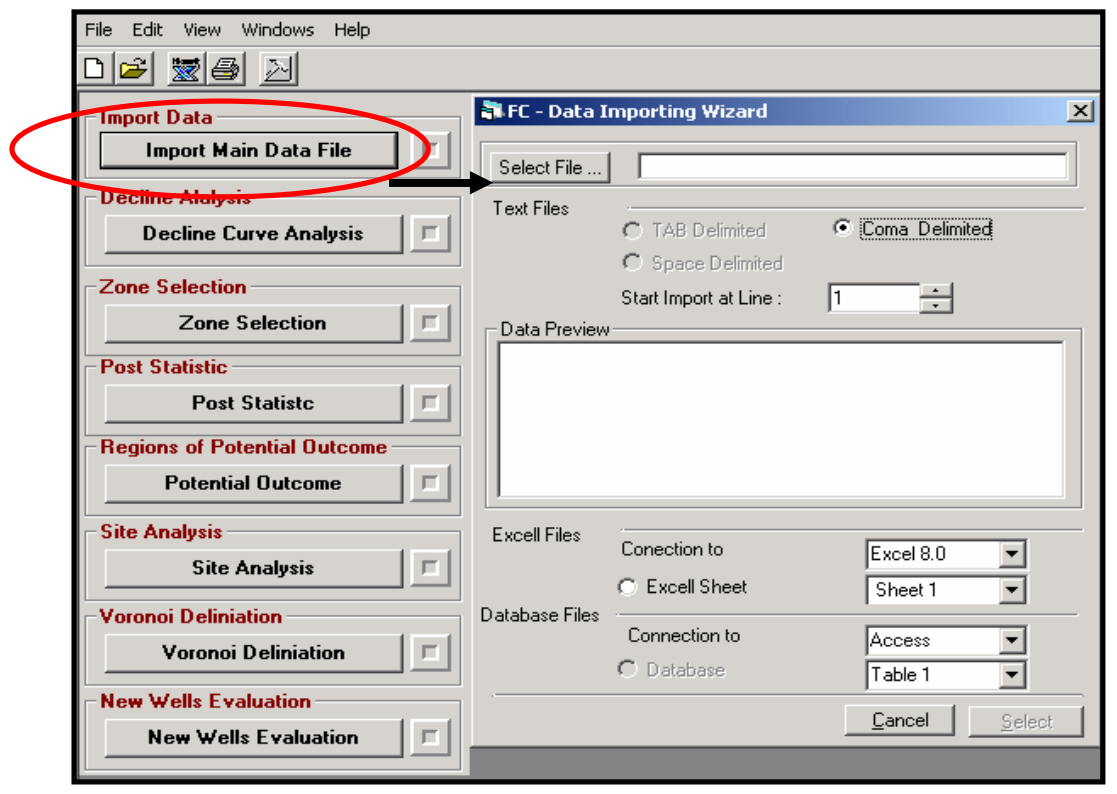

\section{Figure 3.75 "Import Main Data File" Button Will Enable User to Select the Input} File and Enter it in the Software

Using "Import Main Data File" button, the software allows us to determine path to the main Excel file, import it and choose among Excel sheets.

Upon determining the location of the main data file, the following picture will appear allowing the user first to load header from Excel spread sheet, and require determining Well name, Time and Gas/Water/Oil production.

\begin{tabular}{|c|c|c|c|c|c|c|c|c|}
\hline \multicolumn{9}{|c|}{ 1, Data File Succesfully Opened ... } \\
\hline \multicolumn{2}{|c|}{ O Well Name } & \multicolumn{2}{|c|}{$\begin{array}{l}\mathrm{O} \text { Latitude } \\
\mathrm{O} \text { Longitude }\end{array}$} & ODate & $\begin{array}{l}\text { O Dil } \\
\text { O Gas } \\
\text { Water }\end{array}$ & Pressure & $\begin{array}{l}\text { ONetPay } \\
\text { O Porosity } \\
\text { O Water Saturati }\end{array}$ & $\begin{array}{l}\text { Attribute } \\
\text { on }\end{array}$ \\
\hline & ID & & Time & Date & Gas [M & Acf/Month] & Water [bbl/Month] & 0il [bbl/Month) \\
\hline & Well & lame & Time [Date] & Time (Date) & Gas (ms & $\mathrm{cot} / \mathrm{m})$ & Water $(b \mathrm{~b} / \mathrm{s} / \mathrm{m})$ & Gas $[\mathrm{mscl} / \mathrm{m})$ \\
\hline \multirow[t]{2}{*}{1} & & & & & & & & 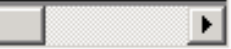 \\
\hline & & & & & & \multicolumn{2}{|c|}{ 1. Load Data Header } & Import Data \\
\hline
\end{tabular}

Figure 3.76 Loading and Importing Data Form 
Second step is to Import Data using button no. 2 "Import Data".

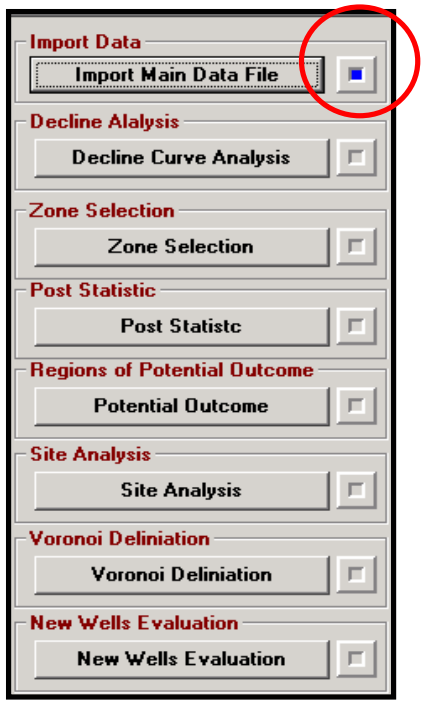

After importing data from Excel, a blue box will show up, confirming successful introduction operation.

\section{Figure 3.77 The Main Consol after the Successful Import of the Main Data File}

When the import of the main data file is done, IPDE-IDEA will store all inputs (100 wells) in the previously created data folder. Now, when all files are inside the software, one can go to the next step - performing a DCA.

After the import of the data from Excel, and clicking on the "Decline Curve Analysis" button, the blue box will show up, confirming a successful operation. 


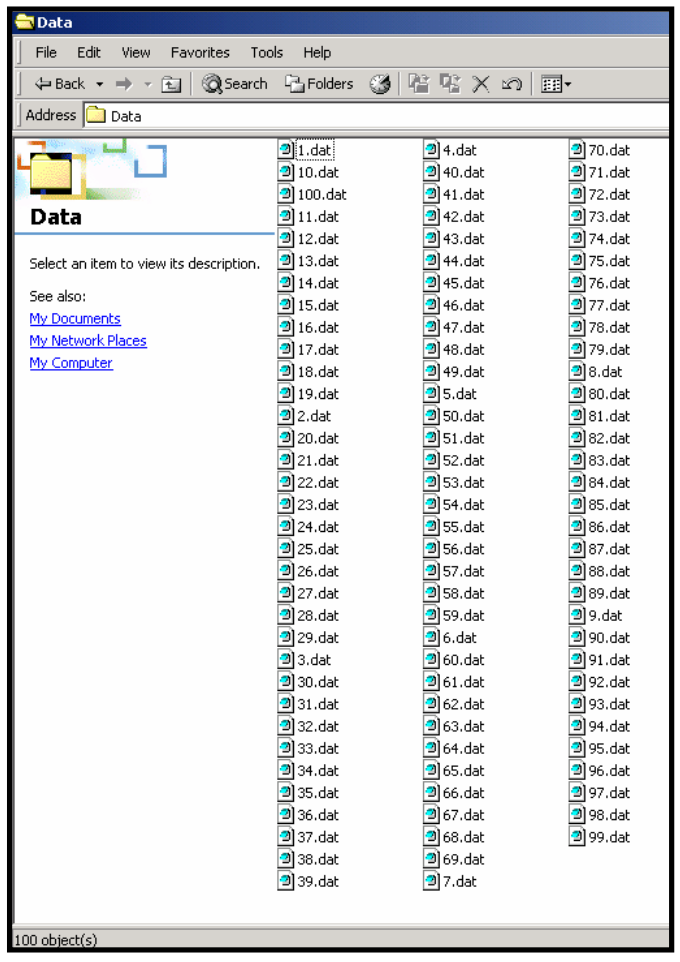

Figure 3.78 Input Files Created by IPDE-IDEA

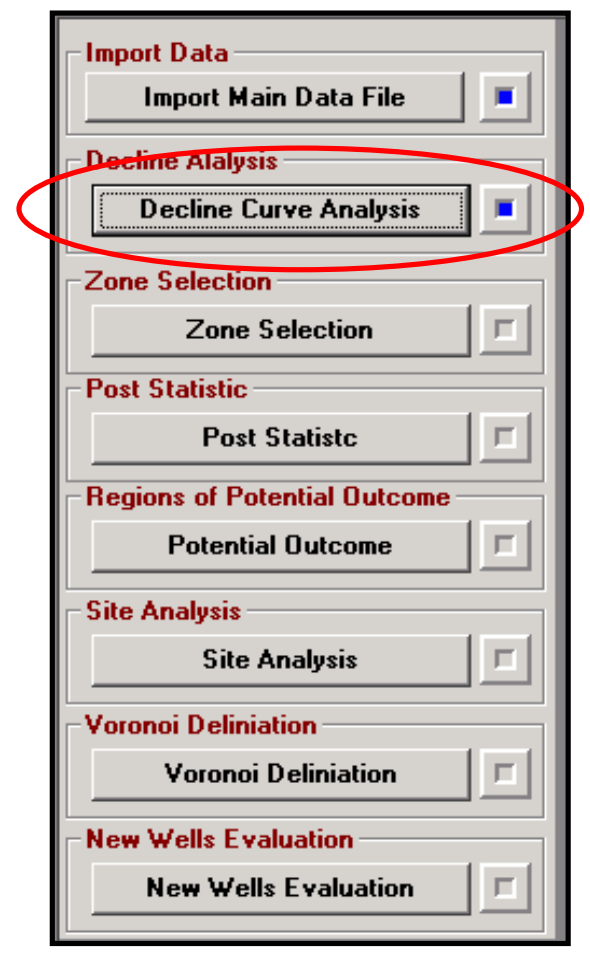

Figure 3.79 Main Consol Showing Activation of DCA

The Gas, Water and Oil Production (Output from the simulator) has been now imported in the IPDE-IDEA software. The goal of this step is to perform the Decline Curve Analysis for 20 years of CBM production, and obtain production indicators for each of the wells. It is acceptable if good matching of predicted production with the actual one can be accomplished in 10 or 15 years. The green curve is the actual and blue one predicted production.

Decline Curve Analysis module is the heart of this software. Once it is opened, the main form will be shown having four tabs:

1. Analysis;

2. All Curves;

3. Decline Results;

4. All data. 


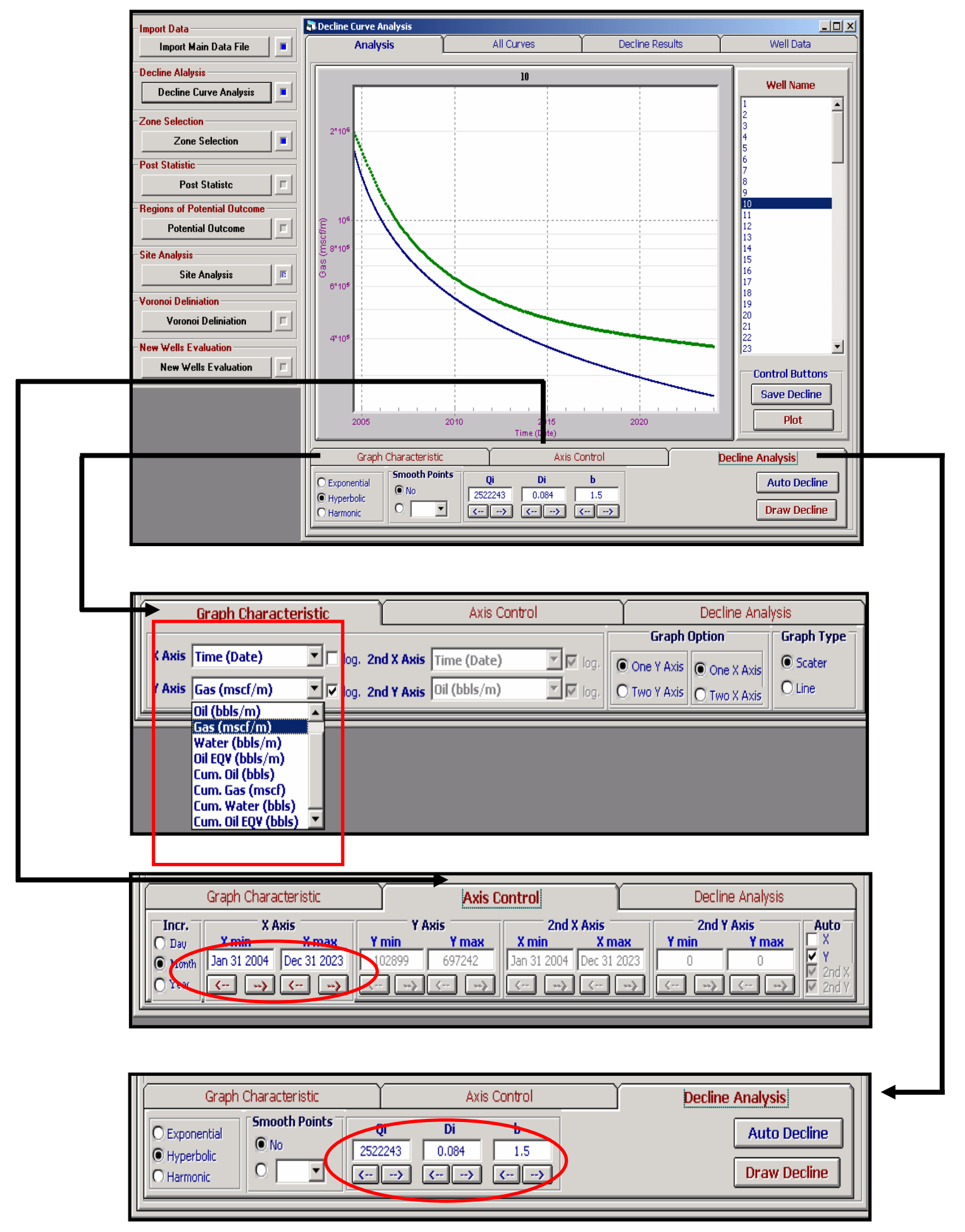

Figure 3.80 Performing DCA 
When the main data file is imported, and a dat file is created by IPDE-IDEA software, one can start performing DCA. Clicking on "Decline Curve Analysis" button, the main form will appear. On that form, four existing tabs allow the user to perform different steps and adjust parameters to the imported curve.

The "Analysis" tab allows the user to choose the well that the DCA should be performed on, no matter whether it is gas or water production. Once the production curve is plotted, auto decline option can be used.

Under "Graphic Characteristics" tab, the user can choose among different offered options, but in this case only gas and water production have been investigated.

"Axis Control "offers an option of time span when that user wants to perform a DCA.

"Decline Analysis" introduces three buttons for the Production Indicators. Using them, it is very easy to change these three main parameters, and at the same time to see the altering position of the predicted curve, while the actual one stays still.

Changing PIs, user is trying to match actual production with the predicted one. One of the most important things using this method is to match the very beginning of actual production curve. If that angle can be matched, the chances to match the rest of the curve rise significantly. In the case of this study, the goal was to match the real curve with the predicted one in the period of time between zero and fifteen years, but any matching of the curve for a period of time equal or higher than five years, is considered to be acceptable.

Once DCA is performed and matching of the predicted and actual curve is adequate or acceptable, the next tab "All Curves" will show definite matching of the two curves.

Under "Decline Results", Gas and Water forms will show the user the results/Production Indicators of matching for each curve (well) that has been undergone by DCA. The fourth tab in the "Decline Curve Analysis" section is called "Well Data". Since Simulation made in CMG simulator has been based on twenty years of production, and time is based 
on month units in the IPDE-IDEA software, this module contains different parameters for an investigated well for all 240 months of actual production.

After performing DCA for all wells whose gas and water production have been entered in the main data file (Excel spreadsheet), IPDE-IDEA will provide us with 13 parameters mentioned above, as well as 3 Production Indicators (qi, Di and b). 


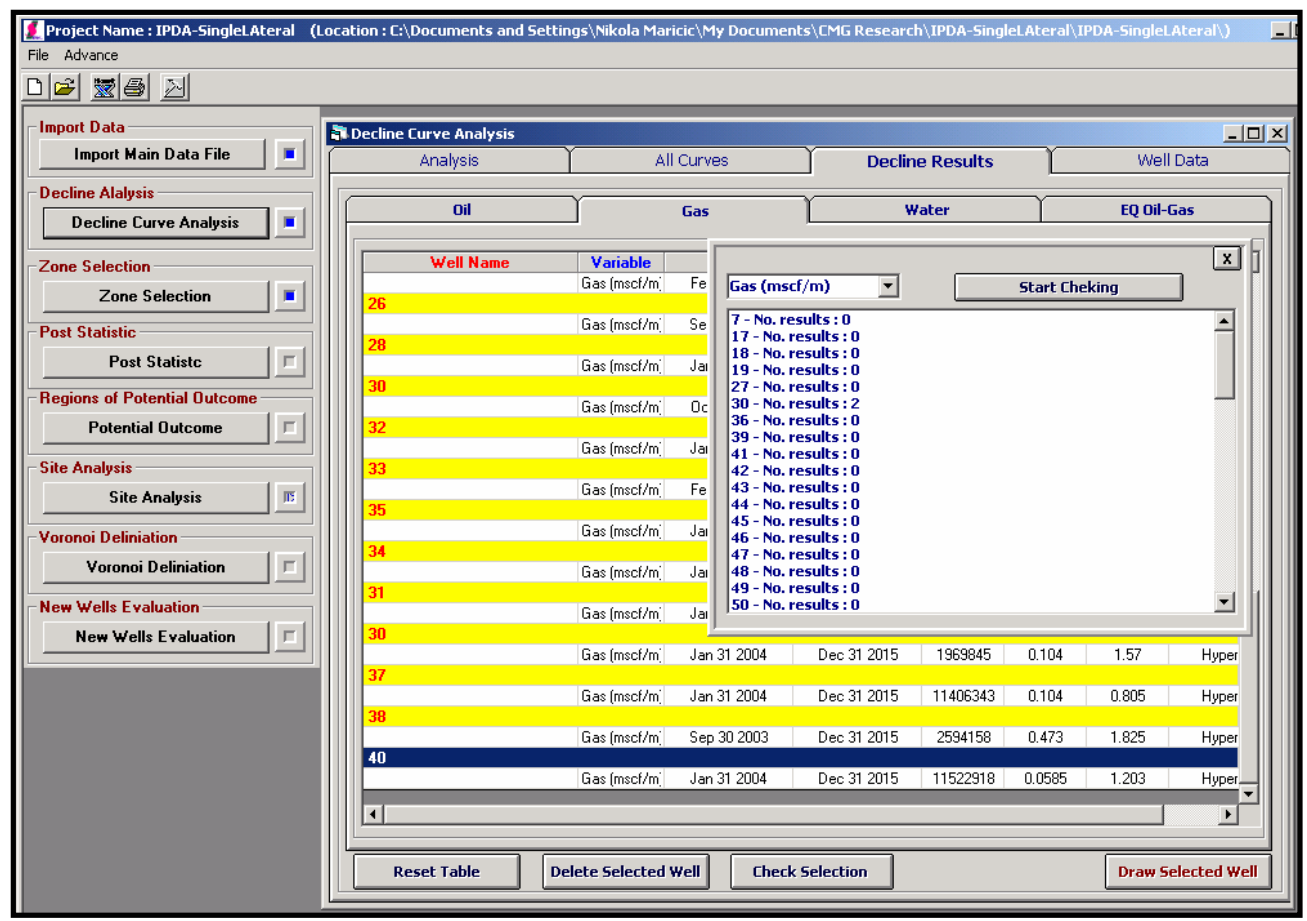

Figure 3.81 The Wells that DCA Has Performed (for the Gas Production) Are Highlighted \& Wells that Need to be Analyzed)

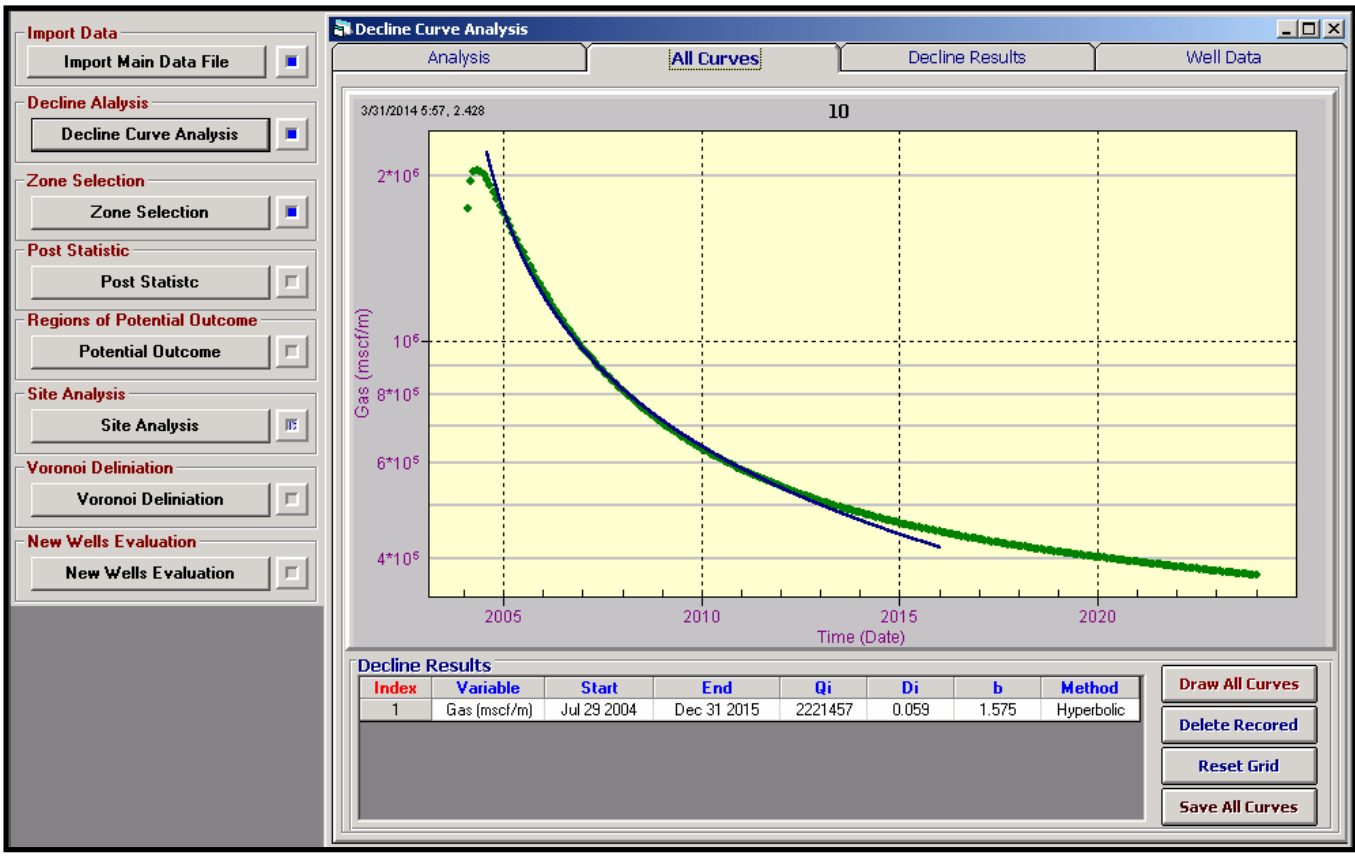

Figure 3.82 The Matching of the Two Curves after Performing the Decline Curve Analysis 


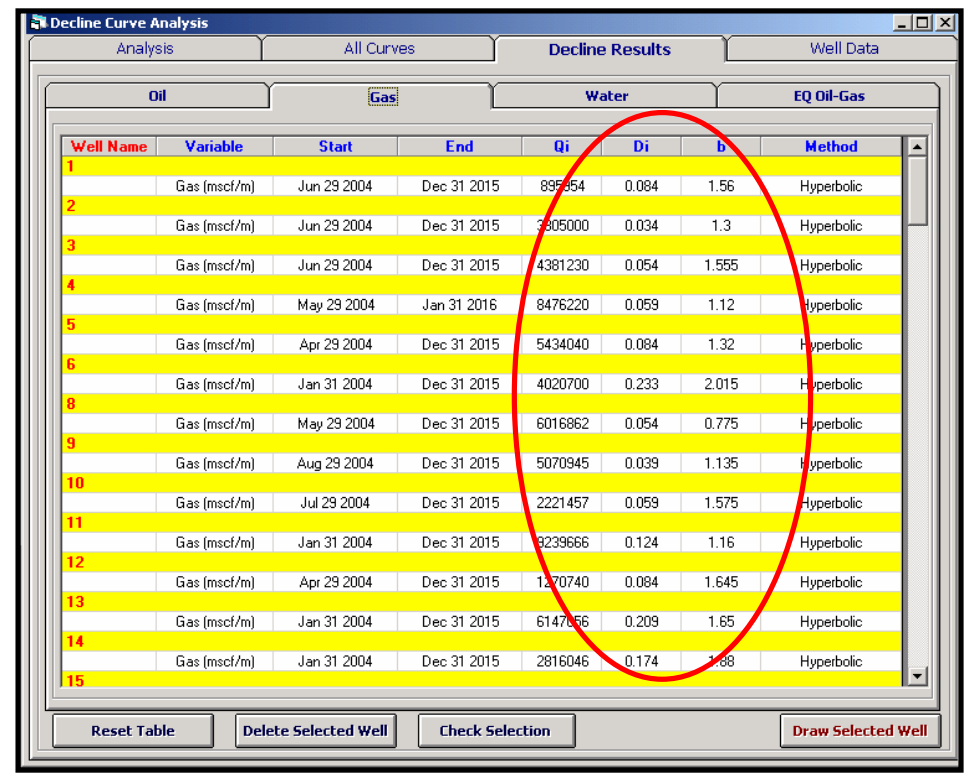

Figure 3.83 Production Indicators Obtained as the Result of the Decline Curve Analysis (qi, Di and b)

\begin{tabular}{|c|c|c|c|c|c|c|c|c|c|}
\hline \multicolumn{2}{|l|}{ Import Data - } & \multicolumn{6}{|c|}{ 5. Decline Curve Analysis } & \multicolumn{2}{|c|}{$-\mid \underline{|x|}$} \\
\hline Import Main Data File & - & \multicolumn{2}{|c|}{\begin{tabular}{|c|} 
Analysis \\
\end{tabular}} & \multicolumn{2}{|r|}{ All Curves } & \multicolumn{2}{|c|}{ Decline Results } & \multicolumn{2}{|c|}{ Well Data } \\
\hline \multicolumn{2}{|l|}{ Decline Alalysis - } & Index & Time [Date] & Gas [mscf/m] & Water [bbls/m] & Cum. Gas (mscf) & Cum. Water [bbls] & Cum. Oil EQv [bbls] & $\Delta$ \\
\hline \multirow{2}{*}{ Decline Curve Analysis } & \multirow{2}{*}{ 曰 } & 1 & $1 / 31 / 2004$ & 504408 & 4165 & 504 & 4 & 84 & \\
\hline & & 2 & $2 / 29 / 2004$ & 651630 & 2353 & 1155 & 6 & 192.5 & \\
\hline \multirow{2}{*}{\multicolumn{2}{|c|}{ Zone Selection- }} & 3 & $3 / 31 / 2004$ & 686172 & 1871 & 1841 & 7 & 306.833333333333 & \\
\hline & & 4 & $4 / 30 / 2004$ & 697242 & 1599 & 2538 & 8 & 423 & \\
\hline Zone Selection & \multirow[t]{2}{*}{ घ } & 5 & $5 / 31 / 2004$ & 694098 & 1402 & 3232 & 9 & 538.666666666667 & \\
\hline \multirow{2}{*}{\multicolumn{2}{|c|}{ Post Statistic }} & 6 & $6 / 30 / 2004$ & 683481 & 1259 & 3915 & 10 & 652.5 & \\
\hline & & 7 & $7 / 31 / 2004$ & 668028 & 1145 & 4583 & 11 & 763.833333333333 & \\
\hline Post Statistc & \multirow[t]{2}{*}{ 드 } & 8 & $8 / 31 / 2004$ & 649632 & 1053 & 5232 & 12 & 872 & \\
\hline \multirow{2}{*}{\multicolumn{2}{|c|}{ Regions of Potential Outcome }} & 9 & $9 / 30 / 2004$ & 631677 & 982 & 5863 & 994 & 977.1666666666667 & \\
\hline & & 10 & $10 / 31 / 2004$ & 612546 & 921 & 6475 & 1915 & 1079.166666666667 & \\
\hline \multirow[t]{2}{*}{ Potential Outcome } & \multirow{2}{*}{ 디 } & 11 & $11 / 30 / 2004$ & 594342 & 871 & 7069 & 2786 & 1178.166666666667 & \\
\hline & & 12 & $12 / 31 / 2004$ & 576873 & 829 & 7645 & 3615 & 1274.166666666667 & \\
\hline \multicolumn{2}{|l|}{ Site Analysis - } & 13 & $1 / 31 / 2005$ & 558558 & 790 & 8203 & 4405 & 1367.166666666667 & \\
\hline \multirow{2}{*}{ Site Analysis } & \multirow{2}{*}{ ए厂 } & 14 & $2 / 28 / 2005$ & 542826 & 759 & 8745 & 5164 & 1457.5 & \\
\hline & & 15 & $3 / 31 / 2005$ & 526272 & 729 & 9271 & 5893 & 1545.166666666667 & \\
\hline \multirow{2}{*}{\multicolumn{2}{|c|}{ Voronoi Deliniation - }} & 16 & $4 / 30 / 2005$ & 510819 & 703 & 9781 & 6596 & 1630.166666666667 & \\
\hline & & 17 & $5 / 31 / 2005$ & 495711 & 678 & 10276 & 7274 & 1712.666666666667 & \\
\hline \multirow[t]{2}{*}{ Voronoi Deliniation } & \multirow{2}{*}{ 드 } & 18 & $6 / 30 / 2005$ & 481659 & 657 & 10757 & 7931 & 1792.83333333333 & \\
\hline & & 19 & $7 / 31 / 2005$ & 467961 & 636 & 11224 & 8567 & 1870.666666666667 & \\
\hline \multicolumn{2}{|l|}{ New Wells Evaluation } & 20 & $8 / 31 / 2005$ & 454887 & 618 & 11678 & 9185 & 1946.33333333333 & \\
\hline \multirow{12}{*}{ New Wells Evaluation } & \multirow[t]{12}{*}{ 다 } & 21 & $9 / 30 / 2005$ & 442902 & 601 & 12120 & 9786 & 2020 & \\
\hline & & 22 & $10 / 31 / 2005$ & 431190 & 585 & 12551 & 10371 & 2091.83333333333 & \\
\hline & & 23 & $11 / 30 / 2005$ & 420384 & 571 & 12971 & 10942 & 2161.83333333333 & \\
\hline & & 24 & $12 / 31 / 2005$ & 410124 & 558 & 13381 & 11500 & 2230.166666666667 & \\
\hline & & 25 & $1 / 31 / 2006$ & 399852 & 544 & 13780 & 12044 & 2296.666666666667 & \\
\hline & & 26 & $2 / 28 / 2006$ & 391209 & 534 & 14171 & 12578 & 2361.83333333333 & \\
\hline & & 27 & $3 / 31 / 2006$ & 382188 & 523 & 14553 & 13101 & 2425.5 & \\
\hline & & 28 & $4 / 30 / 2006$ & 373848 & 512 & 14926 & 13613 & 2487.666666666667 & \\
\hline & & 29 & $5 / 31 / 2006$ & 365697 & 502 & 15291 & 14115 & 2548.5 & \\
\hline & & 30 & $6 / 30 / 2006$ & 358167 & 493 & 15649 & 14608 & 2608.166666666667 & \\
\hline & & 31 & $7 / 31 / 2006$ & 350772 & 484 & 15999 & 15092 & 2666.5 & -1 \\
\hline & & 4 & & & & & & & \\
\hline
\end{tabular}

Figure 3.84 Well Data Form Containing Parameters for Current Investigated Well for the Monthly Basis for 20 Years of Production 


\begin{tabular}{|c|c|c|c|c|c|c|c|c|c|c|c|c|}
\hline ne & & & & & & & & & & & & \\
\hline 1 & 4080651 & 5974506 & 7704279 & 1842210 & 3917031 & 5866368 & 7650129 & 17671149 & 24086440 & 35089230 & 102899 & 49574 \\
\hline 2 & 22376700 & 32883900 & 42590520 & 10407120 & 21757560 & 32525190 & 42494640 & 100946742 & 140532192 & 210552588 & 533661 & 93225 \\
\hline 3 & 22376700 & 32883900 & 42590520 & 10407120 & 21757560 & 32525190 & 42494640 & 100946742 & 140532192 & 210552588 & 533661 & 93225 \\
\hline 4 & 47166450 & 67826820 & 85953570 & 23984430 & 47166450 & 67826820 & 85953570 & 185088030 & 246184749 & 341972550 & 600303 & 69335 \\
\hline 5 & 26591160 & 37961730 & 48094200 & 13940580 & 26591160 & 37961730 & 48094200 & 102358002 & 136567389 & 193068639 & 340218 & 96572 \\
\hline 6 & 21698253 & 27532545 & 32486313 & 14110950 & 21698253 & 27532545 & 32486313 & 60900120 & 81548628 & 118980807 & 310023 & 107394 \\
\hline 7 & 6786792 & 9176907 & 11162034 & 3786057 & 6786792 & 9176907 & 11162034 & 21513297 & 28778960 & 43448548 & 191518 & 62984 \\
\hline 8 & 39418530 & 54563370 & 67426800 & 21130950 & 39418530 & 54563370 & 67426800 & 133039710 & 171287790 & 224470401 & 228805.8 & 269355406 \\
\hline 9 & 32925570 & 47500200 & 60736650 & 17009310 & 32925570 & 47500200 & 60736650 & 135831339 & 185051280 & 266568942 & 524106 & 355613412 \\
\hline 10 & 12072096 & 17684109 & 22922541 & 5744253 & 11851725 & 17613762 & 22922541 & 53201760 & 72804162 & 107071095 & 373977 & 157156404 \\
\hline 11 & 50107520 & 65634400 & 78184492 & 29497720 & 50107520 & 65634400 & 78184492 & 141447724 & 179787316 & 236762060 & 374978 & 285822651 \\
\hline 12 & 6513648 & 9379809 & 11938341 & 3332034 & 6513648 & 9379809 & 11938341 & 26057139 & 35219034 & 51441663.3 & 159307.8 & 73937050.8 \\
\hline 13 & 28371960 & 37475691 & 45029052 & 16629420 & 28371960 & 37475691 & 45029052 & 84512268 & 110598849 & 156762654 & 391989 & 216348624 \\
\hline 14 & 14014923 & 18740205 & 22745913 & 8185035 & 14014923 & 18740205 & 22745913 & 44679489 & 60103188 & 87840288 & 221933.1 & 122378933 \\
\hline 15 & 16073472 & 21277854 & 25616775 & 9340818 & 16073472 & 21277854 & 25616775 & 48400674 & 63311697 & 89845473 & 296636.7 & 128784261 \\
\hline
\end{tabular}

\section{Figure 3.85 Production Indicators Obtained as the Result of the Decline Curve Analysis}




\subsection{Data Preparation for the Neural Network Modeling - IPDE Software}

In order to create a file that will be an input file for the IDEA-Neural Networks Modeling Software, three different outputs need to be put together.

1. Input Data for the CMG simulator;

2. Output data from IPDE-IDEA software;

3. Production Indicators (Qi,Di and b) from the IPDE-IDEA software.

Combining all of these three sets of data in the fashion used will be the main topic of this chapter, the Main Input File for the Neural Network Software is created.

\begin{tabular}{|l|l|c|}
\hline \multicolumn{1}{|c|}{ CMG Simulator Inputs } & \multicolumn{1}{|c|}{ IPDE-IDEA Outputs } & Production Indicators \\
\hline Run Number & & Qi \\
\hline Pressure (PSI) & Best 3 Months CUM & Di \\
\hline VI (scf/ton) & Best 6 Months CUM & b \\
\hline PI (psi) & Best 9 Months CUM & \\
\hline Pay Thickness (FT) & Best 12 Months CUM & \\
\hline Fracture Permeability i (md) & First 3 Months CUM & \\
\hline Fracture Permeability j (md) & First 6 Months CUM & \\
\hline Fracture Permeability k (md) & First 9 Months CUM & \\
\hline Coal Desorption Time (days) & First 1 Year CUM & \\
\hline BHP (psi) & First 3 Year CUM & \\
\hline Grid Top depth (ft) & First 5 Year CUM & \\
\hline Porosity Fracture (fr) & First 10 Year CUM & \\
\hline Sw (fracture) \% & Last Production & \\
\hline Lateral Length (ft) & Cumulative & \\
\hline Spacing Between Laterals (ft) & & \\
\hline gmol/lb & & \\
\hline 1/psi & & \\
\hline
\end{tabular}

Table 3.11 Three Columns Having Different Sources and Data are combined In the Unique file that will be Main Input Data File for the Neural Network Modeling 


\begin{tabular}{|c|c|c|c|c|c|c|c|c|c|c|c|c|c|c|}
\hline \multicolumn{7}{|c|}{$\begin{array}{c}\text { Random Inputs for the CMG Simulator } \\
\text { (from } 13 \text { to } 20 \text { parameters depending on a well } \\
\text { configuration) }\end{array}$} & \multicolumn{4}{|c|}{$\begin{array}{l}\text { Outputs from the IPDE-IDEA } \\
\text { (13 Outputs) }\end{array}$} & \multicolumn{4}{|c|}{$\begin{array}{l}\text { Production } \\
\text { Indicators } \\
3 \text { outputs }\end{array}$} \\
\hline RUN No & PRESSURE (PSI) & V (scffton) & ............. & Two Leteral Length (ft) & SBL(ft) & gmolisb & Best 3 Months & Best 6 Months & ............ & Last Production & Cumulative & Qi & Di & b \\
\hline 1 & 313.574 & 463.202 & & 1928.426 & 1247.624 & 0.276869097 & 21632670 & 34366020 & & 299429.1 & 155443107 & 9746239 & 0.501 & 1.17 \\
\hline 2 & 466.802 & 372.122 & & 1379.773 & 1631.426 & 0.222427974 & 21549570 & 38290860 & & 339375 & 224977467 & 7904365 & 0.144 & 0.97 \\
\hline 3 & 493.274 & 365.702 & & 1788.72 & 1205.906 & 0.218590556 & 24419490 & 47289810 & & 482841 & 361765590 & 10606980 & 0.149 & 1.31 \\
\hline 4 & 446.936 & 399.981 & & 10866.203 & 1352.083 & 0.239080096 & 40982400 & 76877910 & & 555252 & 543464073 & 17440002 & 0.114 & 1.005 \\
\hline 5 & 441.479 & 305.757 & & 5518.449 & 1790.636 & 0.182759713 & 79879320 & 147570690 & & 298957.2 & 695769547 & 34554403 & 0.134 & 0.8 \\
\hline 6 & 387.691 & 347.538 & & 9912.611 & 1621.241 & 0.207733413 & 39209910 & 65630790 & & 298989.6 & 305886145 & 16332911 & 0.238 & 1.06 \\
\hline 7 & 548.517 & 311.448 & & 7684.097 & 1845.963 & 0.186161387 & 40123650 & 74366970 & & 633252 & 531272847 & 16512954 & 0.109 & 1.07 \\
\hline 8 & 259.047 & 264.576 & & 7042.638 & 179.783 & 0.15814465 & 42508980 & 74140170 & & 371580 & 333380244 & 15147643 & 0.169 & 0.77 \\
\hline 9 & 523.626 & 384.069 & & 1754.942 & 1739.461 & 0.229569038 & 24107910 & 39388740 & & 402171 & 242309832 & 9434959 & 0.328 & 1.55 \\
\hline 10 & 234.026 & 116.495 & & 6645.815 & 1559.458 & 0.069632397 & 43260750 & 63194310 & & 47336.7 & 175525181 & 20624889 & 0.354 & 0.785 \\
\hline 11 & 410.749 & 347.213 & & 1999.23 & 341.416 & 0.207539151 & 11223870 & 19892346 & & 171618 & 114861268 & 3600852 & 0.139 & 1.055 \\
\hline 12 & 220.029 & 349.403 & & 9049.051 & 486.239 & 0.208848177 & 23202660 & 45353970 & & 475542 & 363718776 & 9409056 & 0.079 & 0.825 \\
\hline 13 & 479.88 & 265.894 & & 2231.475 & 1213.283 & 0.158932457 & 12664950 & 24636840 & & 272474.1 & 187999962 & 4901281 & 0.114 & 1.135 \\
\hline 14 & 542.716 & 261.322 & & 1605.437 & 1019.777 & 0.156199641 & 21914610 & 40345920 & & 449373 & 296644638 & 8789894 & 0.114 & 1.03 \\
\hline 15 & 542.03 & 382.081 & & 9597.245 & 1008.608 & 0.228380753 & 90010260 & 180006150 & & 314820 & 984291543 & 29035316 & 0.109 & 0.785 \\
\hline 16 & 290.637 & 461.603 & & 8975.676 & 1187.591 & 0.275913329 & 56567290 & 89730220 & & 244392.6 & 387618031 & 22526785 & 0.208 & 0.97 \\
\hline 17 & 217.976 & 308.443 & & 10713.79 & 1318.341 & 0.184365212 & 15598320 & 27598830 & & 229223.1 & 177825770 & 4563729 & 0.124 & 1.315 \\
\hline 18 & 233.981 & 114.676 & & 11143.718 & 1267.887 & 0.068545129 & 5220279 & 9519714 & & 138363.3 & 77113119 & 1992903 & 0.144 & 1.485 \\
\hline 19 & 507.009 & 322.106 & & 6560.663 & 1991.143 & 0.192531978 & 26022240 & 44205930 & & 308442 & 236492757 & 10266407 & 0.273 & 1.315 \\
\hline 20 & 243.33 & 283.795 & & 7182.376 & 1147.364 & 0.169632397 & 27378210 & 48000120 & & 314763 & 292833192 & 10476228 & 0.134 & 1.07 \\
\hline 21 & 255.687 & 358.396 & & 6120.346 & 628.707 & 0.214223551 & 34597320 & 58857660 & & 262513.5 & 257315408 & 15104570 & 0.248 & 0.965 \\
\hline 22 & 408.406 & 174.798 & & 4768.959 & 1954.032 & 0.104481769 & 17162430 & 33222960 & & 253634.1 & 246129996 & 7423725 & 0.124 & 1.1 \\
\hline 23 & 326.583 & 304.593 & & 11768.877 & 156.062 & 0.182063957 & 35232990 & 61209150 & & 356436 & 313633401 & 13413658 & 0.194 & 1.03 \\
\hline 24 & 256.821 & 279.846 & & 1450.889 & 565.021 & 0.167271967 & 6297105 & 9430485 & & 64930.5 & 43233158 & 2737848 & 0.599 & 1.405 \\
\hline 25 & 267.037 & 393.682 & & 7416.474 & 1666.891 & 0.235315003 & 45745560 & 79665150 & & 487350 & 439964736 & 17303156 & 0.144 & 1.015 \\
\hline 26 & 472.828 & 421.181 & & 1661.335 & 1689.395 & 0.251751943 & 28351560 & 49842630 & & 439758 & 356266863 & 12718557 & 0.124 & 1.03 \\
\hline 27 & 277.902 & 498.097 & & 4398.158 & 1543.843 & 0.297726838 & 9158859 & 17548395 & & 237246 & 139368950 & 3418972 & 0.134 & 1.435 \\
\hline 28 & 316.07 & 294.873 & & 3484.829 & 1925.963 & 0.176254035 & 71289540 & 127035960 & & 458322 & 703479351 & 30636488 & 0.109 & 0.77 \\
\hline 29 & 482.299 & 323.48 & & 2114.381 & 453.842 & 0.193353258 & 8702427 & 16636893 & & 382266 & 155495241 & 3715157 & 0.104 & 1.01 \\
\hline 30 & 340.332 & 114.568 & & 10172.898 & 896.094 & 0.068480574 & 26817090 & 43908540 & & 92526.3 & 167221268 & 12072052 & 0.218 & 0.8 \\
\hline 31 & 294.364 & 102.423 & & 6421.649 & 1418.402 & 0.06122116 & 32699010 & 52551270 & & 27581.67 & 146465582 & 13640769 & 0.183 & 0.535 \\
\hline 32 & 412.288 & 155.243 & & 11409.684 & 1451.528 & 0.092793186 & 12856740 & 21780180 & & 75137.4 & 99430812 & 4848514 & 0.144 & 0.82 \\
\hline 33 & 287.998 & 188.222 & & 6773.149 & 758.942 & 0.112505678 & 18190500 & 33364860 & & 169158.6 & 221779174 & 7648793 & 0.077 & 0.72 \\
\hline 34 & 230.254 & 396.95 & & 11327.573 & 857.187 & 0.23726838 & 21465480 & 34807500 & & 188870.1 & 178625280 & 9615529 & 0.363 & 1.354 \\
\hline 35 & 565.617 & 348.625 & & 11109.371 & 417.093 & 0.208383144 & 18654690 & 35758140 & & 1033785 & 234113605 & 4435902 & 1.867 & 1.5 \\
\hline 36 & 342.936 & 268.573 & & 4272.817 & 1448.99 & 0.160533772 & 33249780 & 52513140 & & 477864 & 257045154 & 10459276 & 2.01 & 0.895 \\
\hline 37 & 426.905 & 359.585 & & 6498.735 & 1750.015 & 0.21493425 & 33249780 & 52513140 & & 106753.2 & 180278092 & 14054349 & 0.273 & 0.855 \\
\hline 38 & 468.18 & 491.57 & & 8321.161 & 866.666 & 0.293825463 & 37599930 & 69955140 & & 95455.2 & 340511925 & 15963763 & 0.074 & 0.41 \\
\hline 39 & 537.56 & 299.008 & & 10528.217 & 1700.707 & 0.178725643 & 30974460 & 52798350 & & 372003 & 293521995 & 13038550 & 0.253 & 1.265 \\
\hline 40 & 311.725 & 223.73 & & 2543.466 & 1761.563 & 0.133729827 & 7156569 & 10824261 & & 110818.5 & 63348642 & 3132749 & 0.914 & 1.79 \\
\hline 41 & 398.045 & 140.501 & & 4443.972 & 843.321 & 0.08398147 & 10259259 & 15624213 & & 98950.5 & 69843404 & 3966270 & 0.323 & 1.15 \\
\hline 42 & 485.947 & 302.919 & & 10021.337 & 1079.464 & 0.181063359 & 20872830 & 38717910 & & 264886.5 & 258971579 & 8857823 & 0.109 & 0.97 \\
\hline 43 & 312.341 & 247.126 & & 1041.958 & 503.472 & 0.147714286 & 4022046 & 7331403 & & 151055.4 & 56922341 & 1598471 & 0.169 & 1.085 \\
\hline
\end{tabular}

Figure 3.86 Snapshot of the Main Input File for the IDEA Software 


\subsubsection{Neural Network Modeling}

The software IDEA - Intelligent Data Evaluation \& Analysis has been developed by Intelligence Solutions Inc. It has the capability of building one of the most usable and accurate tools from the toolbox of Artificial Intelligence - Neural Networks.

Once the IDEA Software is started, a main console consisting of eight separate parts and eighteen modules is opened. Seven modules have been used to create the predicted model by Neural Networks in this study.

IDEA has a friendly and process oriented interface that will walk user through the problem solving steps. The process is quite simple. User imports data, identifies and easily takes care of all the outliers and missing data, performs some conventional statistical analysis such as regression and frequency distribution, uses Fuzzy Combinatorial Analysis to identify the most important parameters in the dataset, performs Hard K-mean and Fuzzy C-mean analysis to segment the dataset into clusters and prepares them for modeling, uses neural networks to build a model of the dataset, uses genetic algorithms to optimize the model, and finally uses the fuzzy decision support system to build the ultimate knowledge-based expert system (www.IntelligentSolutionsInc.com, 2004.). 


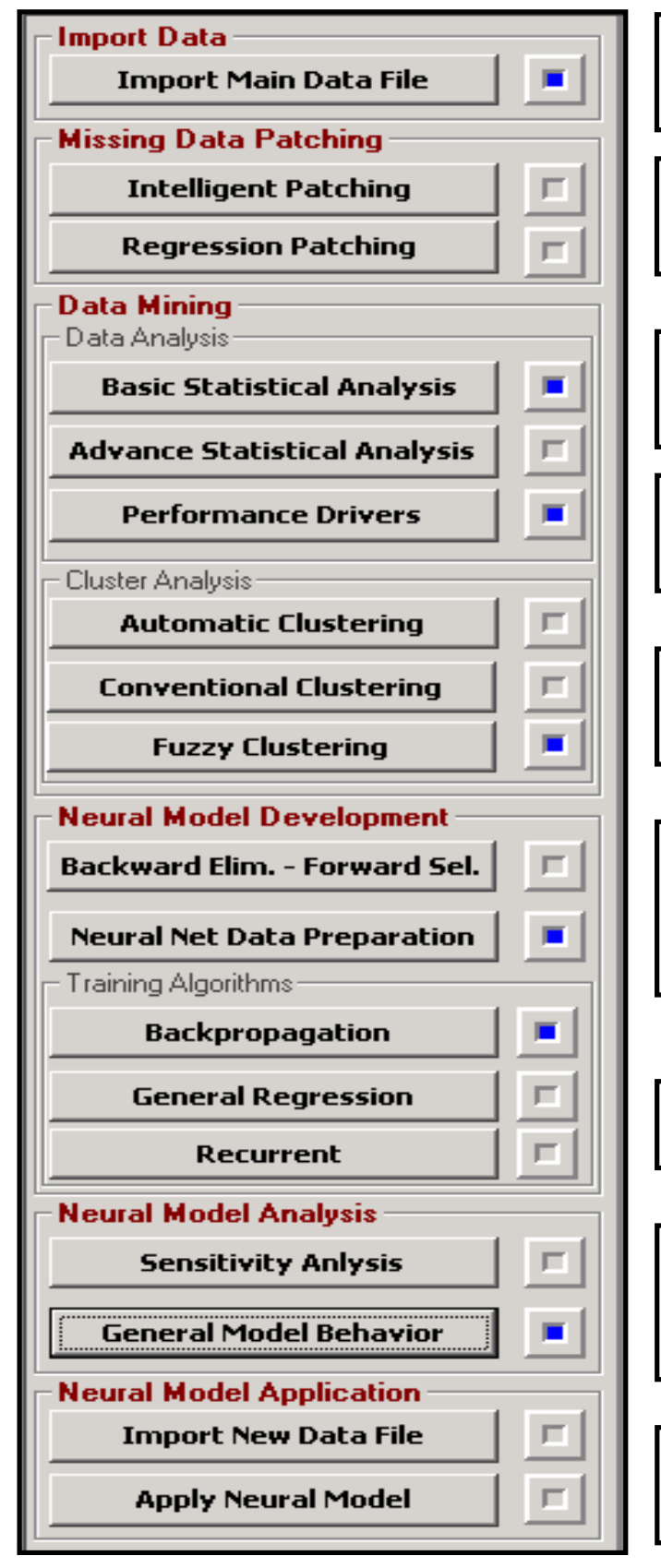

Locating and importing of the Main Data file.

This module reads the data from its original application

Handling the missing data- identifying the best possible value to be used to patch the holes in the data set.

Visual observation of any obvious outlier that might exist in the model

Fuzzy Combinatorial Analysis-Identification of key performance indicators in a process

Creating and analyzing clusters - powerful tool for understanding and exploring the data

Identifying the inputs to the network and partition the dataset into three segments; training, calibration (a.k.a. testing) and verification (a.k.a. production).

Neural Network Model Building-Training Algorithms

This module provides a set of tools that allows user to use the neural network model and make simulation runs to answer important "What If" questions.

Neural Model Application Importing the new file and applying Neural Network Model

\section{Figure 3.87 The Main IDEA Consol with All Explanation for All Existing Modules}

Like the majority of softwares available nowadays, the first step in using this software is to create the main file. Once the location where that file will be stored and the file are named, the software will create a folder having the same name as the file. The extension of that file is .ida. 


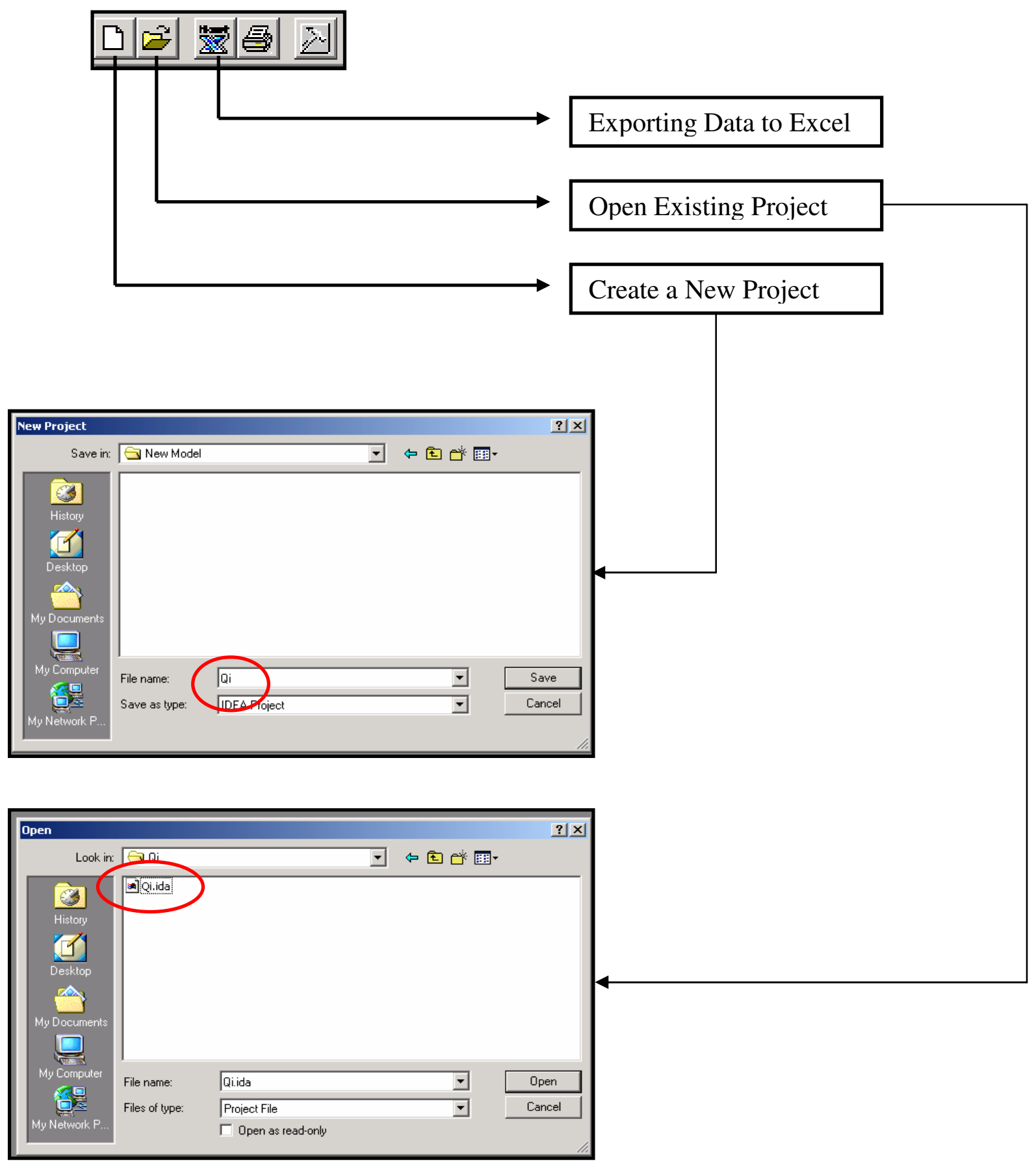

Figure 3.88 IDEA Toolbar Including the Creation of a New File, Opening the New File and Export to Excel Options 
When the IDEA .ida file is created, the first step is to open it by double clicking on it and than import data in. The software has capability to read and use Excel, Access and Text files. In this case, all data are gathered in the Excel spreadsheet. By clicking the "Select File" button, user can browse for the file with the data inside, and upon determining it, choose Excel spread sheet. At the end, the main data file needs to be imported in IDEA by using the "Import" button.

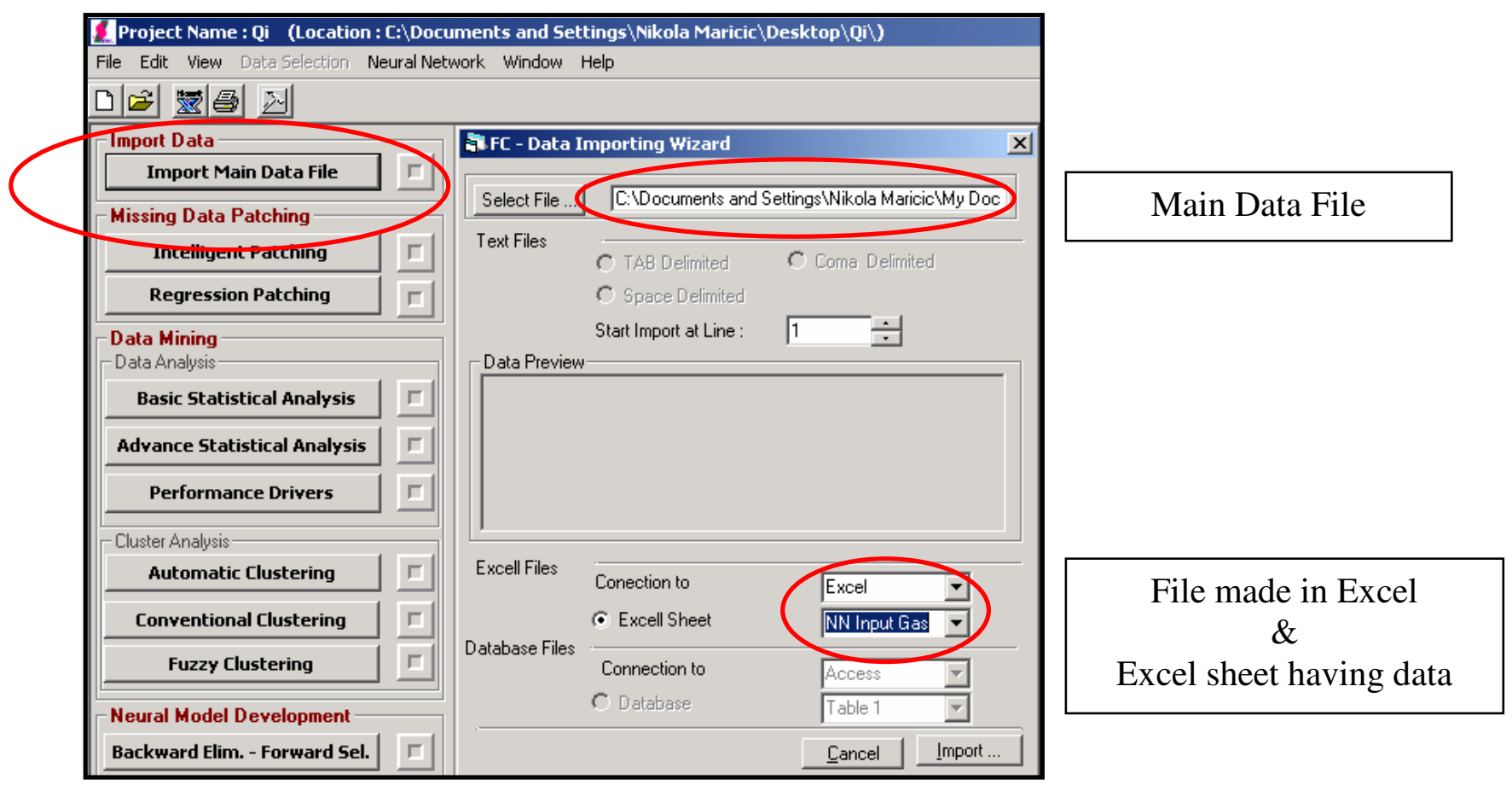

\section{Figure 3.89 The Import of the File Containing the Main Data for the Neural Network Modeling}

When the Main Data File is imported into IDEA, the software can read it and present it to user in the form of "Data Analyzer". Once all the data are successfully imported, another form will open to let the user do two things. First, it lets us look at the data that have been imported. Under the "Spreadsheet" tab, the data in its entirety can be viewed and examined. This way the user will make sure that the right data set has been selected and has been downloaded in its entirety. This form is shown in the following figure.

The second tab in the form is the "Attribute Selection" tab. In this tab, a table appears that includes all the columns of the data set called variables. In the "Attribute" column of this table, you can define each variable to be an "ID", "Input", "Output" or simply not used in 
the analysis. This table will further show some basic, but very important statistics about each of the variables such as minimum, maximum, mean, and standard deviation. All the column activities of the previous tab, such as adding or generating new columns, are presented in this tab (www.IntelligentSolutionsInc.com, 2004. IDEA, IPDE-IDEA Tutorial.).

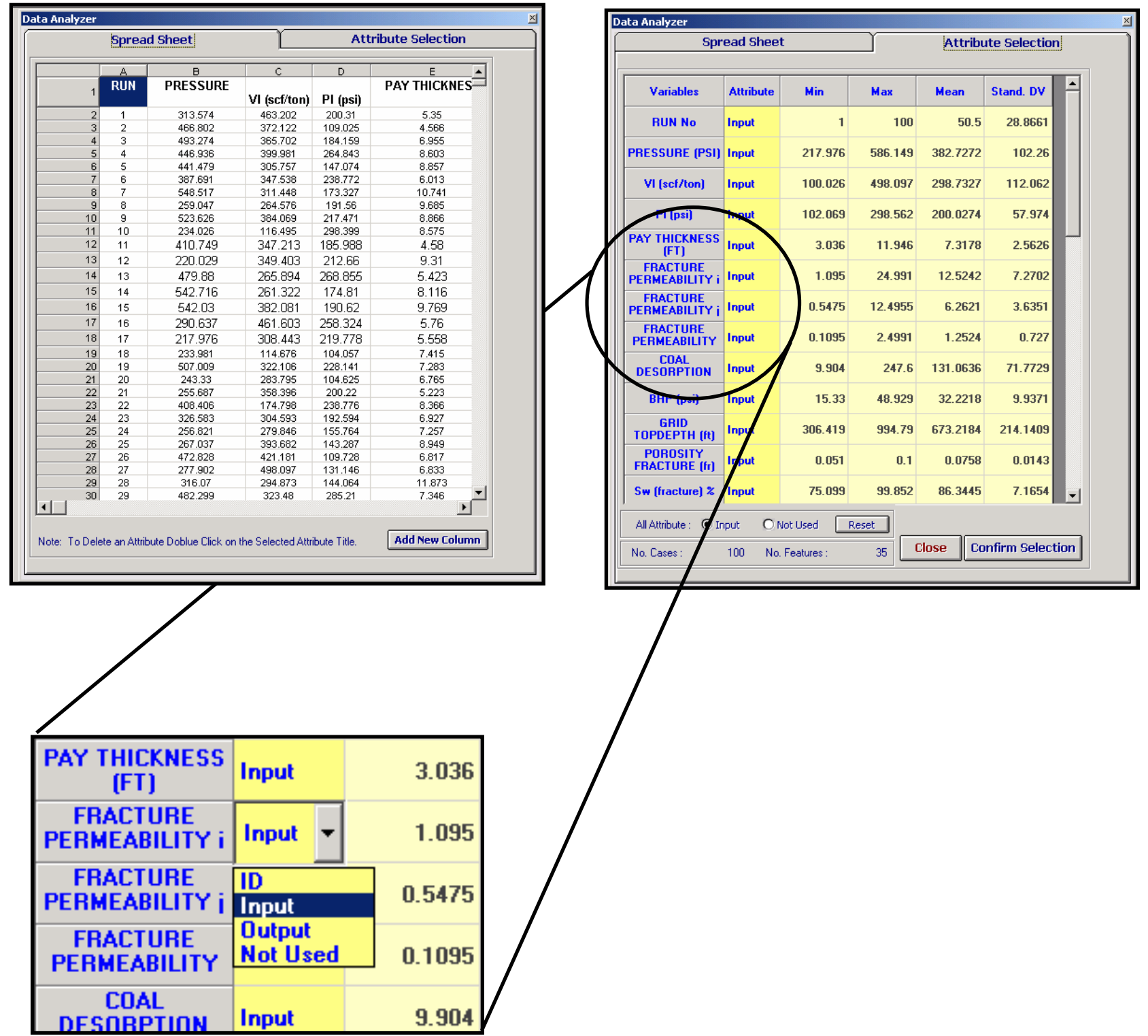

Figure 3.90 Data Analyzer Showing Spread Sheet of Imported Data and Second Tab Attribute Selection 
Number of ID's Inputs, Outputs and the Not Used highly depends on the Neural Network model that the user wants to make. The following table shows input data for the two lateral well configurations with a chosen attribute selection for the predicted value of Qi.

\begin{tabular}{|l|l|}
\hline \multicolumn{1}{|c|}{ INPUT DATA } & \\
\hline & \\
\hline Run No & ID \\
\hline Pressure (Psi) & Input \\
\hline VI (scf/ton) & Input \\
\hline PI (psi) & Input \\
\hline Pay Thickness (ft) & Input \\
\hline Fracture Permeability i (md) & Input \\
\hline Fracture Permeability j (md) & Input \\
\hline Fracture Permeability k (md) & Input \\
\hline Coal Desorption Time (days) & Input \\
\hline BHP (psi) & Input \\
\hline Grid Topdepth (ft) & Input \\
\hline Porosity Fracture (fr) & Input \\
\hline Sw (fracture) \% & Input \\
\hline Two Leteral Length (ft) & Input \\
\hline SBL(ft) & Input \\
\hline gmol/lb & Input \\
\hline 1/psi & Input \\
\hline Best 3 Months CUM & Not Used \\
\hline Best 6 Months CUM & Not Used \\
\hline Best 9 Months CUM & Not Used \\
\hline Best 12 Months CUM & Not Used \\
\hline First 3 Months CUM & Not Used \\
\hline First 6 Months CUM & Not Used \\
\hline First 9 Months CUM & Not Used \\
\hline First 1 Year CUM & Not Used \\
\hline First 3 Year CUM & Not Used \\
\hline First 5 Year CUM & Not Used \\
\hline First 10 Year CUM & Not Used \\
\hline Last Production & Not Used \\
\hline Cumulative & Not Used \\
\hline Qi & Not Used \\
\hline Di & Not Used \\
\hline b & Output \\
\hline & \\
\hline
\end{tabular}

Table 3.12 Two Lateral Well Configurations Attribute Selection for the Predicted Value of "b". 
The next module consists of the sub modules, explains and applies missing data patching in the input file where all data have been stored. Since no missing data exists in the Main Input file, these two modules are not specified for use in this research. Once the Basic Statistic Analysis module is opened, it will show us the following form.

\begin{tabular}{|c|c|c|c|c|c|c|c|c|c|c|c|}
\hline \multicolumn{12}{|c|}{ 7. Statistical Analysis } \\
\hline \multicolumn{2}{|c|}{ Data } & \multicolumn{3}{|c|}{ Regression Analysis } & \multicolumn{2}{|c|}{$\begin{array}{l}\text { Frequency } \\
\text { Distribution }\end{array}$} & \multicolumn{2}{|c|}{ 3D-2D } & \multicolumn{3}{|c|}{ Bubble } \\
\hline Index & RUN No & PRESS & VI & PI [psi] & PAY & FRACT & FRACT & FRACT & COAL & BHP & $\triangle$ \\
\hline Min & & 217.976 & 100.026 & 102.501 & 3.036 & 1.095 & 0.548 & 0.11 & 9.904 & 15.33 & \\
\hline Max & & 586.149 & 498.097 & 298.562 & 11.946 & 24.991 & 12.496 & 2.499 & 247.6 & 48.929 & \\
\hline Mean & & 381.984 & 299.303 & 199.369 & 7.348 & 12.334 & 6.167 & 1.233 & 132.206 & 32.039 & 1 \\
\hline STDV & & 101.818 & 113.371 & 56.835 & 2.542 & 7.29 & 3.645 & 0.729 & 71.816 & 9.832 & \\
\hline 1 & 1 & 313.574 & 463.202 & 200.31 & 5.35 & 14.181 & 7.0905 & 1.4181 & 57.305 & 17.701 & $9-$ \\
\hline 2 & 2 & 466.802 & 372.122 & 109.025 & 4.566 & 20.318 & 10.159 & 2.0318 & 133.514 & 21.274 & 7 \\
\hline 3 & 3 & 493.274 & 365.702 & 184.159 & 6.955 & 17.948 & 8.974 & 1.7948 & 233.354 & 48.772 & 7 \\
\hline 4 & 4 & 446.936 & 399.981 & 264.843 & 8.603 & 21.434 & 10.717 & 2.1434 & 247.6 & 34.647 & 9 \\
\hline 5 & 5 & 441.479 & 305.757 & 147.074 & 8.857 & 21.573 & 10.7865 & 2.1573 & 195.246 & 15.33 & 6 \\
\hline 6 & 6 & 387.691 & 347.538 & 238.772 & 6.013 & 13.046 & 6.523 & 1.3046 & 51.701 & 39.367 & 3 \\
\hline 7 & 7 & 548.517 & 311.448 & 173.327 & 10.741 & 2.072 & 1.036 & 0.2072 & 104.232 & 38.925 & 9 \\
\hline 8 & 8 & 259.047 & 264.576 & 191.56 & 9.685 & 20.282 & 10.141 & 2.0282 & 62.242 & 37.178 & 4 \\
\hline 9 & 9 & 523.626 & 384.069 & 217.471 & 8.866 & 2.393 & 1.1965 & 0.2393 & 24.996 & 19.076 & 3 \\
\hline 10 & 10 & 234.026 & 116.495 & 298.399 & 8.575 & 12.656 & 6.328 & 1.2656 & 9.904 & 34.854 & 4 \\
\hline 11 & 11 & 410.749 & 347.213 & 185.988 & 4.58 & 2.973 & 1.4865 & 0.2973 & 175.736 & 32.599 & 9 \\
\hline 12 & 12 & 220.029 & 349.403 & 212.66 & 9.31 & 15.484 & 7.742 & 1.5484 & 233.443 & 23.262 & 8 \\
\hline 13 & 13 & 479.88 & 265.894 & 268.855 & 5.423 & 13.989 & 6.9945 & 1.3989 & 216.931 & 47.817 & 6 \\
\hline 14 & 14 & 542.716 & 261.322 & 174.81 & 8.116 & 21.469 & 10.7345 & 2.1469 & 186.737 & 41.766 & 3 \\
\hline 15 & 15 & 542.03 & 382.081 & 190.62 & 9.769 & 22.952 & 11.476 & 2.2952 & 175.841 & 15.858 & 4 \\
\hline 16 & 16 & 290.637 & 461.603 & 258.324 & 5.76 & 10.965 & 5.4825 & 1.0965 & 33.065 & 35.703 & 6 \\
\hline 17 & 17 & 217.976 & 308.443 & 219.778 & 5.558 & 4.837 & 2.4185 & 0.4837 & 105.805 & 16.675 & 6 \\
\hline 18 & 18 & 233.981 & 114.676 & 104.057 & 7.415 & 1.095 & 0.5475 & 0.1095 & 90.027 & 24.27 & 3 \\
\hline 19 & 19 & 507.009 & 322.106 & 228.141 & 7.283 & 10.201 & 5.1005 & 1.0201 & 51.789 & 28.81 & 3 \\
\hline$|1|^{n}$ & $3 n$ & 21202 & 203705 & INACOE & c $7 C 5$ & 1004 & $3 \times 13$ & ก 1004 & on 715 & $3+c 0$ & 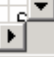 \\
\hline Note : Dout & ble Click on th & Cell to Re & emove the [ & Dutlier. & & Reset & & $\square \mathrm{Ou}$ & tlier & $\square$ Miss & \\
\hline
\end{tabular}

Figure 3.91 Statistical Analysis Form

Here, we are dealing with four different tabs:

1. Data;

2. Regression Analysis;

3. Frequency Distribution;

4. 3D-2D;

5. Bubble.

The Data tab shows imported data, including calculated minimum, maximum, mean and Standard Deviation Factor for all input data. 
Regression Analysis includes several important components. On the left hand side, there are two list boxes. In each of these list boxes, all the features that are parts of the data set are shown. The top list box represents the x-axis, and the bottom list box represents the yaxis in the two-dimensional scatter plot, shown on the right side of the form.

The user may pick any two features in the data set to plot them against one another. The regression plot is displayed along with the $\mathrm{R}^{2}$ of the data, which is the result of a linear regression calculation. One of the features of this form is that you can compare the regressions of different parameters against one another, simply by double clicking on each feature in either of the list boxes (www.IntelligentSolutionsInc.com, 2004. IDEA, IPDE-IDEA Tutorial).

Using the Regression Analysis option, for the purpose of this study, data for the production indicator $\mathbf{b}$ are plotted on $\mathrm{Y}$ axis while the rest of the input will be plotted on the $\mathrm{X}$ axis. Scattered system is more than welcome because it allows Neural Network to learn better and faster, resulting in higher $\mathrm{R}^{2}$.

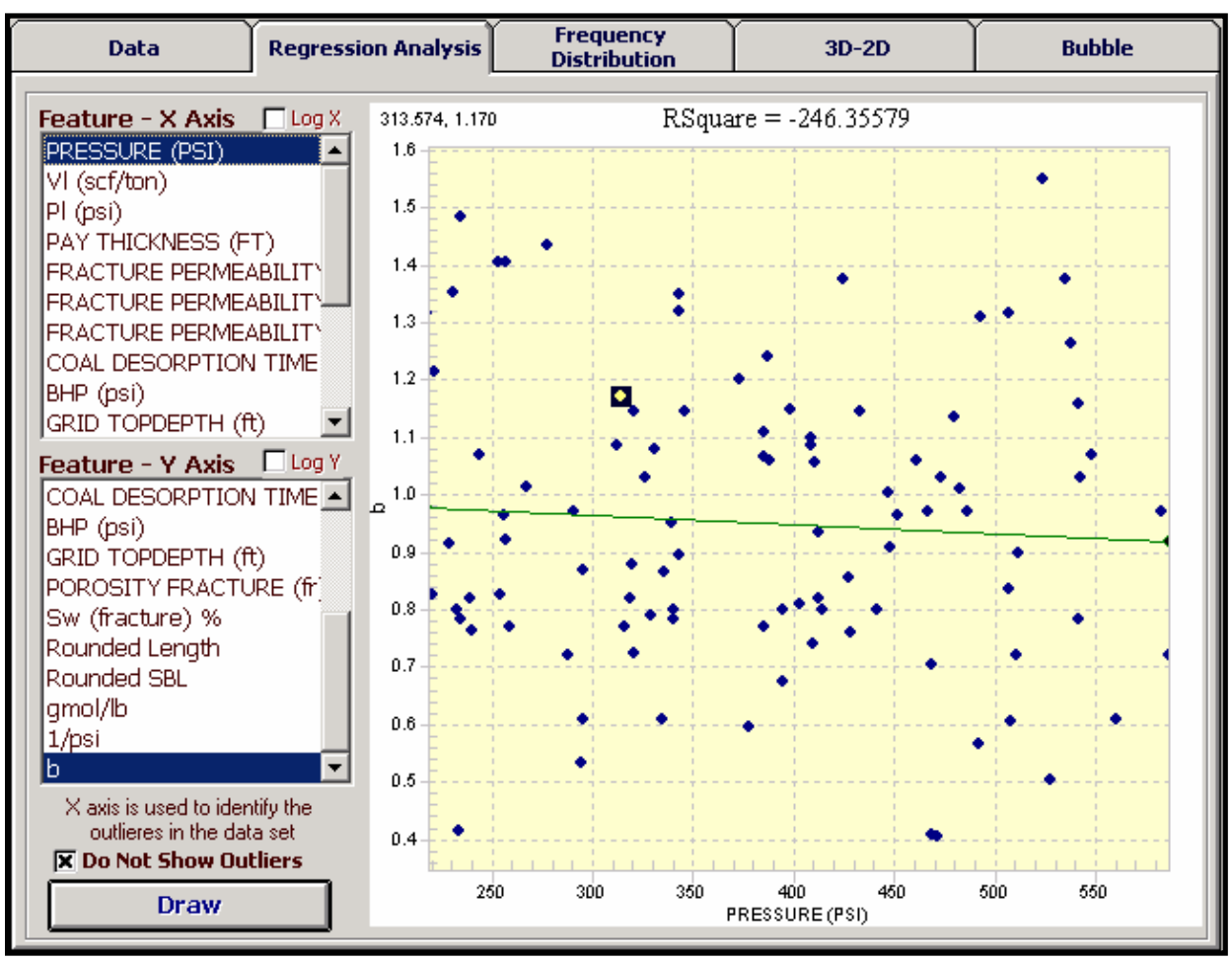

Figure 3.92 Representation of Data - b versus Pressure (psi) 
The last tab in this form shows the frequency distribution of each of the features as they are selected in the left hand side list box, as shown in the following figure. This can be achieved by simply double clicking on each of the features in the list box.

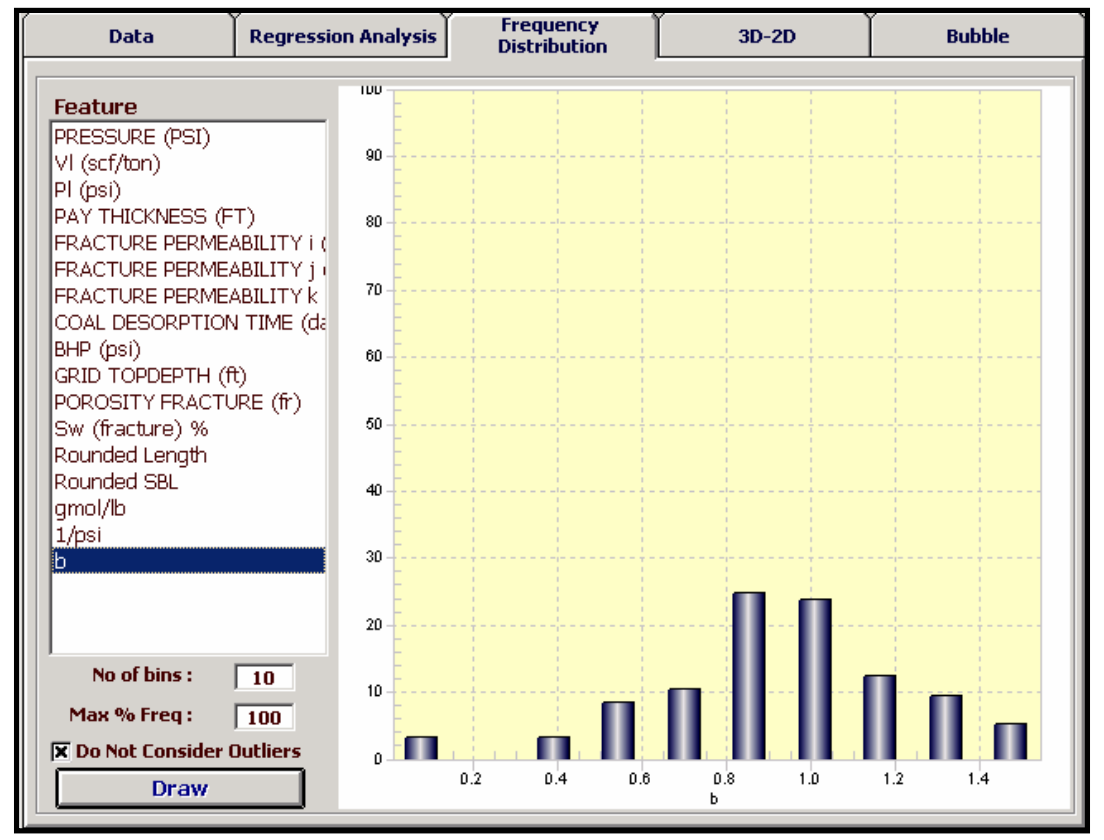

Figure 3.93 Frequency Distribution of Data

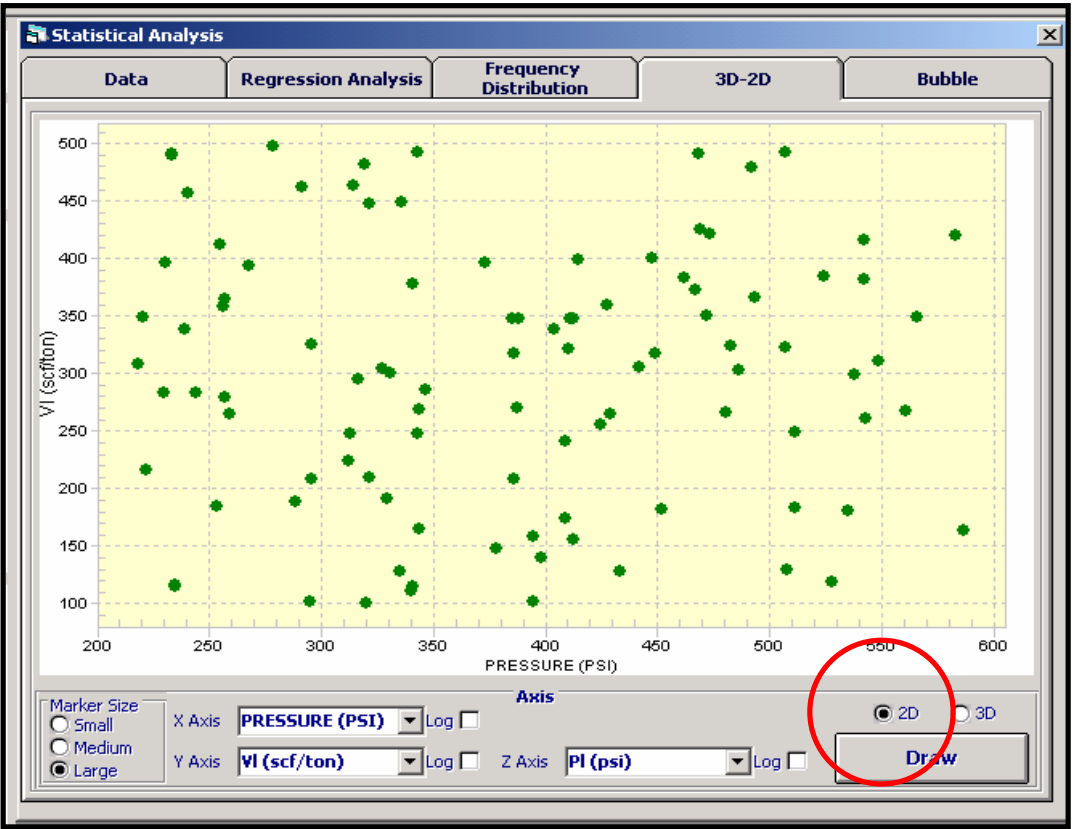

Figure 3.94 2D Data Distribution 


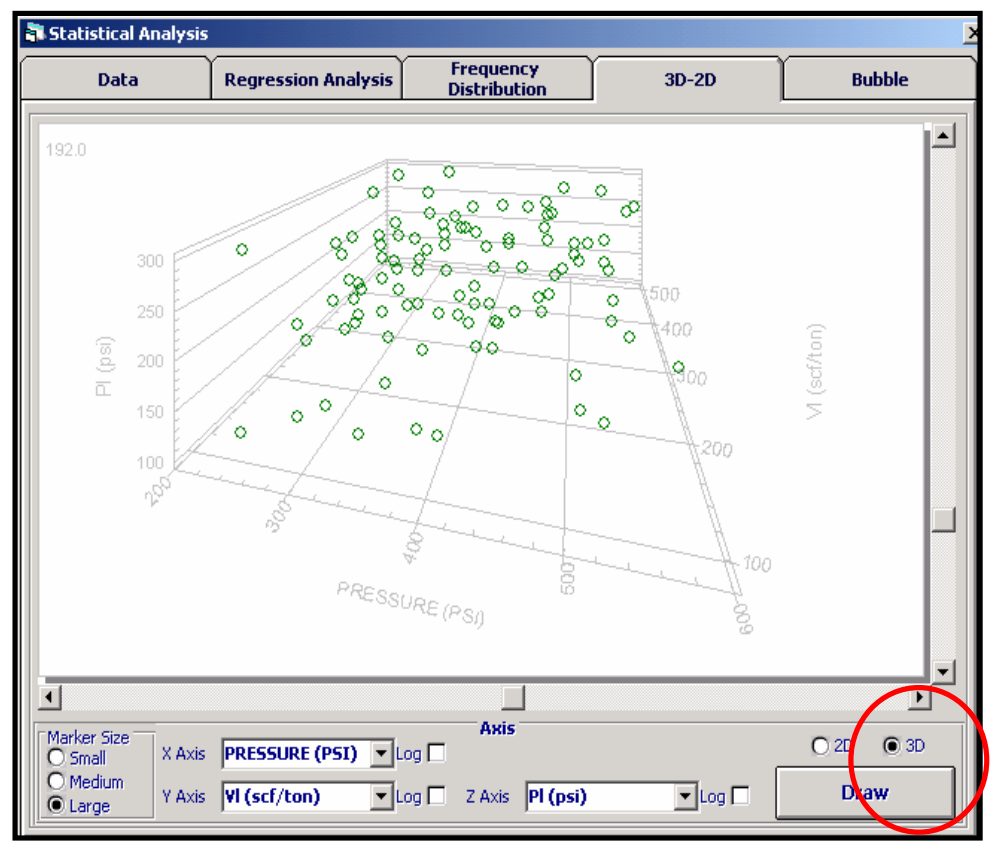

Figure 3.95 3D Data Distribution

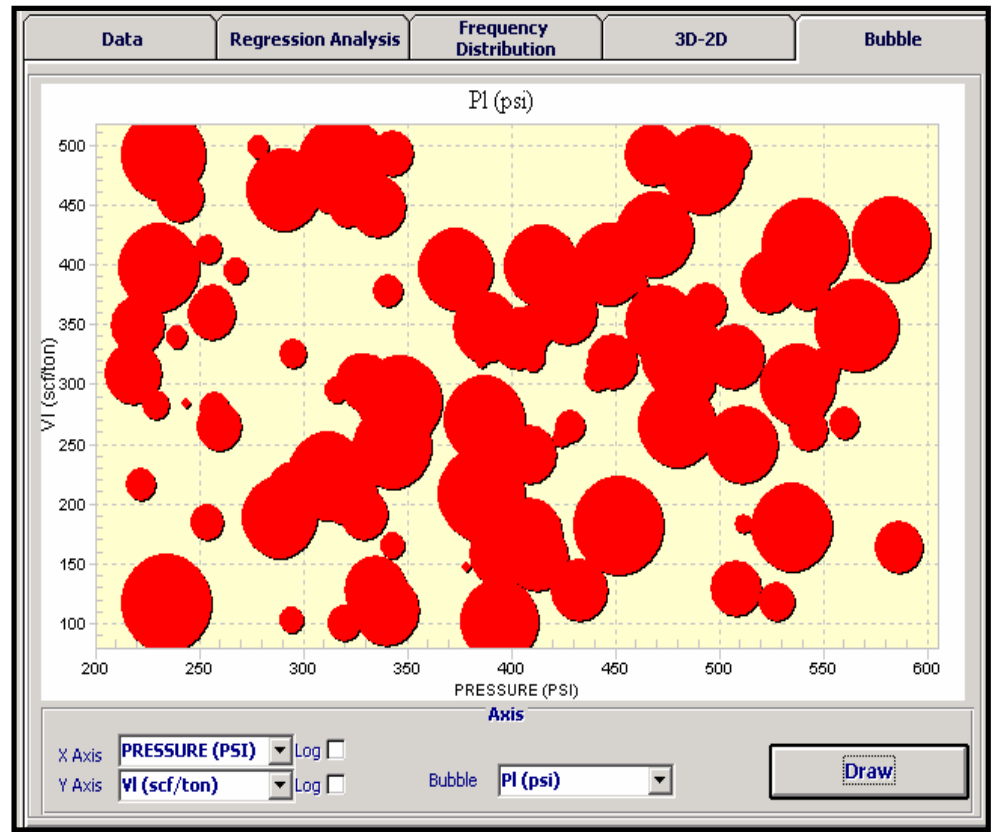

Figure 3.96 Bubble Chart Showing Distributions and Magnitude of Each Input Parameter 


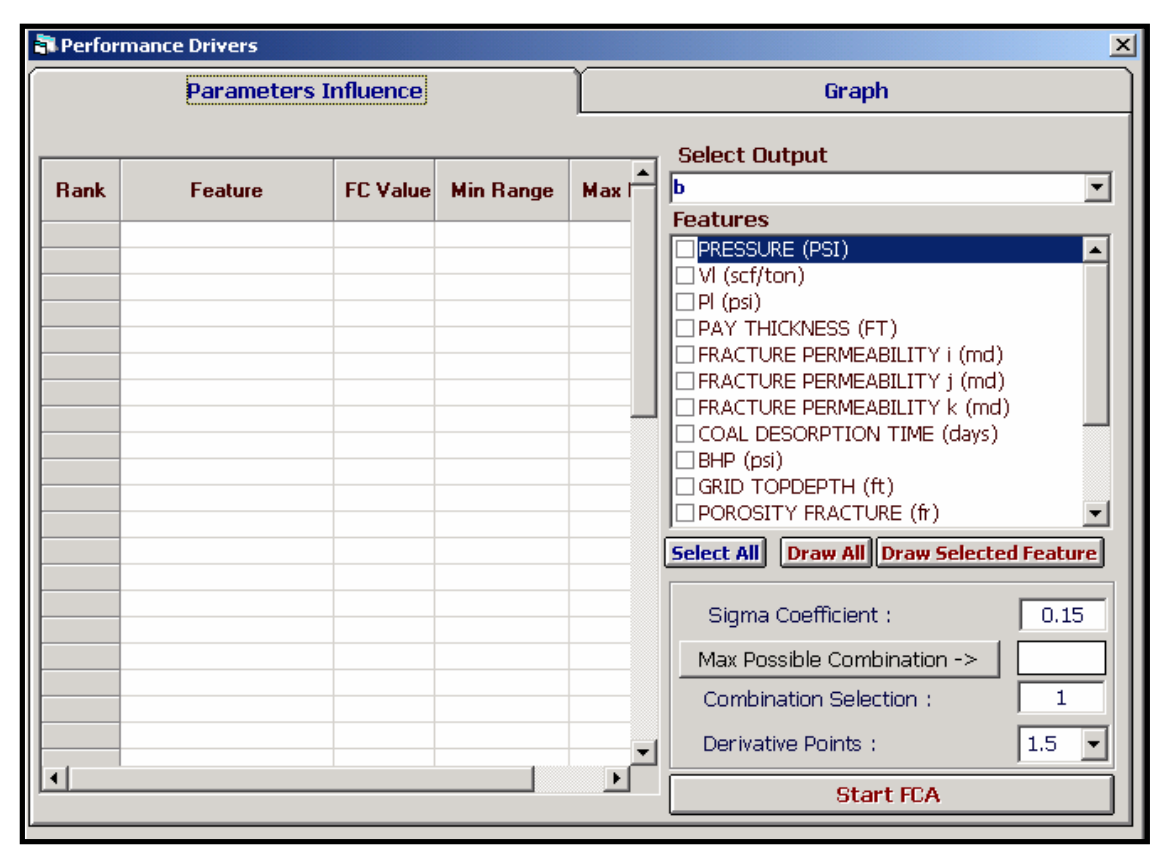

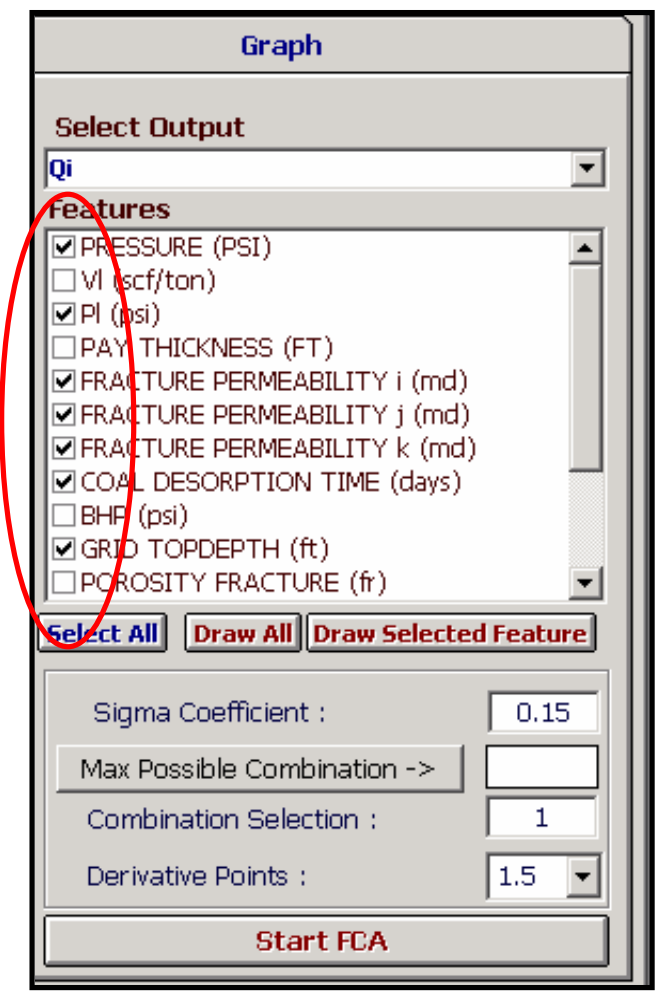

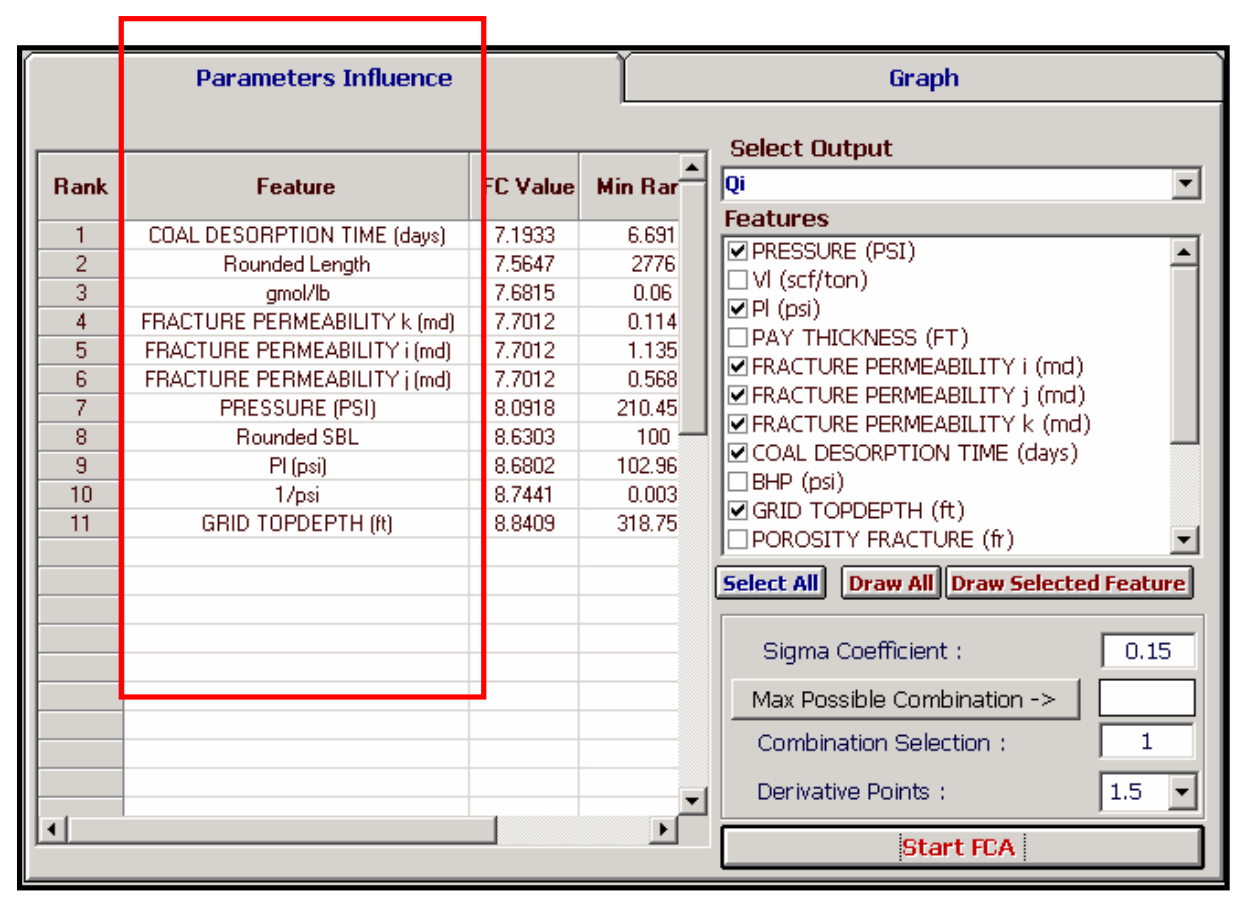

Figure 3.97 Performance Drivers Form, Showing Steps of Output Parameters Selection, Fuzzy Combinatorial Analysis and Identification of the Parameter Contribution 
Option "Draw Selected Feature" creates "Parameter Influence Diagram". The more existed curve looks like strait line, the better results might be obtained.

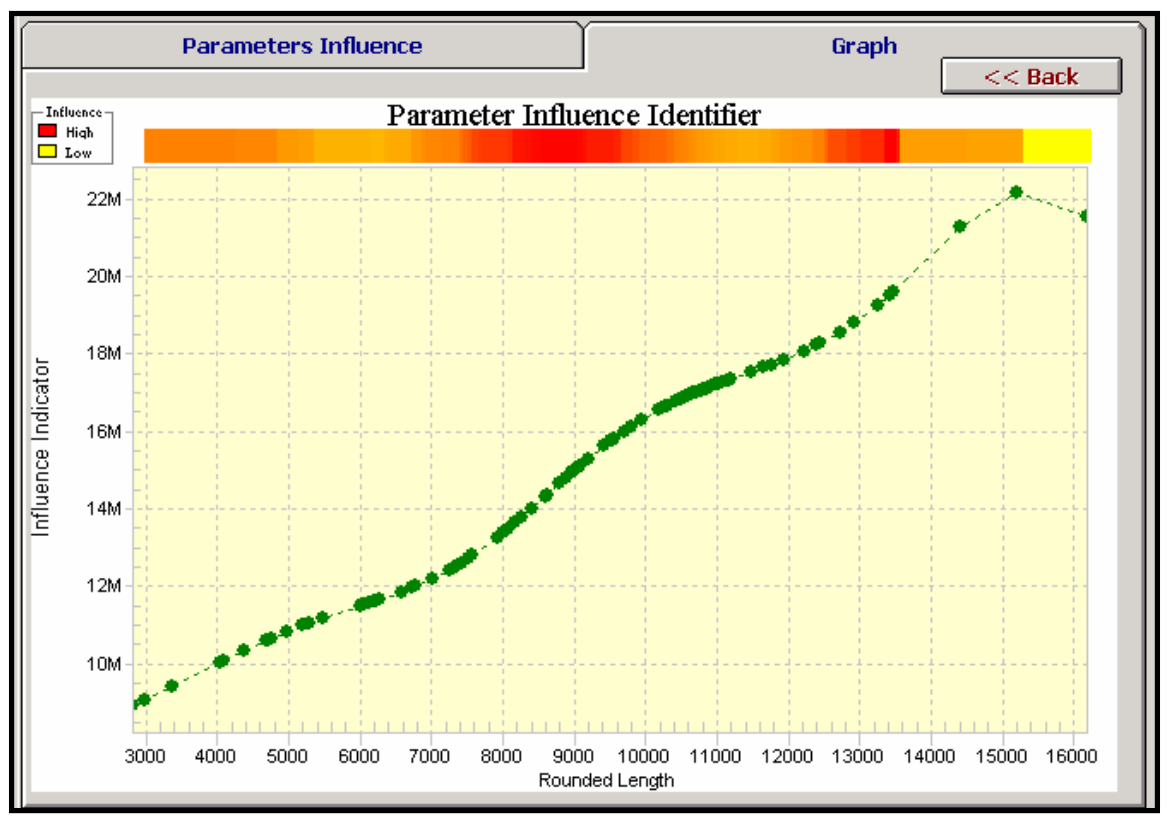

Figure 3.98 The Graphical Presentation of One of the Inputs 
Cluster Analysis module is equipped with three different Cluster Analysis options. Fuzzy Clustering has been used for analyzing input data.

Most clustering algorithms partition the data based on how similar individual records are; the more similar, the more likely that they belong to the same cluster. Their main purpose is to identify clusters that maximize the inter-cluster distance, and minimize the intracluster distance, so that we obtain clearly distinct groups of similar entities. This grouping introduces a "natural" unsupervised classification scheme, based on similarities according to the given distance measure (www.IntelligentSolutionsInc.com, 2004.).

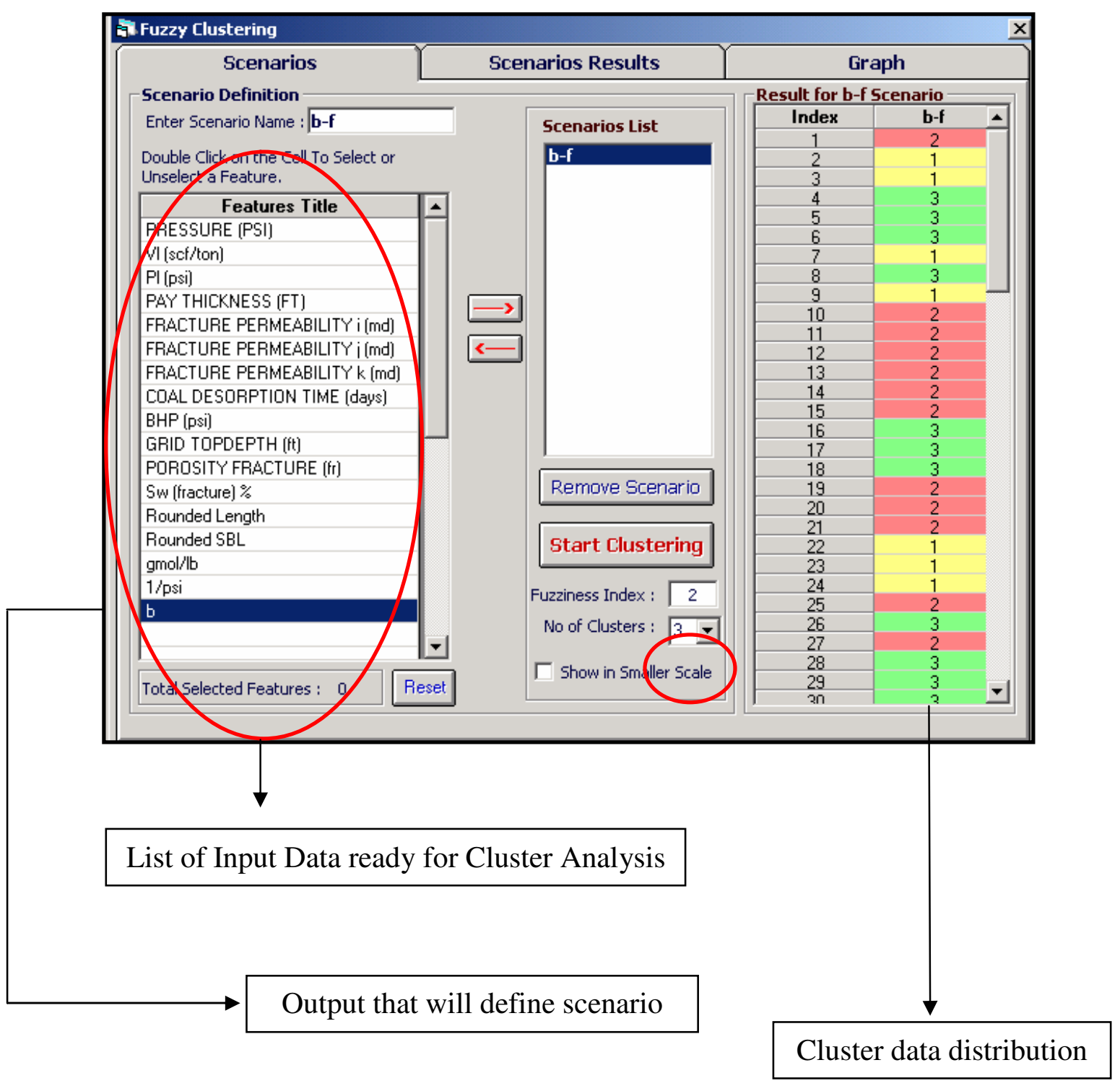

Figure 3.99 The Definition of the Number of Clusters, Scenario and Cluster Data Distribution after Clustering 


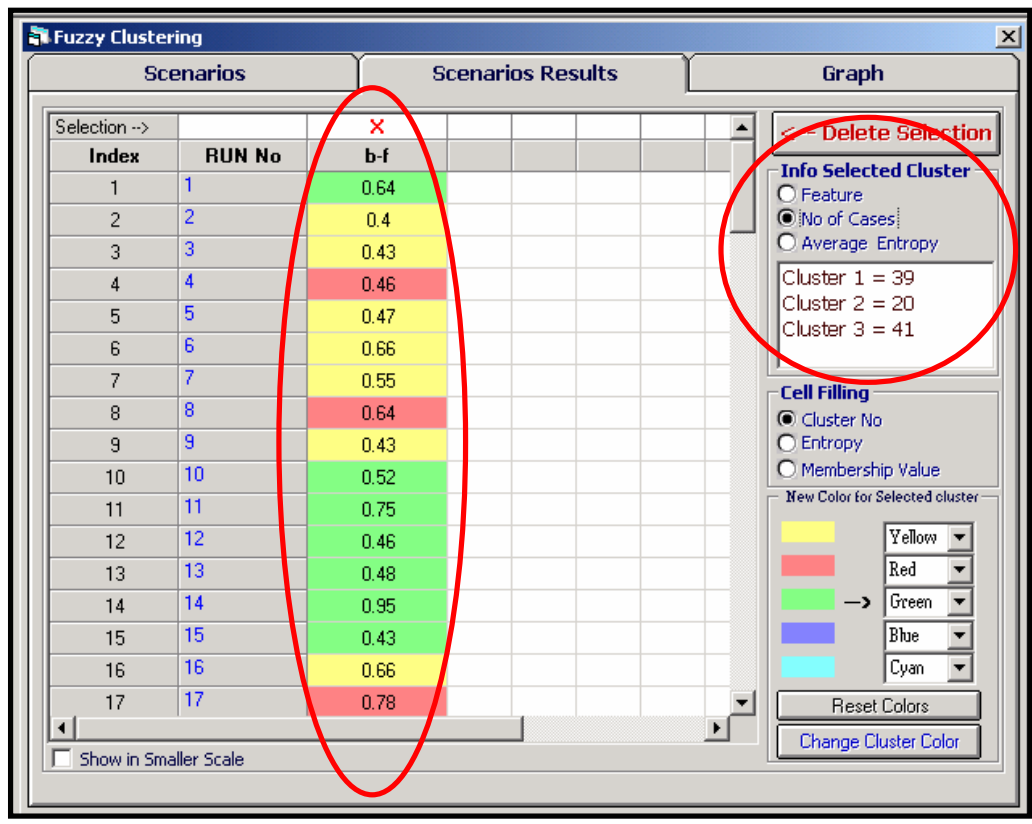

Figure 3.100 Data Arrangement in Clusters and Number of Data Existing in Each Cluster

The last tab in this module is the "Graph" tab. This form allows the user to see the results of the clustering analysis in two or three dimensions.

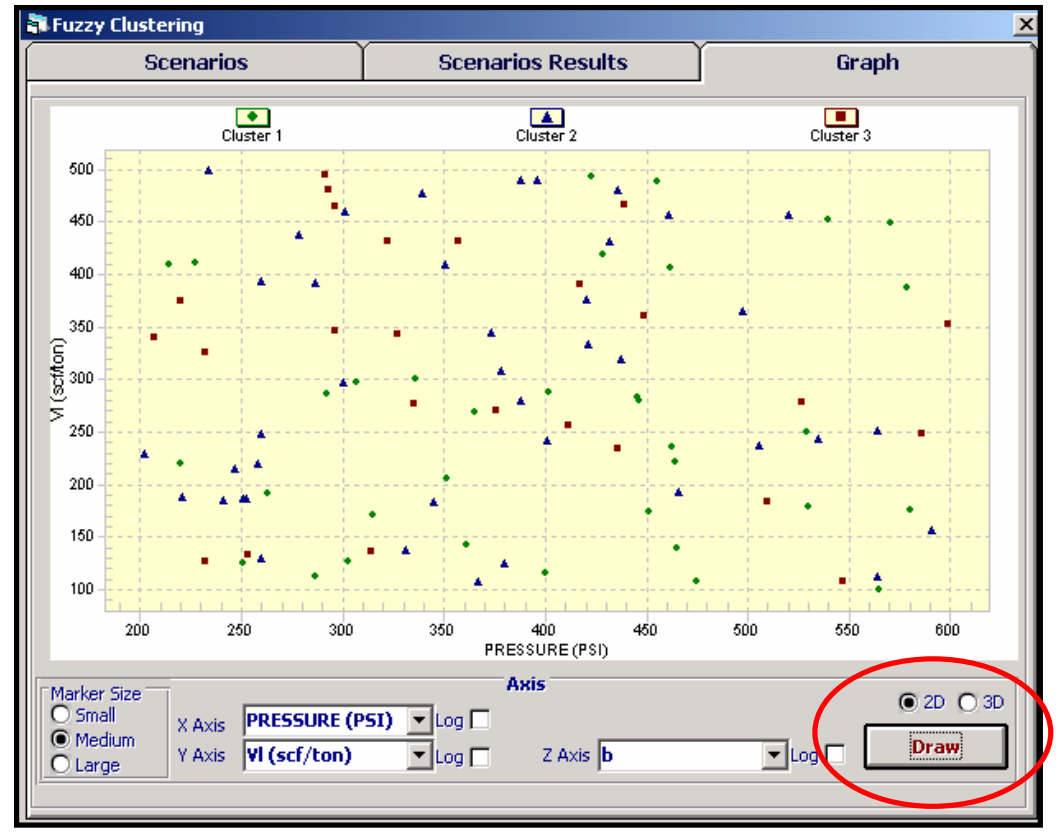

Figure 3.101 Cluster Data Distribution Presented by Graphs /2D 


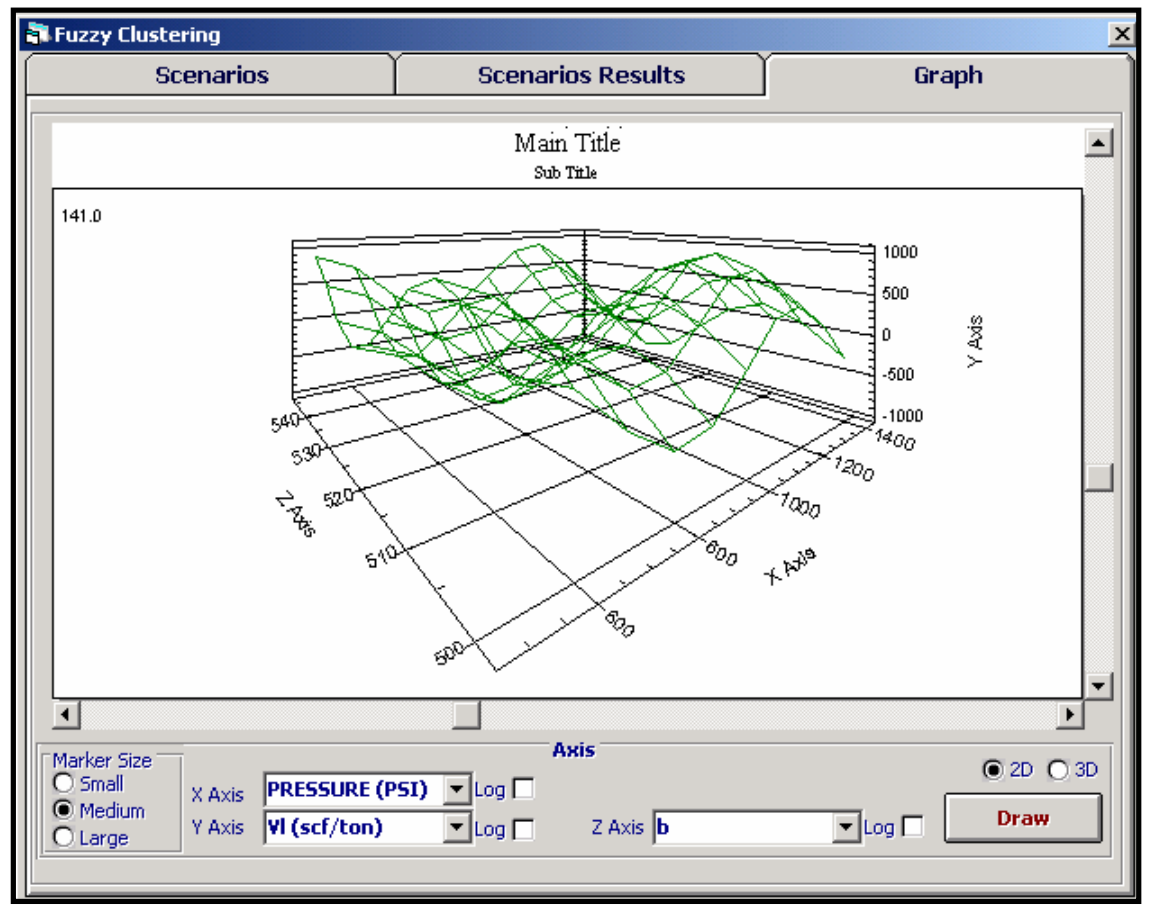

Figure 3.102 Cluster Data Distribution Presented by Graphs 3D-Surface Shape

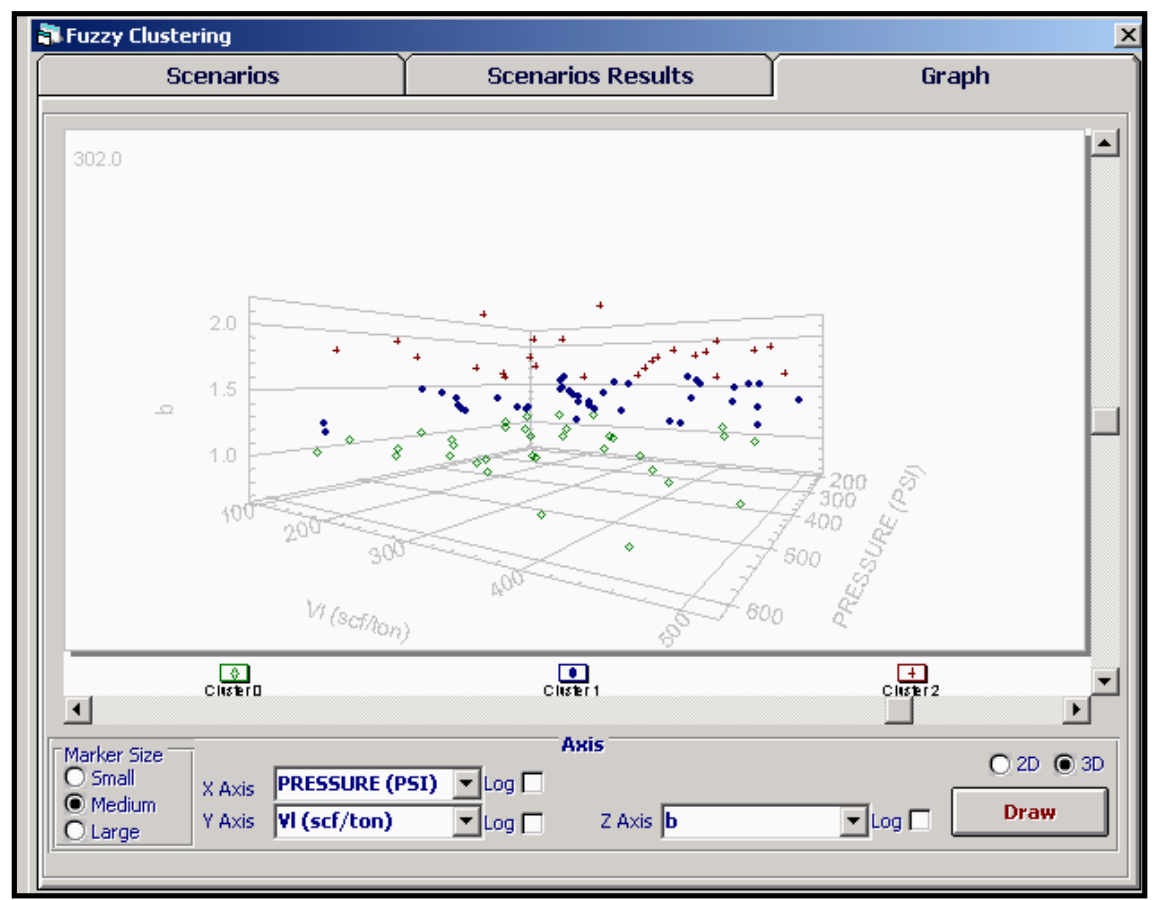

Figure 3.103 Cluster Data Distribution Presented by Graphs 3D 
This module of the software is probably one of the most important modules. In this module, the user identifies the inputs to the network, and partition the dataset into three segments; training, calibration (a.k.a. testing) and verification (a.k.a. production). In order for a neural network to train well and be capable of generalization, it should have a balance set of training, calibration, and verification data. By balance we mean that the data must be statistically representative. This simply means that in order to give the neural network a better chance of success, you have to make sure that all the potential patterns are represented in all three data sets. Obviously, this is very hard to do, because if we had known the patterns in advance, we probably would not have needed the neural networks to begin with. That said, the issue is that there are things that we can do to increase the probability of selecting statistically representative data sets for training, calibration and verification (www.IntelligentSolutionsInc.com, 2004.).

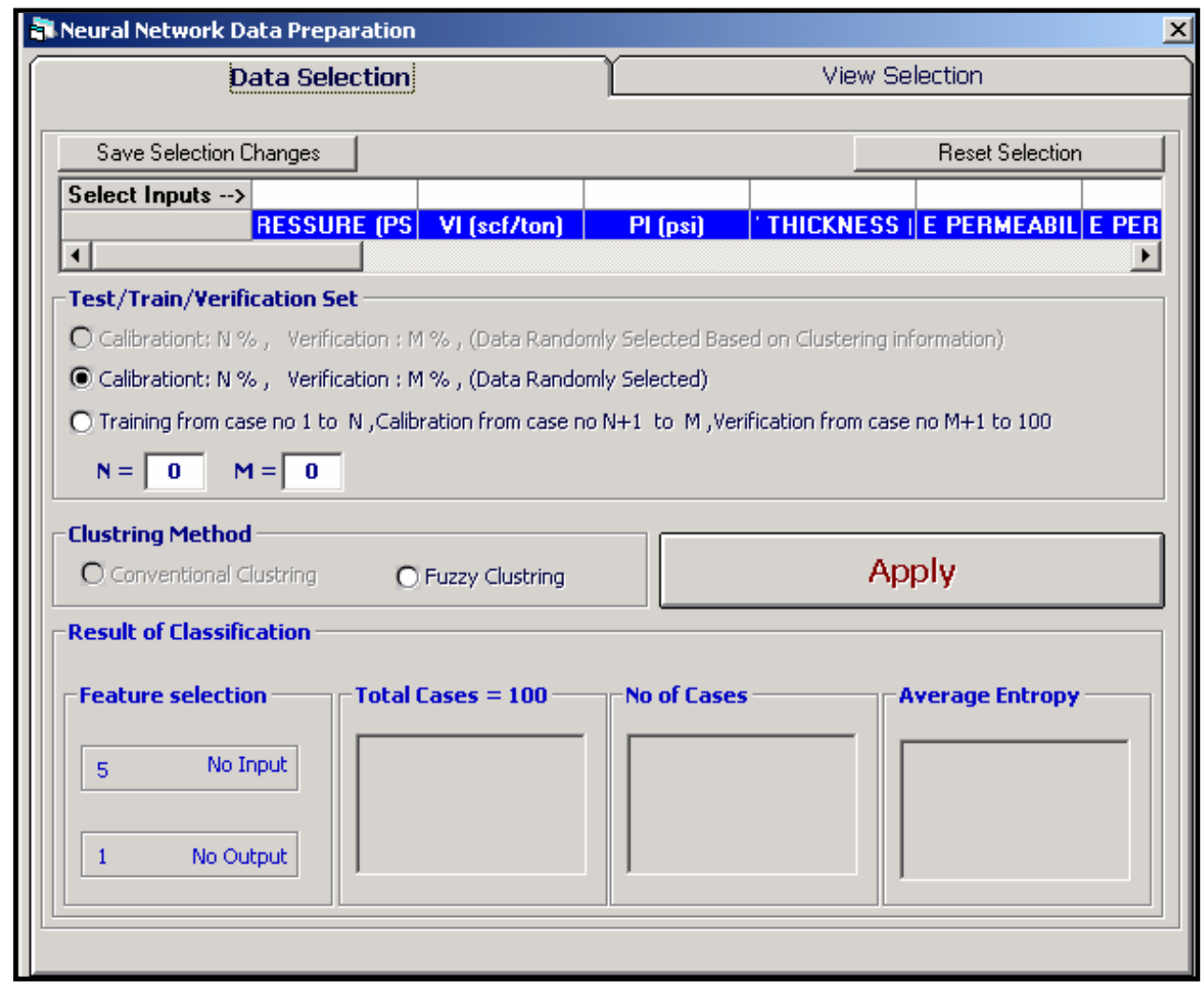

Figure 3.104 Data Selection Form with the Clustering Methods and Train/Test/Verification Options 


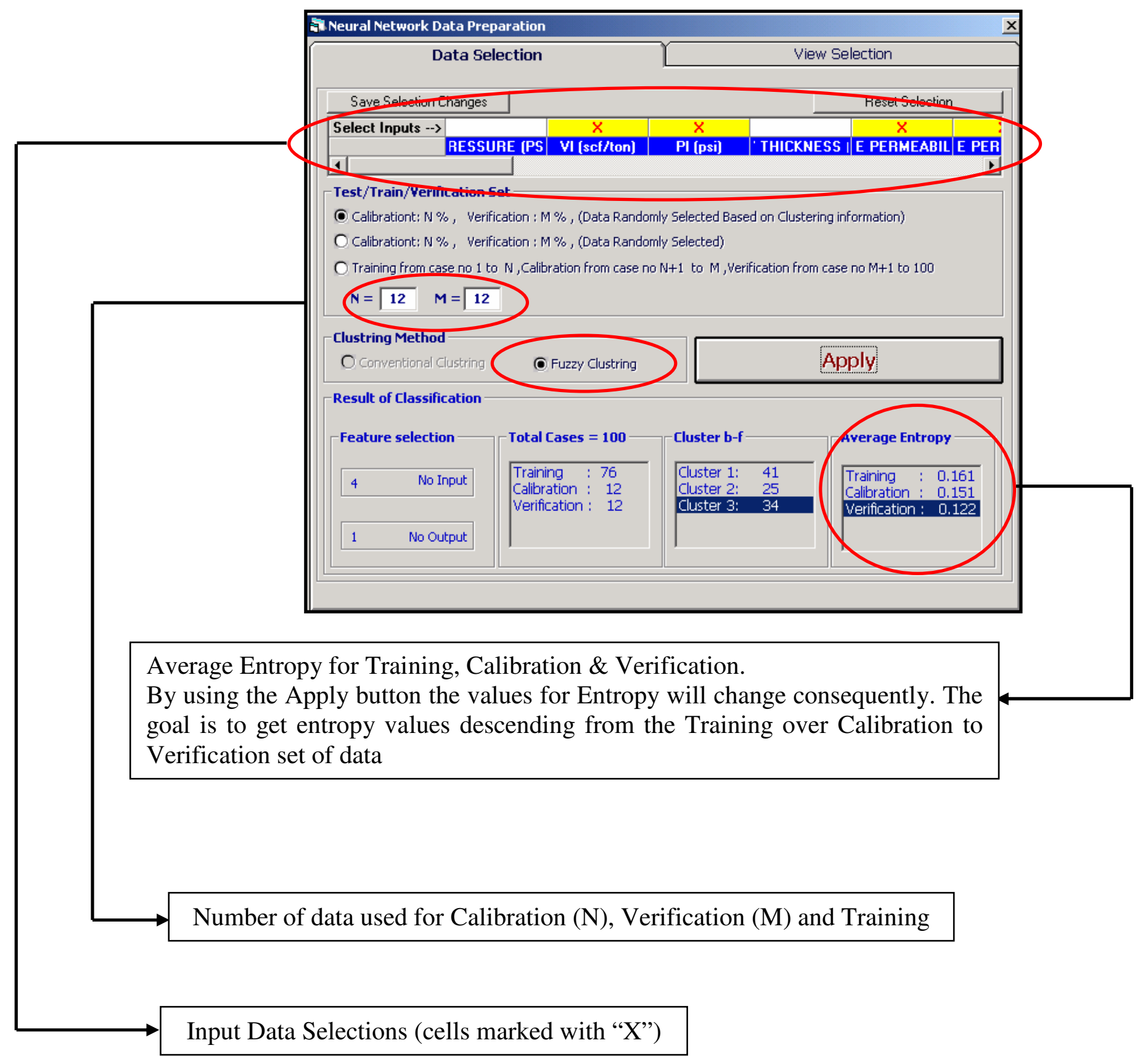

Figure 3.105 Neural Network Data Preparation

Data with the highest ranking value (explained in the "Performance Drivers" module) should be chosen as inputs in the data selection. It is the intention to minimize the input numbers and get good results as outputs from the IDEA. 


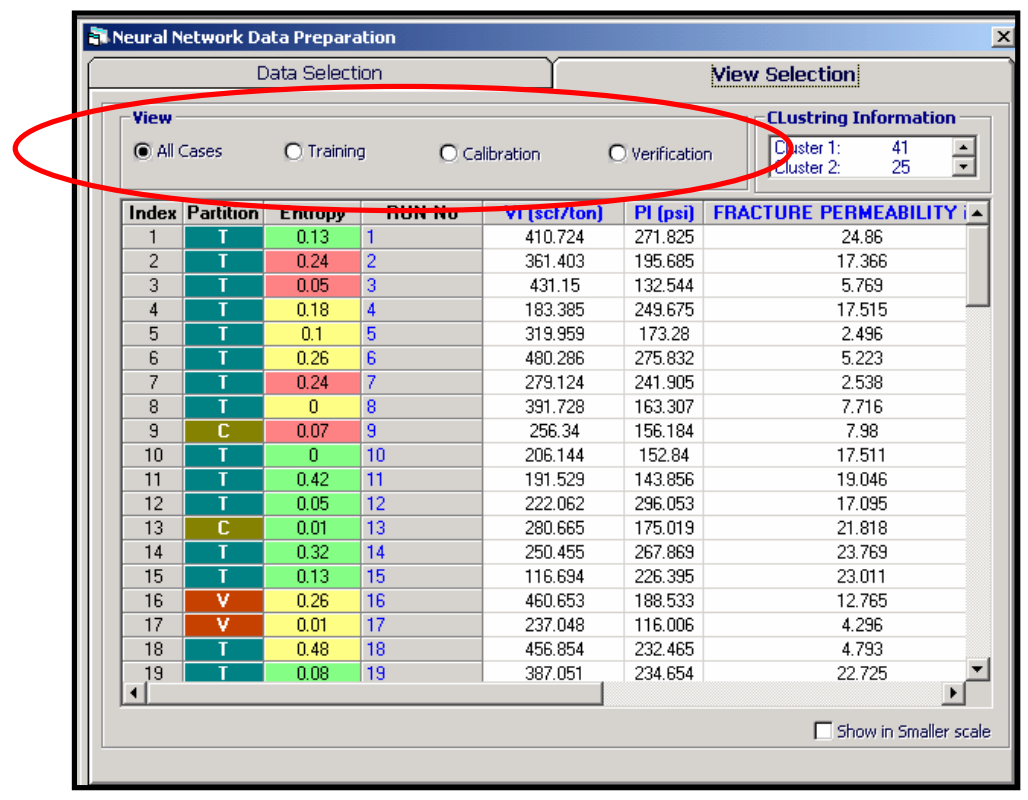

Figure 3.106 Data Selection Tab Allows User to See Entropy Value and All Clusters for Training, Calibration and Verification Sets as Well as Data Form for All Cases

The back propagation neural network module of IDEA $^{\mathrm{TM}}$ includes several advance features to help the user build the best model possible using available data. It includes three forms. The forms are named "Design", "Training", and "Results". The following figure shows the "Design" form of the backpropagation neural network. We will examine all of the features in this form.

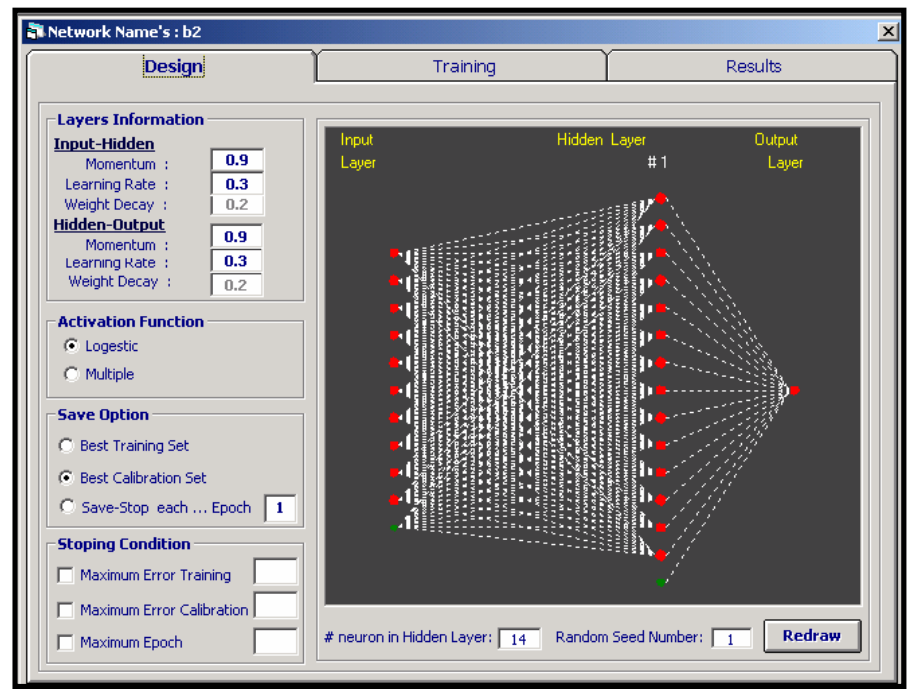

Figure 3.107 One of Possible Neural Network Architectures 


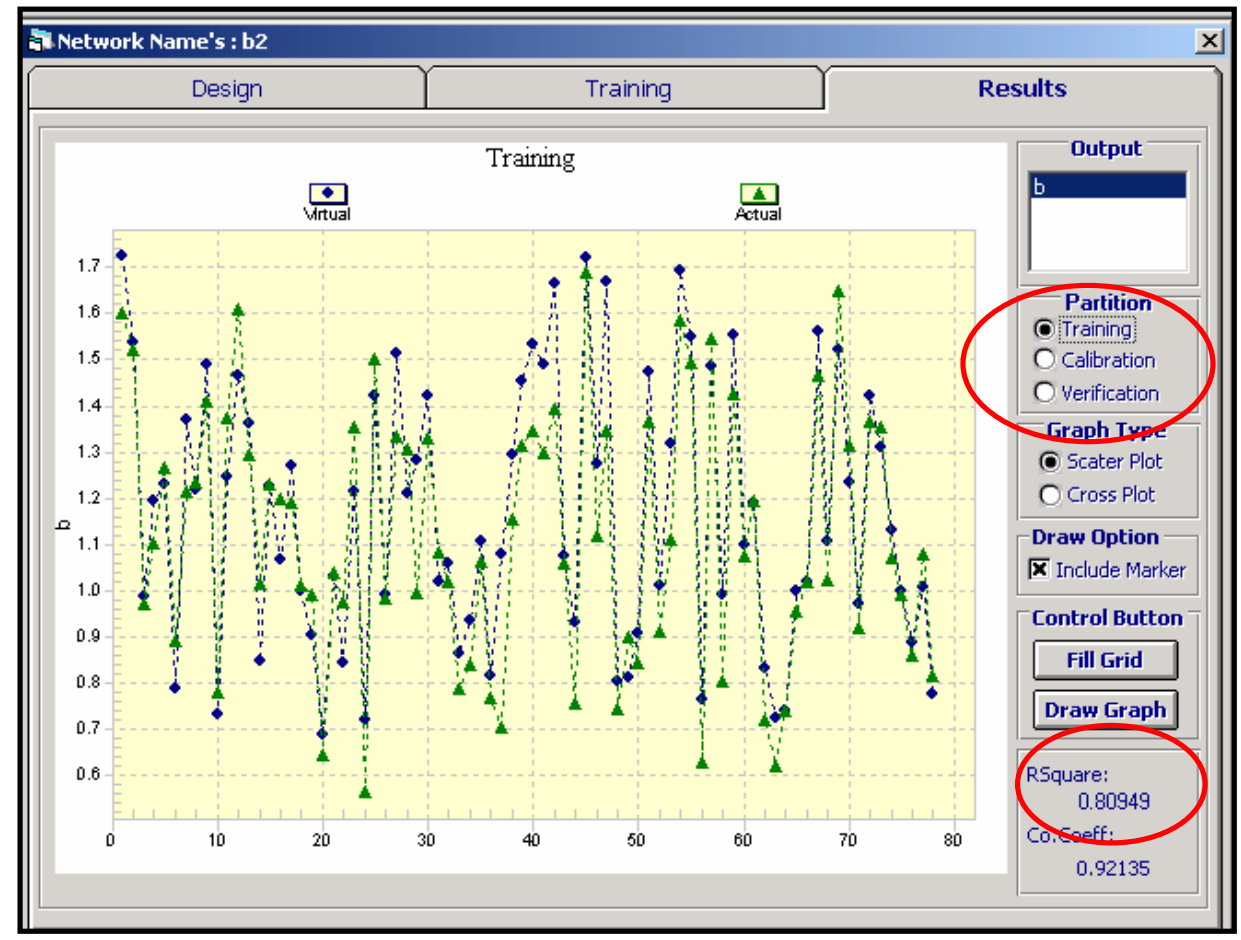

Figure 3.108 Training Data-Actual versus Virtual with Obtained R Square

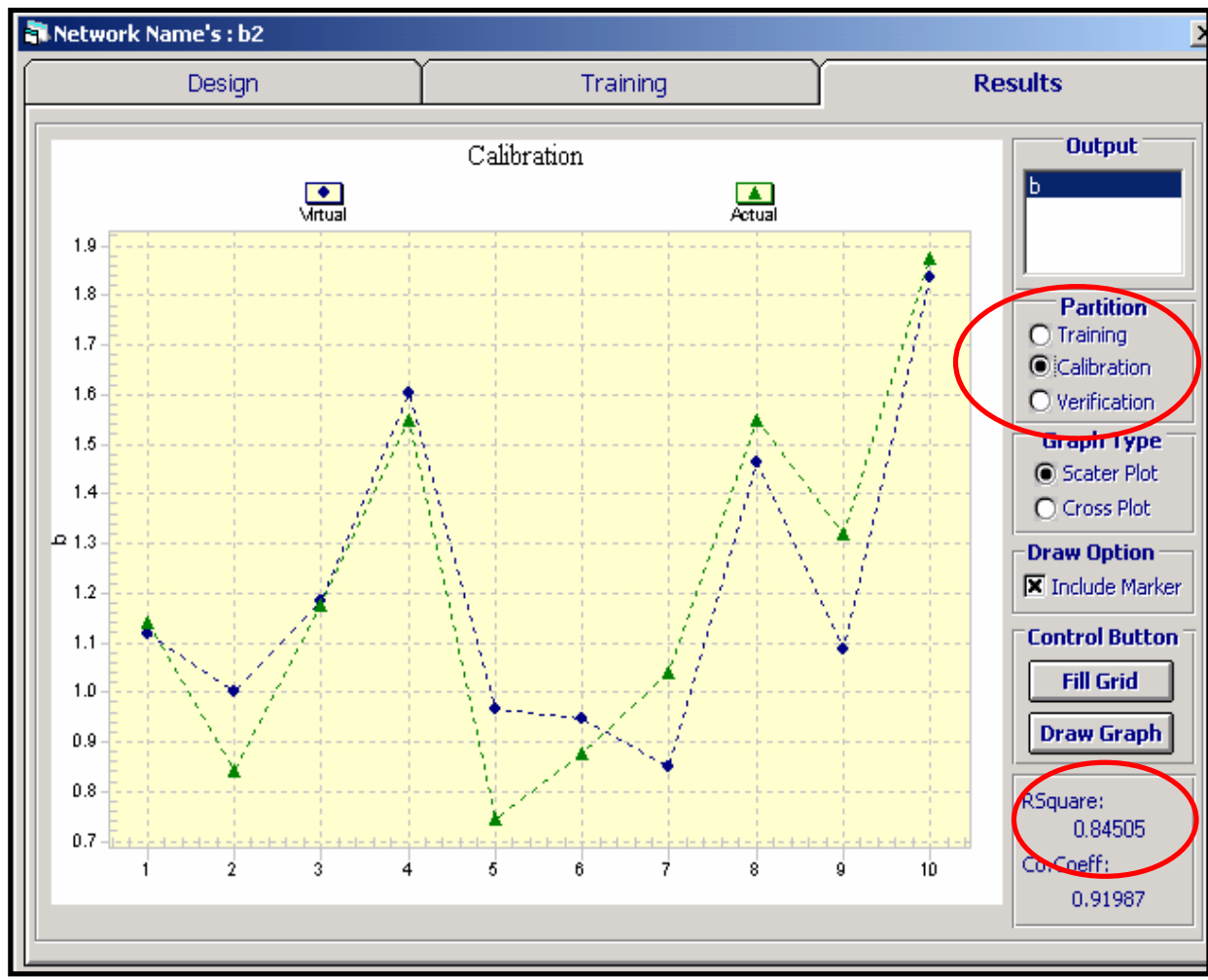

Figure 3.109 Verification Data-Actual versus Virtual with Obtained $\mathbf{R}$ Square 
This module provides a set of tools that allows you to use the neural network model and make simulation runs and answer important "What If" questions.

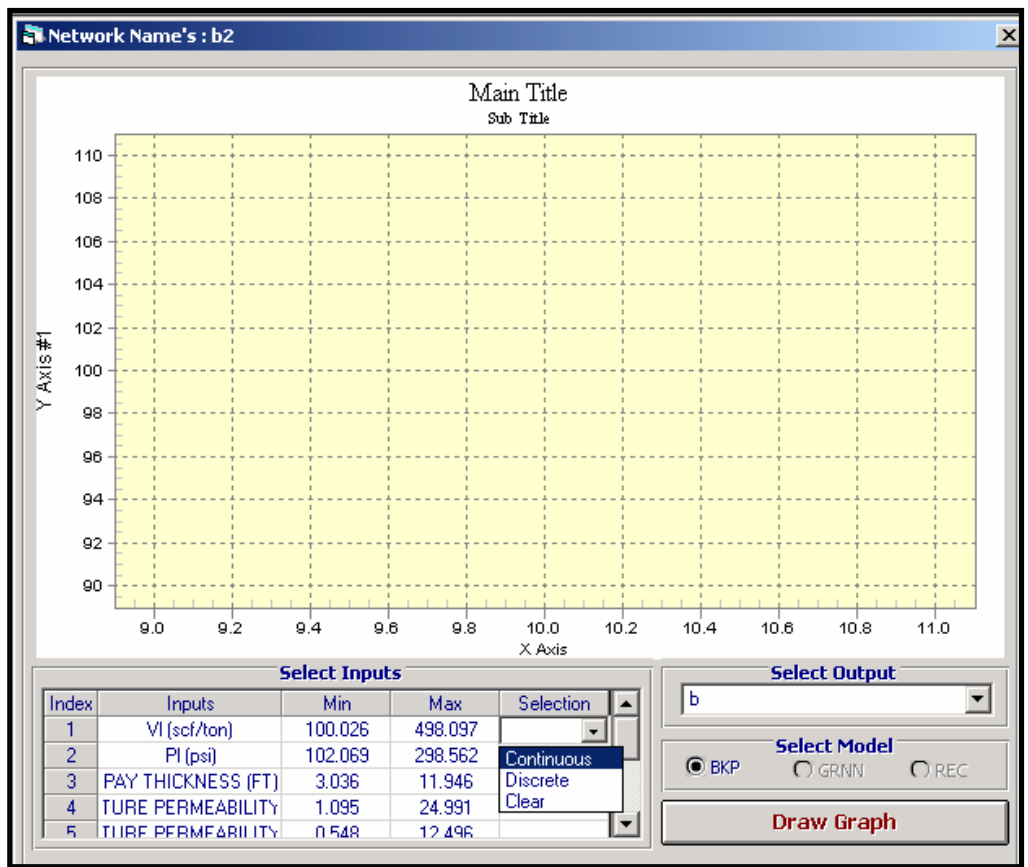

Figure 3.110 General Model Behavior Interface

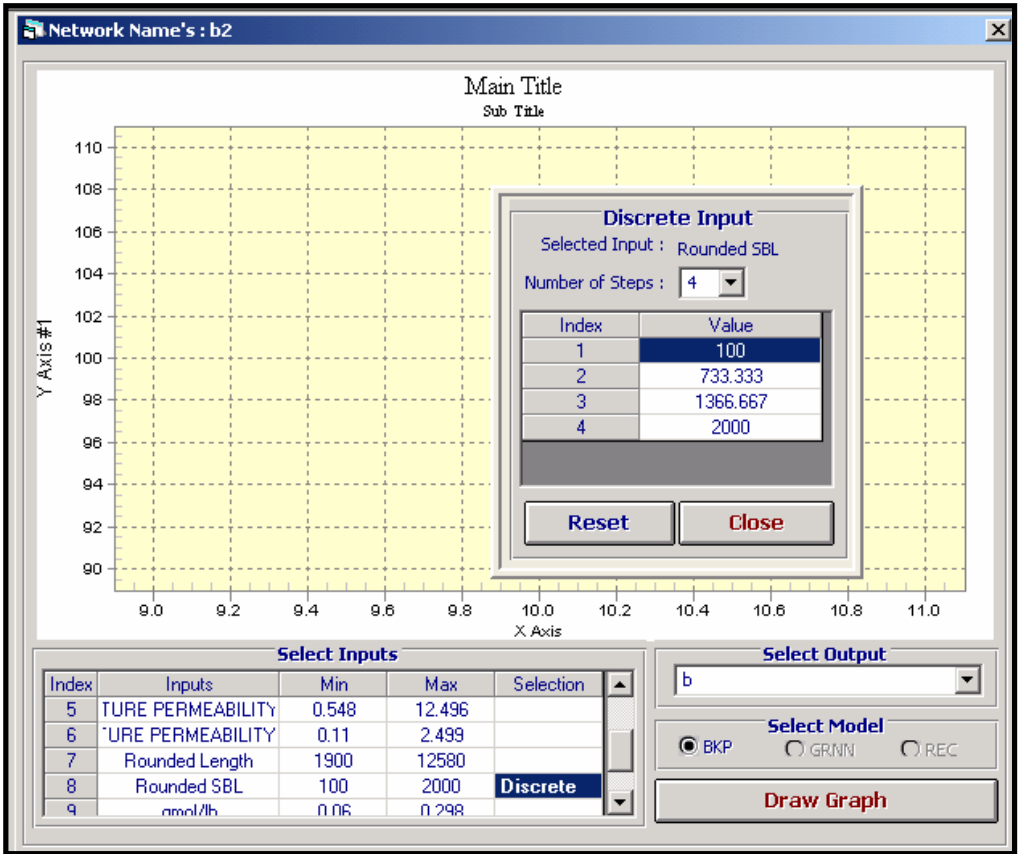

Figure 3.111 General Model Behavior Interface with the Discrete Option 


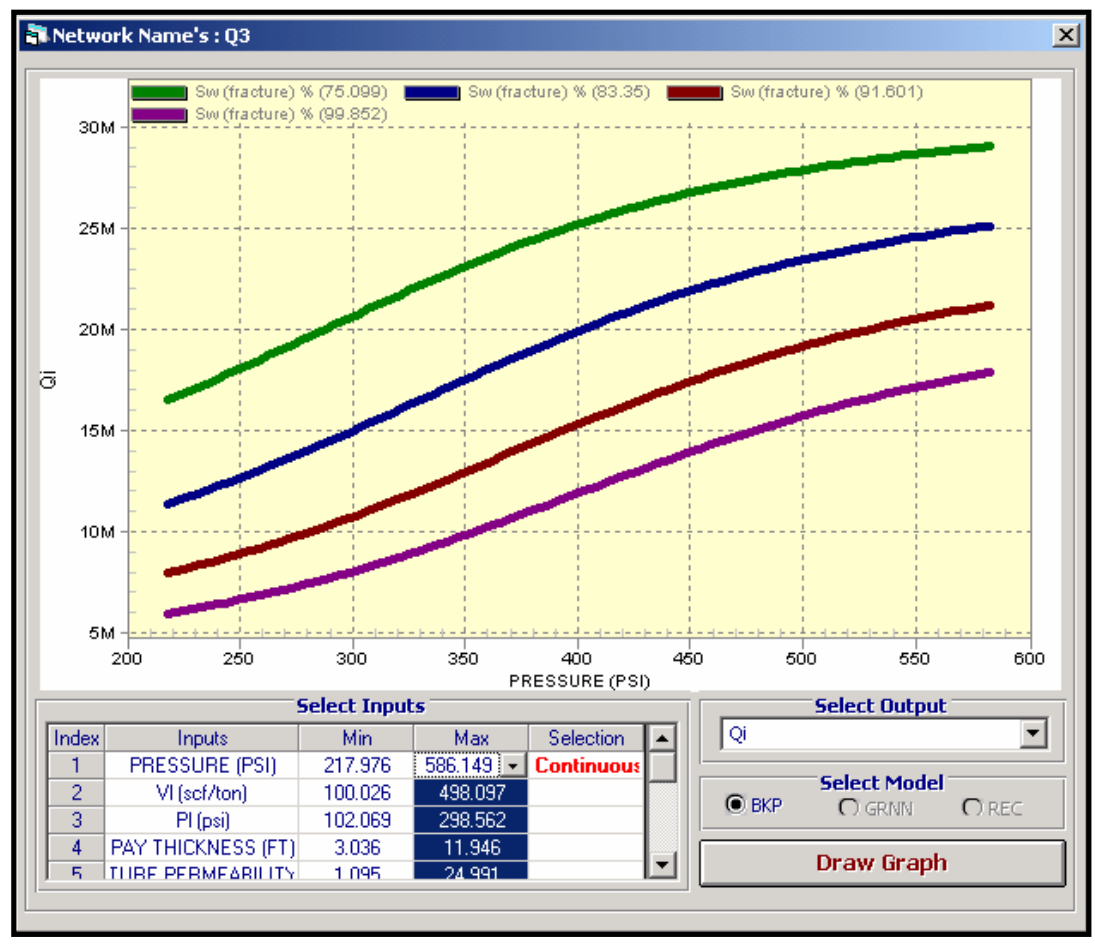

Figure 3.112 Four Curves represent Sw with Different Values, Plotted Pressure Versus Qi 


\section{CHAPTER IV. RESULTS AND DISCUSSIONS}

\subsection{Single lateral well example}

The goal of this study was to perform sensitivity and parametric analysis based on a variety of coal reservoir properties existing in the Appalachian Basin. In order to develop this research, two approaches took place and a high number of simulations were run. As a result, simulations provided us with valuable data used later in the intelligent approach.

Two different base reservoir models were created using the Cartesian system with horizontal wells, with kick off point location in the center of the model, and in the lower right corner. Investigated models represent a two-phase model with two-dimensional flows in a saturated reservoir condition. Both models take into account coal reservoir properties for the Appalachian Basin. In the first approach, sensitivity analysis took place, which investigated system behavior of changing horizontal well configuration. The second part of the first approach took into account simultaneous parametric analysis of both horizontal well configurations, and one of the 15 coal reservoir parameters.

The second approach comprises random generation of coal reservoir parameters, as well as horizontal well configurations including DCA performance, and AI to predict future performance. Output data from 500 simulation runs were tested and trained in order to predict the decline curve performance (b, Qi and Di) for different reservoirs having diverse horizontal well configurations.

The following table shows five different well configurations tested in this study to predict future performance of the Gas and Water production. Three outputs were tested (b,Qi and Di), creating 30 different Neural Network Models with different Architectures.

Also, the number of inputs is different for the different architecture in order to allow us obtaining the higher $\mathrm{R}^{2}$ value, which was ultimate goal.

\footnotetext{
$\mathbf{R}^{2}-\mathbf{T}-$ Testing

$\mathbf{R}^{2}$-C-Calibration

$\mathbf{R}^{\mathbf{2}}-\mathbf{V}$-Verification
} 
The following example will demonstrate the way that the Neural Network Model has been created. The example shown represents a Single lateral well for the gas production with the output "b". The same procedure has been applied to the rest of the wells for all 3 possible outputs, both for gas and water production. The following parameters have been calibrated and changed in order to obtain the best matching between real and predicted data:

1. Input;

3. Network Configuration;

2. Output;

4. Training Process.

\begin{tabular}{|c|c|}
\hline INPUT DATA & ATTRIBUTE \\
\hline Run No & ID \\
\hline Pressure (Psi) & Input \\
\hline $\mathrm{VI}$ (scf/ton) & Input \\
\hline $\mathrm{PI}(\mathrm{psi})$ & Input \\
\hline Pay Thickness (ft) & Input \\
\hline Fracture Permeability i (md) & Input \\
\hline Fracture Permeability j (md) & Input \\
\hline Fracture Permeability k (md) & Input \\
\hline Coal Desorption Time (days) & Input \\
\hline BHP (psi) & Input \\
\hline Grid Topdepth (ft) & Input \\
\hline Porosity Fracture (fr) & Input \\
\hline Sw (fracture) \% & Input \\
\hline Single Lateral Length (ft) & Input \\
\hline gmol/lb & Input \\
\hline $1 / \mathrm{psi}$ & Input \\
\hline Best 3 Months CUM & Not Used \\
\hline Best 6 Months CUM & Not Used \\
\hline Best 9 Months CUM & Not Used \\
\hline Best 12 Months CUM & Not Used \\
\hline First 3 Months CUM & Not Used \\
\hline First 6 Months CUM & Not Used \\
\hline First 9 Months CUM & Not Used \\
\hline First 1 Year CUM & Not Used \\
\hline First 3 Year CUM & Not Used \\
\hline First 5 Year CUM & Not Used \\
\hline First 10 Year CUM & Not Used \\
\hline Last Production & Not Used \\
\hline Cumulative & Not Used \\
\hline Qi & Not Used \\
\hline $\mathrm{Di}$ & Not Used \\
\hline b & Output \\
\hline
\end{tabular}

Table 4.1 Input/Not Used Data 
After determining the number of inputs and one output (in this case "b"), the existence of one outlier has been found. That outlier (data number 86), has been erased from the NN modeling process.

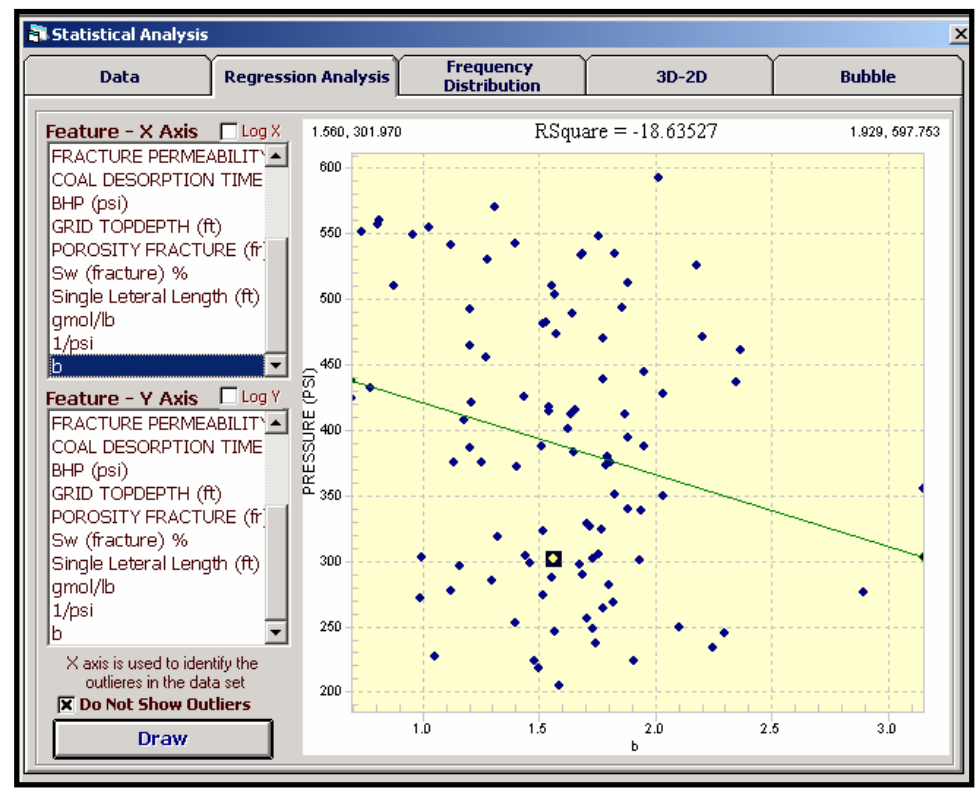

Figure 4.1 Searching for an Outlier

\begin{tabular}{|c|c|c|c|c|c|c|c|c|c|c|c|}
\hline \multicolumn{12}{|c|}{ A. Statistical Analysis } \\
\hline \multicolumn{2}{|c|}{ Data } & \multicolumn{3}{|c|}{ Regression Analysis } & \multicolumn{2}{|c|}{$\begin{array}{l}\text { Frequency } \\
\text { Distribution }\end{array}$} & \multicolumn{2}{|c|}{ 3D-2D } & \multicolumn{3}{|c|}{ Bubble } \\
\hline Index & RUN No & PRESS & VI & PI [psi] & PAY & FRACT & FRACT & FRACT & COAL & BHP & $\triangle$ \\
\hline Min & & 204.806 & 102.201 & 100.072 & 3.119 & 1.009 & 0.504 & 0.101 & 6.589 & 15.548 & \\
\hline Max & & 592.839 & 498.354 & 299.304 & 11.933 & 24.842 & 12.421 & 2.484 & 247.766 & 49.977 & \\
\hline Mean & & 388.594 & 297.553 & 200.702 & 7.612 & 12.913 & 6.456 & 1.291 & 128.453 & 35.343 & 1 \\
\hline STDV & & 105.569 & 101.453 & 59.012 & 2.653 & 7.316 & 3.658 & 0.732 & 71.181 & 10.162 & \\
\hline 77 & 77 & 373.166 & 213.577 & 206.023 & 10.482 & 12.903 & 6.4515 & 1.2903 & 43.174 & 49.84 & 3 \\
\hline 78 & 78 & 549.413 & 136.861 & 280.557 & 9.83 & 7.335 & 3.6675 & 0.7335 & 111.969 & 32.899 & 5 \\
\hline 79 & 79 & 272.151 & 309.833 & 296.819 & 3.6 & 15.954 & 7.977 & 1.5954 & 247.766 & 31.581 & 8 \\
\hline 80 & 80 & 417.434 & 427.379 & 227.91 & 6.84 & 19.037 & 9.5185 & 1.9037 & 69.655 & 25.078 & 9 \\
\hline 81 & 81 & 548.316 & 337.442 & 296.25 & 8.288 & 4.564 & 2.282 & 0.4564 & 109.145 & 43.006 & 3 \\
\hline 82 & 82 & 530.4 & 213.139 & 187.282 & 3.818 & 18.266 & 9.133 & 1.8266 & 23.447 & 20.601 & 9 \\
\hline 83 & 83 & 281.387 & 347.847 & 191.214 & 8.666 & 6.959 & 3.4795 & 0.6959 & 53.639 & 24.177 & 6 \\
\hline 84 & 84 & 551.033 & 184.1 & 206.55 & 10.121 & 19.604 & 9.802 & 1.9604 & 155.353 & 41.269 & 4 \\
\hline 85 & 85 & 268.89 & 264.098 & 223.698 & 8.979 & 5.86 & 2.93 & 0.586 & 110.125 & 43.928 & 3 \\
\hline 86 & 86 & 442.961 & 252.506 & 112.656 & 9.245 & 18.025 & 9.0125 & 1.8025 & 34.539 & 41.217 & 5 \\
\hline 87 & 87 & 248.999 & 412.297 & 193.612 & 6.217 & 1.544 & 0.772 & 0.1544 & 47.004 & 48.664 & 8 \\
\hline 88 & 88 & 299.033 & 267.934 & 139.05 & 4.62 & 18.529 & 9.2645 & 1.8529 & 126.207 & 47.753 & 6 \\
\hline 89 & 89 & 374.952 & 498.354 & 293.651 & 7.905 & 1.499 & 0.7495 & 0.1499 & 141.773 & 40.046 & 9 \\
\hline 90 & 90 & 289.954 & 371.39 & 294.535 & 10.314 & 2.497 & 1.2485 & 0.2497 & 162.368 & 37.096 & 6 \\
\hline 91 & 91 & 503.527 & 342.562 & 107.442 & 9.854 & 18.415 & 9.2075 & 1.8415 & 140.848 & 48.273 & 7 \\
\hline 92 & 92 & 245.733 & 450.976 & 279.77 & 3.809 & 5.518 & 2.759 & 0.5518 & 109.04 & 27.365 & 8 \\
\hline 93 & 93 & 560.08 & 184.474 & 252.216 & 3.903 & 20.276 & 10.138 & 2.0276 & 153.559 & 46.453 & 7 \\
\hline 94 & 94 & 482.438 & 261.614 & 207.685 & 4.243 & 7.43 & 3.715 & 0.743 & 215.661 & 39.899 & 5 \\
\hline 95 & 95 & 542.65 & 470.602 & 197.268 & 6.923 & 22.298 & 11.149 & 2.2298 & 180.445 & 30.253 & 6 \\
\hline $1^{\circ 0}$ & oc & $2007 C K$ & 271027 & $20 A \cap A A$ & $070 ?$ & 13020 & $C \operatorname{CSCF}$ & 10303 & $1307 x$ & 1) 775 & \\
\hline Note: Dout & ble Click & ellt & onve the & & & Reset & & $\square \mathrm{Ou}$ & & $\square$ Mis & \\
\hline
\end{tabular}

Figure 4.2 Outlier Is Excluded From an NN Modeling 
The number of inputs was 15 at the beginning. However, after analyzing the parameters' influence, the four parameters from the bottom of the list (parameters with the least influence) have been removed from the future calculation.

\begin{tabular}{|l|l|l|}
\hline No. & \multicolumn{1}{|c|}{ PARAMETER } & \multicolumn{1}{c|}{ STATUS } \\
\hline 1 & Single Lateral Length (ft) & Used \\
\hline 2 & Fracture Permeability i (md) & Used \\
\hline 3 & Fracture Permeability j (md) & Used \\
\hline 4 & Fracture Permeability k (md) & Used \\
\hline 5 & BHP (psi) & Used \\
\hline 6 & Pressure (Psi) & Used \\
\hline 7 & Coal Desorption Time (days) & Used \\
\hline 8 & Porosity Fracture (fr) & Used \\
\hline 9 & Sw (fracture) \% & Used \\
\hline 10 & $1 /$ psi & Used \\
\hline 11 & Pay Thickness (ft) & Used \\
\hline$\underline{12}$ & gmol/lb & $\underline{\text { NOT Used }}$ \\
\hline$\underline{13}$ & $\underline{\text { Vl (scf/ton) }}$ & $\underline{\text { NOT Used }}$ \\
\hline$\underline{14}$ & $\underline{\text { Pl (psi) }}$ & $\underline{\text { NOT Used }}$ \\
\hline$\underline{15}$ & $\underline{\text { Grid Topdepth (ft) }}$ & $\underline{ }$ \\
\hline & & \\
\hline
\end{tabular}

Table 4.2 Used and Not Used Input Parameters

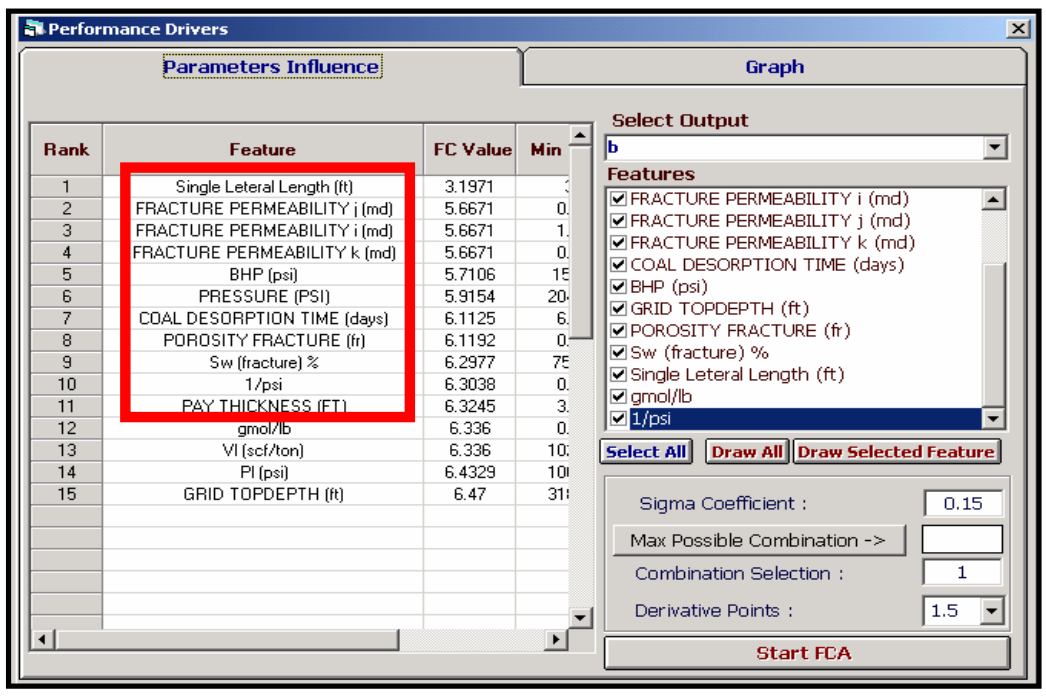

Figure 4.3 Used and Not Used Input Parameters 
The set of input data has been divided into 3 clusters having 12, 60 and 27 data for each cluster.

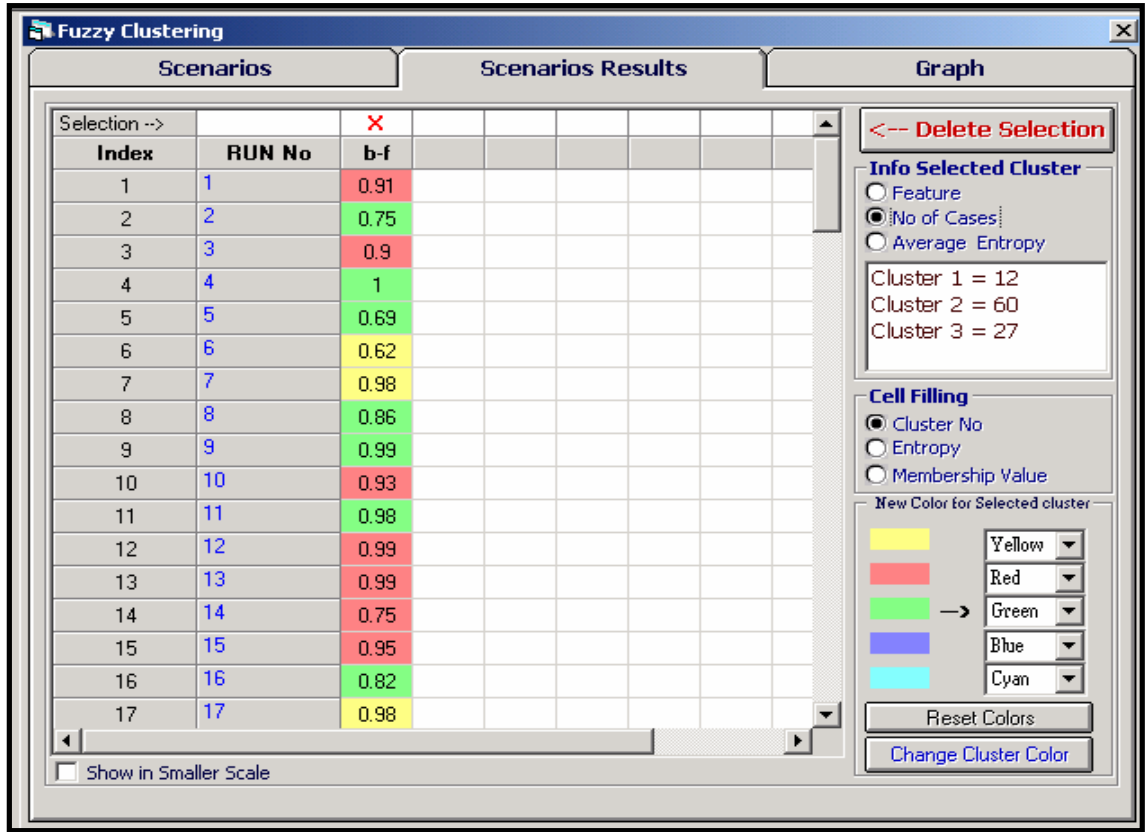

Figure 4.4 Scenario Results-Clusters

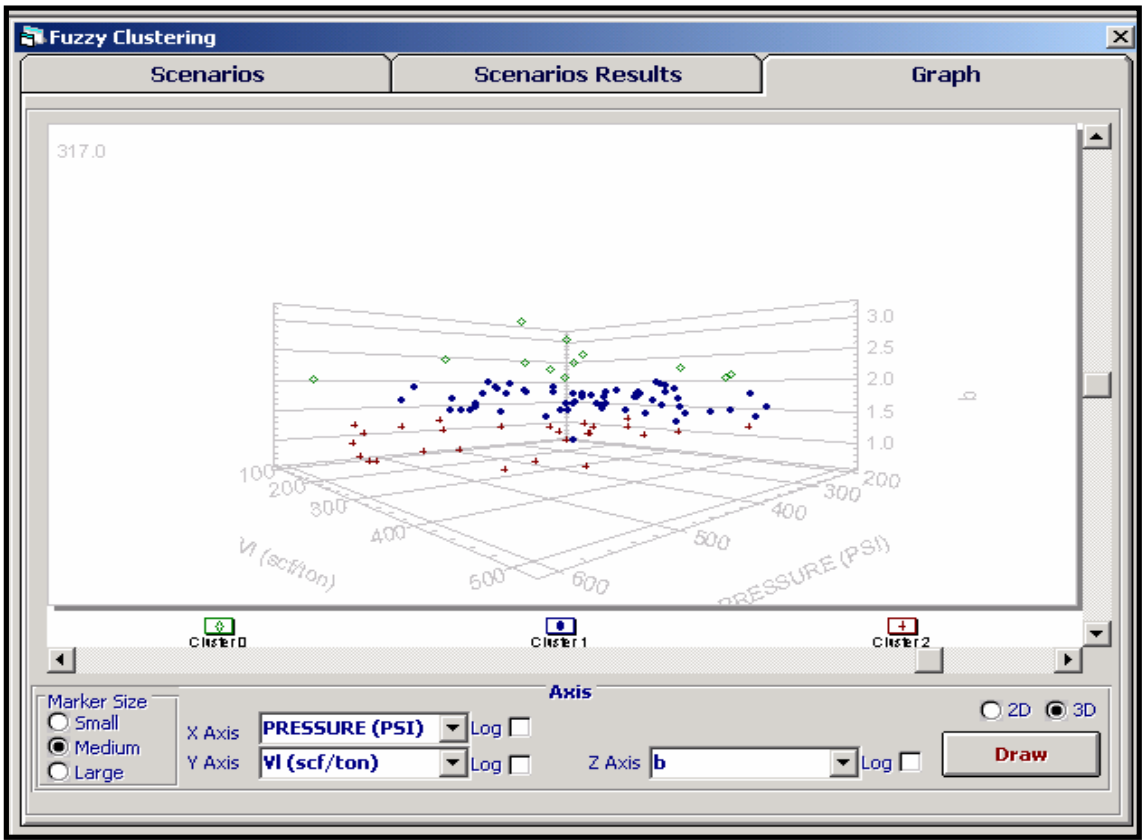

Figure 4.5 Scenario Results-Clusters 3D View 
In this case, $80 \%$ of data were used for Training, $10 \%$ for Calibration and $10 \%$ for Verification. Having 100 data as input, it gives us 80 data for Training (excluding one as an outlier equals to 79), 10 data for calibration, and the same number for verification. The number of data is pretty much uniform, taking into account the percentage of data used for Training testing and Calibration. As a result, the average entropies are very close to each other, having results, 0.149 for Training, 0.148 for Calibration, and 0.086 for Verification.

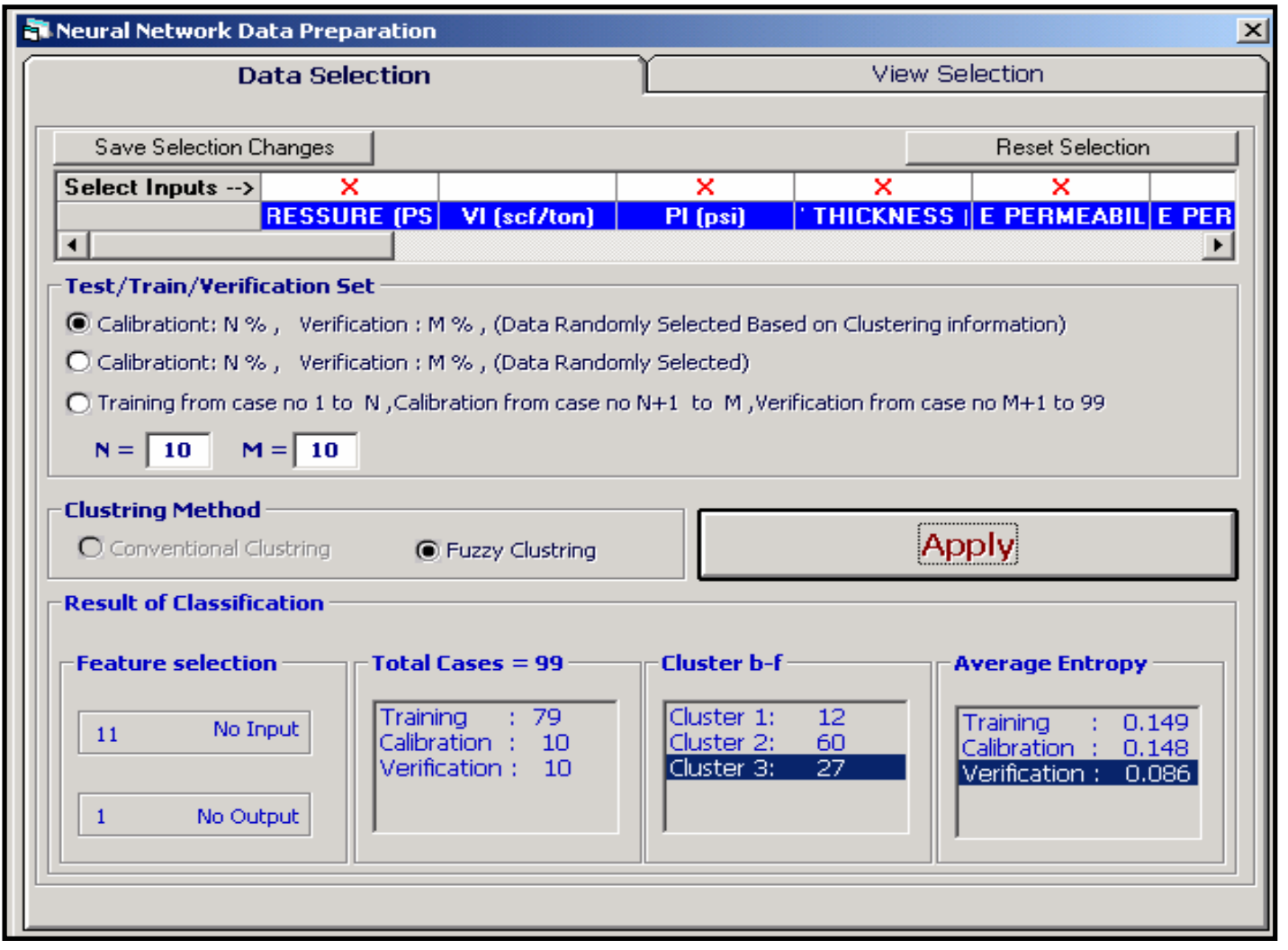

Figure 4.6 Neural Network Data Preparation 
For the different cases, a different $\mathrm{NN}$ architecture was used. As mentioned above, out of 15 maximum inputs, 11 were used in the Input layer. Changing the number of neurons in the hidden layer, it turns out that the most effective number that provides us with the highest $\mathrm{R}^{2}$, for this case is 12 , with the random seed number of one. However, in the whole study, the range of neurons in hidden layers was from a minimum of 7 to a maximum of 18, and the range for random seed numbers was from 1 to 3 . Each time when results were not accurate enough, these numbers were corrected. Concerning the momentum in Input and Output hidden layer, in this case the number was kept the same, 0.3. However, the maximum value used in the study was 0.9 , and it varies from case to case.

Changing the speed of learning rate can significantly improve the final results. Again 0.9 was the maximum speed of the learning rate, for both Hidden Input and Hidden Output layers. For this purpose, that speed has been lowered to 0.05 , which slows the learning rate significantly, and the time needed for obtaining good results is longer. However, changing all these parameters, and adjusting the learning speed to a slow 0.05 , turned into very good results at the end.

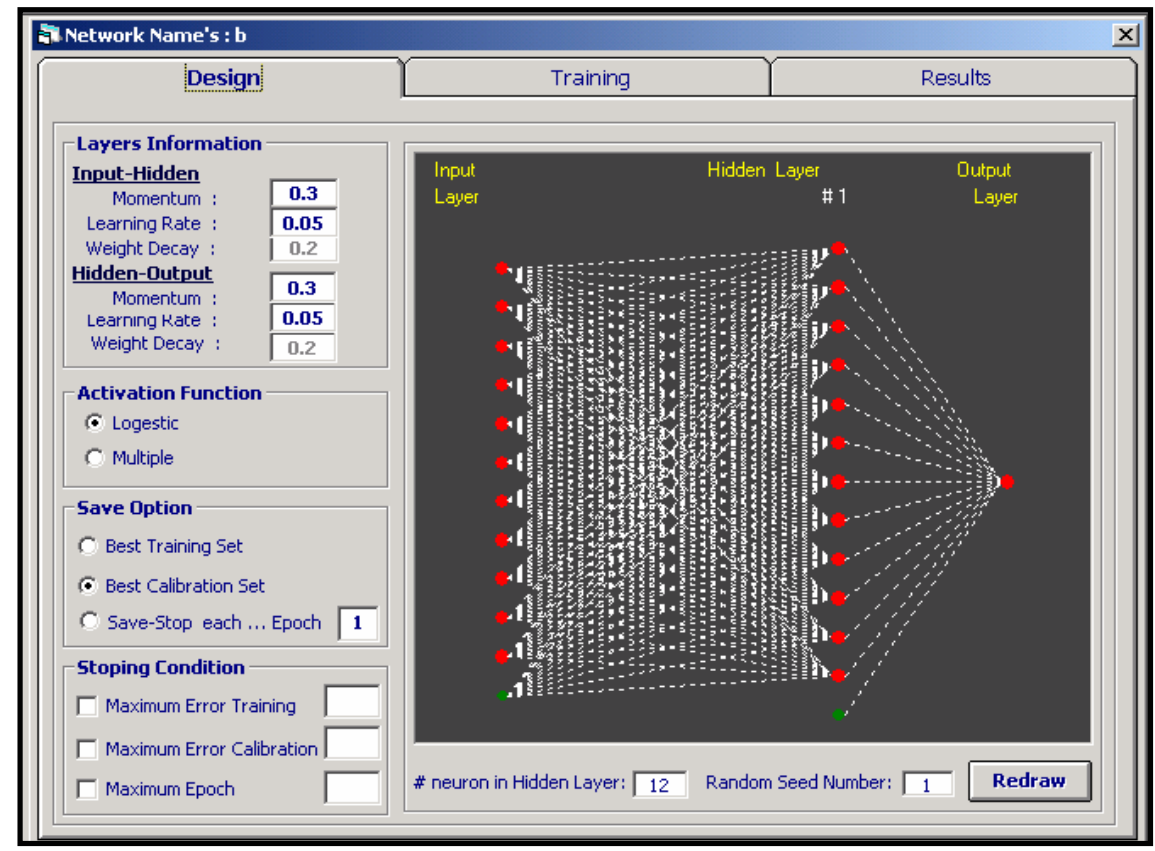

Figure 4.7 Neural Net Architecture Used in this Example 


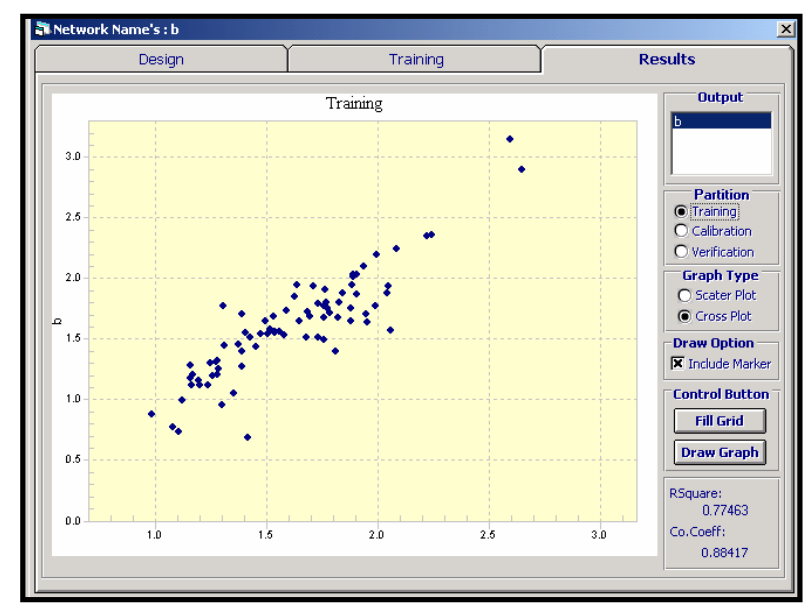

Figure 4.8 Cross Plot of Training Data Showing Accuracy of 0.78

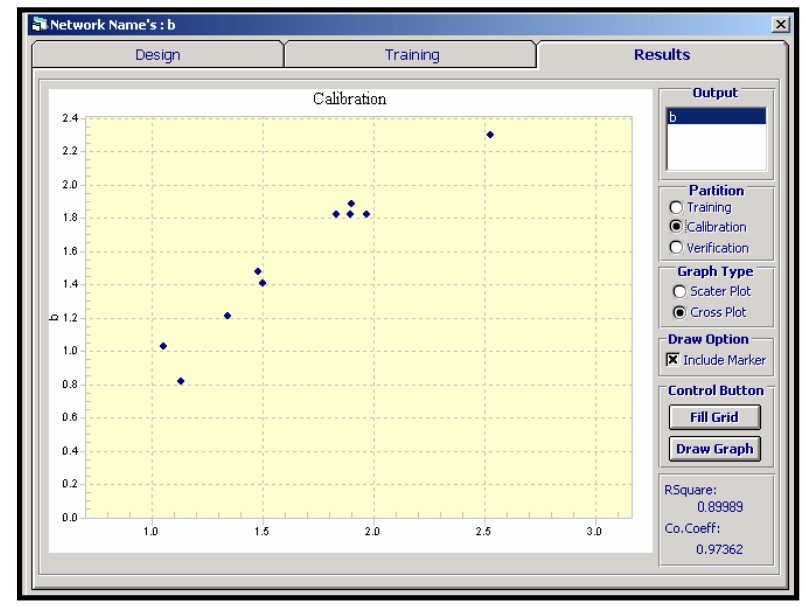

Figure 4.9 Cross Plot of Calibration Data Showing Accuracy of 0.89

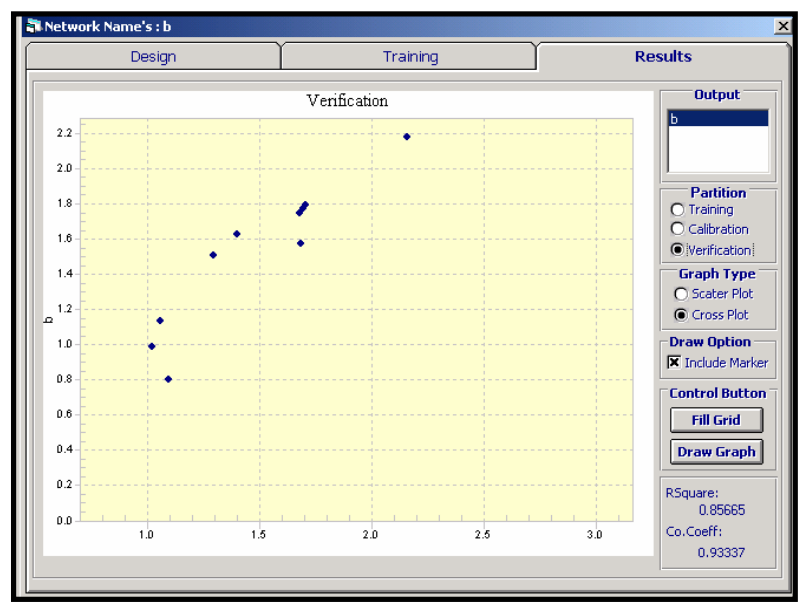

Figure 4.10 Cross Plot of Verification Data Showing Accuracy of 0.85 


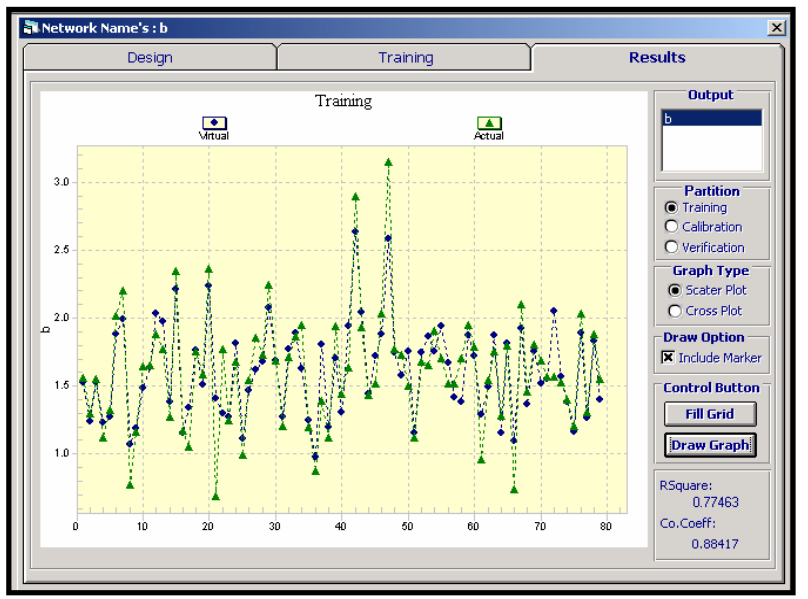

Figure 4.11 Cross Plot of Training Data Showing Accuracy of 0.77

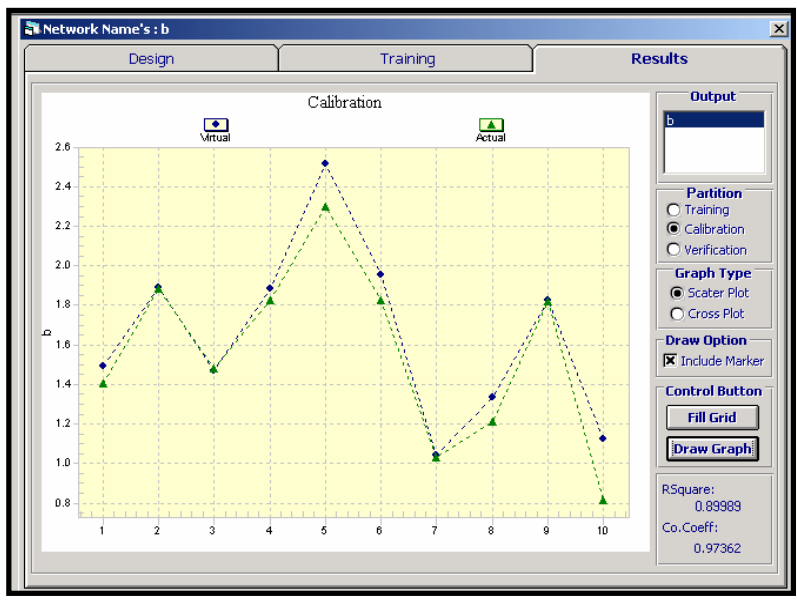

Figure 4.12 Cross Plot of Calibration Data Showing Accuracy of 0.89

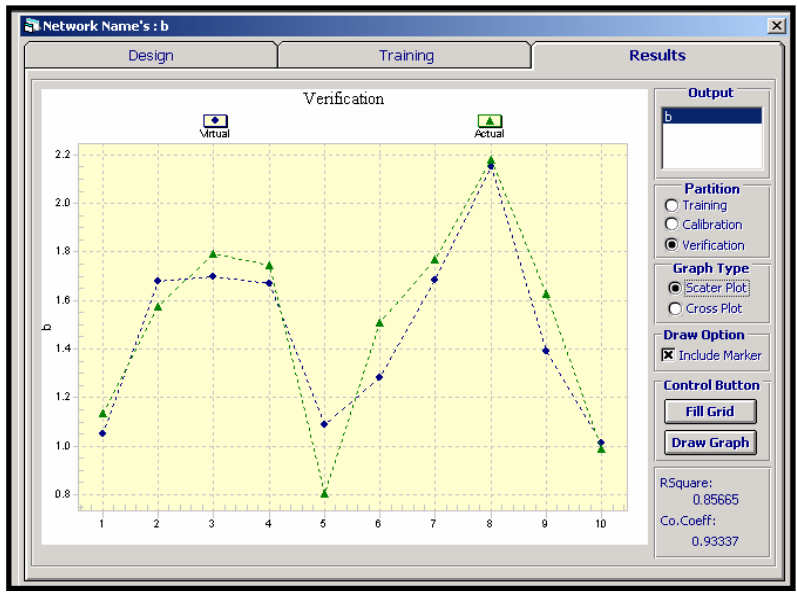

Figure 4.13 Cross Plot of Verification Data Showing Accuracy of 0.85 


\subsection{Intelligent Modeling Results}

The following table shows all the results for the 30 Neural Network Models created in this study.

\begin{tabular}{|c|c|c|c|c|c|c|c|}
\hline No & Well Configuration & Gas/Water & Output & Number of Inputs & R2-T & R2-C & R2-V \\
\hline 1 & Single lateral & Gas & $\mathrm{b}$ & 11 & 0.77 & 0.89 & $\mathbf{0 . 8 5}$ \\
\hline 2 & Single lateral & Gas & Di & 6 & 0.9 & 0.89 & $\mathbf{0 . 8 9}$ \\
\hline 3 & Single lateral & Gas & Qi & 15 & 0.9 & 0.9 & 0.73 \\
\hline 4 & Single lateral & Water & $\mathrm{b}$ & 9 & 0.5 & 0.5 & 0.91 \\
\hline 5 & Single lateral & Water & Di & 9 & 0.95 & 0.42 & 0.70 \\
\hline 6 & Single lateral & Water & Qi & 9 & 0.86 & 0.68 & 0.75 \\
\hline 7 & Dual lateral & Gas & $\mathrm{b}$ & 14 & 0.66 & 0.78 & 0.88 \\
\hline 8 & Dual lateral & Gas & Di & 14 & 0.89 & 0.76 & 0.88 \\
\hline 9 & Dual lateral & Gas & Qi & 14 & 0.91 & 0.68 & 0.88 \\
\hline 10 & Dual lateral & Water & $\mathrm{b}$ & 14 & 0.73 & 0.73 & 0.91 \\
\hline 11 & Dual lateral & Water & $\mathrm{Di}$ & 16 & 0.99 & 0.89 & $\mathbf{0 . 8 3}$ \\
\hline 12 & Dual lateral & Water & $\mathrm{Qi}$ & 13 & 0.89 & 0.80 & 0.82 \\
\hline 13 & Trilateral & Gas & $\mathrm{b}$ & 10 & 0.98 & 0.42 & 0.70 \\
\hline 14 & Trilateral & Gas & Di & 15 & 0.84 & 0.6 & 0.86 \\
\hline 15 & Trilateral & Gas & Qi & 12 & 0.90 & 0.63 & 0.89 \\
\hline 16 & Trilateral & Water & $\mathrm{b}$ & 11 & 0.88 & 0.85 & 0.87 \\
\hline 17 & Trilateral & Water & $\mathrm{Di}$ & 15 & 0.85 & 0.80 & $\mathbf{0 . 8 3}$ \\
\hline 18 & Trilateral & Water & Qi & 11 & 0.88 & 85 & 0.86 \\
\hline 19 & Quad lateral & Gas & $\mathrm{b}$ & 10 & 0.67 & 0.88 & 0.85 \\
\hline 20 & Quad lateral & Gas & $\mathrm{Di}$ & 10 & 0.9 & 0.87 & $\mathbf{0 . 8 3}$ \\
\hline 21 & Quad lateral & Gas & $\mathrm{Qi}$ & 10 & 0.71 & 0.62 & 0.74 \\
\hline 22 & Quad lateral & Water & $\mathrm{b}$ & 10 & 0.88 & 0.85 & 0.8 \\
\hline 23 & Quad lateral & Water & $\mathrm{Di}$ & 10 & 0.80 & 0.79 & $\mathbf{0 . 8 7}$ \\
\hline 24 & Quad lateral & Water & $\mathrm{Qi}$ & 10 & 0.84 & 0.84 & 0.93 \\
\hline 25 & Pinnate & Gas & $\mathrm{b}$ & 13 & 0.86 & 0.84 & 0.81 \\
\hline 26 & Pinnate & Gas & $\mathrm{Di}$ & 8 & 0.88 & 0.83 & 0.87 \\
\hline 27 & Pinnate & Gas & $\mathrm{Qi}$ & 14 & 0.69 & 0.96 & 0.84 \\
\hline 28 & Pinnate & Water & $\mathrm{b}$ & 10 & 0.93 & 0.87 & $\mathbf{0 . 8 3}$ \\
\hline 29 & Pinnate & Water & $\mathrm{Di}$ & 10 & 0.96 & 0.81 & 0.81 \\
\hline 30 & Pinnate & Water & Qi & 11 & 0.93 & 0.67 & 0.87 \\
\hline
\end{tabular}

Table 4.3 Training, Calibration and Verification Results

The next 30 Graphs show only verification results for all well configurations, both for gas and water productions, for b, Qi and Di outputs, respectively. 


\section{Results-Graphs- Single laterals}

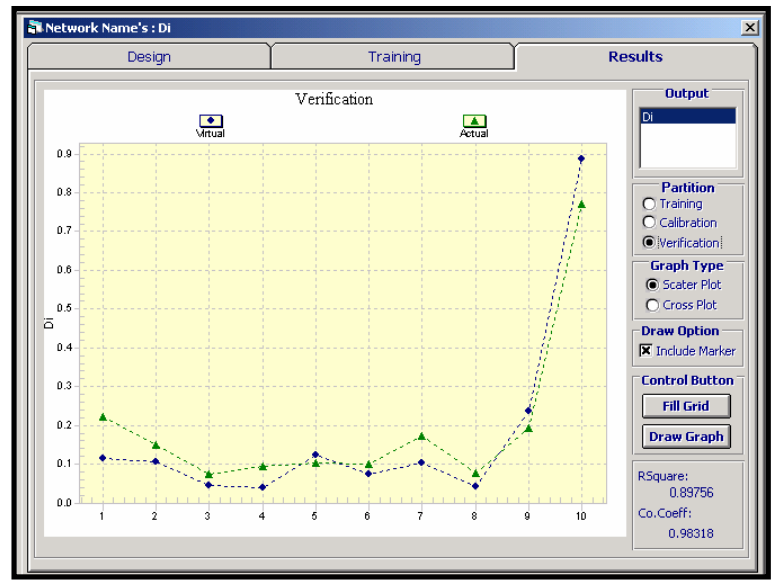

Figure 4.14 Single Lateral Well Verification Results for the Output "b"-Gas

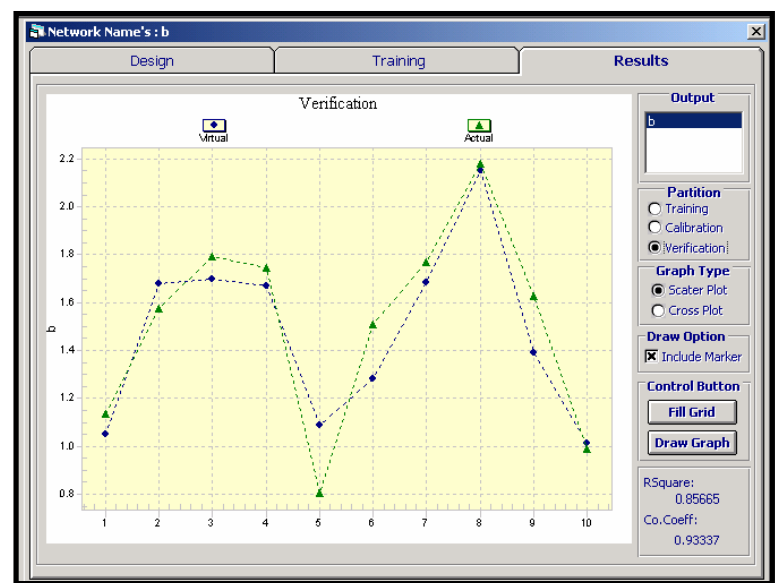

Figure 4.15 Single Lateral Well Verification Results for the Output "Di'- Gas

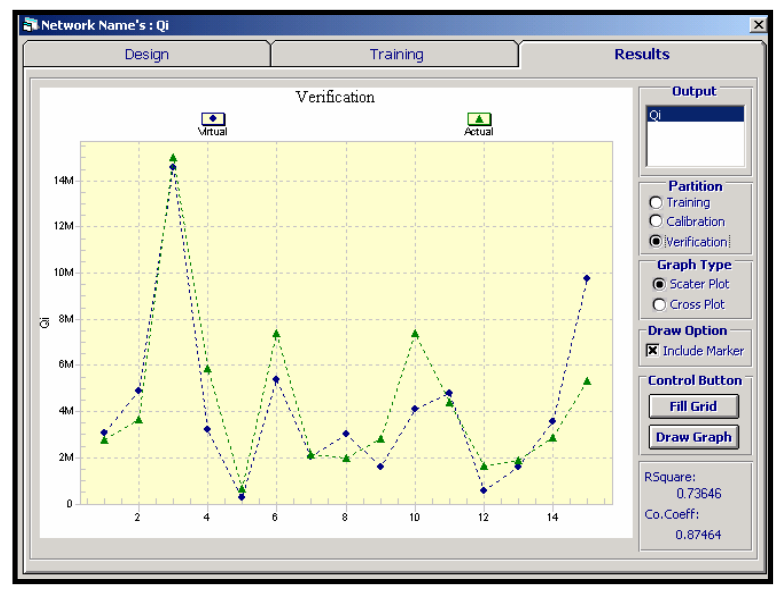

Figure 4.16 Single Lateral Well Verification Results for the Output “Qi”- Gas 


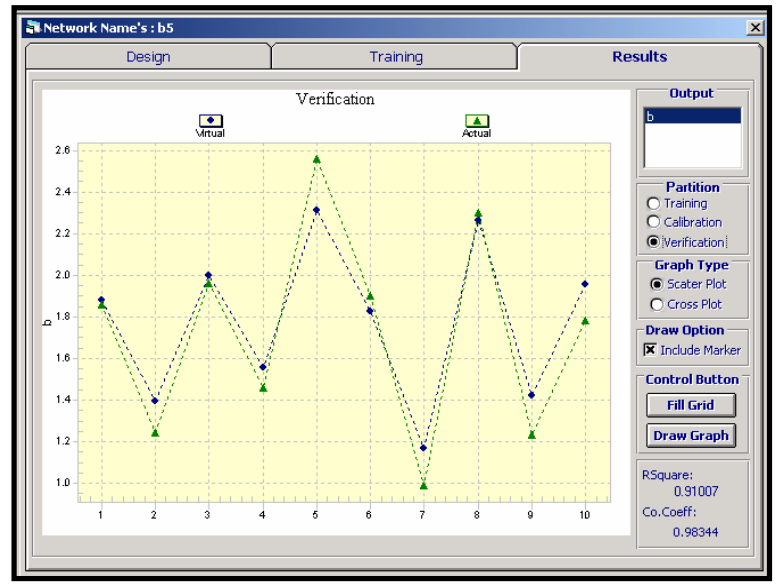

Figure 4.17 Single Lateral Well Verification Results for the Output “b”- Water

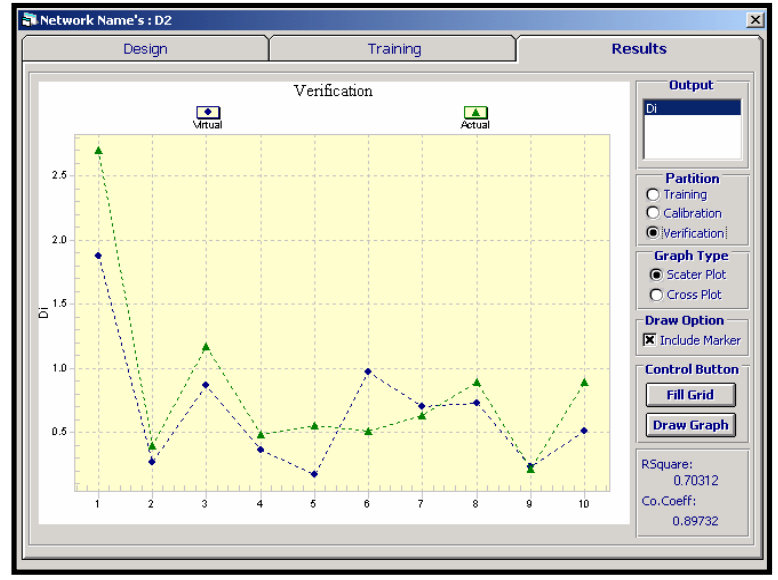

Figure 4.18 Single Lateral Well Verification Results for the Output "Di"- Water

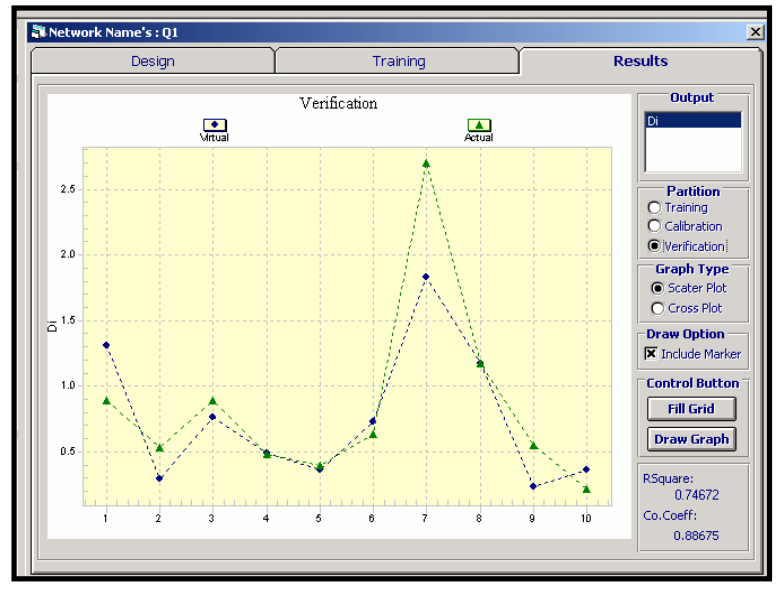

Figure 4.19 Single Lateral Well Verification Results for the Output "Qi”- Water 


\section{Results-Graphs- Dual laterals}

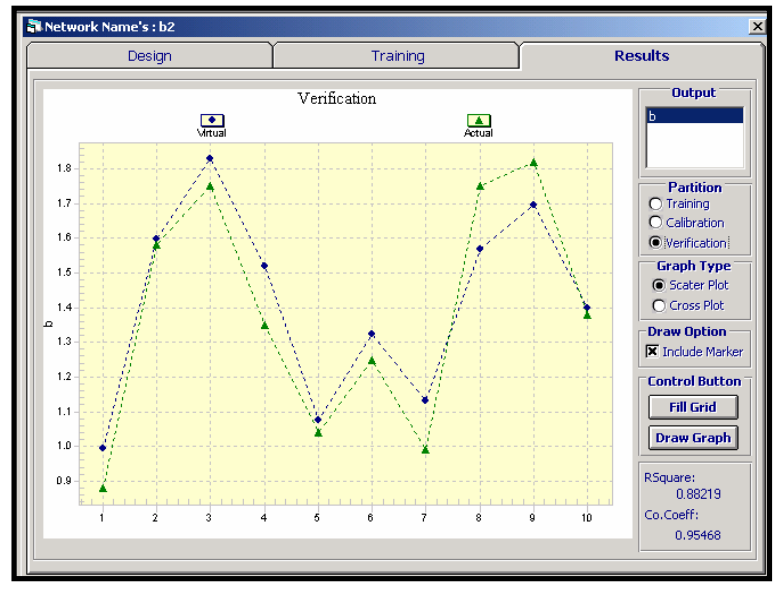

Figure 4.20 Dual Lateral Well Verification Results for the Output "b"-Gas

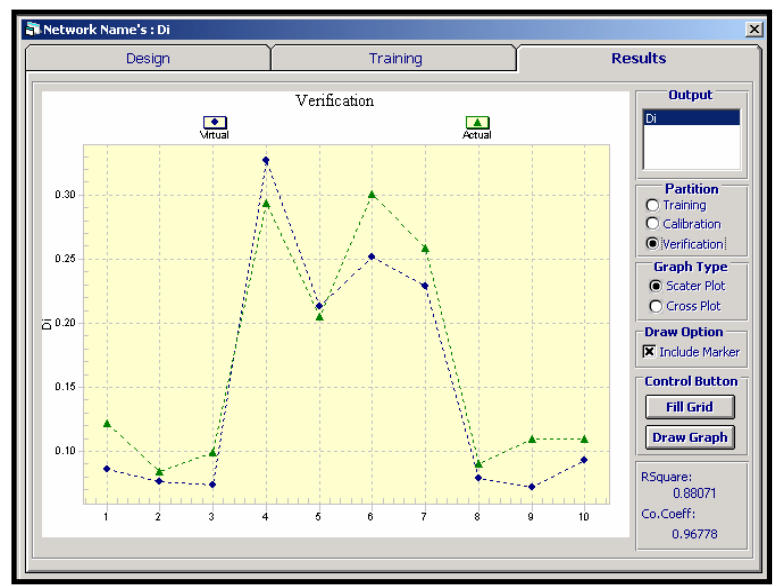

Figure 4.21 Dual Lateral Well Verification Results for the Output "Di"-Gas

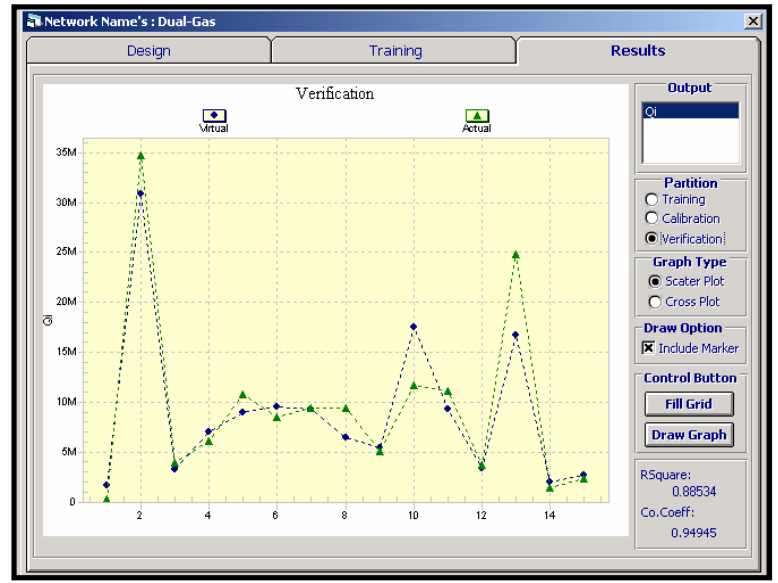

Figure 4.22 Dual Lateral Well Verification Results for the Output “Qi”-Gas 


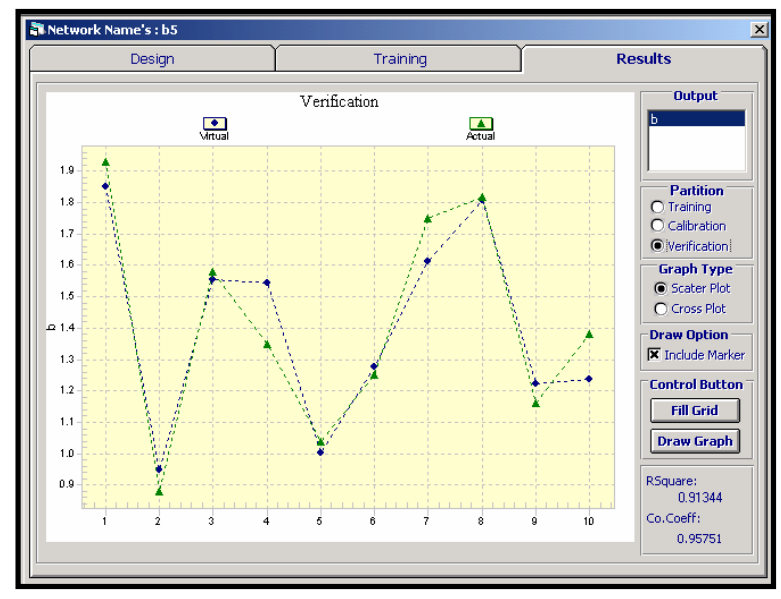

Figure 4.23 Dual Lateral Well Verification Results for the Output "b"-Water

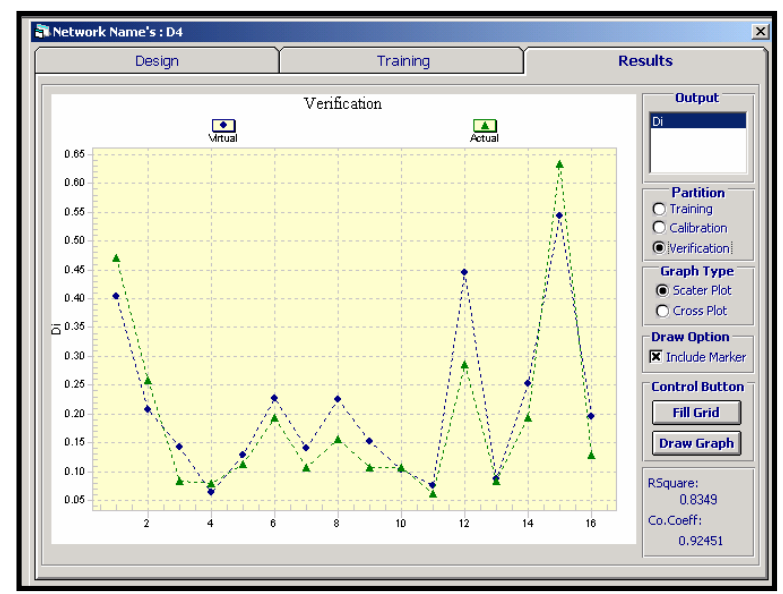

Figure 4.24 Dual Lateral Well Verification Results for the Output "Di"Water

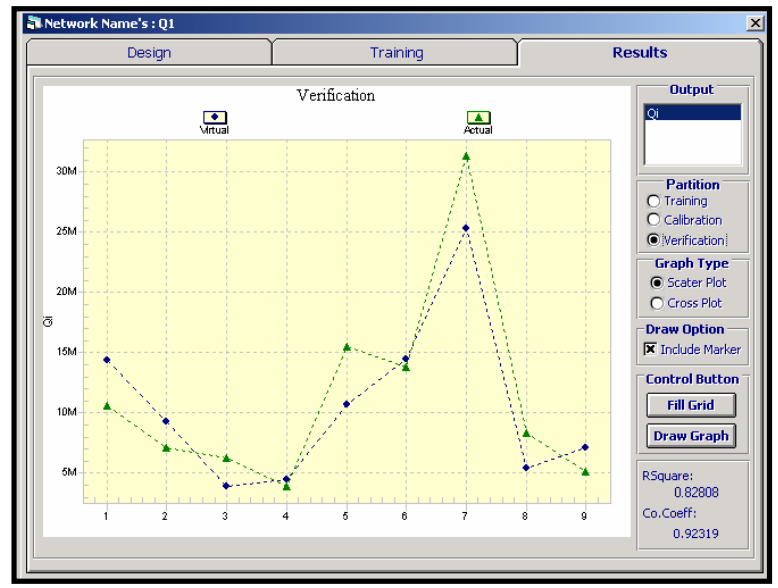

Figure 4.25 Dual Lateral Well Verification Results for the Output “Qi”-Water 


\section{Results-Graphs- Tri laterals}

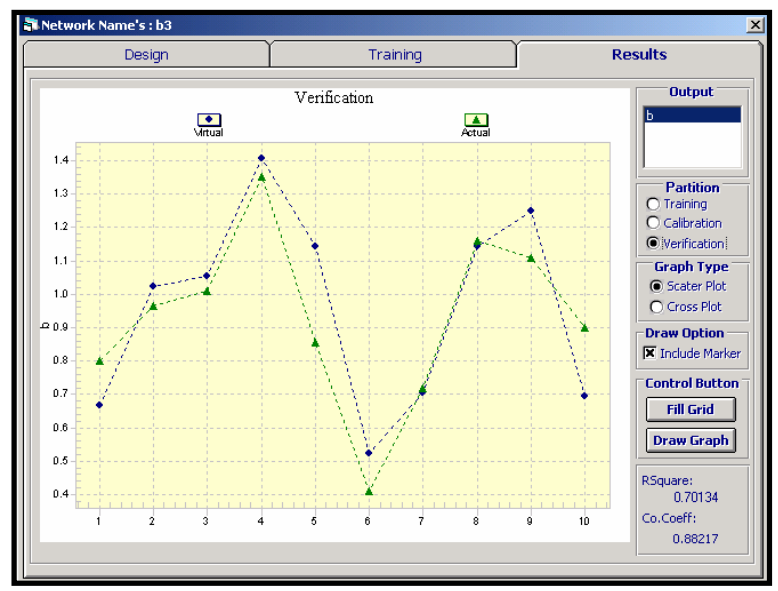

Figure 4.26 Tri Lateral Well Verification Results for the Output "b"-Gas

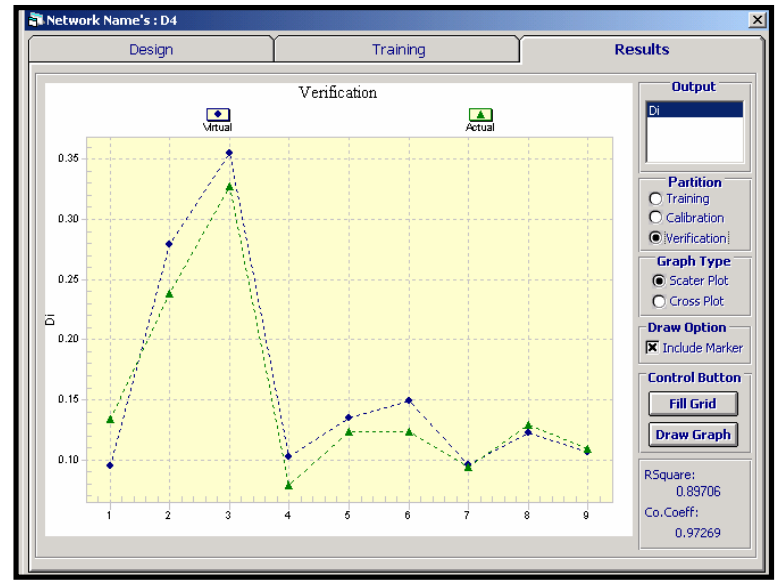

Figure 4.27 Tri Lateral Well Verification Results for the Output 'Di”-Gas

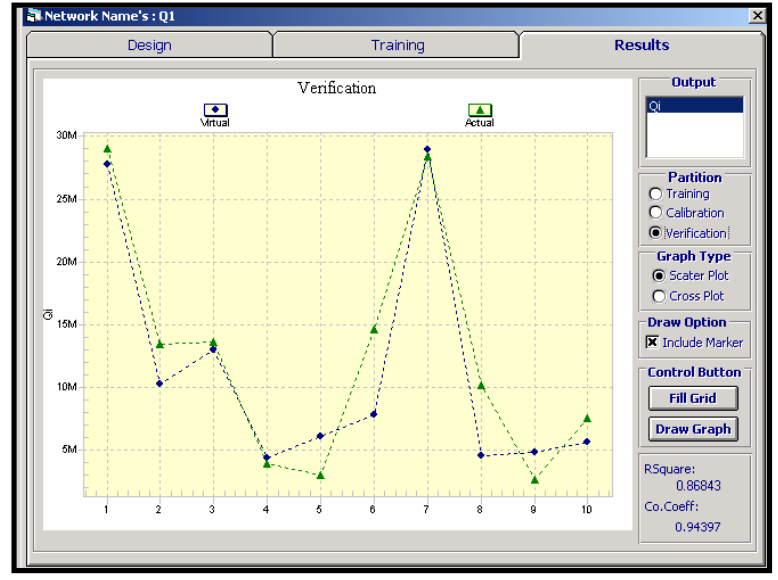

Figure 4.28 Tri Lateral Well Verification Results for the Output “Qi”-Gas 


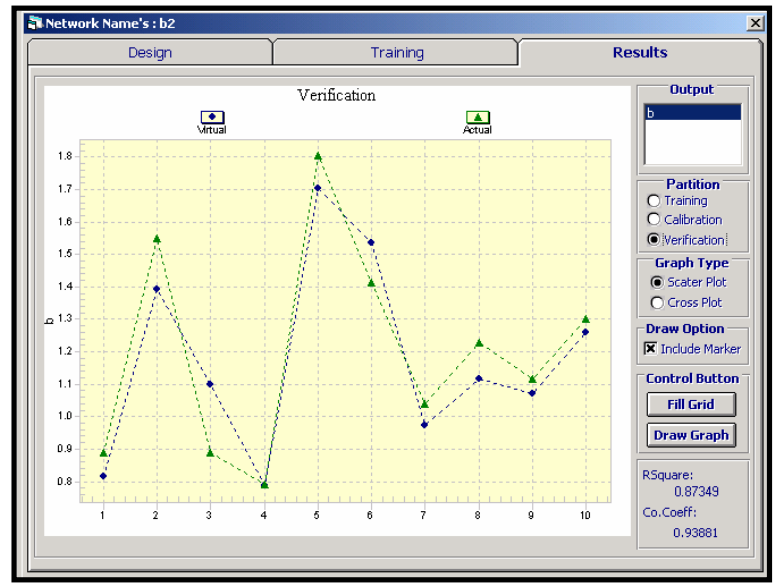

Figure 4.29 Tri Lateral Well Verification Results for the Output “b”-Water

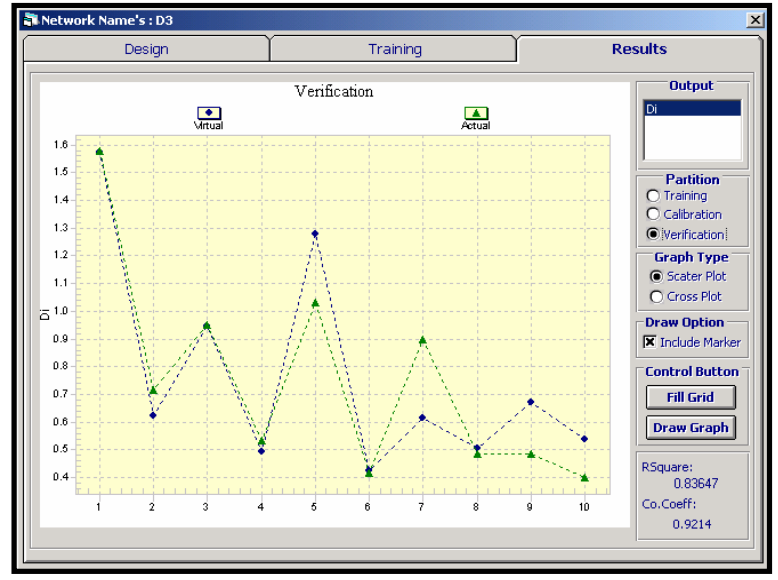

Figure 4.30 Tri Lateral Well Verification Results for the Output "Di"-Water

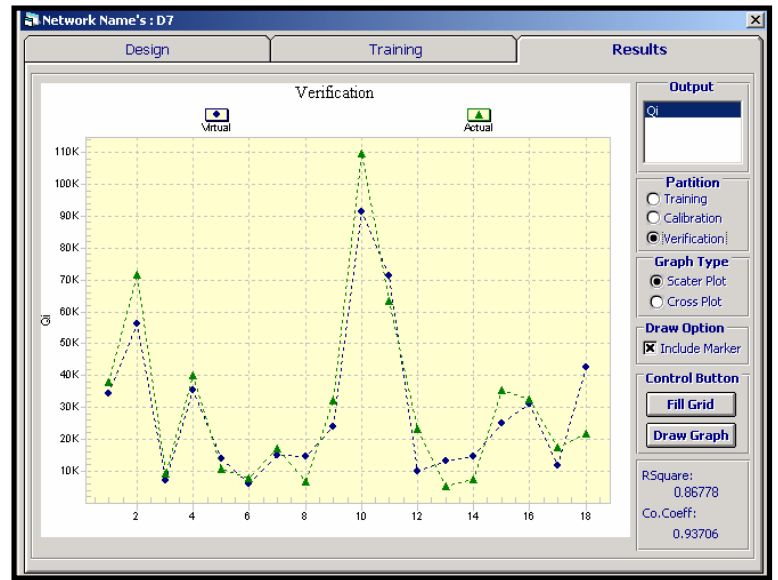

Figure 4.31 Tri Lateral Well Verification Results for the Output “Qi”-Water 


\section{Results-Graphs- Quad laterals}

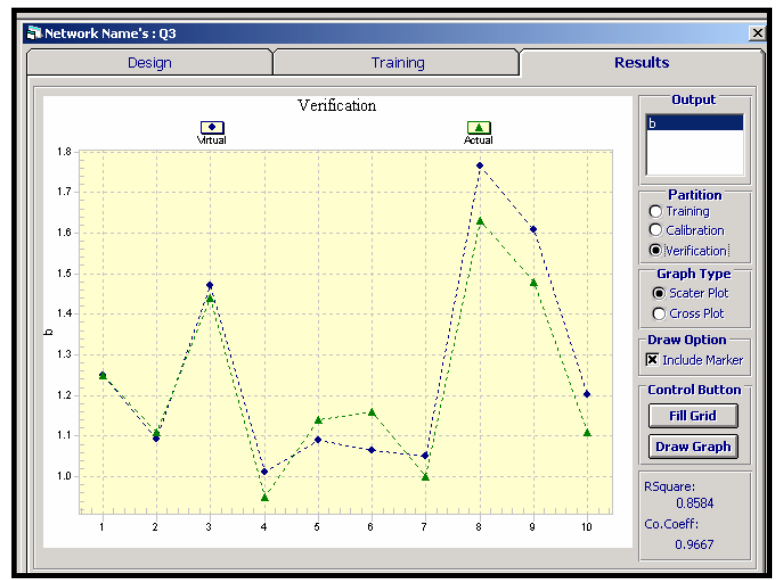

Figure 4.32 Quad Lateral Well Verification Results for the Output "b"-Gas

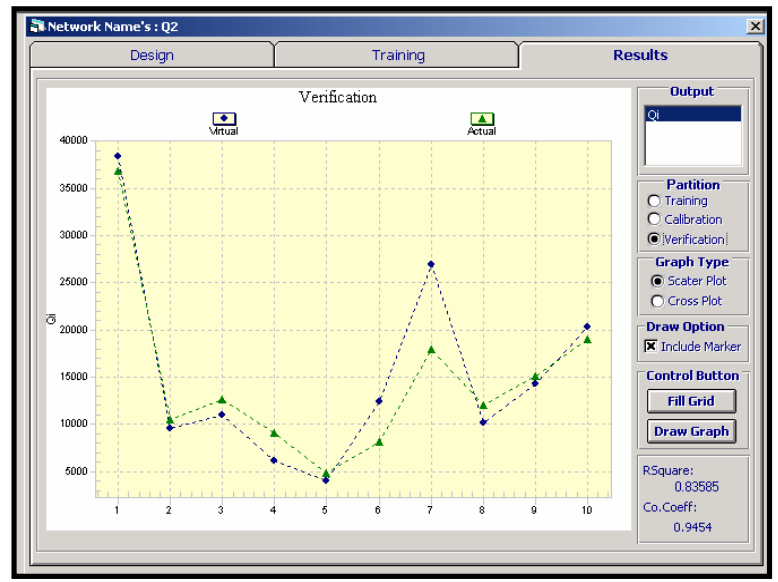

Figure 4.33 Quad Lateral Well Verification Results for the Output "Qi”-Gas

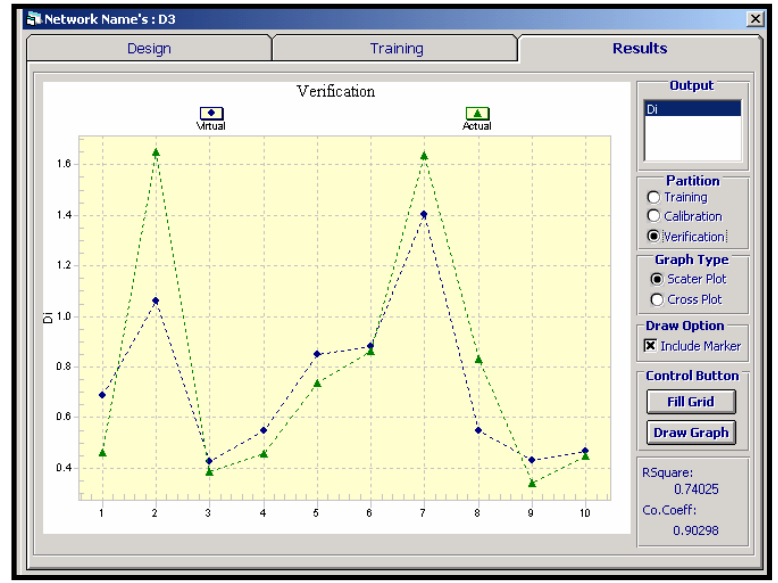

Figure 4.34 Quad Lateral Well Verification Results for the Output "Di"-Gas 


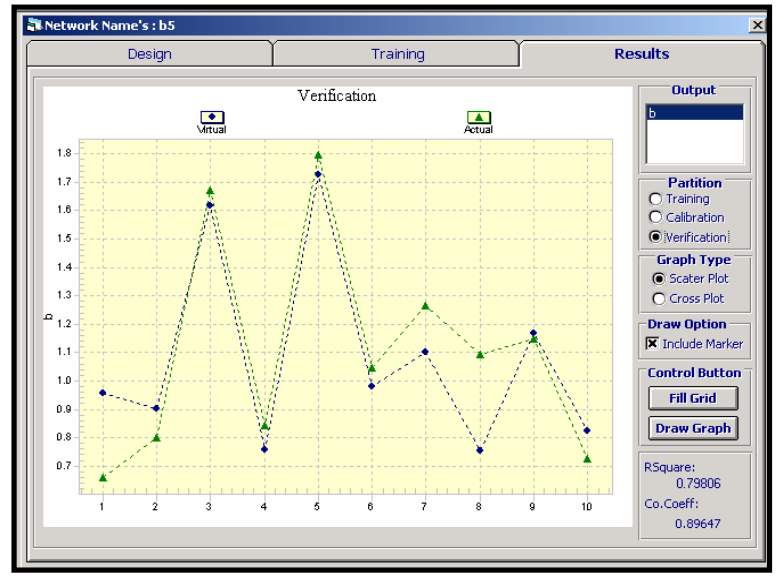

Figure 4.35 Quad Lateral Well Verification Results for the Output "b"-Water

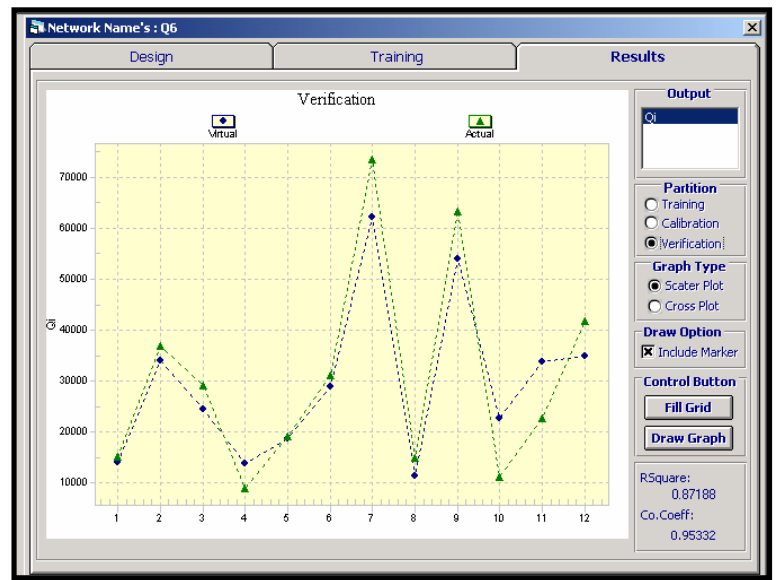

Figure 4.36 Quad Lateral Well Verification Results for the Output “Qi”-Water

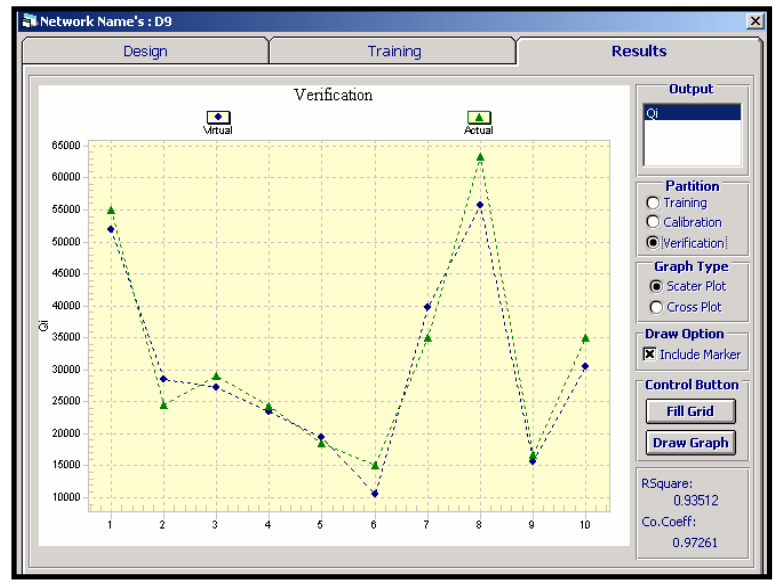

Figure 4.37 Quad Lateral Well Verification Results for the Output “Di”-Water 
Results-Graphs- Pinnate

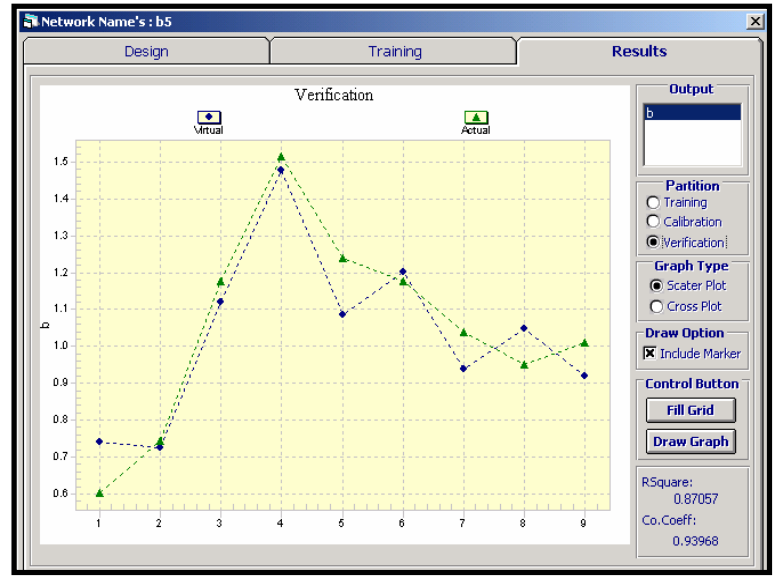

Figure 4.38 Pinnate Well Verification Results for the Output "b"-Gas

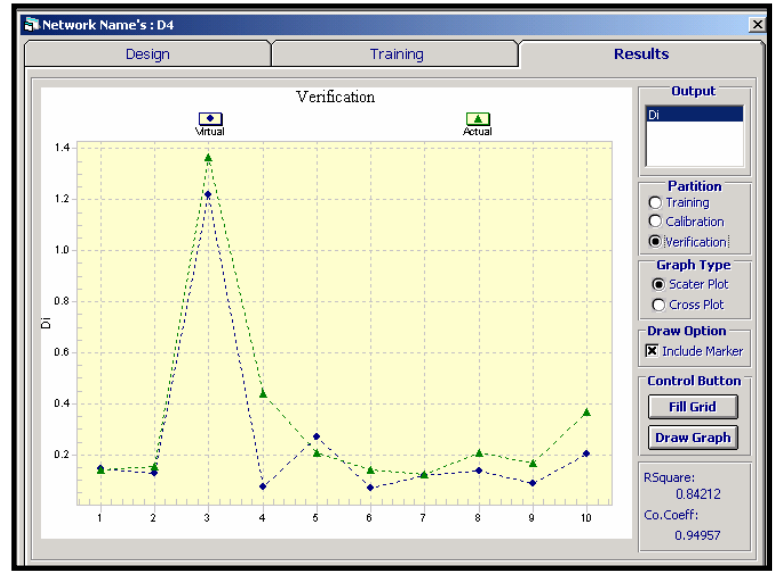

Figure 4.39 Pinnate Well Verification Results for the Output "Di"-Gas

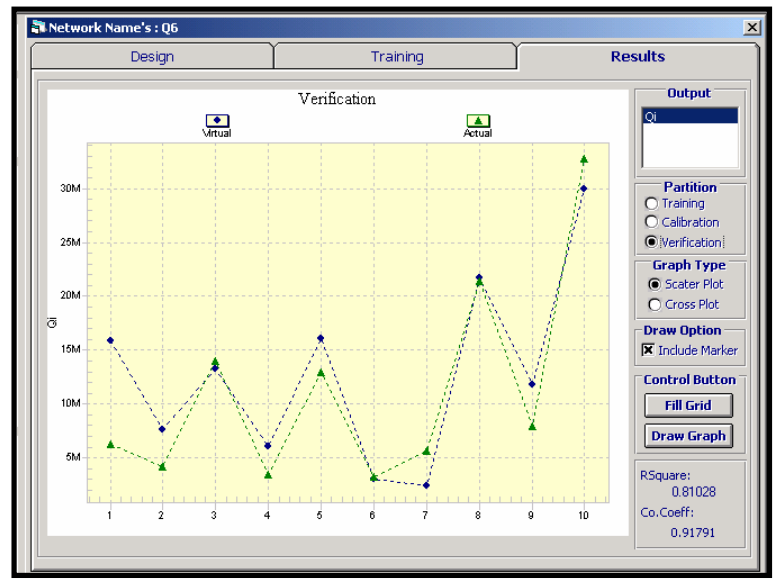

Figure 4.40 Pinnate Well Verification Results for the Output “Qi”-Gas 


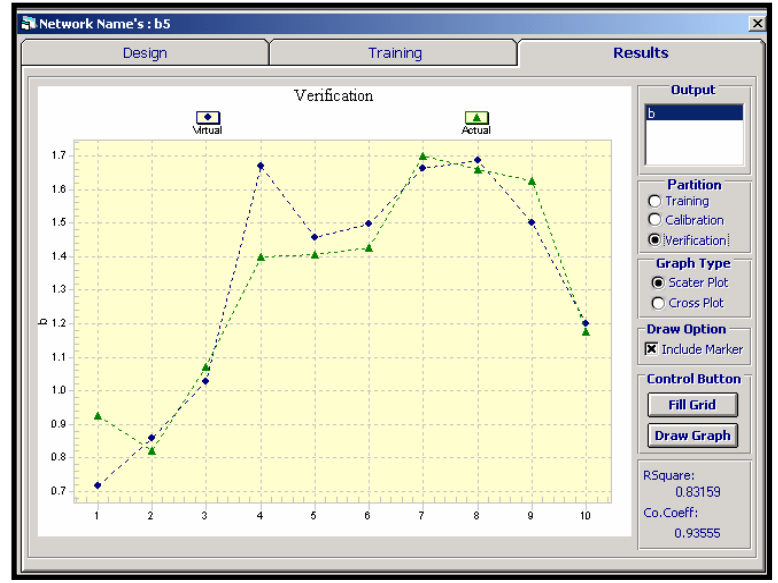

Figure 4.41 Pinnate Well Verification Results for the Output 'b"-Water

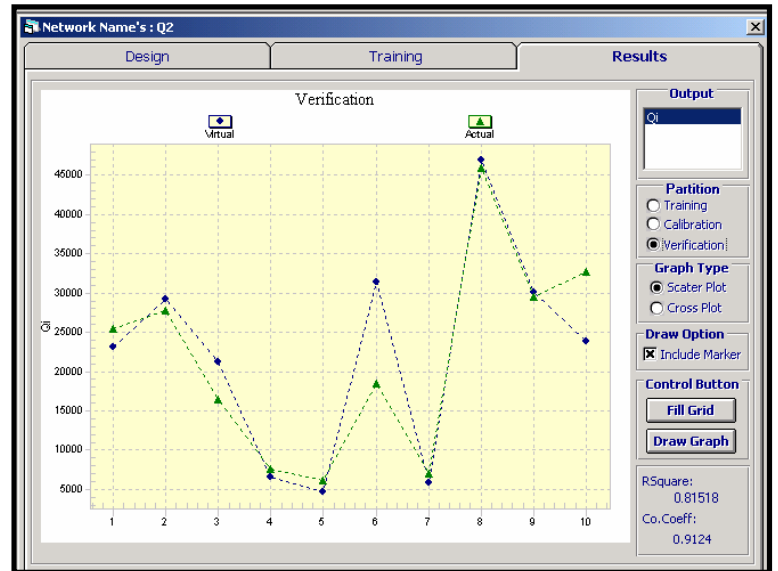

Figure 4.42 Pinnate Well Verification Results for the Output “Qi”-Water

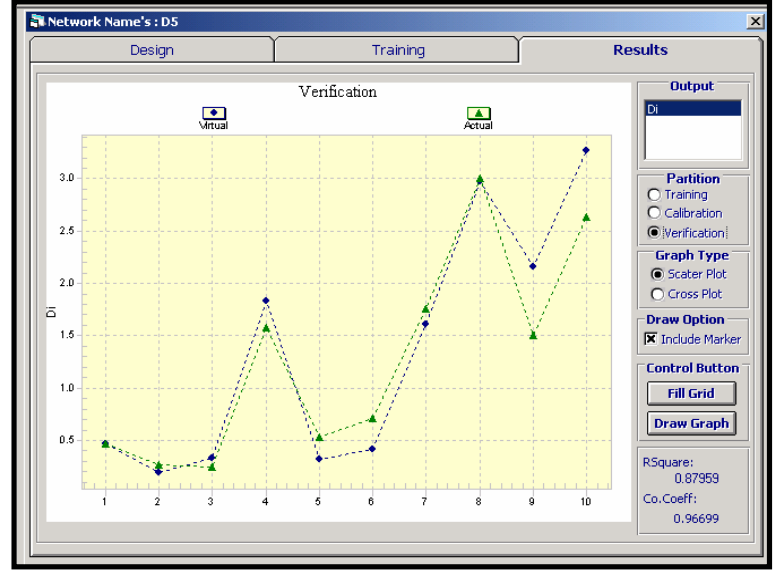

Figure 4.43 Pinnate Well Verification Results for the Output "Di"-Water 


\section{CHAPTER V. CONCLUSIONS}

The main focus of this study was to evaluate the influence of various horizontal well configurations on different CBM recovery from coals found in the Appalachian Basin. After detailed sensitivity analysis and parametric study of the horizontal wells on the heterogeneous coal reservoirs, an intelligent modeling and analysis were performed in order to examine the feasibility of developing of predicted model. The following conclusions were drawn from this research:

1. CBM recovery from Appalachian Basin can benefit significantly from horizontal drilling.

2. High rates of return can be expected if optimum horizontal well configuration is used.

3. An optimum horizontal well configuration is a combination of total horizontal length, and number of laterals, and the spacing between laterals.

4. Using the right methodology, Artificial Intelligence can accurately predict CBM production in the Appalachian Basin. 


\section{CHAPTER VI. FUTURE WORK}

The future work is related to the creation of a software application that will gather all data provided and obtained by this study. That application would allow the user to type certain properties of CBM, suggesting the optimum well configuration to be created in reservoir, having conditions entered. Hopefully, this simple, but powerful tool to predict the performance of CBM wells with good accuracy will be available in the near future, contributing to the development and growth of gas reservoirs in the Northeast region of the USA.

1. The results of this research showed that optimization of HWC in the Appalachian Basin for CBM production is feasible.

2. A new intelligent tool should be developed to perform this analysis for the independent producers.

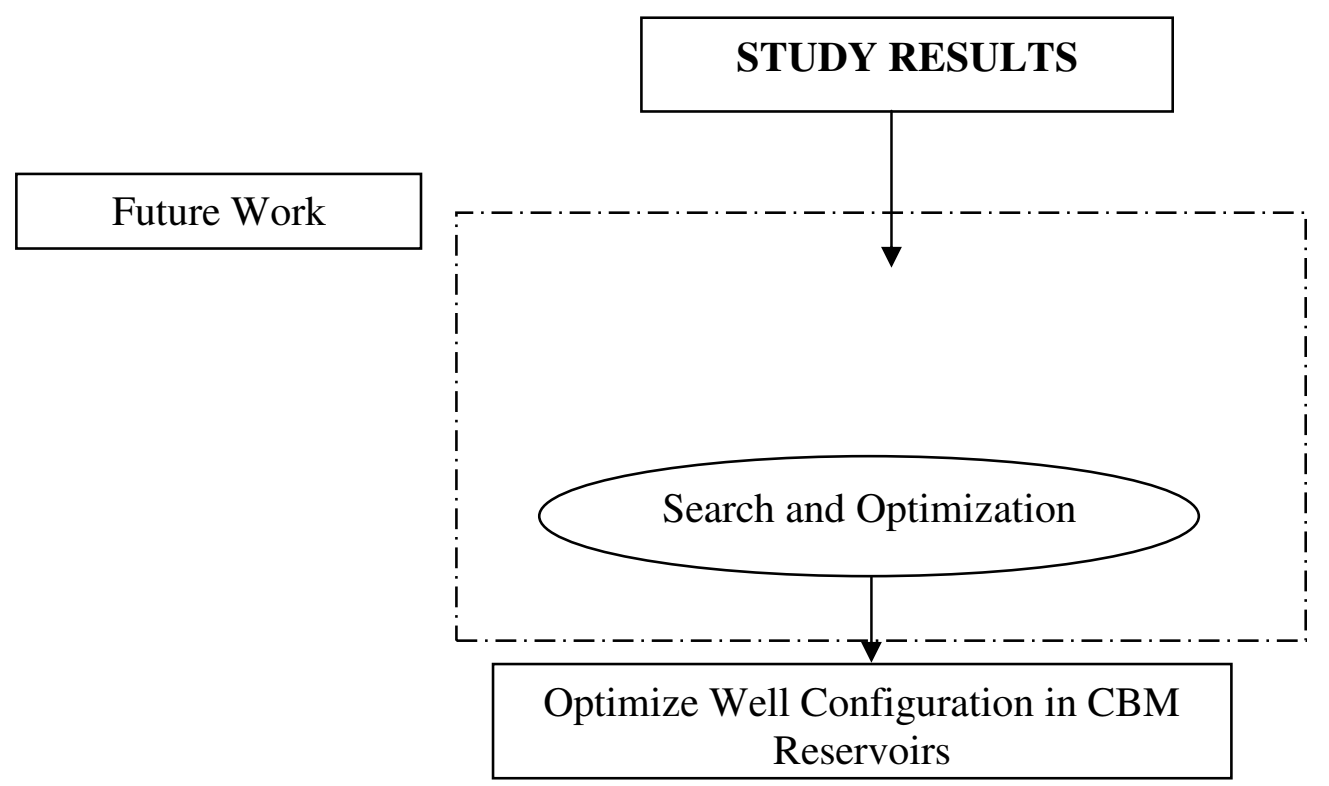

Figure 6.1 Future Work 


\section{REFERENCES}

CMG Reservoir Simulator Tutorial, 2003

Deimbacher, F., Economides, M., Heinemann, Z. 1992. Comparison of Methane Production From Coalbed Using Vertical or Horizontal Fractured Wells. SPE 21280, JPT (August, 1996)

Ertekin, T., Sung, W., Schwerer, F., 1986 Production Performance Analysis of Horizontal Drainage Wells for Degasification of Coal Seams. SPE 15453. Annual Technical Conference and Exhibition, New Orleans, Louisianna

Garcia, A., 2004. Development of Gas production type curves for coalbed methane reservoirs. MS Thesis West Virginia University. Morgantown, WV.

Hower, L., 2003 Coalbed Methane Reservoir Simulation: An Evolving Science SPE84424 Annual Technical Conference and Exhibition, Denver, Colorado

Jacques Hagoort \& Assoc., 2002 Automatic Decline Curve Analysis of Wells in Gas Reservoirs.

Mawor, J., Paul, G., Saulsberry, L., Schafer, S., Scraufnagel, A., Sparks, P., and Zuber, M., 1996. A Guide to Coal bed Methane Reservoir Engineering. GRI eds. Chicago, Ill.

Nelson, C., 1999 Effects of Coalbed Reservoir Property Analysis Methods on Gas-InPlace Estimates SPE 57443 SPE Eastern Regional Meeting, Charleston, WV

Osisinyia, S., Scaffizel, R., 1996 A Review of Horizontal Drilling and Completion Techniques for Recovery of Coalbed Methane SPE 37131 SPE International Conference of Horizontal Well Technology, Calgary, Canada

Remner D., Ertekin, T., Sung, W. and King G., 1984 A Parametric Study of the Effects of Coal Seam Properties on Gas Drainage Efficiency SPE 13366. Eastern Regional Meeting, Charleston, WV

Schraufnagel, R., Hill, D., McBane, R., 1994 Coalbed Methane - A Decade of Success SPE 28581 Annual Technical Conference and Exhibition, New Orleans, Louisiana

www.glossary.oilfield.slb.com, 2004

www.IntelligentSolutionsInc.com, 2004. IDEA, IPDE-IDEA Tutorial

Zuber, M., Boyer II, C., 2001. Analysis of Coalbed Methane Production Trends and Variability Impact. Tuscaloosa, Alabama, Proceedings, International Coalbed Methane Symposium. 